\title{
Cordierite Silicon Nitride Filters
}

DE93 000204

\author{
Final Report
}

Work Performed Under Contract No.: DE-AC21-88MC25201

\author{
For \\ U.S. Department of Encrgy \\ Office of Fossil Energy \\ Morgantown Energy Technology Center \\ P.O. Box 880 \\ Morgantown, West Virginia 26507-0880
}

By

John Sawyer and Bill Buchan

Acurex Environmental Corporation

555 Clyde Avenue

P.O. Box 7044

Mountain View, California 94039-7044

$$
\text { and }
$$

Rick Duiven and Mark Berger

Aerotherm Corporation

A Subsidiary of Dyncorp

580 Clyde Avenue

P.O. Box 7040

Mountain View, California 94039-7044

and

Joseph Cleveland and John Ferri

GTE Products Corporation

Hawes Street

Towanda, Pennsylvania 18848 


\begin{abstract}
The objective of this project was to develop a silicon nitride based crossflow filter. This report summarizes the findings and results of the project. The project was phased with Phase I consisting of filter material development and crossflow filter design. Phase II involved filter manufacturing, filter testing under simulated conditions and reporting the results.

In Phase I, Cordierite Silicon Nitride (CSN) was developed and tested for permeability and strength. Target values for each of these parameters were established early in the program. The values were met by the material development effort in Phase I. The crossflow filter design effort proceeded by developing a macroscopic design based on required surface area and estimated stresses. Then the thermal and pressure stresses were estimated using finite element analysis.

In Phase II of this program, the filter manufacturing technique was developed, and the manufactured filters were tested. The technique developed in\%olved press-bonding extruded tiles to form a filter, producing a monolithic filter after sintering. Filters manufactured using this technique were tested at Acurex and at the Westinghouse Science and Technology Center. The filters did not delaminate during testing and operated and high collection efficiency and good cleanability. Further development in areas of sinteing and filter design is recommended.
\end{abstract}


TABLE OF CONTENTS

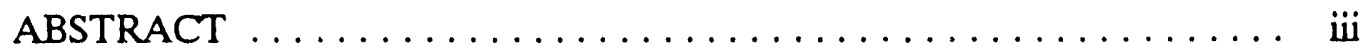

SECTION 1 PROGRAM SUMMARY $\ldots \ldots \ldots \ldots \ldots \ldots \ldots \ldots \ldots \ldots \ldots \ldots \ldots \ldots$

1.1 PROGRAM PURPOSE AND GOALS $\ldots \ldots \ldots \ldots \ldots \ldots \ldots \ldots$

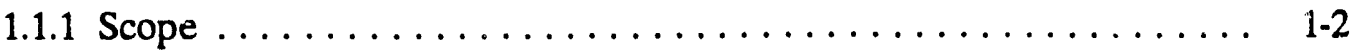

1.2 PROGRAM DESCRIPTION . . . . . . . . . . . . . . .

1.3 SUMMARY OF RESULTS $\ldots \ldots \ldots \ldots \ldots \ldots \ldots \ldots \ldots \ldots \ldots$

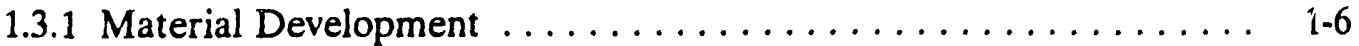

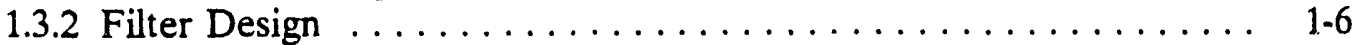

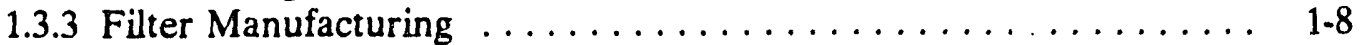

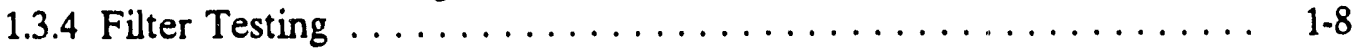

1.4 CONCLUSIONS AND RECOMMMENDATIONS $\ldots \ldots \ldots \ldots \ldots .1 .9$

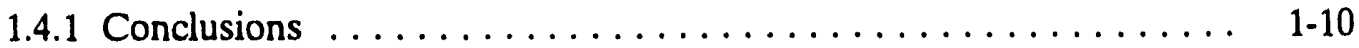

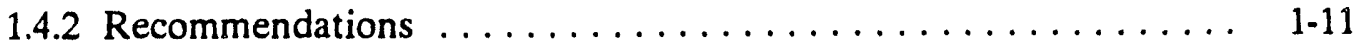

SECTION 2 CROSSFLOW FILTER DESIGN $\ldots \ldots \ldots \ldots \ldots \ldots \ldots \ldots \ldots \ldots$

2.1 CONCEPTUAL DESIGN $\ldots \ldots \ldots \ldots \ldots \ldots \ldots \ldots \ldots \ldots \ldots \ldots \ldots \ldots \ldots$

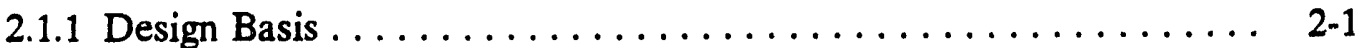

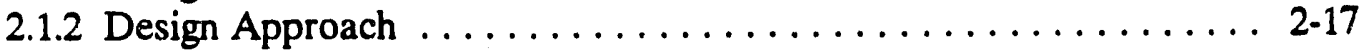

2.2 MACROSCOPIC DESIGN .................. 2-19

2.2.1 Stress Derating . . . . . . . . . . . . . . . . . . 2-21

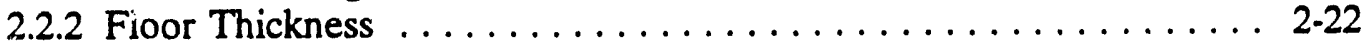

2.2 .3 Channel Width . . . . . . . . . . . . . . . . . . 22

2.2 .4 Rib Sizing . . . . . . . . . . . . . . . . . . . . 2.25

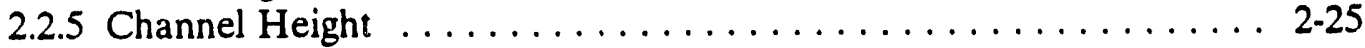

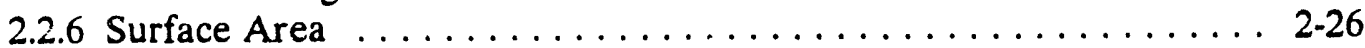

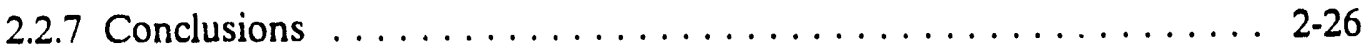

2.3 STRESS ANALYSIS $\ldots \ldots \ldots \ldots \ldots \ldots \ldots \ldots \ldots \ldots \ldots \ldots$

2.3.1 Approach-Pulse Cleaning Transient . . . . . . . . . . . . 2-29

2.3.2 Modei Geometry . . . . . . . . . . . . . . . . . . . . . 2.29

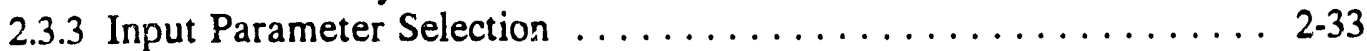

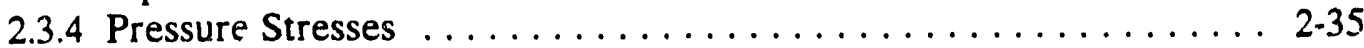

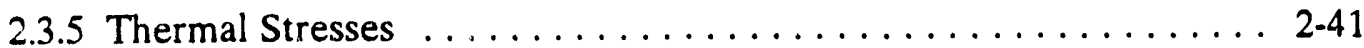

2.3 .6 Results . . . . . . . . . . . . . . . . . . . 2.44

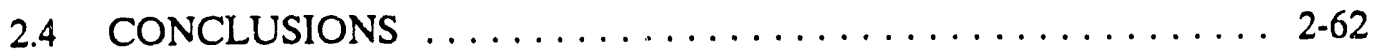


TABLE OF CONTENTS (Continued)

SECTION $3 \quad$ FILTER PROPERTY OPTIMIZATION $\ldots \ldots \ldots \ldots \ldots \ldots \ldots \ldots$

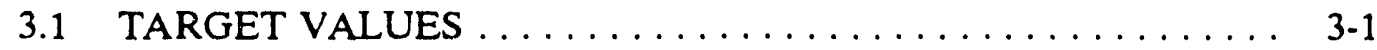

3.1.1 Permeability ........................... 3-1

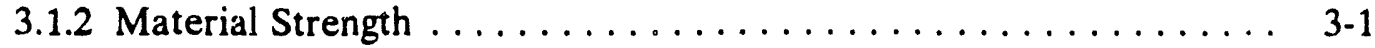

3.2 MANUFACTURING TECHNIQUES $\ldots \ldots \ldots \ldots \ldots \ldots \ldots \ldots . . \ldots .2$

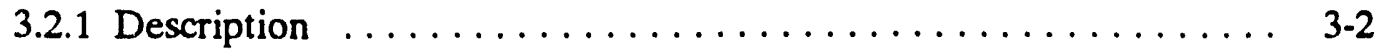

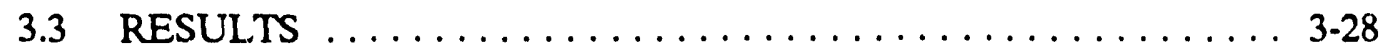

3.3.1 Alignment During Extrusion . . . . . . . . . . . . . . 3-28

3.3.2 Permeability Versus Composition ................ 3-33

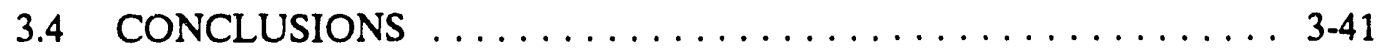

SECTION 4 SUMMARY OF RESULTS AND RECOMMENDATIONS $\ldots \ldots \ldots \ldots$ 4-1

4.1 SUMMARY OF RESULTS $\ldots \ldots \ldots \ldots \ldots \ldots \ldots \ldots \ldots \ldots$ 4-1

4.1.1 Material Development $\ldots \ldots \ldots \ldots \ldots \ldots \ldots \ldots \ldots$ 4-1

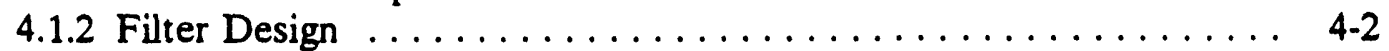

4.2 RECOMMENDATIONS .................... 4-4

SECTION $5 \quad$ FILTER TESTING $\ldots \ldots \ldots \ldots \ldots \ldots \ldots \ldots \ldots \ldots \ldots \ldots$

5.1 FILTER TESTING $\ldots \ldots \ldots \ldots \ldots \ldots \ldots \ldots \ldots \ldots \ldots \ldots$

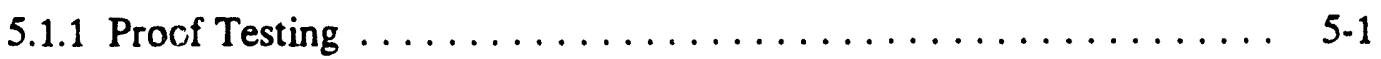

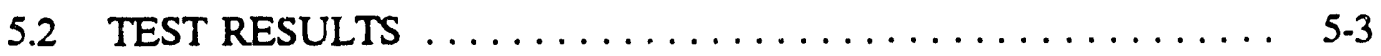

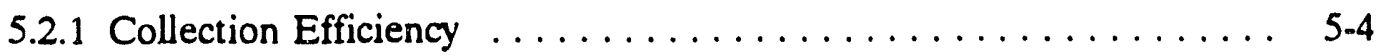

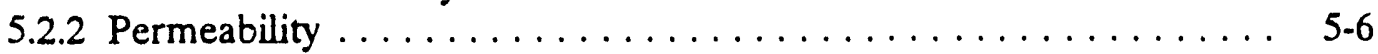

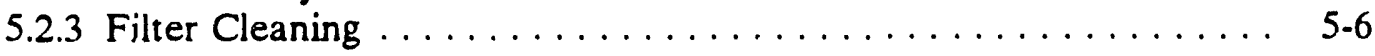

SECTION 6 SUMMARY OF RESULTS AND RECOMMENDATIONS $\ldots \ldots \ldots$. $\ldots$ -

6.1 SUMMARY OF RESULTS $\ldots \ldots \ldots \ldots \ldots \ldots \ldots \ldots \ldots \ldots \ldots$

6.1.1 Material Development $\ldots \ldots \ldots \ldots \ldots \ldots \ldots \ldots \ldots \ldots \ldots . \ldots \ldots$ 6.1

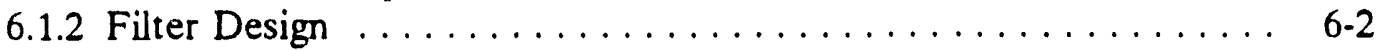


TABLE OF CONTENTS (Concluded)

6.2 RECOMMENDATIONS ................... 6.7

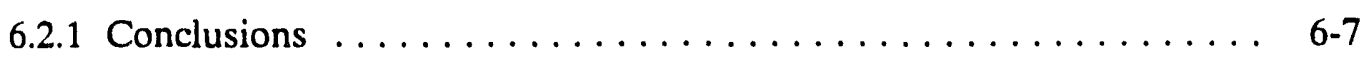

6.2 .2 Recommendations . . . . . . . . . . . . . . . . . .

REFERENCES $\ldots \ldots \ldots \ldots \ldots \ldots \ldots \ldots \ldots \ldots \ldots \ldots \ldots \ldots \ldots \ldots \ldots \ldots \ldots$

APPENDIX A DOE PERFORMANCE AND DESIGN GUIUELINES AND

RECOMMENDATIONS FOR CROSSFLOW FILTERS . . . . . . . A A-1

APPENDIX B CSN TECHNICAL REPORT THERMAL MODEL APPROACH FOR

CROSSFLOW FILTER $\ldots \ldots \ldots \ldots \ldots \ldots \ldots \ldots \ldots \ldots$ B-1

APPENDIX C CORRESPONDENCE BETWEEN MESH SIZE AND PHYSICAL

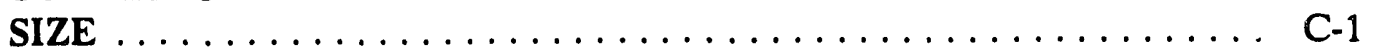

APPENDIX D PERMEABILITY MEASUREMENT $\ldots \ldots \ldots \ldots \ldots \ldots \ldots \ldots \ldots$ D-1

APPENDIX E MODULUS OF RUPTURE DATA $\ldots \ldots \ldots \ldots \ldots \ldots \ldots \ldots$

APPENDIX F TECHNIQUE FOR MEASURING SHEAR AND YOUNG'S MODULUS

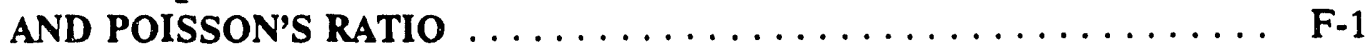

APPENDIX G POROSIMETRY DATA $\ldots \ldots \ldots \ldots \ldots \ldots \ldots \ldots \ldots$ G.1

APPENDIX iI SUMMARY OF PROOF-TEST DATA $\ldots \ldots \ldots \ldots \ldots \ldots \ldots \ldots$

APPENDIX I PRESSURE DROP VERSUS TIME FOR INDIVIDUAL PROOF-TEST

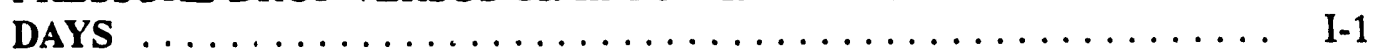




\section{LIST OF ILLUSTRATIONS}

Figure 1-1. Overall approach-CSN Filter Test Program $\ldots \ldots \ldots \ldots \ldots \ldots \ldots$

Figure 1-2. Work breakdown structure with organizational responsibilitiesCSN Filter Test Program ....................... 1-5

Figure 2-1. Process flow diagram of the PFBC process $\ldots \ldots \ldots \ldots \ldots \ldots \ldots$

Figure 2-2. Process flow diagram of the BGC Lurgi IGCC process . . . . . . . 2-7

Figure 2-3. Process flow diagram of the KRW IGCC $\ldots \ldots \ldots \ldots \ldots \ldots \ldots \ldots$

Figure 2-4. Process flow diagram of the Texaco IGCC process $\ldots \ldots \ldots \ldots . \ldots 2$

Figure 2-5. Process flow diagram of direct coal-fired turbine systems $\ldots \ldots \ldots 2-15$

Figure $2-6 . \quad$ Filter design flow chart $\ldots \ldots \ldots \ldots \ldots \ldots \ldots \ldots \ldots \ldots \ldots$

Figure 2-7. Flow chart for preliminary stress analysis $\ldots \ldots \ldots \ldots \ldots \ldots \ldots$

Figure 2-8. Description of the channel variables used in the stress analysis $\ldots \ldots \ldots 2-23$

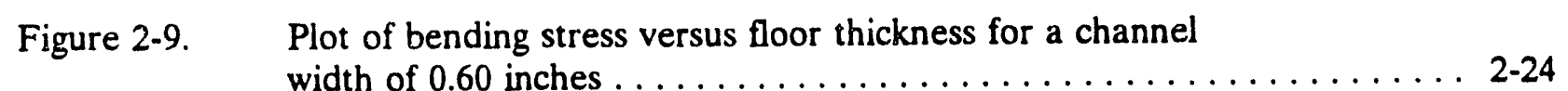

Figure 2-10. Channel width and bending stress are a squared relationship $\ldots \ldots \ldots 2-25$

Figure 2-11. Plot of channel height versus surface area for $\mathrm{FT}=0.06 \ldots \ldots 2-27$

Figure 2-12. Final channel dimensions $\ldots \ldots \ldots \ldots \ldots \ldots \ldots \ldots \ldots \ldots \ldots$

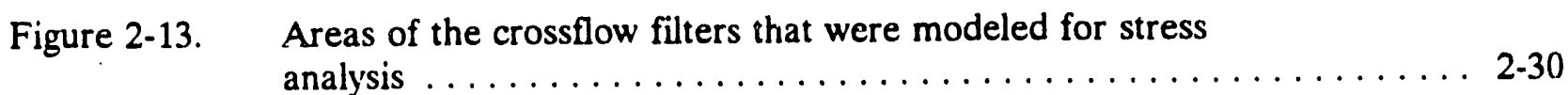

Figure 2-14. Grid structure used in the analysis of the floor $\ldots \ldots \ldots \ldots \ldots$

Figure 2-15. Grid structure used in the analysis of the back wall $\ldots \ldots \ldots \ldots 2-32$

Figure $2-16 . \quad$ Floor model, 10 psi purge pressure $\ldots \ldots \ldots \ldots \ldots \ldots \ldots \ldots$

Figure 2-17. Back wall model, 10 psi purge pressure $\ldots \ldots \ldots \ldots \ldots \ldots \ldots \ldots$

Figure 2-18. Floor model, maximum principal stress contours, $10 \mathrm{psi}$

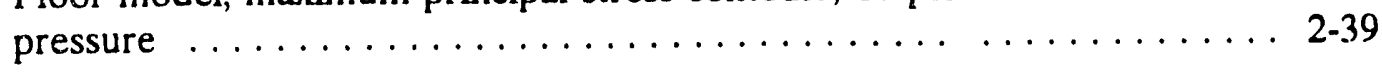

Figure 2-19. Back wall model, maximum principal stress contours, 10 psi

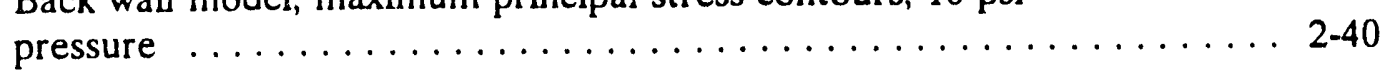




\section{LIST OF ILLUSTRATIONS (Continued)}

Figure 2-20. Boundary conditions for the floor $\ldots \ldots \ldots \ldots \ldots \ldots \ldots \ldots \ldots \ldots$

Figure 2-21. Boundary conditions for the back wall $\ldots \ldots \ldots \ldots \ldots \ldots \ldots \ldots$

Figure 2-22. Temperature predictions for the floor $\left(T_{\text {purs }}=1225^{\circ} \mathrm{F}\right) \ldots \ldots 2-45$

Figure 2-23. Temperature predictions for the floor $\left(\mathrm{T}_{\text {pure }}=475^{\circ} \mathrm{F}\right) \ldots \ldots 2-46$

Figure 2-24. Temperature predictions for the back wall $\left(\mathrm{T}_{\text {purge }}=1225^{\circ} \mathrm{F}\right) \ldots 2-47$

Figure 2-25. Floor model, time $=0.09 \mathrm{~s}$, air temperature $=475^{\circ} \mathrm{F} \ldots \ldots \ldots \ldots$

Figure 2-26. Floor model, time $=0.50 \mathrm{~s}$, air temperature $=475^{\circ} \mathrm{F} \ldots \ldots \ldots \ldots 2-49$

Figure 2-27. Floor model, time $=0.09 \mathrm{~s}$, air temperature $=1225^{\circ} \mathrm{F} \ldots \ldots \ldots \ldots$

Figure 2-28. Floor model, time $=0.50 \mathrm{~s}$, air temperature $=1225^{\circ} \mathrm{F} \ldots \ldots \ldots 2-51$

Figure 2-29. Back wall model, time $=0.09 \mathrm{~s}$, air temperature $=1225^{\circ} \mathrm{F} \ldots \ldots 2-53$

Figure 2-30. Back wall model, time $=0.50 \mathrm{~s}$, air temperature $=1225^{\circ} \mathrm{F} \ldots \ldots 2-54$

Figure 2-31. Grid structure used in the spatially uniform method $\ldots \ldots \ldots \ldots$

Figure 2-32. Temperature prediction using the spatially uniform method $\ldots \ldots \ldots 2-57$

Figure 2-33. Floor model, time $=0.09 \mathrm{~s}$, air temperature $=475^{\circ} \mathrm{F}$, spatially uniform method ......................... 2-59

Figure 2-34. Floor model, time $=0.50 \mathrm{~s}$, air temperature $=475^{\circ} \mathrm{F}$, spatially uniform method ........................ 2-60

Figure 2-35. Crossflow filter and filter mount design $\ldots \ldots \ldots \ldots \ldots \ldots \ldots$

Figure 3-1. Permeability versus floor thickness required to meet 5 inches water $\Delta \mathrm{P} 10 \mathrm{ft} / \mathrm{min}$ face velocity $\ldots \ldots \ldots \ldots \ldots \ldots \ldots \ldots \ldots \ldots$

Figure 3-2. $100 x$ scanning electron micrograph of 80 -mesh wood flour $\ldots \ldots \ldots 3-3$

Figure 3-3. $200 x$ scanning electron micrograph of 80 -mesh wood flour $\ldots \ldots \ldots 3-3$

Figure 3-4. $\quad 500 x$ scanning electron micrograph of 325 -mesh walnut shells $\ldots \ldots \ldots 3-5$

Figure 3-5. $\quad 1000 x$ scanning electron micrograph of 325 -mesh walnut shells $\ldots \ldots .3-5$

Figure 3-6. $200 x$ scanning electron micrograph of 325 -mesh walnut shells $\ldots \ldots \ldots 3-9$ 


\section{LIST OF ILLUSTRATIONS (Continued)}

Figure 3-7. 500x scanning electron micrograph of 325 -mesh walnut shells $\ldots \ldots \ldots$ 3-9

Figure 3-8. 200x scanning electron micrograph of 200-mesh walnut shells $\ldots \ldots \ldots 3-11$

Figure 3-9. $\quad 500 \mathrm{x}$ scanning electron micrograph of 200 -mesh walnut shells $\ldots \ldots \ldots 3-11$

Figure 3-10. 200x scanning electron micrograph of $-120+270$ mesh walnut shell $\ldots \quad$ 3-13

Figure 3-11. 500x scanning electron micrograph of $-120+270$ mesh-walnut shells ........................... 3-13

Figure $3-12$. Data sheet of micromerograph results $\ldots \ldots \ldots \ldots \ldots \ldots \ldots$

Figure 3-13. Simpson mix muller with material in initial mixing stage $\ldots \ldots \ldots 3-17$

Figure 3-14. Sections of extrusion die with various sizes of die inserts $\ldots \ldots \ldots$ 3-17

Figure 3 -15. Press with assembled extrusion die $\ldots \ldots \ldots \ldots \ldots \ldots \ldots \ldots \ldots$

Figure $3-16$ Material being extruded in extrusion rig $\ldots \ldots \ldots \ldots \ldots \ldots \ldots$

Figure 3-17. Samples of extruded pieces pressed together $\ldots \ldots \ldots \ldots \ldots \ldots$

Figure 3-18. Samples of material extruded with various die inserts $\ldots \ldots \ldots$ 3-25

Figure 3 -19. $\quad \mathrm{X}$-ray of sintered sample $\ldots \ldots \ldots \ldots \ldots \ldots \ldots \ldots \ldots \ldots \ldots$

Figure 3-20. 100x scanning electron micrograph of fracture surface of sample with $-120+270$ mesh walnut shell filler. Fracture taken perpendicular to direction of extrusion. . . . . . . . . . . . . . . . . .

Figure 3-21. 100x scanning electron micrograph of fracture surface of sample with $-120+270$ mesh walnut shell filler. Fracture taken parallel to direction

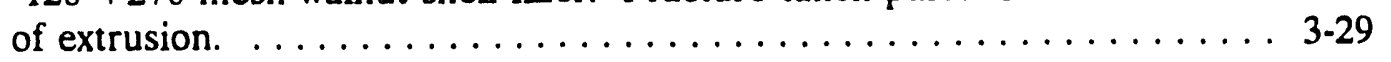

Figure $3-22 . \quad$ Perpendicular fracture at $200 x \ldots \ldots \ldots \ldots \ldots \ldots \ldots \ldots \ldots \ldots \ldots \ldots$

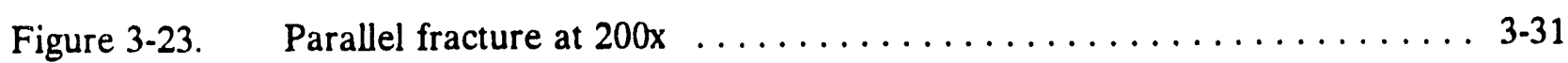

Figure 3-24. Variation of permeability with extruded sample thickness . . . . . . . 3-34

Figure $3-25$. Variation of face velocity with amount of filter $\ldots \ldots \ldots \ldots \ldots$ 3-35

Figure 3-26. Frequency distribution of three different methods of screening
material to $-120+270$ mesh $\ldots \ldots \ldots \ldots \ldots \ldots \ldots \ldots \ldots \ldots \ldots \ldots \ldots$ 


\section{LIST OF ILLUSTRATIONS (Concluded)}

Figure 3-27. Cumulative distribution of three different methods of screening material to $-120+270$ mesh $\ldots \ldots \ldots \ldots \ldots \ldots \ldots \ldots \ldots \ldots \ldots \ldots \ldots .38$

Figure 3-28. Effect of pressing extruded surface to remove extrusion roughness . . . . 3-39

Figure 3-29. Data page of permeability and face velocity testing results $\ldots \ldots \ldots$. . . . .

Figure 3-30. Mercury porosimeter test of sample with walnut shells screened

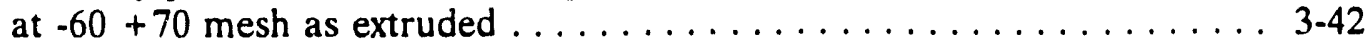

Figure 3-31. Mercury porosimeter test of sample extruded and then pressed to eliminate surface roughness $\ldots \ldots \ldots \ldots \ldots \ldots \ldots \ldots \ldots \ldots \ldots \ldots$

Figure 3-32. Variation of permeability testing technique $\ldots \ldots \ldots \ldots \ldots \ldots \ldots$

Figure 5-1. Collection efficiency for CSN filter testing $\ldots \ldots \ldots \ldots \ldots \ldots \ldots$

Figure 5-2. Permeability during testing for first test filter $\ldots \ldots \ldots \ldots \ldots \ldots \ldots$

Figure 5-3. Permeability during testing for second test filter $\ldots \ldots \ldots \ldots \ldots \ldots$

Figure 5-4. Face velocity and pulse pressure during testing $\ldots \ldots \ldots \ldots \ldots \ldots$ 


\section{LIST OF TABLES}

Table 2-1. Filter design bases

Table 2-2. Ceramic filter gas compositions and operating conditions in advanced power systems .......................... 2-5

Table 2-3. Thermal properties of the filter element $\ldots \ldots \ldots \ldots \ldots \ldots \ldots$

Table 2-4. Structural material properties $\ldots \ldots \ldots \ldots \ldots \ldots \ldots \ldots \ldots \ldots$

Table 2-5. $\quad$ Maximum principal tensile stress $\ldots \ldots \ldots \ldots \ldots \ldots \ldots \ldots \ldots \ldots$

Table 2-6. Comparisons of assumed and measured values of Young's Modulus and Poisson's Ratio .......................... 2-61

Table 5-1. Proof testing conditions $\ldots \ldots \ldots \ldots \ldots \ldots \ldots \ldots \ldots \ldots \ldots \ldots$

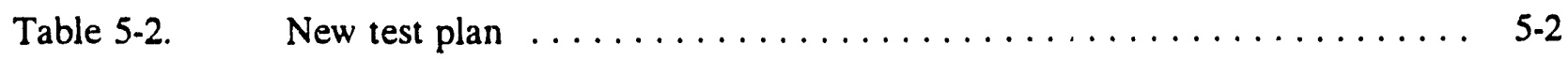

Table 5-3. $\quad$ Actual test plan $\ldots \ldots \ldots \ldots \ldots \ldots \ldots \ldots \ldots \ldots \ldots \ldots \ldots \ldots \ldots \ldots$

Table 5-4. $\quad$ Filter test summary $\ldots \ldots \ldots \ldots \ldots \ldots \ldots \ldots \ldots \ldots \ldots \ldots$ 


\section{SECTION 1}

\section{EXECUTIVE SUMMARY}

Currently, several high-temperature particulate cleanup devices are being developed with Department of Energy (DOE) support. These particulate cleanup devices are being developed for use in advanced power generation systems such as the Integrated Gasification Combined Cycle (IGCC), Pressurized Fluidized-Bed Combustor (PFBC), and Direct Coal-Fired Turbine (DCFTT). Ceramic candle filters, and ceramic crossflow filters are the leading candidates for these applications. Ceramic candle filters are rigid tubular filters generally flanged at one end. Ceramic crossflow filters are rigid filters derived from ceramic recuperator design and have very high surface area per unit volume.

Since crossflow filters possess a high surface area per unit volume, they offer a significant economic advantage over other types of filters from a system-cost point of view. Typically, a fullscale crossflow filter has approximately $10 \mathrm{ft}^{2}$ of surface area in approximately $0.3 \mathrm{ft}^{3}$. Other types of filters (bag and candle) cannot match the surface area density even with extended surface area approaches. For example, to match the surface area of crossflow filters, the extended surface filter volume required from bag and candle filters is a factor of three larger. Thus, crossflow filters would encompass a smaller volume for the same filter surface area (Reference 1).

\subsection{PROGRAM PURPOSE AND GOALS}

The crossflow filter has experienced a series of durability problems that limit its lifetime and, hence, lower the economic advantage of this filter approach. The durability problems are primarily related to delamination of the floor of the crossflow from the rib, and mounting flange breakage. 
Historically, crossflow filter durability problems have been due to a combination of design and material problems. Recent work by Westinghouse in the design of the crossflow and its ancillary components has led to improvements in filter manufacturing; however, material problems that limit the crossflow lifetime persist.

Due to its design, construction, and operating conditions, the crossflow is subject to thermal stresses that can be of the same order of magnitude as the current mixed oxide material (aluminamullite) strength (2000 to $3000 \mathrm{psi}$ ). The development of crossflow filters comprised of such materials as silicon nitride, which are strong and stable at the temperatures typically experienced in hot-gas particulate cleanup systems, would help solve many of the material problems currently encountered with these filters. Even though the cost of silicon nitride material is higher than the costs of the currently used mixed oxides, the increase in lifetime and durability of the silicon nitride materials may overcome this price disadvantage, providing an economic incentive.

\subsubsection{Scope}

The objective of this project to develop and evaluate silicon nitride as the ceramic used to manufacture ceramic crossflow filter elements. The proposed silicon nitride crossflow filter will provide filtration performance equal to the currently available crosiflow filters, while providing substantially increased lifetime and strength. The ultimate goal of this project is to develop a monolithic crossflow (no glued joints).

\subsection{PROGRAM DESCRIPTION}

Based on the desire to develop silicon nitride into a material suitable for crossflow filters, a program was defined that delineated the development steps. The first step was to select a silicon nitride material suitable for development. GTE of Towanda, Pennsylvania, has both crossflow experience and silicon nitride material manufacturing capabilities. After discussions with GTE, cordierite silicon nitride (CSN) was selected for crossflow filter development. A program was defined to develop CSN and manufacture crussflow filters. Figure 1-1 depicts the overall approach 


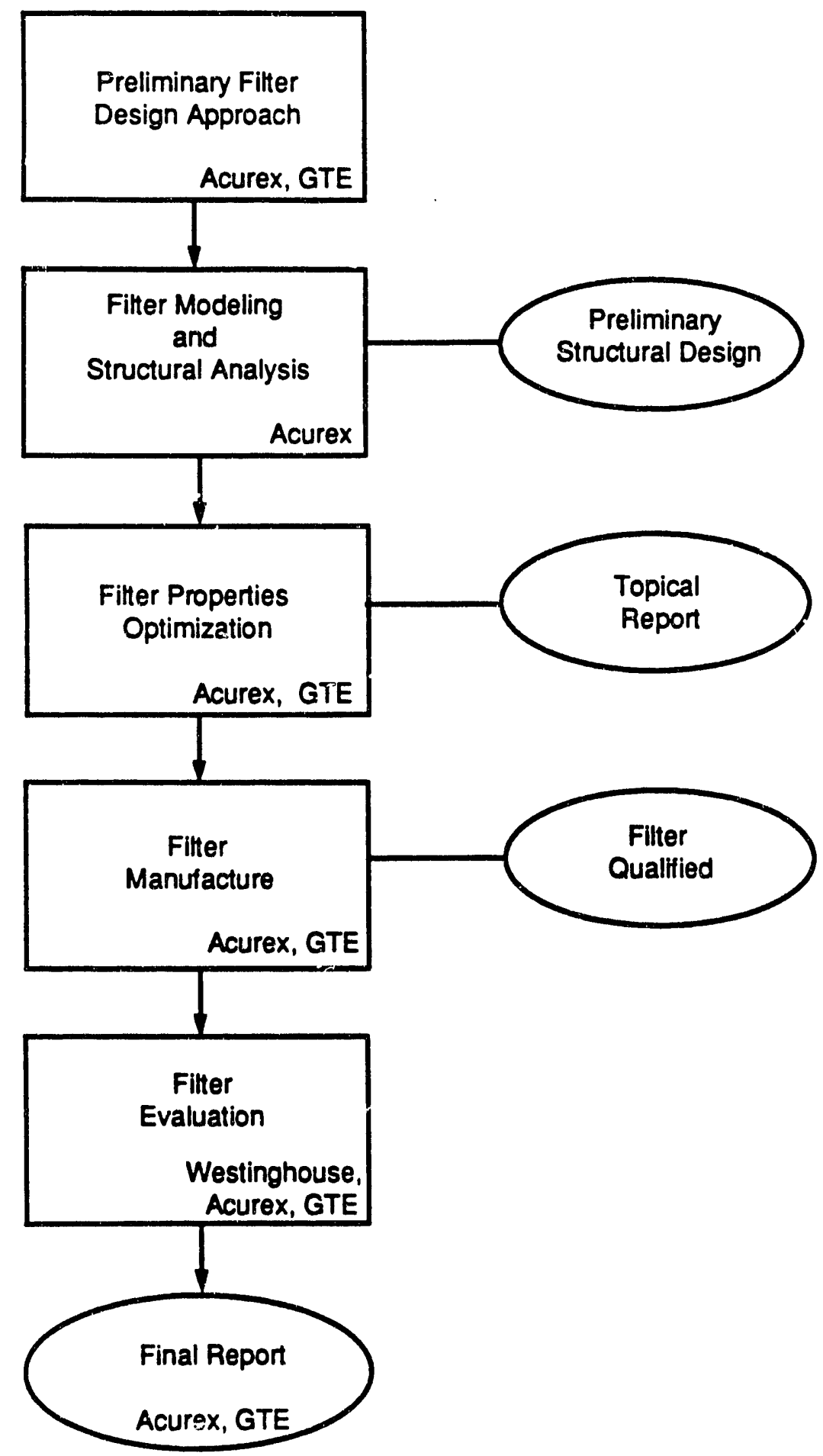

Figure 1-1. Overall approach-CSN Filter Test Program 
for the CSN Filter Test Program. Five tasks were identified, each of which will be discussed briefly below. Figure 1-2 shows the work breakdown structure for this program organizational responsibilities for each team member.

The goal of Task 1 was to prepare a Preliminary Filter Design Approach that incorporated a justification of material selection as well as the filter design bases.

Task 2 involved design of the crossflow filter and Structural Analysis for CSN filter design. The objective of this task was to obtain a preliminary structural design for the CSN filter through stress analyses.

Task 3 was Filter Property Optimization. The objective of this task was to develop material to meet desired material preparation of permeability and strength. Test specimens were manufactured to examine porosity ranges and optimize the balance between filtration efficiency and pressure drop. The porosity and pore size were determined. Gas flowrate capabilities were measured at a set pressure drop at each porosity level investigated. Furthermore, the mechanical properties of the filter material were determined. The properties determined included modulus of rupture, bulk density, porosity, permeability, pore size, shear modulus, and modulus of elasticity.

Task 4 was Filter Manufacturing. With the final filter design obtained in Task 3, a set of quarter- and half-scale filters were manufactured at GTE facilities. Quarter-scale filters were located at Acurex. The filters were qualified at a stress level higher than that expected under actual operating conditions. Destructive examination of one filter verified the failure strength of the material.

Task 5 was Filter Evaluation. Once filters were qualified, they were tested at the Westinghouse Science \& Technology Center. The testing included collection efficiency measurement, cleanability assessments, and a preliminary assessment of the material durability. 
Task/Subtask

1 Preliminary Filter Design Approach

1.1 Set Porosity Ranges

1.2 Set Flowrate Ranges

1.3 Determine Mechanica! Properties

1.4 Write Filter Manufacturing Procedure

1.5 Determine NDT and Destrucive Tests

1.6 Describe Filter Evaluation Apparatus

1.7 Determine Filter Analysis Techniques

1.8 Write Test Plan
1.8.1
1.8 .2
1.8 .3
Draft
DOE Review
Final

(Acurex)

(Acurex)

(Acurex, GTE)

(GTE)

(GTE)

(Acurex, Westinghouse)

(Acurex, GTE)

(Acurex, GTE, Westinghouse)

(Acurex, GTE)

(Acurex)

$2 \quad$ Modeling and Structural Analysis

2.1 Determine Recommended Operating Conditions

2.2 Determine Fiiter Properties

2.3 Filter Preliminary Design

3 Filter Property Optimization

3.1 Manufacture Test Specimens

3.2 Analyze Test Specimens

(GTE)

3.2.1 Characterize Porosity

(Acurex, GTE)

3.2.2 Measure Gas Flowrate

3.2.3 Measure Thermal/Mechanical Properties

3.2.4 Perform Stress Analysis

3.2.5 Final Filter Design

$4 \quad$ Filter Manufacture

4.1 Manufacture Filters

4.2 Qualify Filters
4.3.1
4.3.2
Nondestructive Testing
Destrurtive Proof Testing

$5 \quad$ Filter Evaluation

5.1 Select Test Facility

5.2 Specify Test Operating Conditions

5.3 Test Filters

5.4 Post-test Assessment and Recommendations

(GTE)

(Acurex, GTE)

5.3.1 Examine Filter Properties

5.3.2 Compare Pre- and Post-test Results

5.3.3 Recommendations

6 Reporting

6.1 Management Plan

6.2 Monthly Progress Reports

6.3.1 Prefers Draft

6.3.2 DOE Reviews

6.3.3 Submit Final

(Acurex)

(Acurex)

(Acurex, Westinghouse)

(Acurex, GTE)

6.3 Final Report

(Acurex)

(Acurex)

(Acurex, GTE, Westinghouse)

Figure 1-2. Work breakdown structure with organizational responsibilities-CSN Filter Test Program 


\subsection{SUMMARY OF RESULTS}

CSN material has been developed into material suitable for the manufacture of crossflow filters. The CSN riaterial is CSN25, or 25 percent cordierite with silicon nitride. GTE developed the material and manufacturing process and Acurex Corporation designed the crossflow filter, completed preliminary assessment of the CSN filters.

\subsection{Material Development}

DOE established permeability guidelines of 5 in w.c. pressure drop for a clean filter at 10 $\mathrm{ft} / \mathrm{min}$ face velocity at standard temperature and pressure. GTE has developed a material that meets these permeability requirements. The material is 50 percent filler with the filler being 95 percent walnut shells and 5 percent wood flour. The walnut shells have been screened to 60 to 70 mesh. This material has a permeability of 1800 millidarcies with a thickness of 0.06 in.

\subsubsection{Filter Design}

The filter design was accomplished using two methods within the framework of modifying the current crossflow filter design. First, a filter geometry was determined based on the material thickness produced by GTE and allowable stresses calculated using concentrated loads. Next, this geometry was analyzed for thermal and structural stresses using finite element analysis. Two parts of the filter were analyzed: the porous floor and rib and the backwall where the clean channel ends. The stress analysis was centered around analysis of a pulse cleaning transient.

During the design phase of our program, discussions with DOE and Westinghouse led to the determination that crossflow filter flanges were an area of high stress during thermal transients and operation. Therefore, we took the approach of designing a flangeless filter and filter mounting system. This approach allowed us to eliminate one possible weak location within the crossflow filter structure. 


\subsubsection{Macroscopic Design}

To design the filter, concentrated loads were assumed for the filter porous floor. Then, a floor thickness was assumed and the channel width and rib thickness were calculated based on a calculated allowable stress. The stress was calculated based on stress derating factors, safety factors, and the assumed tensile strength of the CSN material.

Initially, a floor thickness of 0.09 in was assumed; however, GTE was manufacturing thinner samples than this. Consequently, the design was amended to assume a floor thickness of 0.06 in. The channel width was set to meet the allowable stress for the 0.06 -in floor thickness.

Acurex developed a unique design for mounting the crossflow filter during this effort. Because of flange cracking other crossflow users experienced, Acurex has designed a filter with no flange and a mount for the filter (see Figure 2-35 in Section 2.4). The approach of this mount is to provide a means for factory assembly of a unit that has been preloaded into the mount. The entire mount is then shipped to the site and mounted onto the manifold. Also, the mount material selection and design provides for a mount that matches thermal expansion of the filter over the expected operating temperature range. This approach should offer significant advantages over the shipping of unmounted crossflow filters.

\subsubsection{Stress Analysis}

Two finite element stress analyses were completed on selected parts of the filter. The two sections of the filter are shown in Figure 2-13 in Section 2.3. The porous floor and backwall were analyzed to determine the stress due to the thermal effects of pulse cleaning.

A model was developed for each section of the filter. The thermal model was based on axial temperature distribution calculations for flow through porous media. The porous media relationship was used to calculate the temperature distribution in the porous floor during a pulse cleaning transient. The temperature distribution was then combined with the material properties to determine the thermal stresses, and the locations or maximum and minimum principal stress. 
For the porous floor, the area of maximum stress was calculated to be the fillet radius where the porous floor meets the rib. The maximum stress in the backwall analysis occurs at the $90^{\circ}$ angle formed by the intersection of the clean channel wall and the backwall. The stresses calculated by the finite element model are shown in Table 2-5 in Section 2.3.6.4.

\subsubsection{Filter Manufacturing}

As stated previously, the overall goal of this project was to produce a monolithic crossflow filter. Most crossflow filters are manufactured using glued joints between the ribs and the floor. The monolithic crossflow, however, uses no glue, but is, instead, sintered. The advantage of this approach is higher strength and durability.

GTE's approach to producing a sintered filter was to extrude plates with ribs in place. The plates were placed in a mold with channel formers. The plates were pressed together, then the assembly was sintered.

Initially, small 1/4-scale (2.75-in x 2.75-in x 1.75-in) filters were produced for Acurex. Then, the filter size was scaled up to $1 / 2$-scale ( 6 in $\times 6$ in $\times 2$ in), the size required for testing at Westinghouse. This approach allowed GTE to develop the manufacturing technique on small filters, which are easily handled, and then to scale-up to process larger filters.

Using this technique, GTE successfully developed a glue-less press bonding filter manufacturing process able to take advantage of the low-stress design developed in Task 2. Examination of filters produced by this process show that they have high strength and sinter to a monolith.

\subsubsection{Filter Testing}

Almost 200 total hours of exposure including 75 total hours of dust feeding at $1,600^{\circ} \mathrm{F}$ and 150 psig were completed separately on two crossflow filters. Examination of both filters showed that the filters did not delaminate or crack due to operating conditions. One filter did fail as a result of trapped dust cracking a corner off the filter as the filter mount contracted during cooldown. 
The filters showed high callection efficiency during steady state operation. However, testing showed that the filter gasket surface area needs to be increased as the mount gasket failed several times during testing. However, when the gasket problems were solved, the filters generally had collection efficiencies between 99.5 percent and 99.99 percent.

Filter operating characteristics were within the range of typical operation. Filter face velocity ranged from 7 to $15 \mathrm{fpm}$ and maximum pressure drop at those conditions ranged from 35 to 135 in. w.c.

The second filter was operated at , fpm only, so that the steady-state operation characteristics of the filter could be determined. The filter appeared to be fairly close to conditioned at the end of testing, with the result that the permeability had dropped approximately 25 percent from unused condition.

Stable pulse pressure, cleaning cycle interval and clean filter pressure drop were obtained during testing of the second filter. At $7 \mathrm{fpm}$, the maximum pulse pressure was 430 psig at an operating pressure of $150 \mathrm{psig}$, and pulse cleaning occurred approximately every 30 minutes. Clean filter pressure drop was approximately 20 in. w.c.

\subsection{CONCLUSIONS AND RECOMMENDATIONS}

The results of this project show that CSN is an attractive material for crossflow filters. The design of the crossflow filter was changed to reflect some of the continuing problems which plague other crossflow filter materials, primarily flange breakage and delamination, and to take advantage of CSN's material properties.

Corrosion resistance of the CSN material is yet to be determined. However, since material strength for the CSN material is approximately twice that of other crossflow filter materials, it may be better able to withstand the effects of corrosion than other materials

Even though, the developed material looks promising for this application, the real accomplishment of this project was development of the press-bonding manufacturing technique. All 
testing indicates that this technique produces a monolithic ceramic upon sintering. In addition, this technique is applicable to other materials.

\subsubsection{Conclusions}

\subsubsection{Filter Design}

1. A crossflow filter design has been developed which meets the design criteria established at the beginning of the project.

2. The filter design incorporates stress reducing features such as fillet radii at all corners. In addition, the approach of eliminating the filter flange was taken to eliminate one problem area in the conventional filter design. The combination of these two approaches produced a filter whose material strength is twice the calculated stresses.

3. Gasket durability problems during testing indicated that the gasket surface area of the filter needs to be increased.

\subsubsection{Filter Manufacturing}

1. The material developed has high permeability ( $>1200$ millidarcies) and high strength $(\approx 5300 \mathrm{psi})$.

2. The manufacturing technique developed produces a monolithic filter upon sintering. The manufacturing technique also decreases the surface porosity.

\subsubsection{Filter Testing}

1. Filter qualification tests showed that the filter was strong and not subject to delamination.

2. During filter testing, the filter exhibited high collection efficiency, and completed testing without delamination.

3. The first filter tested failed when one corner broke during cooldown. The break was attributed to trapped dust compressing the filter as the mount contracted during cooldown. 
4. At $7 \mathrm{fpm}$ the filter exhibited stable cleaning cycle length and pulse pressure requirements.

\subsubsection{Recommendations}

CSN has shown a great deal of promise as a crossflow filter material. This project has allowed a significant portion of the development of this product to a commercial filter. However, the design, material and manufacturing need refinement.

1. The design should be modified to include:

- larger gasket area to increase gasket durability

- larger dirty-side channels to increase filter cleanability

2. The manufacturing process should be refined further. The following areas need improvement:

- filter press-bonding to eliminate decreasing surface permeability

- sintering to eliminate or reduce shrinkage (microwave sintering is a possibility)

Once improvements are made to the design and manufacturing process, the filter should be scaled to full size and a larger-scale demonstration should be planned. 


\section{SECTION 2}

\section{CROSSFLOW FILTER DESIGN}

Acurex and GTE selected CSN as the material that would be developed into a crossflow filter. CSN was selected as crossflow filter material based on several material characteristics. GTE's experienced has shown CSN to be easy to extrude into complex shapes, and also bonds very well. In addition, CSN sintering does not require significant nitrogen overpressure as does reaction bonded silicon nitride. In addition, the fully dense material is very strong (90 ksi) and the strength is maintained to temperatures up to $1,150^{\circ} \mathrm{C}$, and has a low coefficient of thermal expansion. These properties when contrasted against other materials, are very attractive and led us to select CSN as the material to develop into crossflow filters.

Given that CSN is the basis for the crossflow filter development, filter design proceeded in several steps:

- Process applications were defined for the crossflow filter system

- Filter system operating conditions for each process were defined

- A conceptual design was developed based on the crossflow filter operating conditions and current crossflow filter designs

- The conceptual design was compared to the material manufacturing capabilities in terms of permeability and thickness

- A final design was developed

- Thermostructural stress analyses of select parts of the crossflow were completed to verify the design 
Table 2-1. Filter design bases

Particulate removal efficiency 99.99 percent

Pressure drop, maximum $\quad 5$ in water at $10 \mathrm{ft} / \mathrm{min}$ clean gas face velocity

Filter porosity

10 to 50 percent

Minimum operating lifetime $16,000 \mathrm{hr}$

Half-scale dimensions:

Filter element $(\mathrm{H} \times \mathrm{W} \times \mathrm{L}) \quad 6$ in $\times 2$ in $\times 6$ in

Flange $(\mathrm{T} \times \mathrm{W} \times \mathrm{L}) \quad$ Flangeless

Minimum surface area $\quad 1.25 \mathrm{ft}^{2}$

\subsection{CONCEPTUAL DESIGN}

\subsubsection{Design Basis}

The design of the crossflow filter was based on guidelines summarized in Table 2-1 and shown in Appendix A.

In order to help establish the design bases for the crossflow filter, we defined process applications for the filter. The filter is primarily being developed for application in the advanced coal-conversion processes being developed by DOE. These processes are:

- Pressurized Fluidized-Bed Combustion (PFBC)

- Integrated Gasification Combined Cycle (IGCC)

- Direct Coal-Fired Turbine (DCFT)

Selected processes of each type were defined and operating conditions for each process determined so that we could define the operating conditions of the crossflow filter in detail. The processes are discussed in the following sections.

\subsubsection{PFBC Process}

The PFBC process utilizes a fluidized-bed reactor to combust coal and to capture sulfur with dolomite. The reactor is pressurized, which leads to higher sulfur sorption, lower $\mathrm{NO}_{\mathrm{x}}$ emissions, and smaller reactor dimensions than would exit if combustion wer? carried out under atmospheric 
conditions (Reference 2). A schematic of the PFBC process is shown in Figure 2-1. Five unit operations comprise the process:

- Coal/dolomite preparation

- $\mathrm{PFBC}$

- Steam turbine cycle

- Particulate removal

- Turbo expansion

Each of these unit operations is discussed below.

Coal/dolomite preparation involves grinding and drying prewashed feed. Vibrating feeders transport the coal/delomite feed. The feed is pulverized and dried with circulation gas prior to being fed to the combustor. Exhaust gas from the turbo expander can be used as circulation gas. Moisture-laden circulation gas is then cleaned in a baghouse prior to release to the atmosphere. The dried coal/dolomite is fed to the combustor through a lockhopper.

The PFBC is a fluidized-bed that operates at approximately $1600^{\circ} \mathrm{F}$ and 55 to $225 \mathrm{psig}$. Dried coal/dolomite is conveyed to the combustor through a lockhopper. Compressed air is supplied as a reactant. The combustion of organic material is essentially complete. Combustion gas from the combustor contains nitrogen, oxygen, carbon dioxide, and water, along with small amounts of carbon monoxide, hydrogen, sulfur dioxide, and alkali. Table 2-2 shows a typical composition of components in the raw gas. Significant amounts of oxygen are expected, creating an oxidizing condition in the combustion gas. Combustion gas is then routed to the particulate cleanup system. Spent dolomite and ash are rejected from the bed and collected for disposal.

As in conventional electricity production, a steam cycle is included in the PFBC. Highpressure steam $\left(1000^{\circ} \mathrm{F}, 3500 \mathrm{psi}\right)$ is generated from the fluid bed. This steam then passes through a series of steam turbines that spin a generator producing electricity. Low-pressure steam from the steam turbines is condensed and cycled back into the fluidized-bed combustor. 

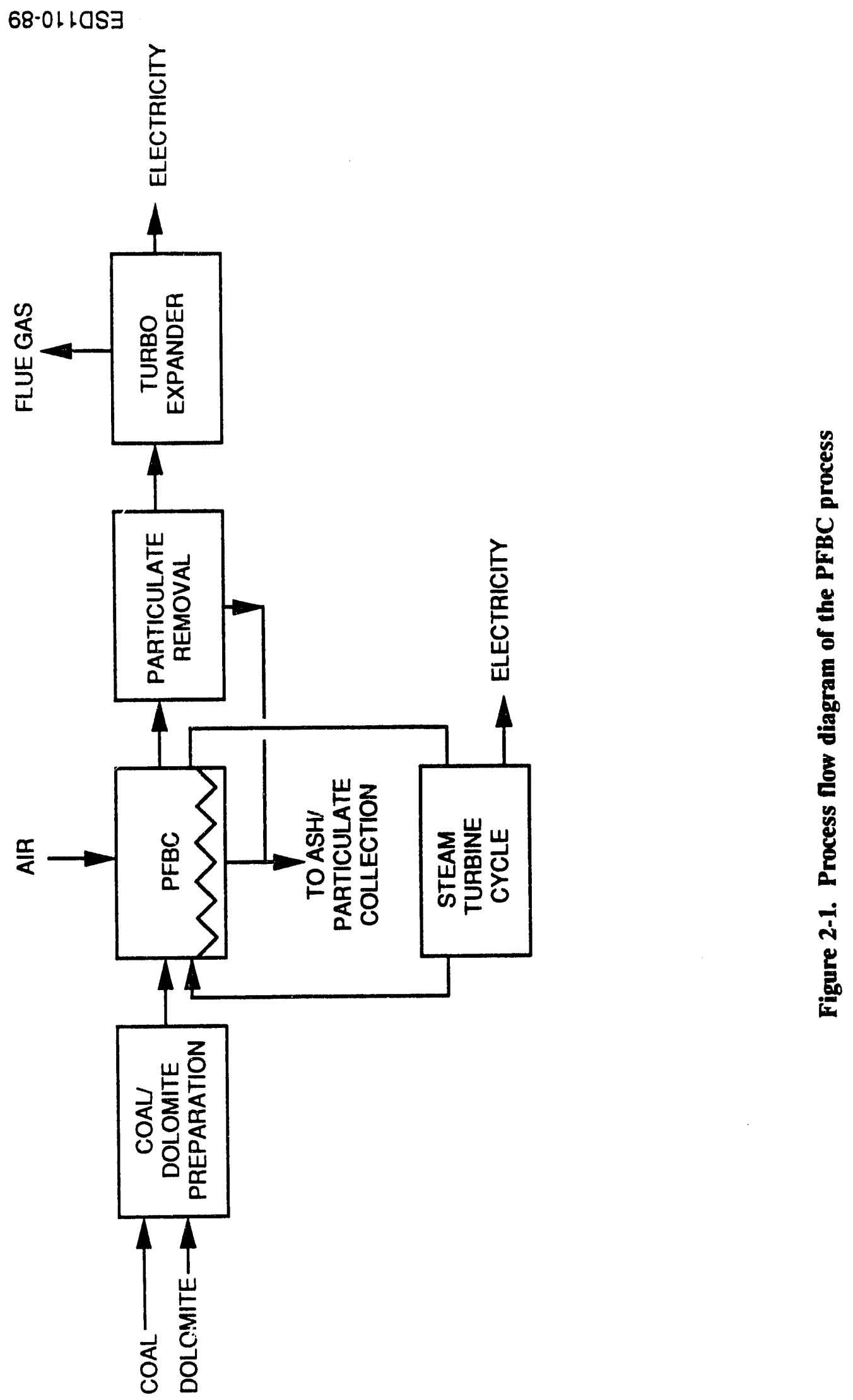


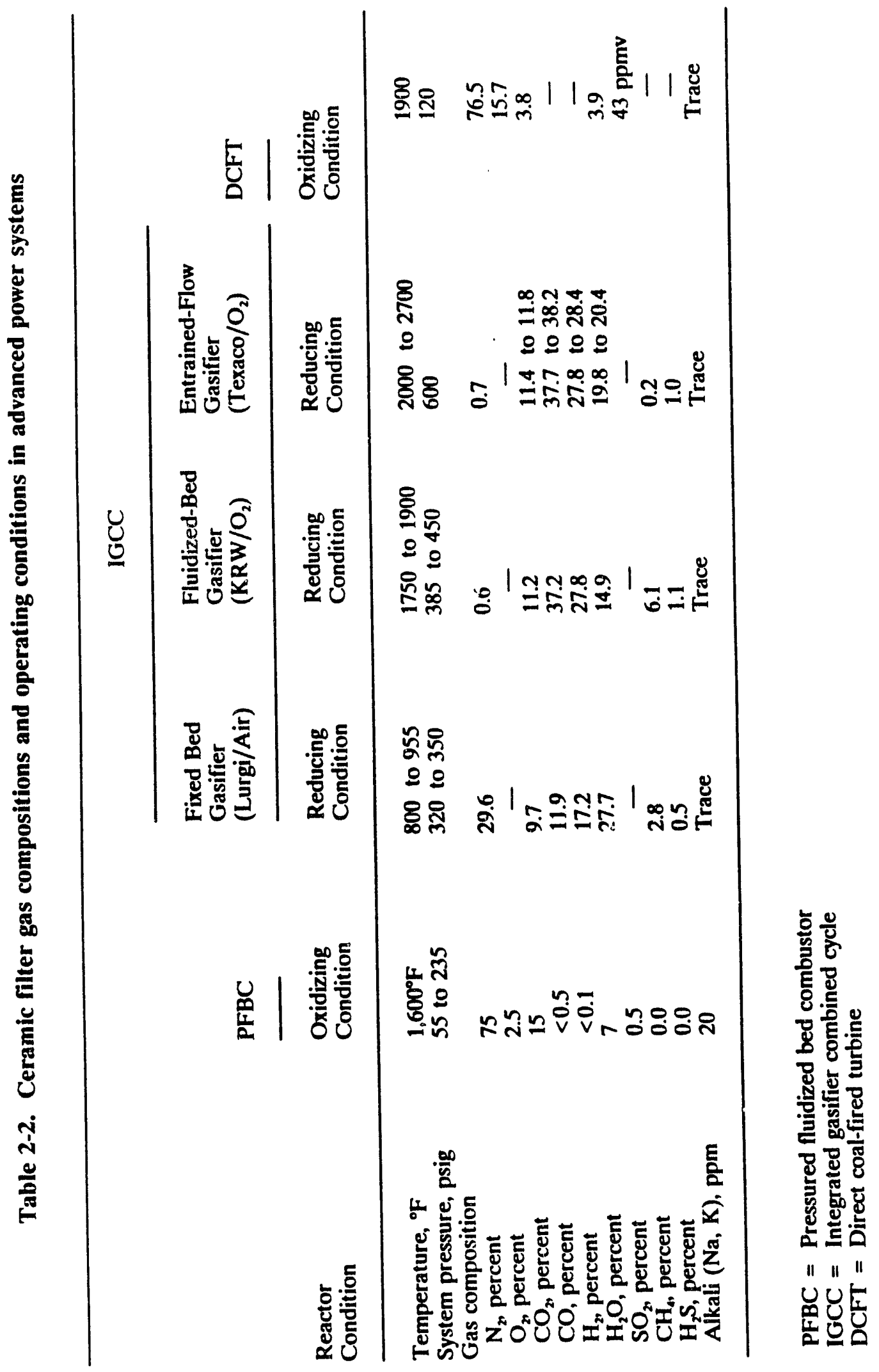


Particulate in the combustion gas from the PFBC must be removed before the gas enters the turbo expander. Particulate in the raw gas must be removed to $22 \mathrm{ppm}_{\mathrm{w}}$ with particles smaller than $5 \mu \mathrm{m}$. Particulate removal is conducted in two stages; the first stage employs a cyclone or set of cyclones, and the second stage employs a high-temperature filter. Collected particulate is conveyed with collected ash from the PFBC to storage for disposal.

Clean fuel gas from the particulate removal system is introduced to the turbo expander. The turbo expander generates electricity and drives the compressor, which compresses the air feed to the PFBC.

\subsubsection{IGCC Process}

There are three major types of gasifiers:

- Fixed bed

- Fluidized-bed

- Entrained bed

The operating conditions of each type of gasifier are sufficiently different that we defined a set of operating conditions for each type. We picked specific gasifier processes that are under dcvelopment and are likely candidates for commercialization within the next ten years. For fixed bed gasification, the BGC-Lurgi process operating conditions were used; for the fluidized-bed gasifier, the KRW process operating conditions were used; and for the entrained bed gasifier, the Texaco gasifier operating conditions were used.

\subsubsection{BGC Lurgi IGCC Process}

The BGC Lurgi process utilizes a fixed-bed gasifier to gasify coal. Introduced in the early 1950s, this process is currently at the demonstration stage (Reference 3). A schematic of the airblown BGC Lurgi process is shown in Figure 2-2. Seven unit operations comprise this process:

- Coal preparation

- Gasification

- High-temperature cooling and particulate removal 

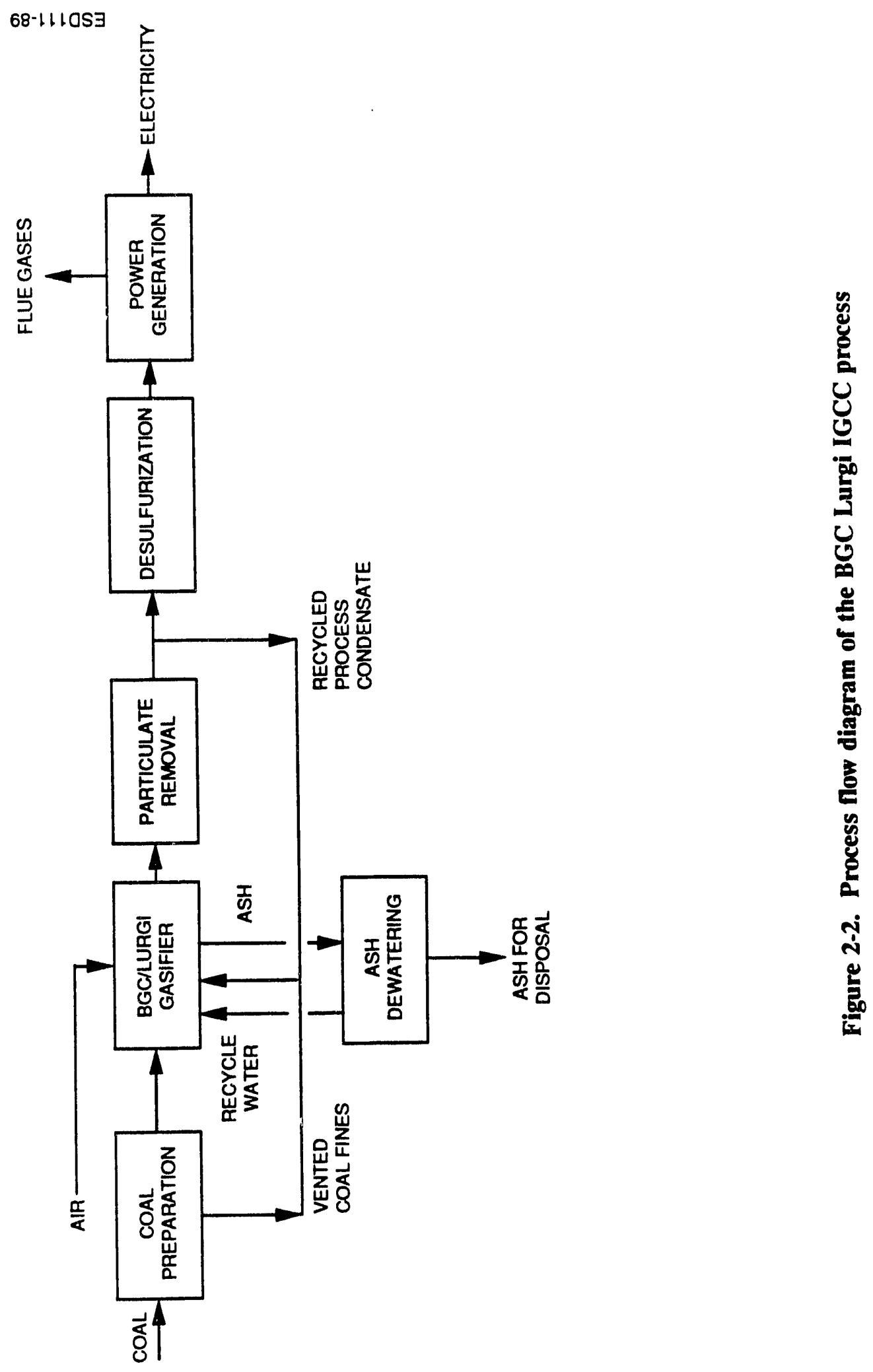
- Low-temperature cooling

- Ash dewatering

- Desulfurization

- Power generation

Each of these unit operations is discussed below.

Coal preparation involves grinding and drying prewashed coal. Vibrating feeders are used to transport the coal feed. The coal is pulverized and dried with circulation gas prior to being fed to the gasifier. Moisture-laden circulation gas, used to dry the coal feed, is cleaned in a baghouse prior to release to the atmosphere. Coal fines trapped in the baghouse are fed with process condensate to the gasifier. The dried coal is fed to the gasifier through a lockhopper.

The gasifier is a fixed-bed that operates between 800 and $900^{\circ} \mathrm{F}$, and 320 and 350 psig. Dried coal is fed by gravity from the lockhopper. High-pressure steam and oxygen, along with additional recycled process condensate, are introduced into the gasifier as reactants near the bottom of the bed. The steam rate is controlled to allow the coal to form into a molten slag. Recycle process condensate is routed from the gas cooling operation prior to desulfurization.

Combustion occurs at the bottom of the fixed-bed. Ash, which has only a negligible amount of unburned hydrocarbon, is discharged periodically to a quench chamber below the bed. Hot raw gas moves up from the bed, preheating the coal feed. Table 2-2 shows a generic composition of components in the raw gas. Raw gas containing mainly carbon monoxide, carbon dioxide, hydrogen, methane, hydrogen sulfide, nitrogen, and water vapor is formed. Appreciable amounts of tars, oils, naphtha, phenols, fatty acids, and ammonia may also be present. Raw gas is routed to particulate removal and cooling operations. Particulate in the raw gas must be removed prior to the entrance of the gas into the gas turbine system. Particulate removal is accomplished by high-temperature filtration. However, the raw gas must be heated to levels above the condensation points of tars and other heavy organics prior to filtration. 
The ash slurry from the slag quench chamber is transported to the dewatering operation. Ash is settled, dewatered, and disposed of in a landfill. Clarified water is recycled back to the slag quench chamber.

Clean fuel gas from the desulfurization system is introduced into the power generation system. Exhaust gas from the gas turbine enters the heat recovery steam generator, which supplies steam for the steam generator.

\subsubsection{KRW IGCC Process}

The KRW process utilizes a fluidized-bed gasifier to gasify coal. This process is currently at the pilot-scale stage. It is suitable for a wide variety of feedstocks because of its relative insensitivity to ash or sulfur content in the coal (Reference 4). A schematic of the KRW process is shown in Figure 2-3. Seven unit operations comprise the KRW process:

- Coal preparation

- Air separation

- Gasification

- High-temperature cooling and particulate removal

- Low-temperature cooling

- Desulfurization

- Power generation

Each of these unit operations is discussed below.

Coal preparation involves grinding and drying prewashed coal. Vibrating feeders transport coal to a hammer mill, which pulverizes it. Coal fines are then dried with steam-heated nitrogen, the dryer circulation gas. Moisture-laden circulation gas is then cleaned in a baghouse prior to its release to the atmosphere. The dried coal is fed to the gasifier through a lockhopper.

An air separation plant supplies the gasifier with oxygen. Oxygen, which is separated from air, is compressed and fed to the gasifier as oxidant. Separated nitrogen can be used in coal 

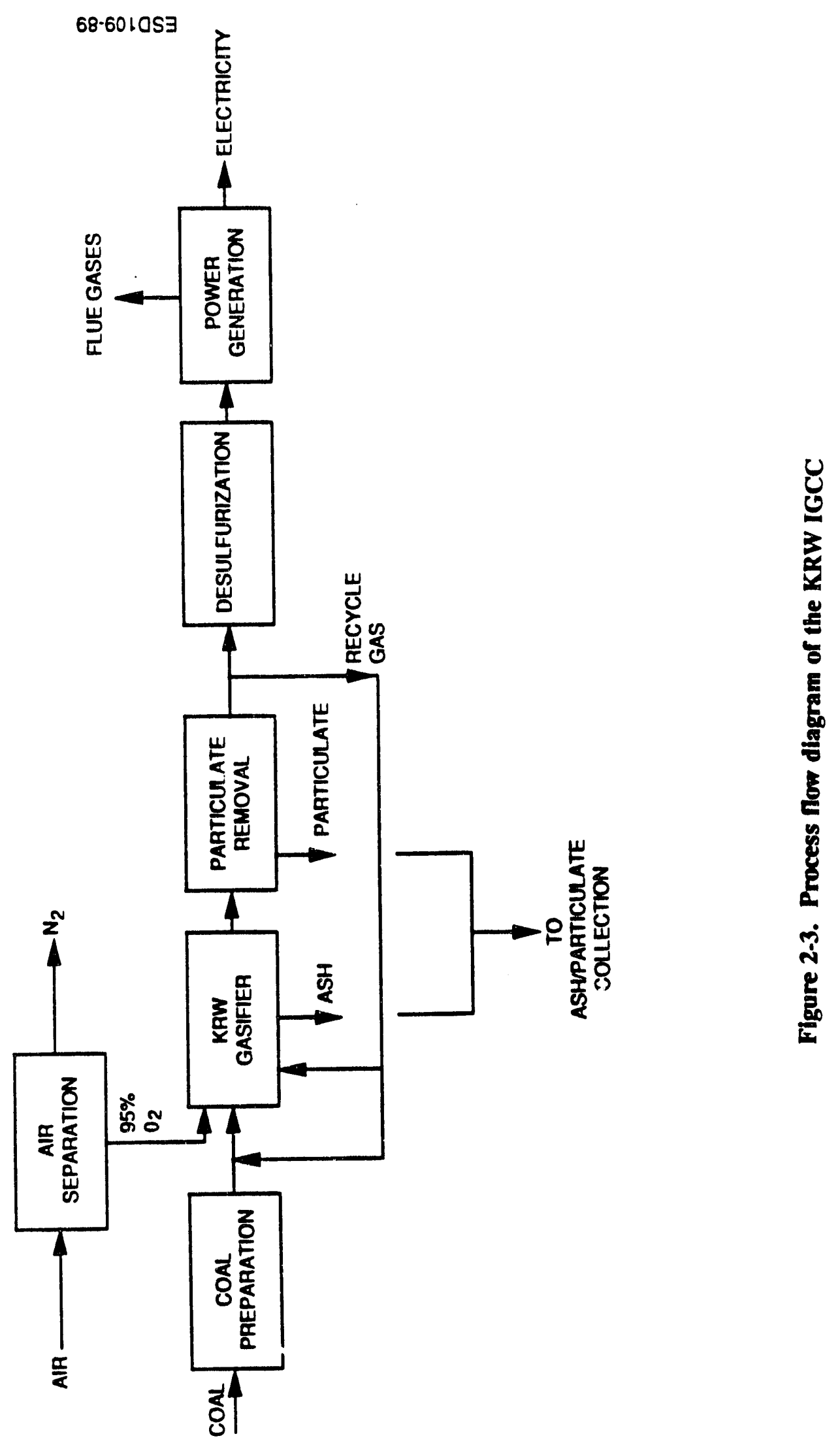
preparation to dry coal, as pressurization gas in the lockhopper, or in particulate removal to pulseclean the filter system.

The gasifier is a fluidized-beo that operates between 1750 and $1900^{\circ} \mathrm{F}$, and 385 and 450 psig. Dried coal is conveyed to the gasifier with recycle gas. High-pressure steam and oxygen, along with additional recycle gas, are introduced into the gasifier as reactants. Recycle gas, which has been cooled and scrubbed prior to desulfurization, aids gasifier fluidization, ash cooling, and separation. Since the bed has a large quantity of solids, the gasifier is relatively insensitive to upsets in oxygen flow (Reference 4).

An exothermic reaction results from the gasification of coal. Table 2-2 shows a generic composition of components in the raw gas, which is mainly carbon monoxide, carbon dioxide, hydrogen, methane, hydrogen sulfide, nitrogen, and water vapor. Raw gas is then routed to particulate removal and cooling operations. Some char-ash particles agglomerate, defluidize, and are collected in the annulus of the gasifier.

The raw gas must now be scrubbed of particulate and desulfurized. Particulate removal is conducted in two stages; the first stage is a cyclone and the second stage is a high-temperature filter. Collected particulate is conveyed with collected ash from the gasifier to storage for disposal. Some of the crude gas is recycled back to the gasifier. Hydrogen sulfide is then removed from the crude gas during desulfurization.

Clean fuel is introduced into the power generation system. Fuel gas supplies a gas turbine. Exhaust gas from the gas turbine enters the heat recovery steam generator, which supplies steam for the steam generator.

\subsubsection{Texaco IGCC Process}

The Texaco process utilizes an entrained-bed gasifier to gasify coal. A schematic of the Texaco process is shown in Figure 2-4. In the Texaco process, coal is fed to the gasifier as a slurry, and ash rather than crude gas is recycled. Eight unit operations comprise the Texaco process: 
68-801053

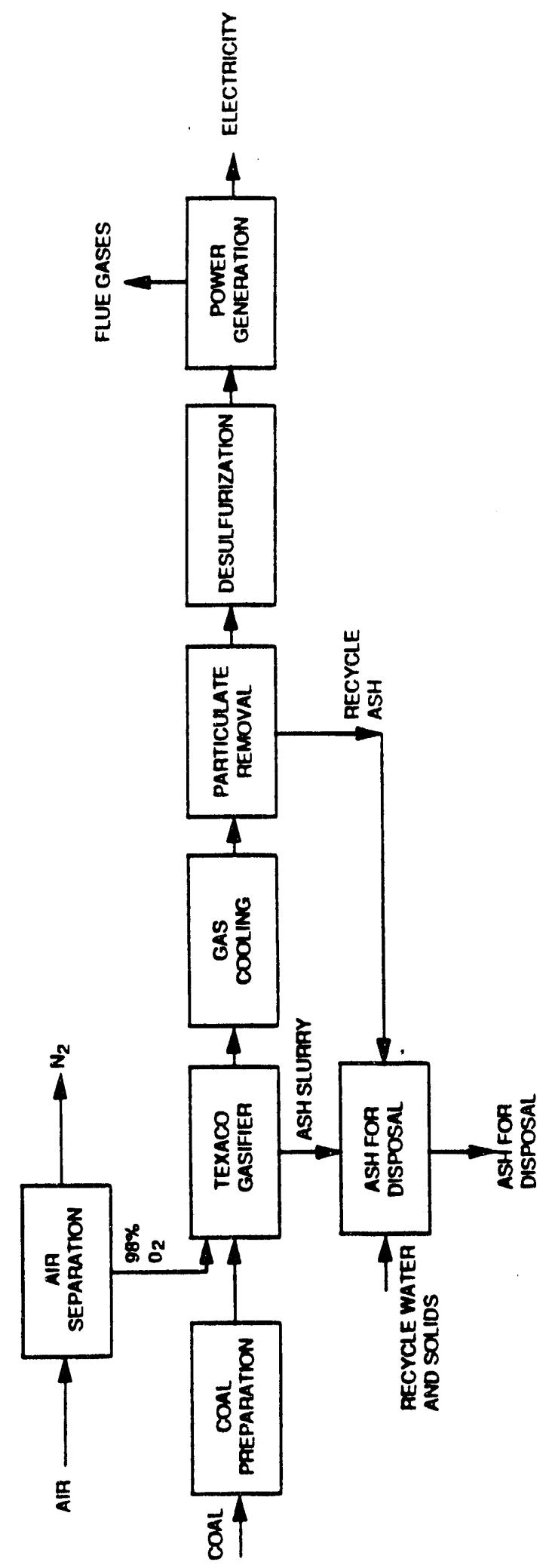

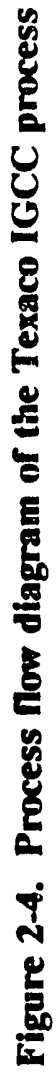


- Coal preparation

- Air separation

- Gasification

- High-temperature cooling and particulate removal

- Ash dewatering

- Low-temperature cooling

- Desulfurization

- Power generation

Each of these unit operations is discussed below.

Coal preparation involves the grinding and blending of prewashed coal with recycle water and solids from ash dewatering. Vibrating feeders transport coal to a grinding mill, which pulverizes the coal wet with recycled solids. The recycled solids slurry comes from the residual wastewater in the ash dewatering operation. The coal slurry is fed to the gasifier at approximately 66.5 percent solids.

An air separation plant is needed to supply the gasifier with oxygen. Oxygen, which is separated from air, is compressed and fed to the gasifier as oxidant. Separated nitrogen may be used in particulate removal to pulse-clean the filter system.

The gasifier is an entrained-bed that operates between 2000 and $2700^{\circ} \mathrm{F}$, and 600 psig. The temperatures are sufficiently above the ash flow point to ensure a free-flowing molten slag (Reference 3). High-pressure steam and oxygen are fed to gasify coal. Hydrogen and carbon in coal react to form carbon monoxide, carbon dioxide, and hydrogen gas. Table 2-2 shows the composition of raw gas from the Texaco process. Water vapor is present in the raw gas in the highest water vapor content of all power generation systems studied in this program. This highwater content may be the result of feeding coal as a slurry rather than as dry fines. Most of the mineral matter and unburned coal that remains as molten slag falls into a water quench, generating an ash slurry. The ash slurry is routed to the ash dewatering operation prior to recycle or disposal. 
Particulate in the raw gas must now be removed prior to using the gas in the gas turbine system. Particulate removal is accomplished with a high-temperature filter, which may be preceded by a set of cyclones. Ash removed during this step may be recycled back with the ash slurry from the gasifier. Gas cooling, which is accomplished by a waste heat boiler, is necessary since raw gas temperatures are approximately $2400^{\circ} \mathrm{F}$ (Reference 5).

The ash slurry from the gasifier and the recycle ash from particulate removal must now be prepared for disposal. These solids slurries are dewatered to approximately $30 \mathbf{w}^{+}$water and disposed of in a landfill. Some of the reclaimed water from the dewatering operation is recycled to the gasifier as quench water and to the grinding mill as coal slurry feed.

Clean fuel is introduced into the power generation system. Exhaust gas from the gas turbine enters the heat recovery steam generator, which supplies steam for the steam generator.

\subsubsection{Solar Turbine's Direct Coal-Fired Turbine Process}

Solar turbines direct coal-fired turbine (DCFT) is an innovative variation of the gas powered turbine. This process is currently at the pilot-scale stage and is shown in Figure 2-5. Eight unit operations comprise the DCFT process:

- Compression

- Coal preparation

- Primary zone

- Impact separation

- Secondary zone

- Secondary cleanup

- Turbine expansion

- Power generation

Each of these unit operations is discussed below.

The compression stage of this process is driven by the power turbine. Inlet air is compressed and fed to the primary combustion zone. 

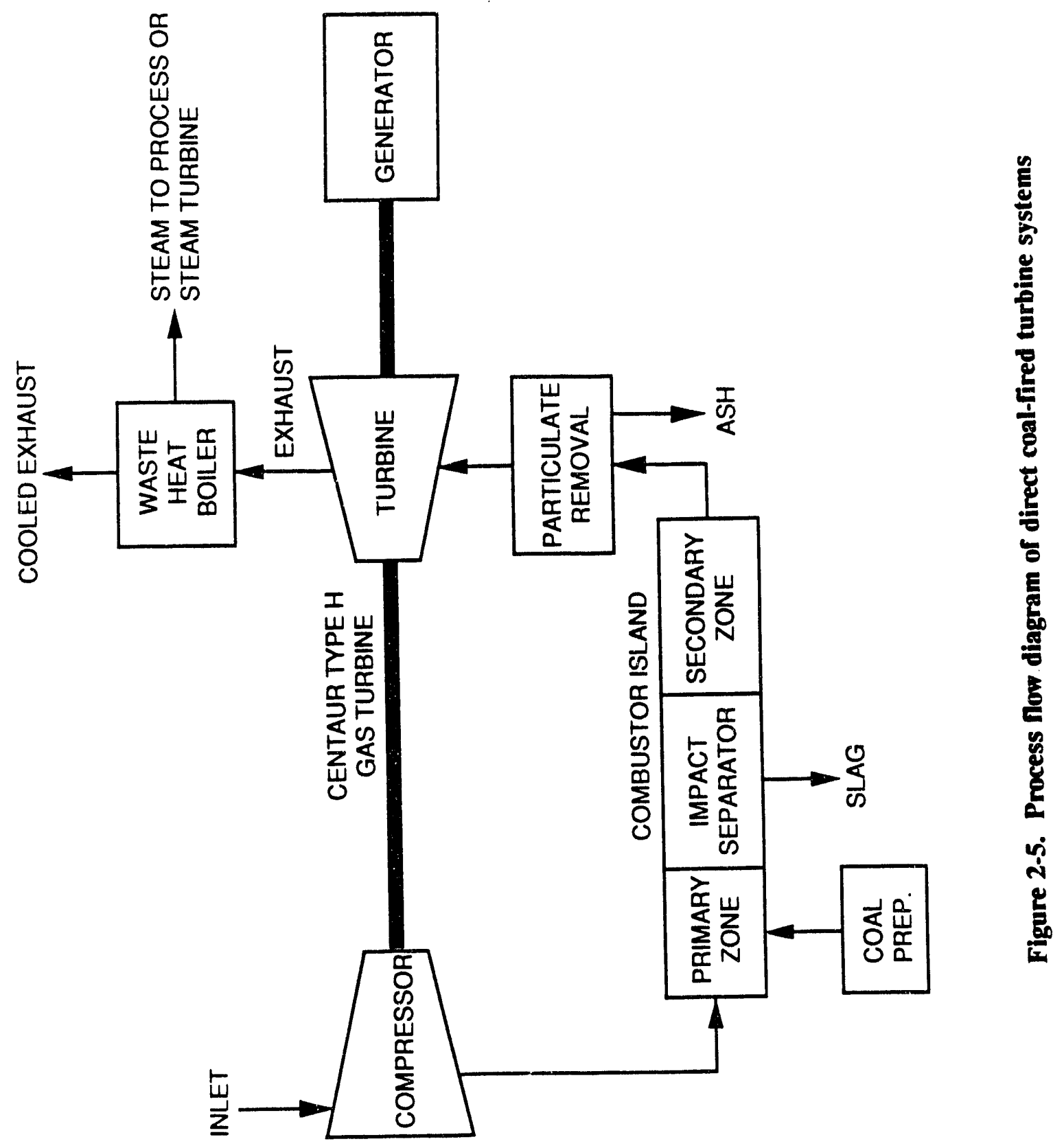
Coal preparation for a coal-water slurry and a dry pulverized feed are both being considered. The selection between these two means of preparing the coal feed has not been made as yet. However, the development of the coal-water slurry feed for this process is much more advanced than the dry pulverized feed in terms of $\mathrm{NO}_{\mathbf{x}}$ emissions, fuel reliability, and general handling (Reference 6). Prepared coal is fed directly into the primary combustion zone.

A two-stage (primary stage and secondary stage) slagging combustion zone with particulate cleanup is inserted between the compressor and turbine sections of the process. The primary combustion zone receives compressed air and prepared coal feed as reactants. This unit operates under slagging conditions in a fuel-rich environment for effective $\mathrm{NO}_{\mathrm{x}}$ control. Slag is continually removed from the pressurized combustor to a collection tank.

A particulate rejection impact separator (PRIS) provides additional slag removal. The PRIS unit, which is a tube matrix design, is located between the primary and secondary combustion zones. The tube matrix design employs a tube bank positioned normal to stream flow. Particulate is removed upon impact with the tube bank. Bench-scale data suggest that the tube matrix design is a superior concept (Reference 6).

The secondary combustion zone (an oxidizing zone) completes the reaction of coal to carbon dioxide, water vapor, and nitrogen gas. Table 2-2 shows the estimated raw gas composition for this process. As with the PFBC process, significant amounts of oxygen are expected to be present in the raw gas, creating an oxidizing condition. Lime-based sorbents are injected in this zone for sulfur oxide control.

Secondary cleanup may be performed with a ceramic filter. Crossflow, bag, or candle filter designs may be used with this process. The filter will generate a clean fuel gas at $1900^{\circ} \mathrm{F}$ and 120 psig.

Clean fuel gas now enters the turbine expander and power generation portion of the process. The clean gas expands through the turbine expander, providing energy to power a generator 
producing electricity. Heat from the turbine exhaust is recovered in a waste heat boiler, which generates steam for process or a steam generator.

\subsubsection{Design Approach}

Once the operating conditions were defined, an approach that defined the overall parameters of the crossflow filter and crossflow filter mount had to be selected. The approach selected by Acurex was to start the design of the crossflow filter by taking the design of the current crossflow filter and incorporating approaches to help reduce operational stresses. The elements of the approach were as follows:

- Reduction of stresses in the channel corners by using a fillet radius

- Development of a flangeless crossflow filter mounting design, as the flanged mounting has presented flange attachment and flatness problems. Also, recent tests of the mixedoxide crossflow filter have indicated that cracking of the filter may start at the flange.

- Development of a factory-assembled mount that is ready for shipment and mounting, so that the crossflow filter is not handled during the installation process

These elements presented the overall approach to the filter design. With this design philosophy defined, the next step was to define the approach for developing the detailed design of the crossflow.

The detailed design started with determination of the thickness of the porous floor. Figure 2-6 is a flow chart showing the steps taken to design the filter. The thickness of the porous floor was treated as an independent variable as it depended on the permeability and thickness that could be manufactured by GTE. Once the porous floor thickness was assumed, a concentrated pressure load was assumed to be acting on the floor. This approach was used to determine the rib spacing and the rib width, since the rib spacing determined the beam length and hence the pressure stress on the floor. The channel height was selected to meet the surface area requirements set by DOE. Channel height selection is based on a compromise. The competing parameters are cleanability and surface area. As the channel height decreases, the surface area increases; however, as the channel height decreases, filter cleanability decreases. Acurex selected a channel height in 


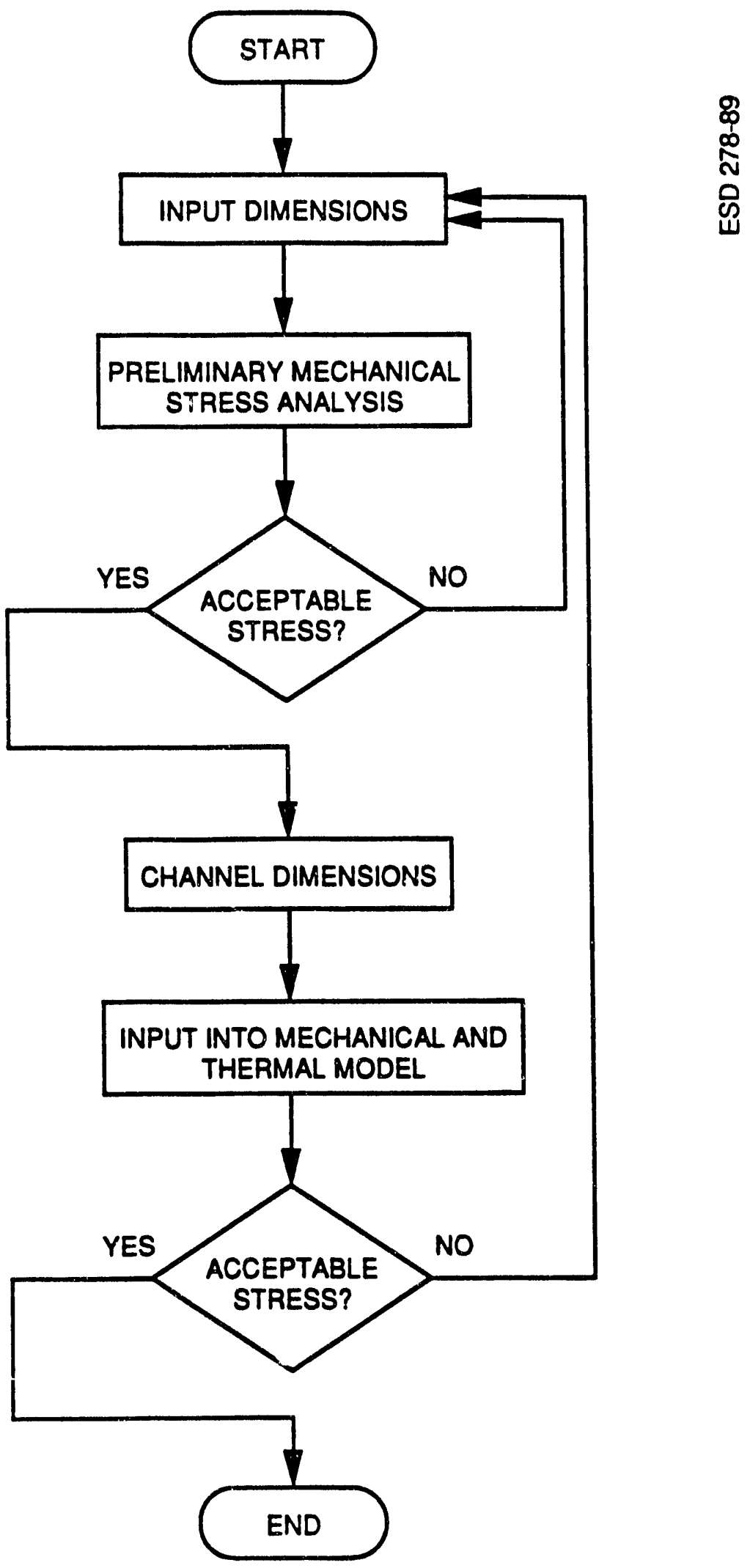

Figure 2-6. Filter design flow chart 
the middle of the range of observed channel heights. In actual application, the channel height may be optimized to account for special properties of a particulate or process.

Once a design was completed, thermostructural stress analyses were completed for selected sections of the crossflow. The primary effort in the stress analyses was focused on 2-dimensional analysis of the channel and the backwall where it joins the clean channel.

The design of the crossflow and mounting approach will be discussed in greater detail in Section 2.2. The thermustructural stress analyses will be discussed in detail in Section 2.3.

\subsection{MACROSCOPIC DESIGN}

Suggested guidelines for the original channel dimensions were given by DOE (see Appendix A). In addition, these guidelines are summarized in Section 2.1.1. Using this information, it was necessary to make some assumptions on the crossflow filter geometry based on preliminary calculations and work done in the past by Westinghouse on mixed-oxide filters. A summary of the range of values for the filter geometry are as follows:

- Channel width $\bar{\Sigma} 0.375$ in

- Channel height $\approx 0.25$ in

- $0.03<$ floor thickness $<0.10$ in

- Surface area $\equiv 1.25 \mathrm{ft}^{2}$

These dimensions are interdependent (i.e., increased floor thickness reduces surface area which may make it necessary to increase channel width to increase the surface area). Therefore, given the number of geometry combinations available, it became necessary to iterate using the flow chart in Figure 2-7. Values were assumed for channel height, channel width, and floor thickness. The loads were applied to the particular geometry and stress concentration factors applied. Rib spacing was calculated and the stress compared to the allowable stress for the material. Then, if greater than the allowable stress, the process was repeated until a low stress design evolved that met the surface area requirements. 
$n_{c}=$ CLEAN CHANNEL HEIGHT

$W_{c}=$ CLEAN CHANNEL WIDTH

FT = FLOOR THICKNESS

$\sigma_{\mathrm{cri}}=$ CALCULATED STRESS

$\sigma=$ DERATED MODULUS STRESS

$\triangle P=$ FILTER PRESSURE DROP

$K_{1}$ - STRESS CONCENTRATION FACTOR (FROM PUBLISHED DATA)

$A_{f}=$ FILTER SURFACE AREA

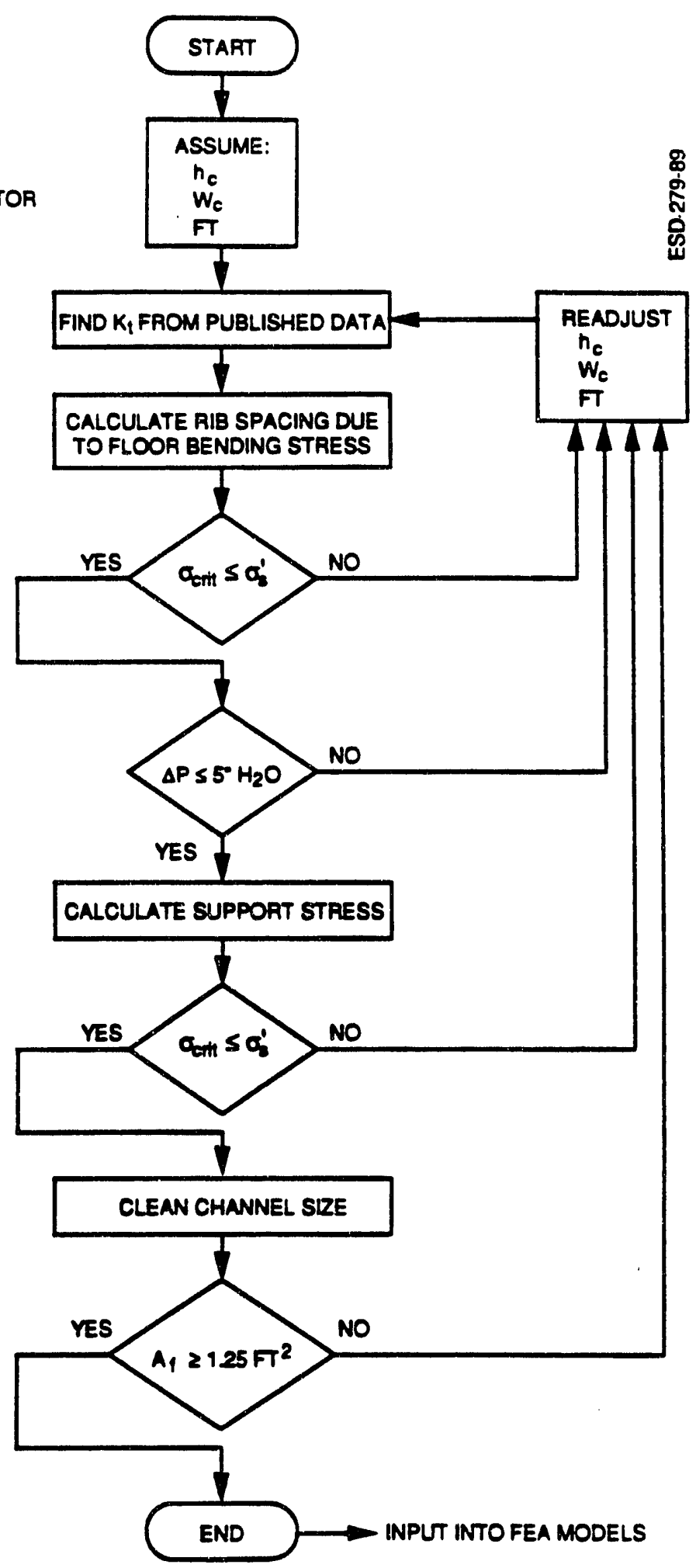

Figure 2-7. Flow chart for preliminary stress analysis 
The design approach was to maximize the filter surface area while minimizing mechanical stresses due to the $10 \mathrm{psi}$ overpressure present during pulse cleaning. Other considerations were filter cleanability, permeability, and manufacturability. Note that the preliminary calculations for mechanical stresses are based on the clean side of the filter, since the cleaning pulse enters through the clean channels and causes bending of the channel floor. The reactions cause tensile stresses to concentrate at the channel fillet.

The major elements of the design involved iterative calculations of channel width, rib width, floor thickness, and channel height based on calculations for an acceptable stress level for CSN. The acceptable stress level was calculated by applying safety factors and stress-derating factors to the expected material strength of $6000 \mathrm{psi}$. The following sections discuss how the factors were used and how the acceptable stress levels were arrived at to select the crosstiow filter geometry.

\subsubsection{Stress Derating}

GTE measured the modulus of rupture to be approximately $5300 \mathrm{psi}$. It was decided to derate the MOR by a factor of safety $(\mathrm{N}=2)$ and a stress concentration factor $(\mathrm{Kt}=4)$. The critical area of stress concentration would likely be at the channel fillet, and would be dependent upon the fillet radius. A study by Westinghouse (Reference 8 ) found an acceptable stress concentration for a fillet with a radius of 0.015 in. Therefore, a value of 0.020 in is a conservative estimate for the preliminary design. The radius was later increased to 0.04 in to further reduce stress at the fillet. Published empirical data (Reference 9) were used to estimate the stress concentration factor. The value of $\mathrm{Kt}=4$ is an approximation based on data for a rectangular hole with rounded corners in an infinitely wide plate subjected to uniaxial tension. In reality, the Kt value is likely to be higher because of end effects caused by adjacent channels. However, an estimate was adequate for the preliminary analysis, as a more detailed analysis in the finite element model was subsequently performed. 


\section{2 .2 Floor Thickness}

Figure 2-8 shows a description of the channel variables used in the stress analysis. Using the safety factors and stress derating factors, the acceptable stress level was calculated to be 750 psi. Preliminary stress calculations that considered the channel floor as a simply supported beam in bending arrived at the following equation:

$$
\sigma=\frac{7.5 W_{c}}{F T^{2}}
$$

where: $\sigma \quad$ = bending stress

$\mathrm{W}_{\mathrm{c}}$ = clean channel width

$\mathrm{FT}=$ floor thickness

Figure 2-9 shows a plot of bending stress versus floor thickness for a channel width of 0.60 in. As can be seen, the stress is a squared relationship to the floor thickness. As the floor thickness approaches 0.06 in, the stress reaches a critical level. Other graphs were generated to show the effect of floor thickness on stress for different channel widths. Increasing the floor thickness adversely affects the surface area because fewer channel layers can be stacked in the filter. Note that the higher floor thickness values (FT >0.75) are also undesirable because of the inability to meet permeability requirements.

\subsubsection{Channel Width}

Bending stress calculations were used to establish the channel width. The following equation was derived for the channel width and was iterated until an allowable stress level was found:

$$
\sigma=2083 W_{c}^{2}
$$

As seen in Figure 2-10, channel width and bending stress is a squared relationship. In order to achieve ideal permeability, the floor thickness was decreased to $0.06 \mathrm{in}$, thus requiring the channel width to be decreased so as to reduce stress to an acceptable level. 
$A R E A=\left[W_{c} N_{c}\right.$ (wide) $W_{d} N_{d}$ (wide) $] 2 N_{\text {(high) }}$

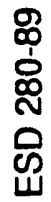

VARIABLES:

$W_{c}=$ CLEAN CHANNEL WIDTH

$W_{d}=$ DIRTY CHANNEL WIDTH

$N_{c}=\#$ CLEAN CHANNELS

$N_{d}=\#$ DIRTY CHANNELS

$N=\#$ CHANNEL LAYERS
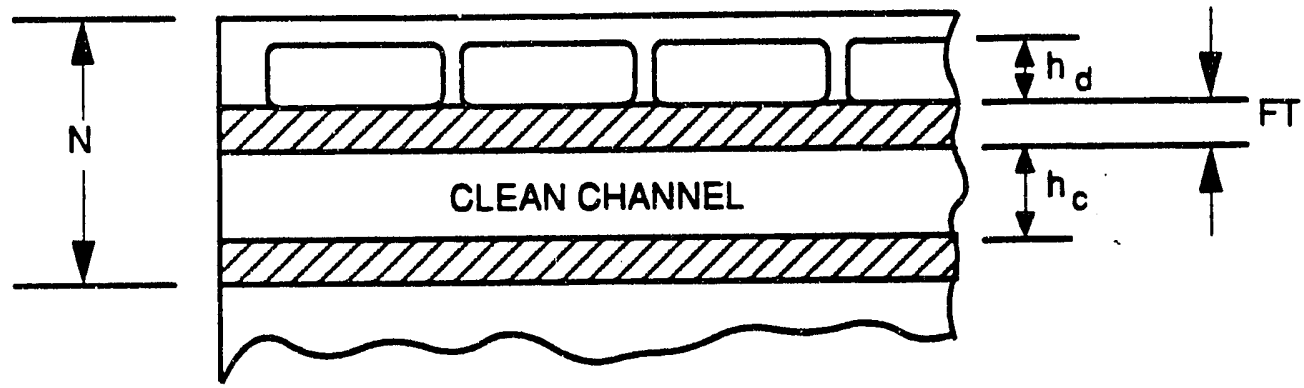

$h_{c}=$ CLEAN CHANNEL HEIGHT

$h_{d}=$ DIRTY CHANNEL HEIGHT

$F T=$ FLOOR THICKNESS

Figure 2.8. Description of the channel variables used in the stress analysis 


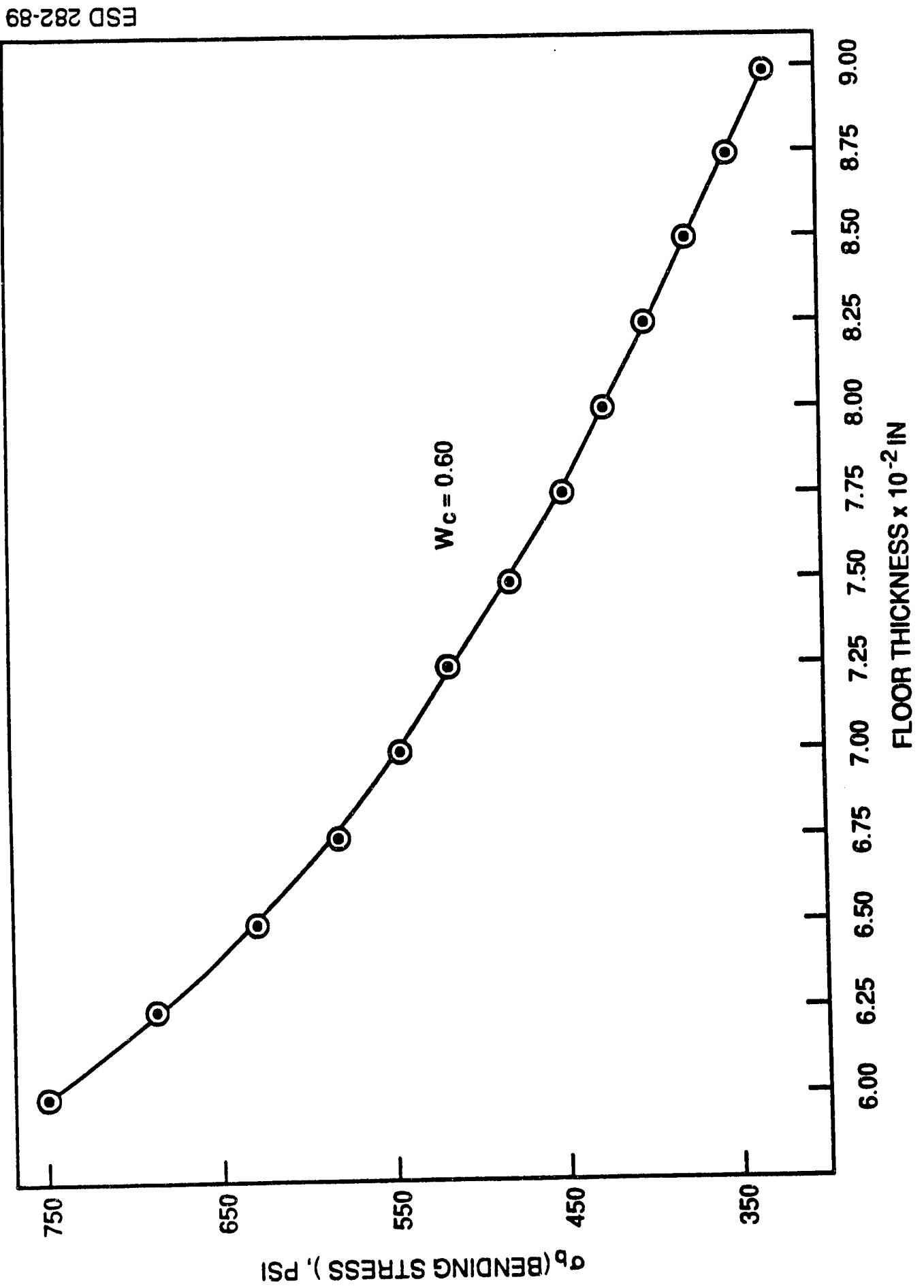

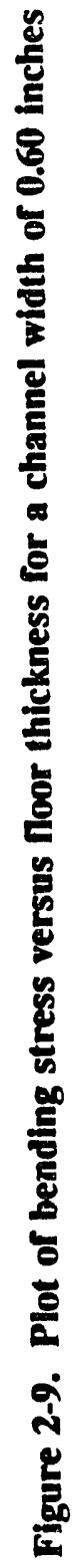




\begin{tabular}{|c|c|c|c|c|c|c|c|c|}
\hline \multirow[b]{2}{*}{$\begin{array}{c}\text { Channel } \\
\text { Width } \\
W_{c}\end{array}$} & \multirow[b]{2}{*}{$\begin{array}{c}\text { Bending } \\
\text { Stress } \\
\sigma \\
\end{array}$} & \multicolumn{2}{|c|}{ Rib Width } & \multicolumn{3}{|c|}{$\begin{array}{c}\text { Clean Side } \\
r_{\nabla}=0.18\end{array}$} & \multicolumn{2}{|c|}{$\begin{array}{c}\text { Dirty Side } \\
r_{\sigma}=0.10\end{array}$} \\
\hline & & $\begin{array}{c}\text { \# Clean } \\
\begin{array}{c}\text { Channels } \\
\text { Wide }\end{array}\end{array}$ & $\begin{array}{c}\text { \# Dirty } \\
\text { Channels } \\
\text { Wide }\end{array}$ & $\begin{array}{c}h_{c}=0.10 \\
\left(\text { Area in }{ }^{2}\right)\end{array}$ & $\begin{array}{l}h_{c}=0.13 \\
\left(\text { Area in }{ }^{2}\right)\end{array}$ & $\begin{array}{l}h_{c}=0.15 \\
\left(\text { Area in }{ }^{2}\right)\end{array}$ & $\begin{array}{c}h_{c}=0.15 \\
\text { (Area) }\end{array}$ & $\begin{array}{c}\# \\
\text { Channels } \\
\text { Wide }\end{array}$ \\
\hline 0.54 & 607 & 2 & 8 & 168 & 140 & 131 & 147 & 9 \\
\hline 0.52 & 563 & 2 & 8 & 156 & 130 & 121 & 136 & 9 \\
\hline 0.50 & 521 & 2 & 8 & 144 & 120 & 112 & 126 & 9 \\
\hline 0.48 & 480 & 3 & 9 & 224 & 187 & 174 & 193 & 10 \\
\hline 0.46 & 441 & 3 & 9 & 206 & 171 & 160 & 178 & 10 \\
\hline 0.44 & 403 & 3 & 9 & 188 & 157 & 146 & $179 *$ & 11 \\
\hline 0.42 & 367 & 3 & 10 & 191 & 159 & 148 & 163 & 11 \\
\hline
\end{tabular}

*Ieration selected for final dimension.

Figure 2-10. Channel width and bending stress are a squared relationship

\subsubsection{Rib Sizing}

Calculations were used to check the stress in the channel support or rib. A small tension component caused by the 10 psi overpressure was thought to occur in the rib. However, this stress was found to be less than $100 \mathrm{psi}$ and is therefore negligible.

\subsubsection{Channel Height}

Adjusting the channel height dimension had two effects:

- Lowering the channel height allows more channel layers to be stacked, thus increasing surface area

- Lowering the channel height adversely affects filter cleanability

Past experience in filter operation indicates that a minimum channel height should be greater than 0.12 in, but less than 0.25 in. However, the higher value would reduce the surface area. The following relationship was derived between channel height and surface area: 


$$
N=\frac{6}{2 F T+2 h}
$$

where: $\mathrm{N}$ = channel layers (Figure 2-7)

$$
\begin{aligned}
& \mathrm{h}=\text { channel height } \\
& F T=\text { floor thickness }
\end{aligned}
$$

Note that the dirty channel height is equal to the clean channel height for manufacturing reasons. Figure 2-11 shows a plot of channel height versus surface area for FT $=0.09$. To allow for good filter cleanability, it was decided to use a channel height of 0.15 , and iterate channel width and rib width to increase the surface area.

\subsubsection{Surface Area}

The general equation derived for the surface area is shown with Figure 2-8. Since the floor thickness was determined by stress analysis and the channel height by cleanability, it was decided to reduce the rib width which is less critical. This allows more channels to be placed end to end, thereby increasing surface area. Although channel width could be used to increase surface area, this value is limited by the bending stress.

\subsubsection{Conclusions}

Figure 2-10 shows the iterations that resulted in the final channel dimensions. The final design resulted in a surface area of $180 \mathrm{in}^{2}\left(1.25 \mathrm{ft}^{2}\right)$, meeting the surface area requirement established by DOE. The final design is shown in Figure 2-12. The channel dimensions are as indicated on the figure. The dirty side of the filter is 11 channels wide and 14 channels high, resulting in 154 dirty side channels. The clean side of the filter is 3 channels wide and 13 channels high, resulting in 39 clean side channels.

\subsection{STRESS ANALYSIS}

Stress analyses were then completed on the crossflow which has the dimensions calculated. 


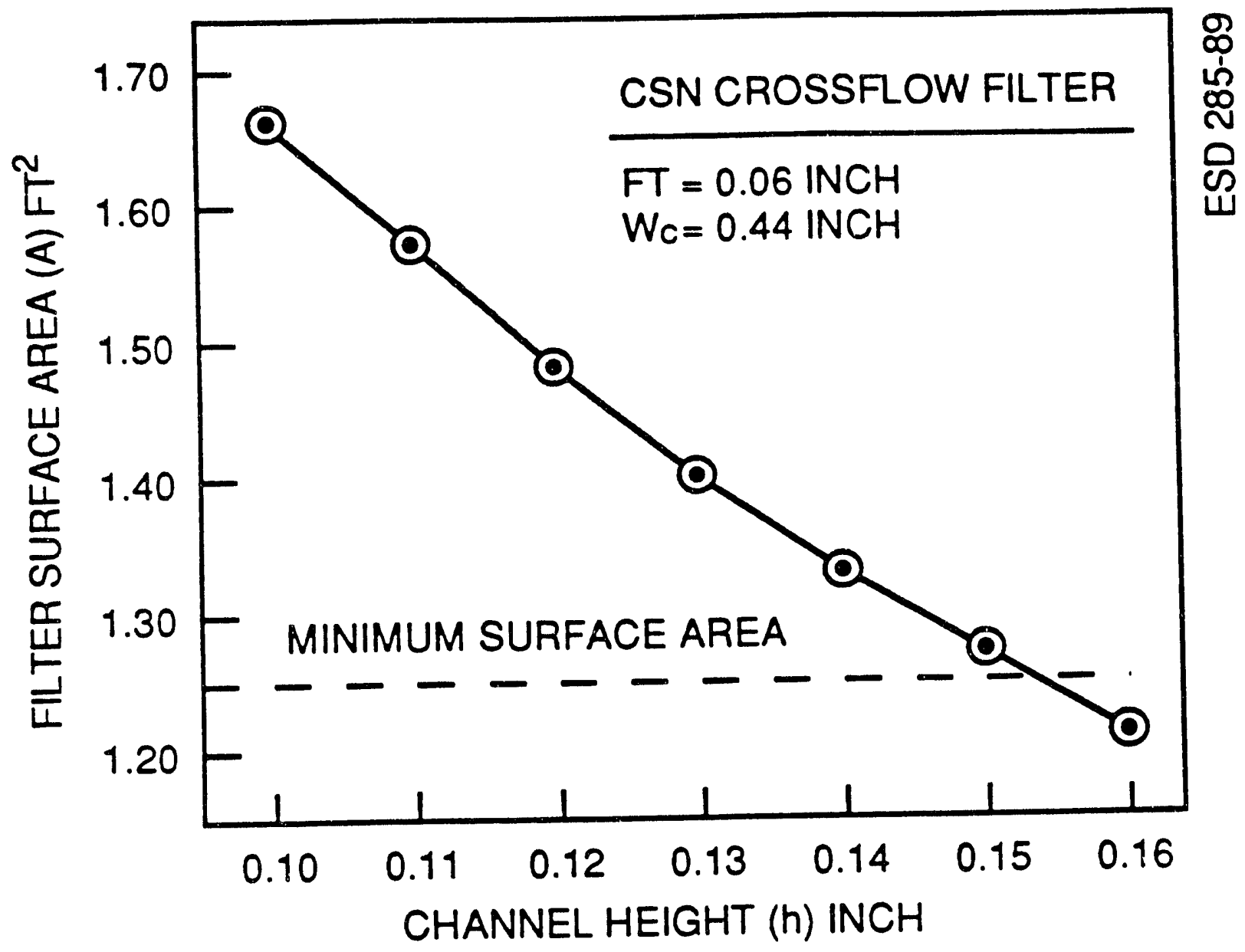

Figure 2-11. Plot of channel height versus surface area for $F T=0.06$ 
CHANNEL DIMENSIONS (ALL IN INCHES)

HALF SCALE FILTER FT $=0.06$ (FLOOR THICKNESS)

CLEAN SIDE $(3 \times 13) \quad W_{C}=0.44$ (CHANNEL WIDTH)

$h_{C}=0.14 \quad$ (CHANNEL HEIGHT)

$r_{W}=0.18 \quad$ (RIB THICKNESS)

$r_{C}=0.04$ (CORNER RADIUS)

$d=0.16 \quad$ (EDGE THICKNESS)

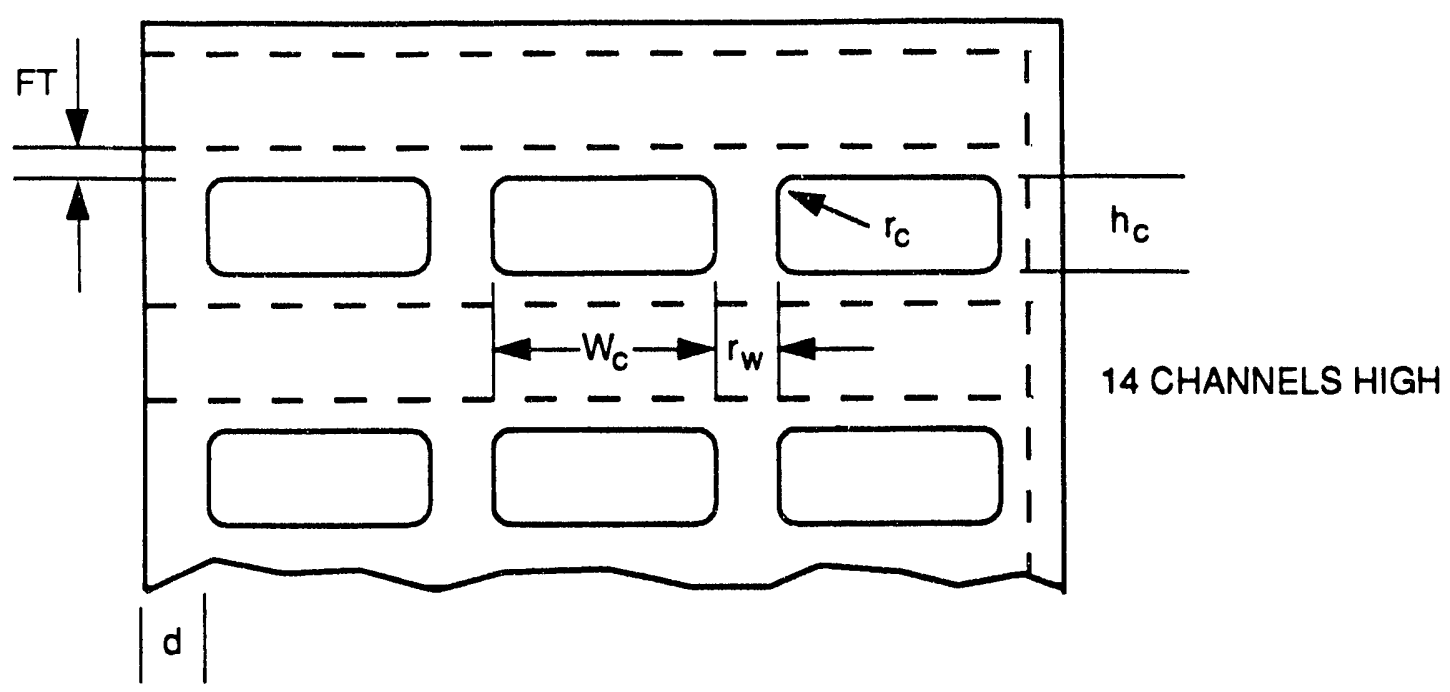

$$
\begin{aligned}
\text { DIRTY SIDE }(11 \times 14) \quad W_{c}=0.44 \\
h_{c}=0.14 \\
r_{w}=0.10 \\
r_{c}=0.04 \\
d=0.08
\end{aligned}
$$

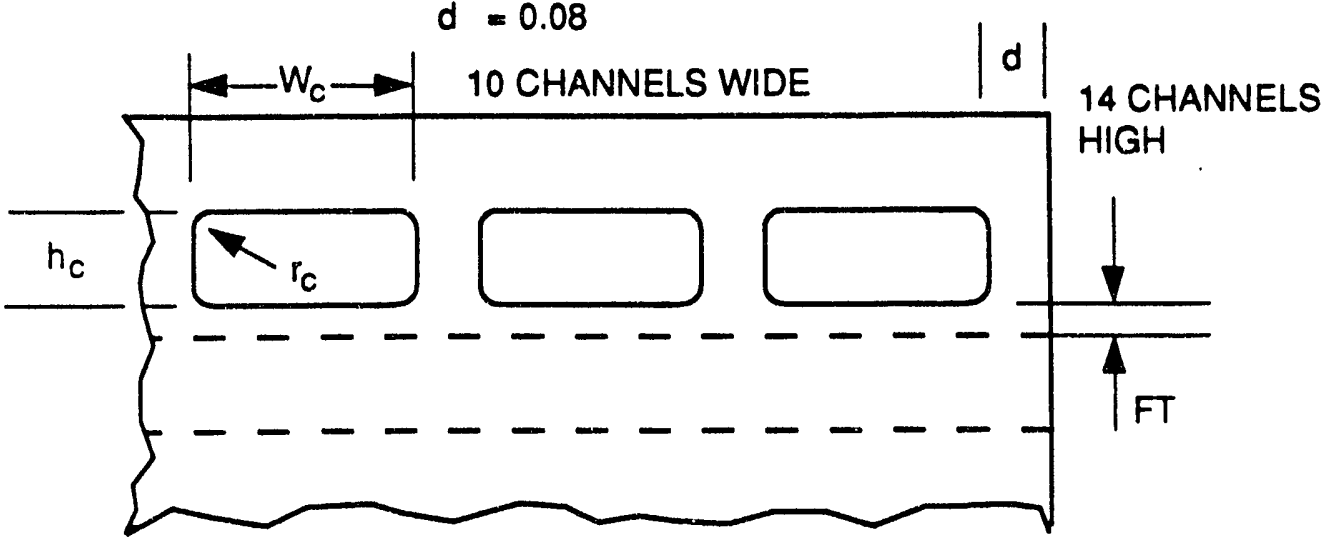

Figure 2-12. Final channel dimensions 


\subsection{Approach-Pulse Cleaning Transient}

Stress analysis of the crossflow filter began with a static analysis of the 10 psi overpressure on the filter element clean channel caused by pulse cleaning. After determining that the filter would survive the 10 psi overpressure without failure, the analysis was repeated to determine the thermal stresses.

Two areas of the filter were modeled: the "floor" and the "back wall" (see Figure 2-13). The floor model was used to simulate the clean channel of the filter. The back wall model was used to simulate the back wall where the clean channel ends at the back wall. The floor was expected to have the highest thermal stresses during the pulse cleaning transient due to the large cooling effect of the pulse air. The back wall was a concern since it is the only joint where a sharp, $90^{\circ}$ angle occurs. This sharp corner was expected to be an area of high stress concentration.

\subsubsection{Model Geometry}

Two models were created for the analysis, one for the "floor" and one for the "back wall." The floor was modeled using a $10 \times 22$ grid (220 nodes), as shown in Figure 2-14. A fine nodal mesh was placed in the corner where both high thermal gradients and high stresses were anticipated. The back wall was modeled with a 464-node grid, shown in Figure 2-15. Axes of symmetry were utilized to simplify the models.

It should be noted that the back wall model incorporates one plane of symmetry that is not a true symmetric plane. This plane is denoted as plane "A" in Figure 2-15. The model, as such, actually assumes two back walls, rather than the one present in the design. There is no true plane of symmetry that can be used to model the back wall, since only one back wall exists. The entire filter would have to be modeled to be absolutely correct. However, the assumed plane of symmetry is not considered to be a drawback to either structural or thermal analyses. Since the symmetric plane is taken through the rib, that portion of the analyses will be correct. Furthermore, since the back wall is sufficiently removed from the rib, little or no interaction between these regions will occur. Finally, the critical tensile stresses will occur in the sharp corner of the back wall, and will 


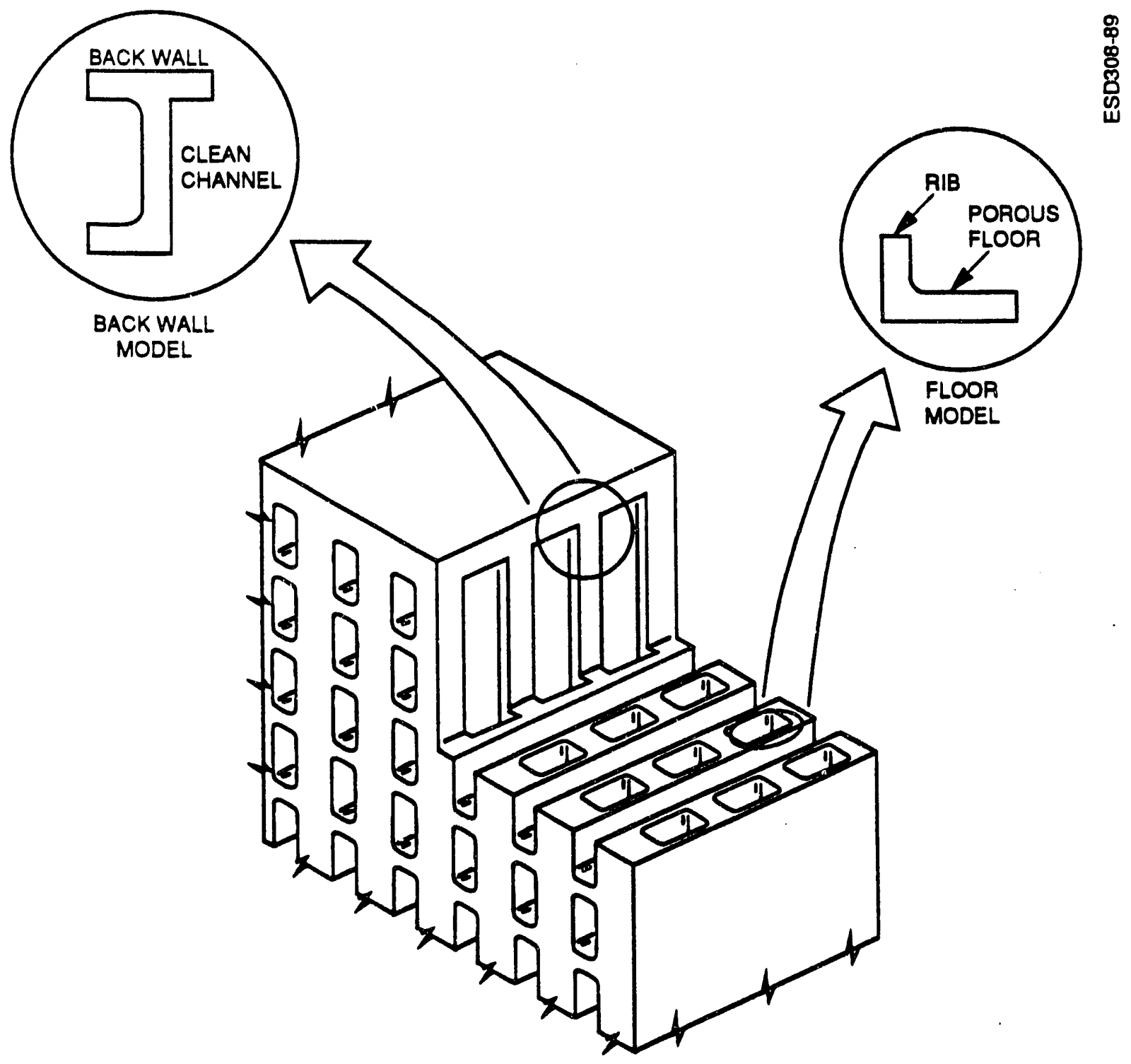

Figure 2-13. Areas of the crossflow filters that were modeled for stress analysis 


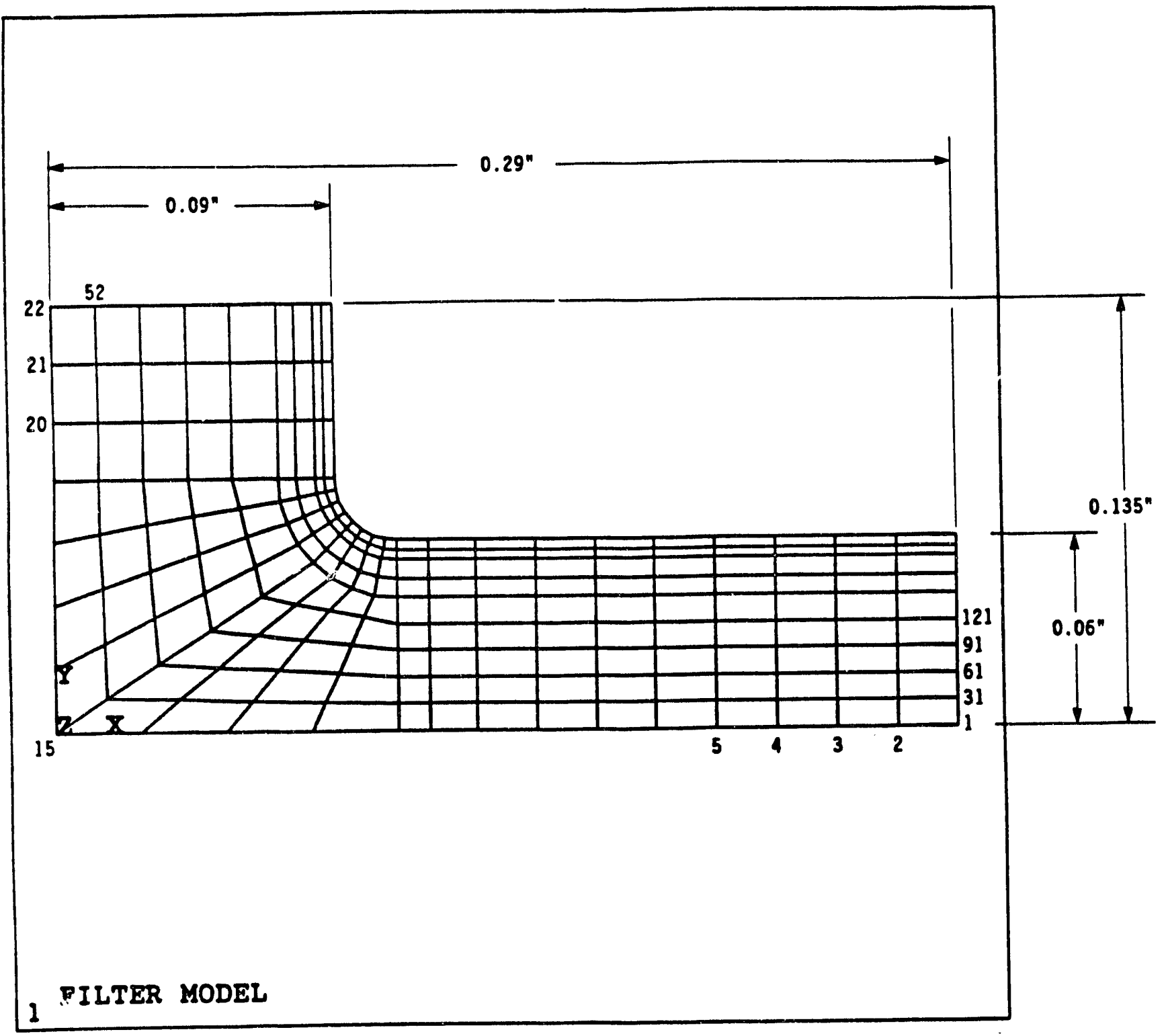

Figure 2-14. Grid structure used in the analysis of the floor 


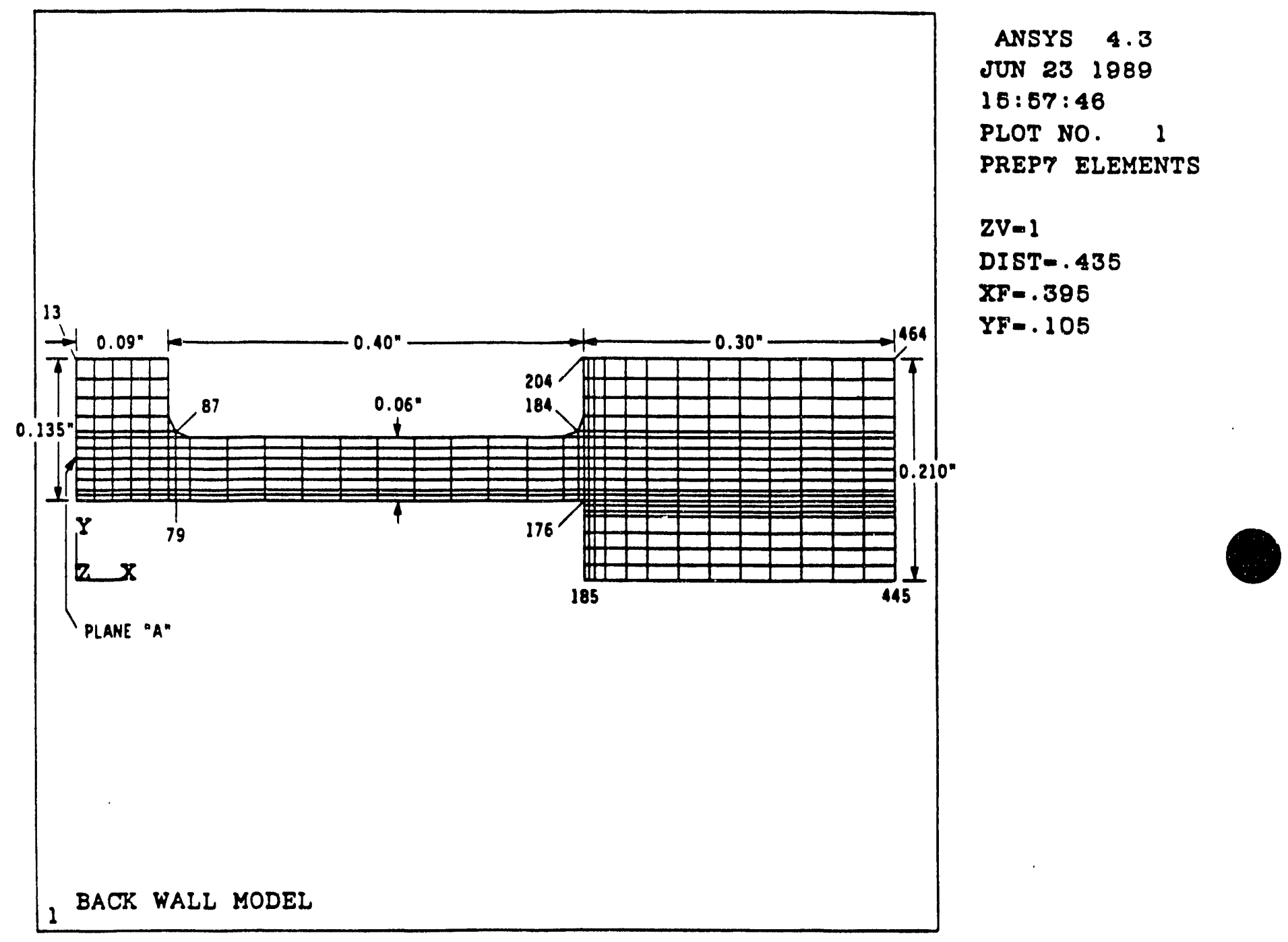

Figure 2-15. Grid structure used in the analysis of the back wall 
not be influenced by the symmetric rib. Thus, the back wall model is a very good approximation of the back wall of the ceramic filter.

\subsubsection{Input Parameter Selection}

\subsubsection{Material Properties}

The filter is assumed to be CSN25 with a density of $82.7 \mathrm{lb} / \mathrm{ft}^{3}$. Specific heat and conductivity values are also for CSN25; however, density was not specified in the property tables. Thermal conductivity and specific heat values are given in Table 2-3. The purge gas was assumed to be air. The material properties used in the structural analysis of the filter are presented in Table 2-4.

\subsubsection{Pulse Cleaning Parameters}

The pulse cleaning gas was assumed to enter the system at two different temperatures. First, an analysis was performed with an inlet temperature of $475^{\circ} \mathrm{F}$. The second analysis assumed a temperature of $1225^{\circ} \mathrm{F}$. In both cases, the pulse velocity through the filter membrane was assumed to be $51 \mathrm{ft} / \mathrm{min}$. The initial filter temperature was $1600^{\circ} \mathrm{F}$.

\subsubsection{Stress Analysis Input Variables}

The effects of two independent variables were examined in the course of completing the stress analysis. These variables are: (1) the amount of flow through the porous media and (2) the temperature of the pulse gas. Darcy's Law was used to calculate the flow through the porous floor. The pressure differential was assumed to be 3 psi. With this differential the flow through the porous media was calculated to be $51 \mathrm{ft} / \mathrm{min}$.

Originally, the flow had been calculated by using the conservative estimate of 10 psi pressure differential across the porous floor (as is used to calculate the bending stress in the floor). However, it was found that the calculated stress was very sensitive to the flow. Therefore, based on the examination of the large temperature drop calculated by the thermal analysis, the flow through the floor was reduced to reflect the level of pressure differential measured experimentally. 
Table 2-3. Thermal properties of the filter element (Reference 7)

\begin{tabular}{|c|c|c|}
\hline $\begin{array}{c}\text { Temperature } \\
\text { F }\end{array}$ & $\begin{array}{c}\text { Specific Heat } \\
\text { BTU/lb } \mathrm{b}_{\mathrm{m}}-\mathrm{F}\end{array}$ & $\begin{array}{c}\text { Conductivity } \\
\text { BTU/ft-s-F }\end{array}$ \\
\hline 73. & 0.166 & $1.48 \times 10^{-3}$ \\
116. & 0.178 & $1.55 \times 10^{-3}$ \\
233. & 0.195 & $1.48 \times 10^{-3}$ \\
404. & 0.218 & $1.48 \times 10^{-3}$ \\
550. & 0.235 & $1.41 \times 10^{-3}$ \\
739. & 0.251 & $1.34 \times 10^{-3}$ \\
1014. & 0.268 & $1.34 \times 10^{-3}$ \\
1311. & 0.286 & $1.21 \times 10^{-3}$ \\
1549. & 0.292 & $1.21 \times 10^{-3}$ \\
1840. & 0.303 & $1.14 \times 10^{-3}$ \\
\hline
\end{tabular}

Table 2-4. Structural material properties (Reference 7)

\begin{tabular}{|l|l|}
\hline Modulus of Elasticity, E & $15.6 \times 10^{6} \mathrm{Fsi}$ \\
Poissons Ratio, $v$ & 0.20 \\
Coefficient of Thermal Expansion, $\alpha$ & $1.89 \times 10^{-6}$ in $/$ in-F \\
\hline
\end{tabular}

The pulse gas temperature was calculated by developing a preliminary design for a pulse cleaning system, calculating pulse flows and temperatures, mixing volumes and venturi sizes.

Two separate cases were examined to determine the pulse gas temperature. In the first case, it was assumed that the pulse was ejected from the nozzle at $100^{\circ} \mathrm{F}$ and mixed with the volume of gas in the manifold at $1600^{\circ} \mathrm{F}$. The volume of air ejected from the pulse nozzle was calculated using the formula:

$$
Q=\sqrt{\frac{k R T}{M}} A\left(\frac{2}{k+1}\right)^{\frac{k+1}{2(k+1)}} \frac{T_{0}}{P_{0}} \frac{P}{T}
$$


where:

$$
\begin{aligned}
\mathrm{Q} & =\text { Gas flowrate scf } / \mathrm{s} \\
\mathrm{k} & =1.4 \text { for air } \\
\mathrm{R} & =\text { Gas constant }=4.968 \times 10^{4} \frac{f^{2} \mathrm{lbm}}{S E C^{2} l b-\text { mole }^{\circ} R} \\
\mathrm{~A} & =\text { Nozzle area, } \mathrm{FT}^{2} \\
\mathrm{~T}_{\mathrm{o}}, \mathrm{P}_{\mathrm{o}} & =\text { Standard temperature and pressure } \\
\mathrm{T}, \mathrm{P} & =\text { Operating temperature and pressure } \\
\mathrm{M} & =\text { Molecular weight }
\end{aligned}
$$

With this approach, the pulse gas temperature was calculated to be $475^{\circ} \mathrm{F}$.

In the second case, it was assumed that a venturi was placed in the pulse cleaning system. A venturi (or jet pump) size was assumed, and the efficiency of the venturi was calculated (Reference 10). It was assumed that the pulse gas at $100^{\circ} \mathrm{F}$ mixed in the venturi throat with air pulled from the plenum at $1600^{\circ} \mathrm{F}$ by the jet pump. This gas stream then mixed with the air in the manifold. This calculation produced a pulse gas temperature of $1225^{\circ} \mathrm{F}$. Investigations on candle filters have indicated that the candle cavity temperature drops to approximately $1100^{\circ} \mathrm{F}$ during pulse cleaning (Reference 11). If we assume that the candle cavity temperature is about the same as the pulse gas temperature, this result indicates that the pulse gas temperature should be about $1100^{\circ} \mathrm{F}$. This temperature is within reasonable limits of the calculated $1225^{\circ} \mathrm{F}$ gas temperature used in the finite element analysis. Acurex did not attempt to measure actual pulse gas temperatures in this project.

\subsubsection{Pressure Stresses}

The structural analysis of the ceramic filter was performed using the ANSYS finite element computer code. ANSYS is a general purpose code that can be utilized to perform a variety of analyses, including static, dynamic, modal, buckling, and thermal (Reference 12). For this application, only static analyses were performed. Two different regions were modeled, the "floor" and the "back wall." The same nodal grids were used for both the thermal and the structural 
analyses. Utilizing the planes of symmetry inherent in the ceramic filter design, only 2-dimensional plane stress analyses were performed using the STIFF42 element of the ANSYS code. This is a 2-dimensional isoparametric stress solid element used for the 2-dimensional modeling of solid structures.

The applied 10 psi pressure loading and the boundary conditions for both the floor and the back wall are shown in Figures $2-16$ and 2-17, respectively. The resulting maximum principal tensile stress distributions are presented in Figures 2-18 and 2-19, superimposed upon the deformed structure. Note that these deformations are magnified by about a factor of 90,000 for clarity. The actual maximum deflections of the beam portions are $4.2 \times 10^{-6}$ in and $3.9 \times 10^{-6}$ in for the floor and back wall, respectively. As would be expected, the maximum stress occurs in the fillet corner for both models. Furthermore, the sharp corner at the back wall is more highly stressed than the fillet region of the floor. Both maximum stresses, however, are fairly low, being 325 psi and 307 psi, respectively. To aid interpretation of the figures, the following legend applies:

$$
\begin{aligned}
& \text { MX = Maximum Principle Stress (psi) } \\
& \text { MN = Minimum Principle Stress (psi) } \\
& \text { NCON = Number of Contours } \\
& \text { VMIN = Minimum Contour Stress (psi) } \\
& \text { VINC = Contour increment (psi) }
\end{aligned}
$$

Therefore, for Figure 2-18,

$$
\begin{aligned}
& \text { Maximum Principle Stress }=307 \mathrm{psi} \\
& \text { Minimum Principle Stress }=0 \mathrm{psi} \\
& \text { Number of Contours }=9 \\
& \text { Minimum Contour Stress }=29.7 \mathrm{psi} \\
& \text { Increment Between Contours }=31 \mathrm{psi}
\end{aligned}
$$




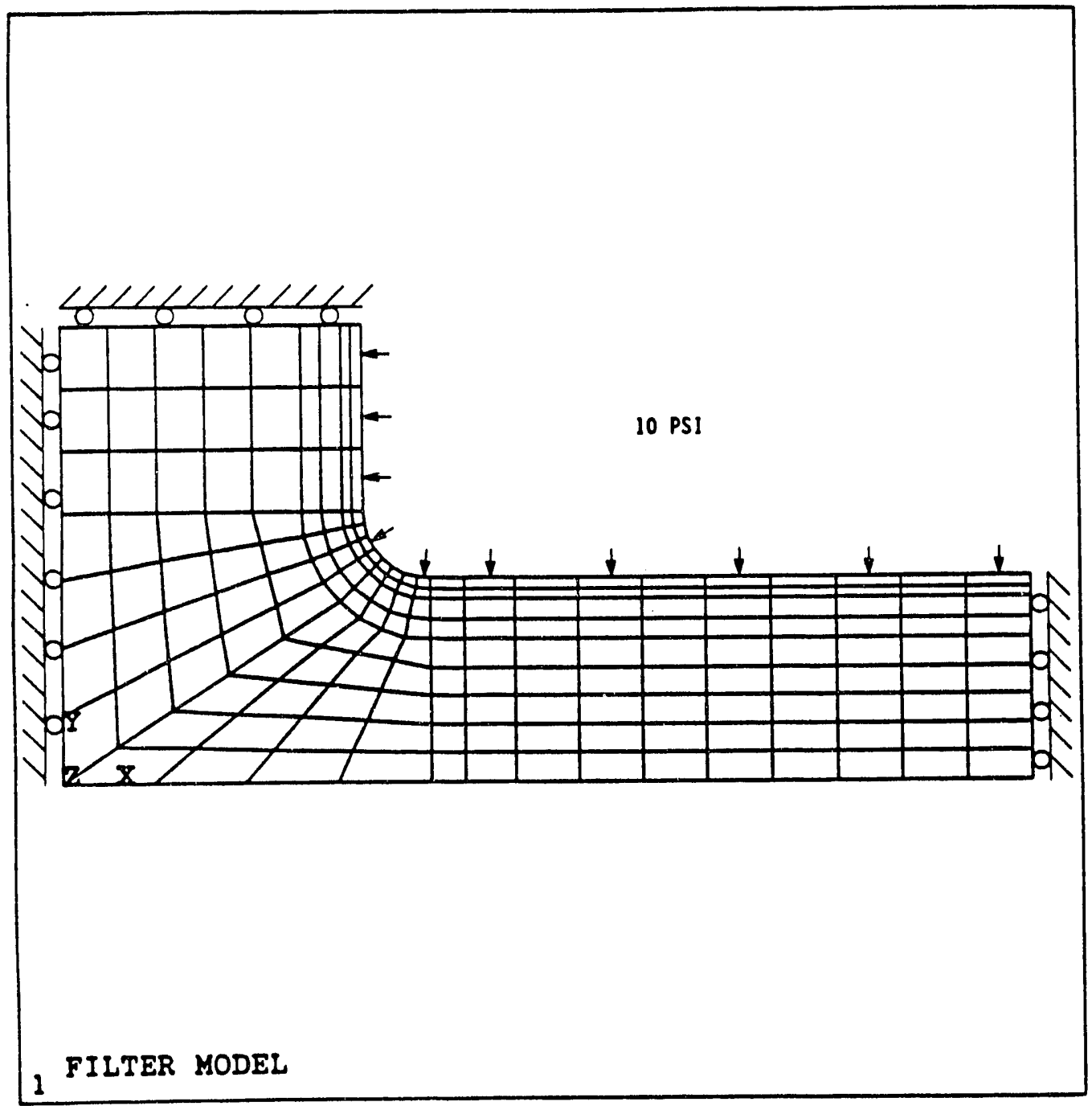

ANSYS 4.3

MAY 241980

$11: 28: 08$

PLOT NO. 1

PREPT ELEMENTS

ZV-1

DIST $=.16$

XF- .145

$Y F=.0875$

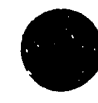

Figure 2-16. Floor model, 10 psi purge pressure 


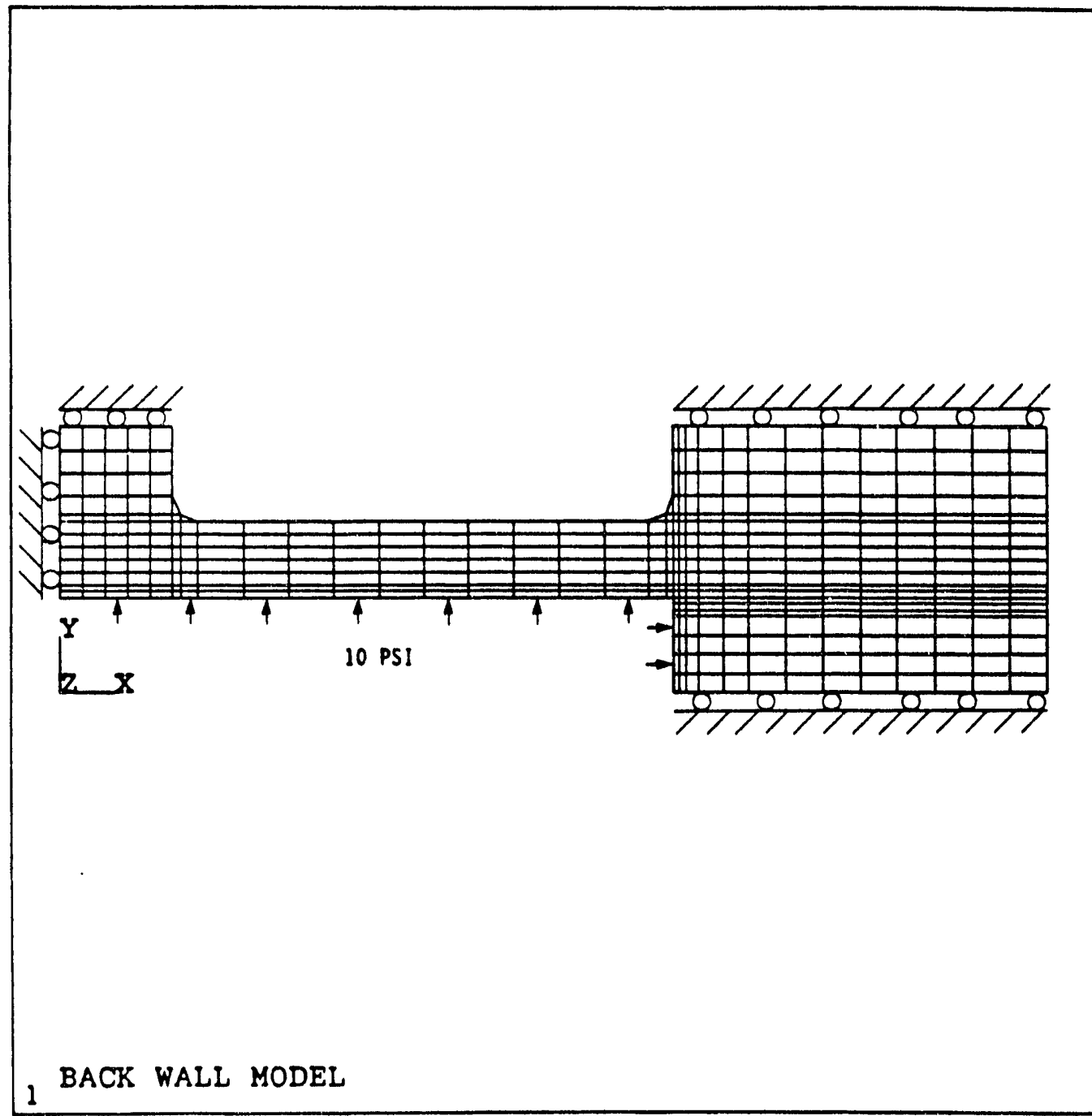

ANSYS 4.3

JUN 231989

$16: 67: 46$

PLOT NO. 1

PREPT ELEMENTS

ZV-1

DIST $=.435$

XF $=.395$

$Y F=.105$

BACK WALL MODEL

Figure 2-17. Back wall model, 10 psi purge pressure 


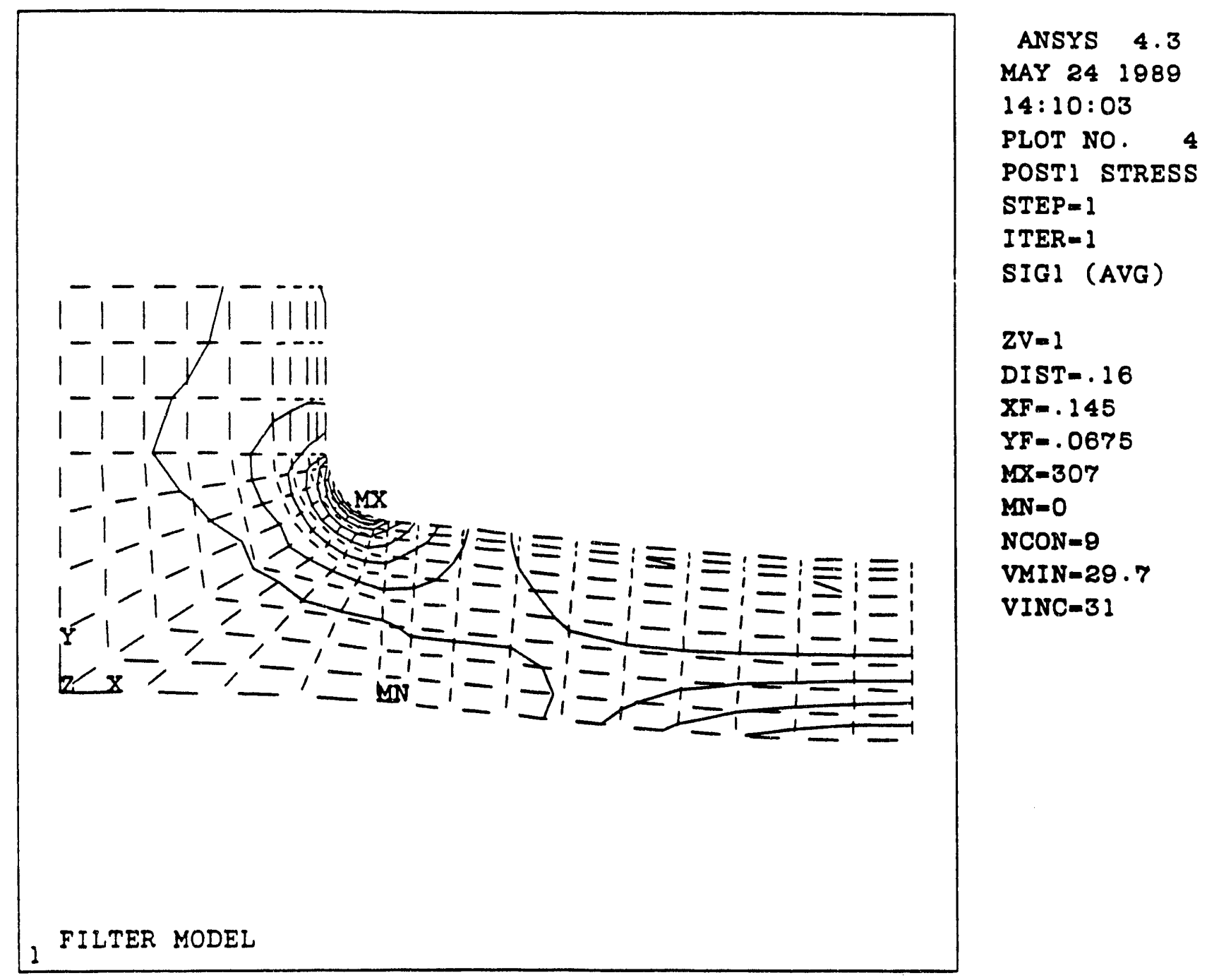

Figure 2-18. Floor model, maximum principal stress contours, 10 psi pressure 


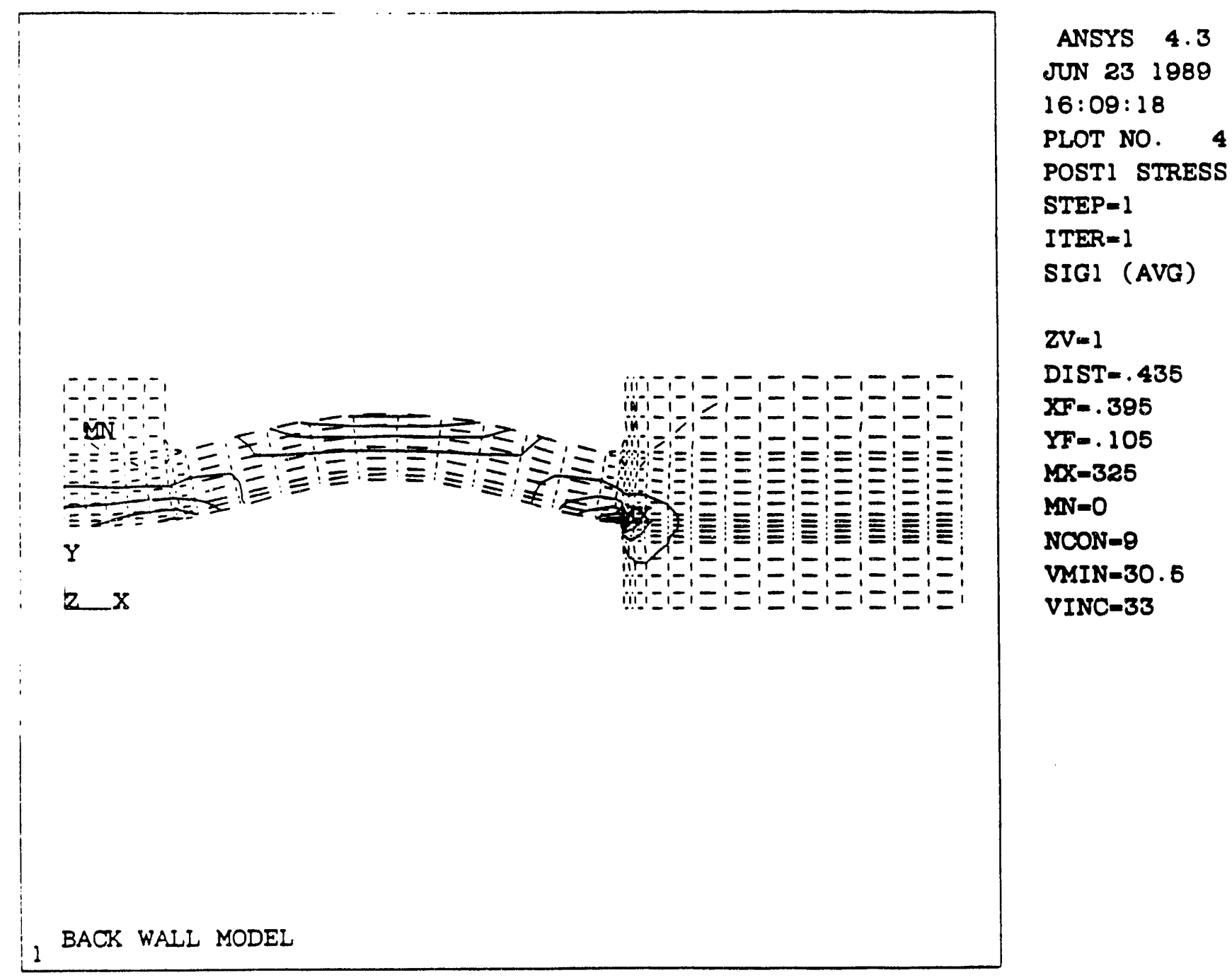

Figure 2-19. Back wall model, maximum principal stress contours, 10 psi pressure 


\subsubsection{Thermal Stresses}

\subsubsection{Thermal Analysis}

A better understanding of the true response of the filter to both the thermal stresses and pressure loading is obtained by first performing a thermal analysis, then inputting the temperature predictions of the thermal analysis into a structural analysis code. The following section describes the thermal analysis used to predict the temperature response of the filter elements.

Thermal analysis of the filter was performed using the SINDA85 code. SINDA85, the Systems Improved Numerical Differencing Analyzer, is a computer program system intended primarily for the analysis of thermal systems represented in electrical analog, lumped parameter form (Reference 13). It is a very general program that can be used to model almost any thermal system. The present analysis used a transient, implicit, forward-backward differencing solution routine. SINDA was modified in the current analysis to include flow through a porous medium. Thermal distributions of flow through fixed beds were used to model the floor response. Node temperatures predicted by SINDA were saved for input into the structural analysis program.

Figures 2-20 and 2-21 show the axes of symmetry and boundary conditions used in the models. The axes of symmetry are treated as insulated boundaries. Boundaries exposed to the pulse gas are assumed to have a convective boundary condition. The boundary conditions are discussed in detail in Appendix B. The convection coefficient is estimated to be $4.26 \mathrm{BTU} / \mathrm{ft}^{2}-\mathrm{s}-\mathrm{F}$, based on fully-developed, laminar flow with constant surface heat flux. Better values for the convection coefficient are not warranted due to the relatively minor effect this coefficient has on the analysis.

Mass flow through the porous membrane is easily modeled by the SINDA code. A purge gas velocity of $51 \mathrm{ft} / \mathrm{min}$ through the filter is assumed. At a pressure of $10 \mathrm{~atm}$ and a temperature of $1225^{\circ} \mathrm{F}$, the mass flux is $0.2071 \mathrm{lb} / \mathrm{ft}^{2}-\mathrm{s}$ through the nodes. The purge gas is assumed to be in thermal equilibrium with the filter membrane as the gas passes through. This assumption can be justified by the intimate contact between the purge gas and the porous filter membrane. 


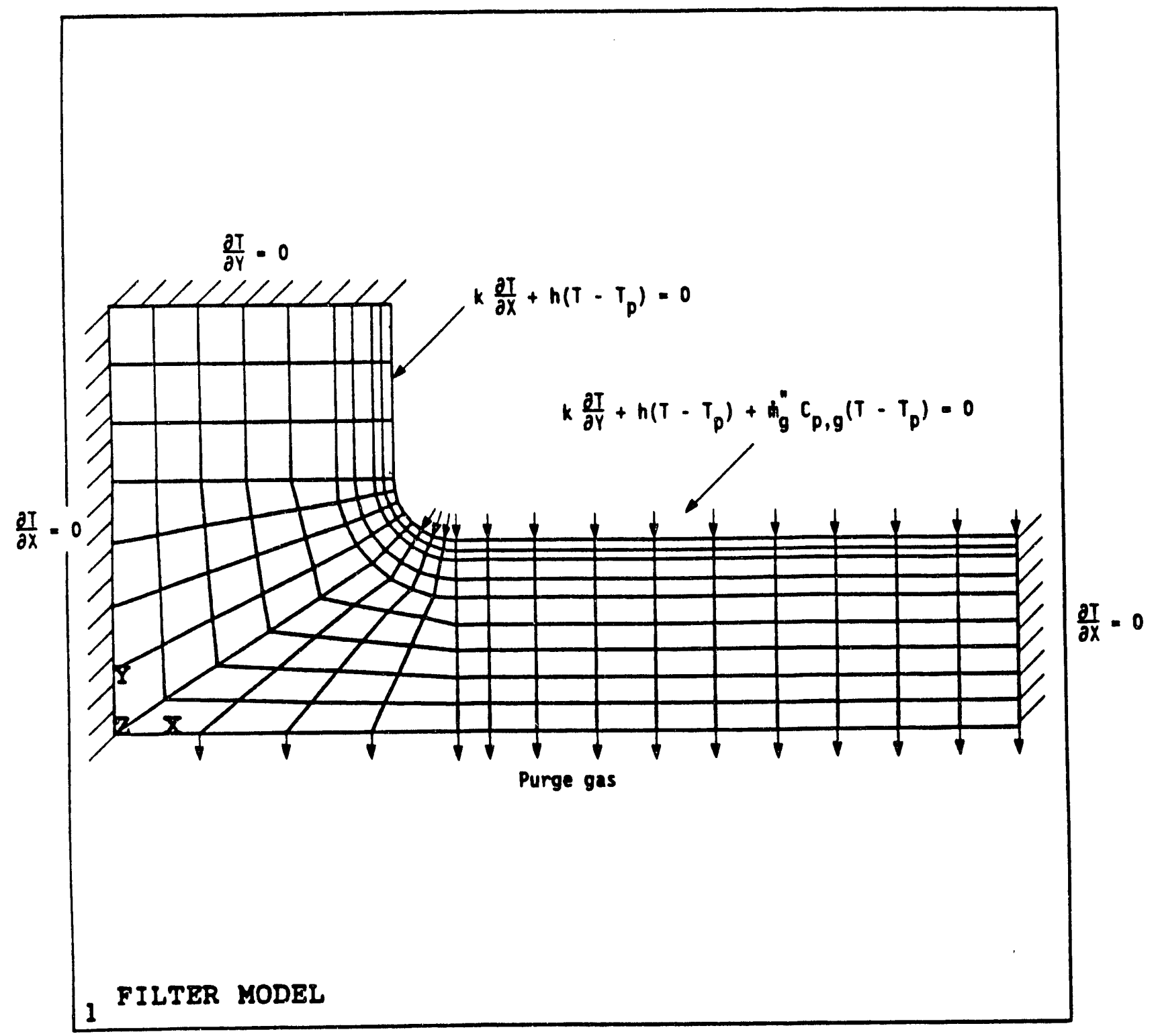

Figure 2-20. Boundary conditions for the floor 


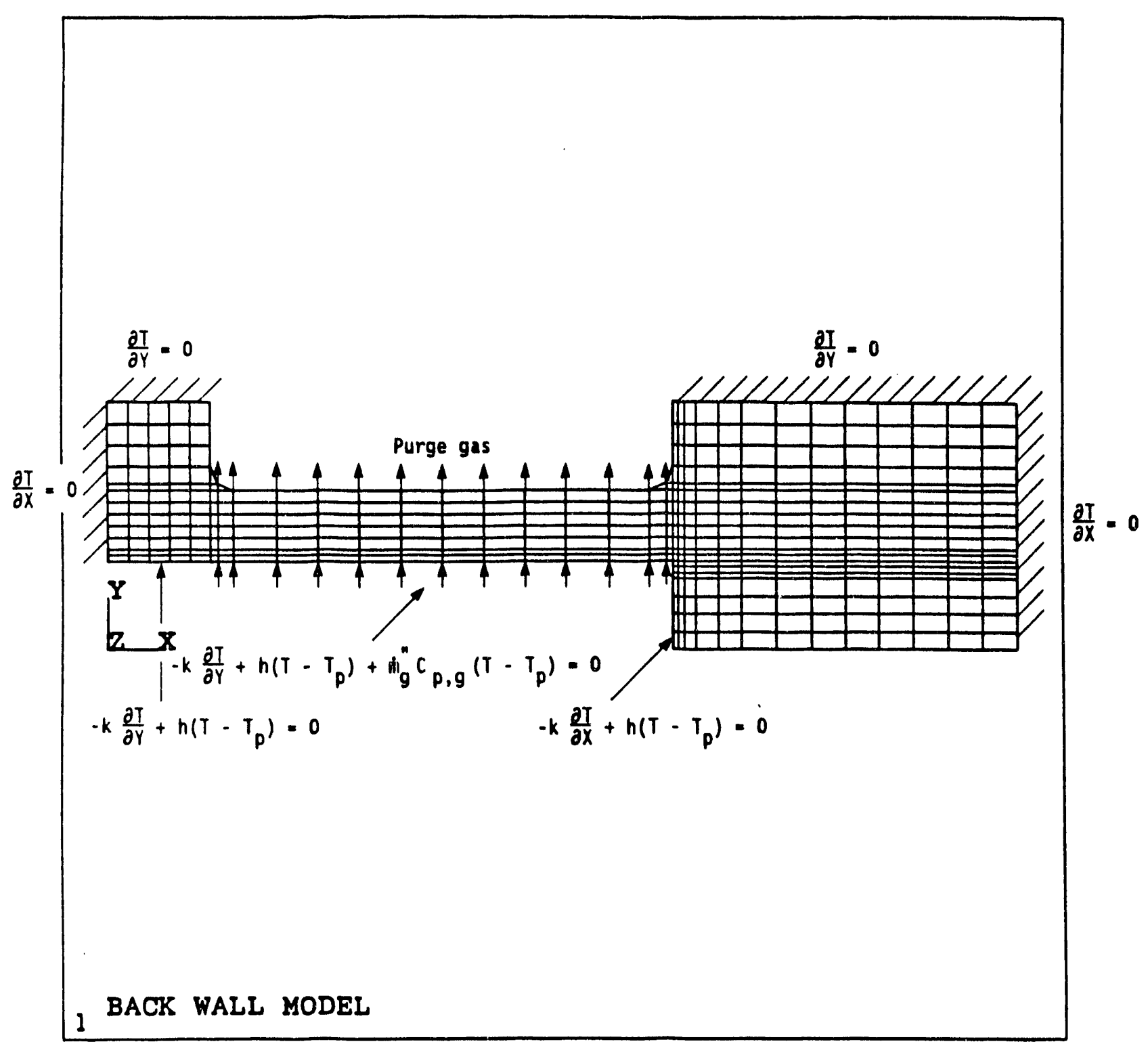

Figure 2-21. Boundary conditions for the back wall 


\subsubsection{Thermostructural Analyses}

As described in the thermal analysis section, two different thermal conditions were analyzed. Initially, the purge gas was assumed to be at $475^{\circ} \mathrm{F}$. This is a very conservative assumption for the gas temperature, but if the resulting stresses are low, this condition envelopes the environment. Only the floor model was analyzed for the $475^{\circ} \mathrm{F}$ purge gas temperature. In addition, two different purge times were investigated, $0.09 \mathrm{~s}$ and $0.50 \mathrm{~s}$. Unfortunately, the stresses at the longer purge time were relatively high, necessitating the examination of a higher pulse gas temperature. For this condition, an air temperature of $1225^{\circ} \mathrm{F}$ was used.

It was known that the maximum thermal stresses should occur at the time of the maximum thermal gradient, that is, at the end of the purge time. However, in order to verify this, the initial $475^{\circ} \mathrm{F}$ condition was structurally analyzed at $0.01,0.05,0.09$ and $0.50 \mathrm{~s}$. As was expected, the stresses continued to increase with time and subsequent analysis times only considered the maximum purge times of 0.09 and/or $0.50 \mathrm{~s}$.

\subsubsection{Results}

\subsubsection{Temperature Predictions}

Figures 2-22 and 2-23 show temperature predictions for the floor element at two purge gas temperatures for a half-second pulse. Figure 2-24 shows similar predictions for the back wall. A simple hand calculation near the center of the porous membrane confirmed the predictions.

\subsubsection{Stress Predictions}

The temperature predictions described above were used to predict the maximum principal stress contours for the $475^{\circ} \mathrm{F}$ gas temperature for the floor model. These stress contours are shown in Figures 2-25 and 2-26 for $0.09 \mathrm{~s}$ and $0.50 \mathrm{~s}$, respectively. The maximum tensile stress occurs near the fillet. The value at $0.50 \mathrm{~s}$ is $8073 \mathrm{psi}$.

Figures $2-27$ and $2-28$ present the stress distributions for a purge gas temperature of $1225^{\circ} \mathrm{F}$, again at purge times of 0.09 and $0.50 \mathrm{~s}$. The maximum stress at the later time is $3396 \mathrm{psi}$. 


\section{ESD FILTER ANALYSIS}

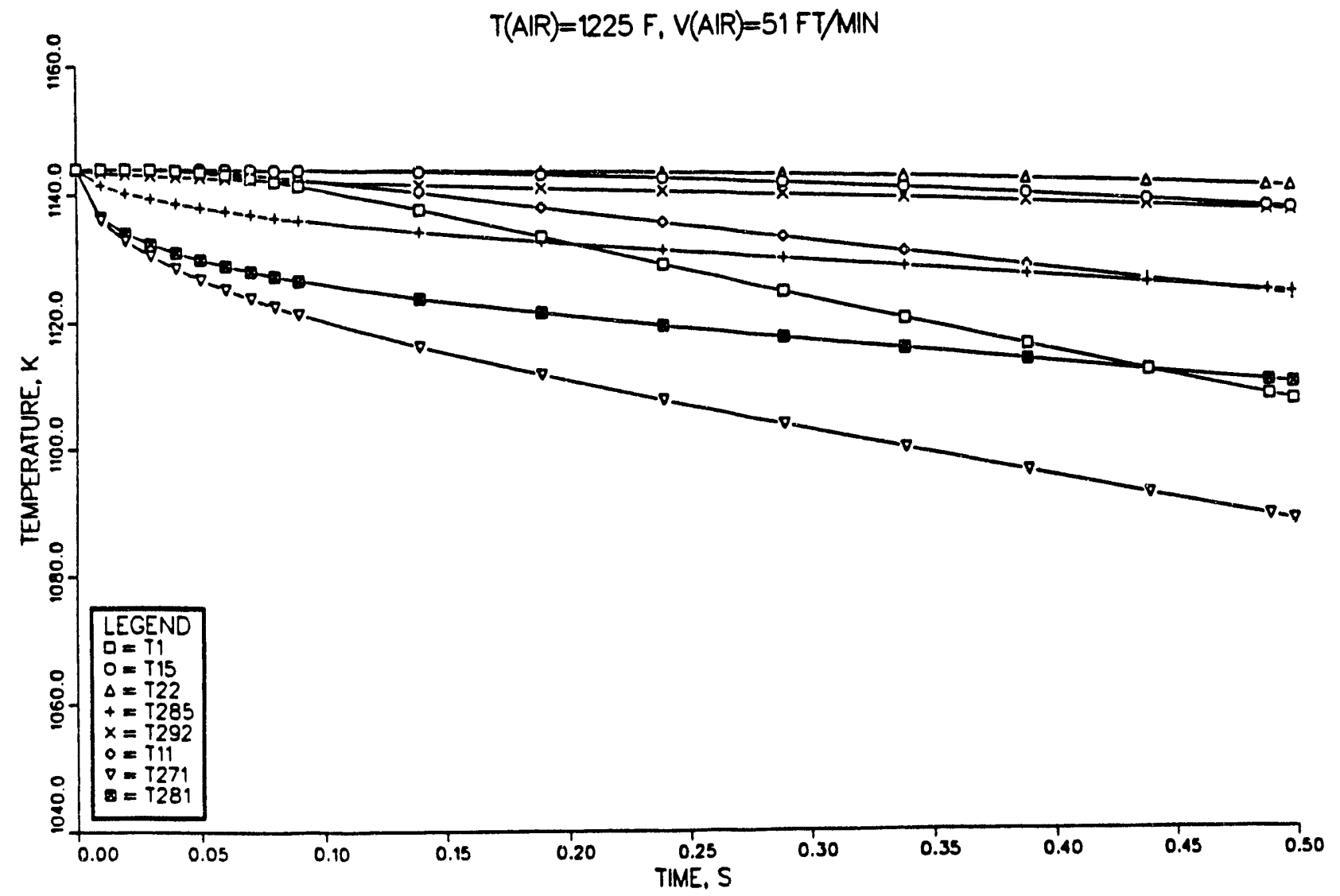

Figure 2-22. Temperature predictions for the floor $\left(T_{\text {purge gas }}=1225^{\circ} \mathrm{F}\right)$ 


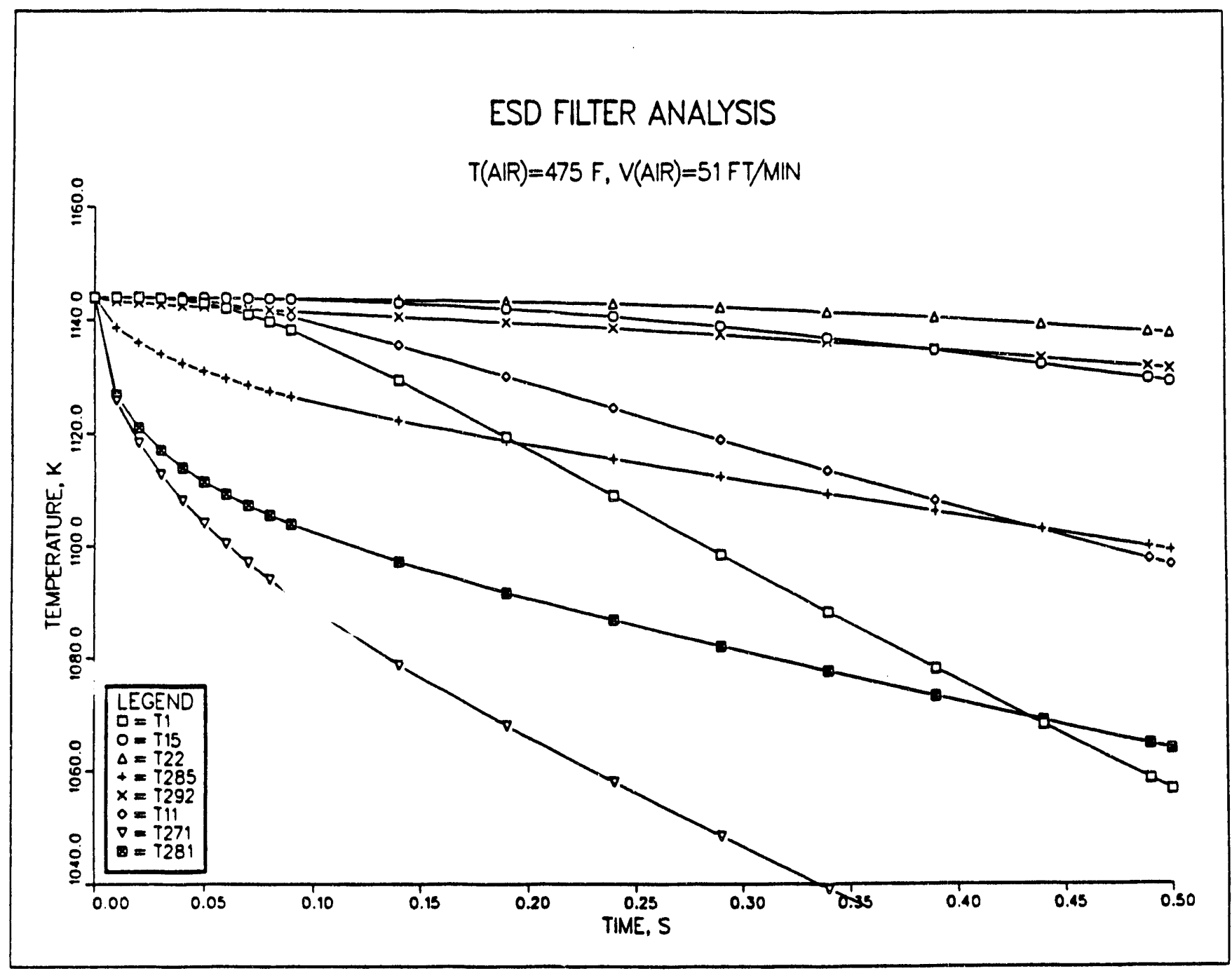

Figure 2.23. Temperature predictions for the floor $\left(T_{\text {purge gas }}=475^{\circ} \mathrm{F}\right)$ 


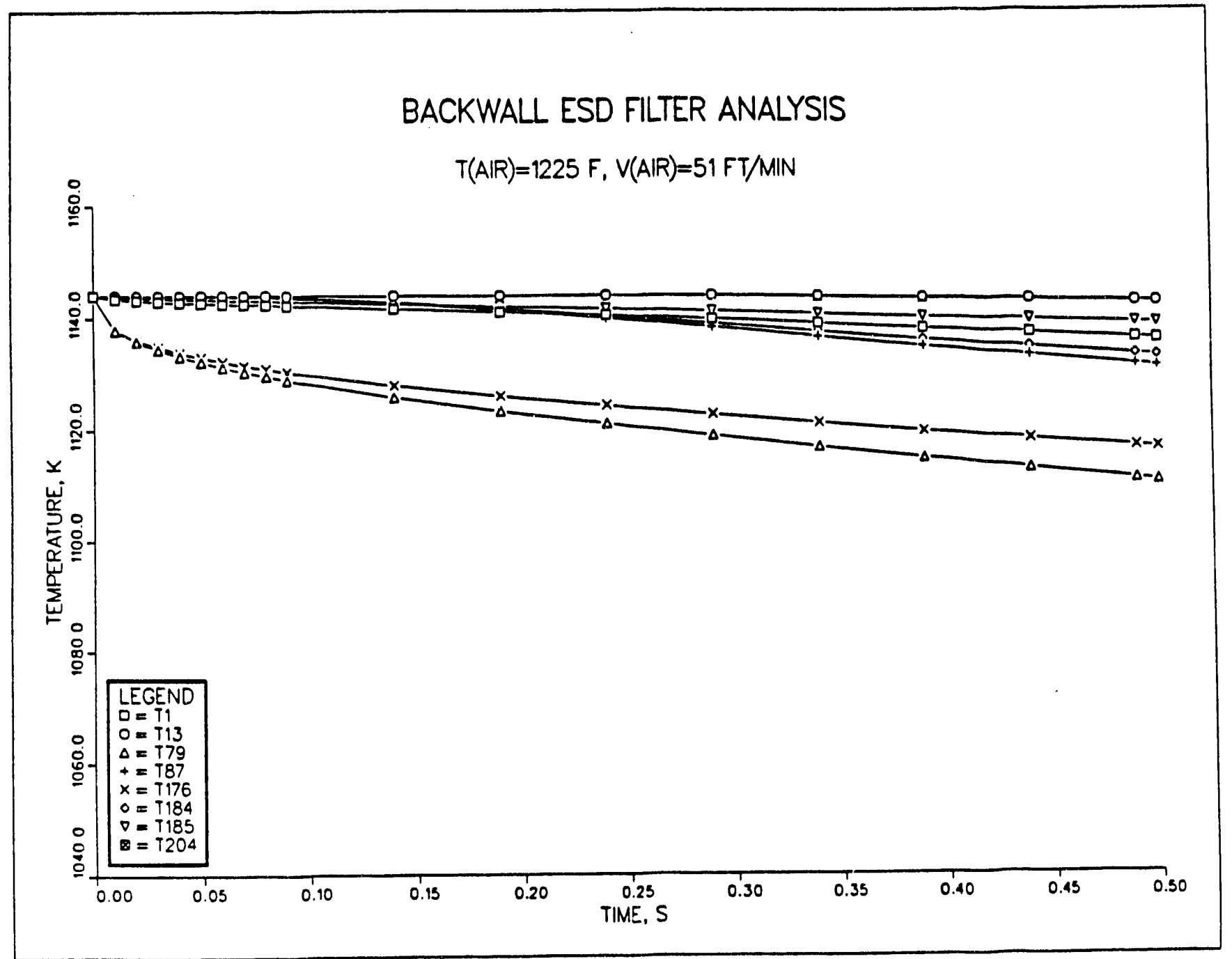

Figure 2-24. Temperature predictions for the back wall $\left(T_{\text {purge gas }}=1225^{\circ} \mathrm{F}\right)$ 


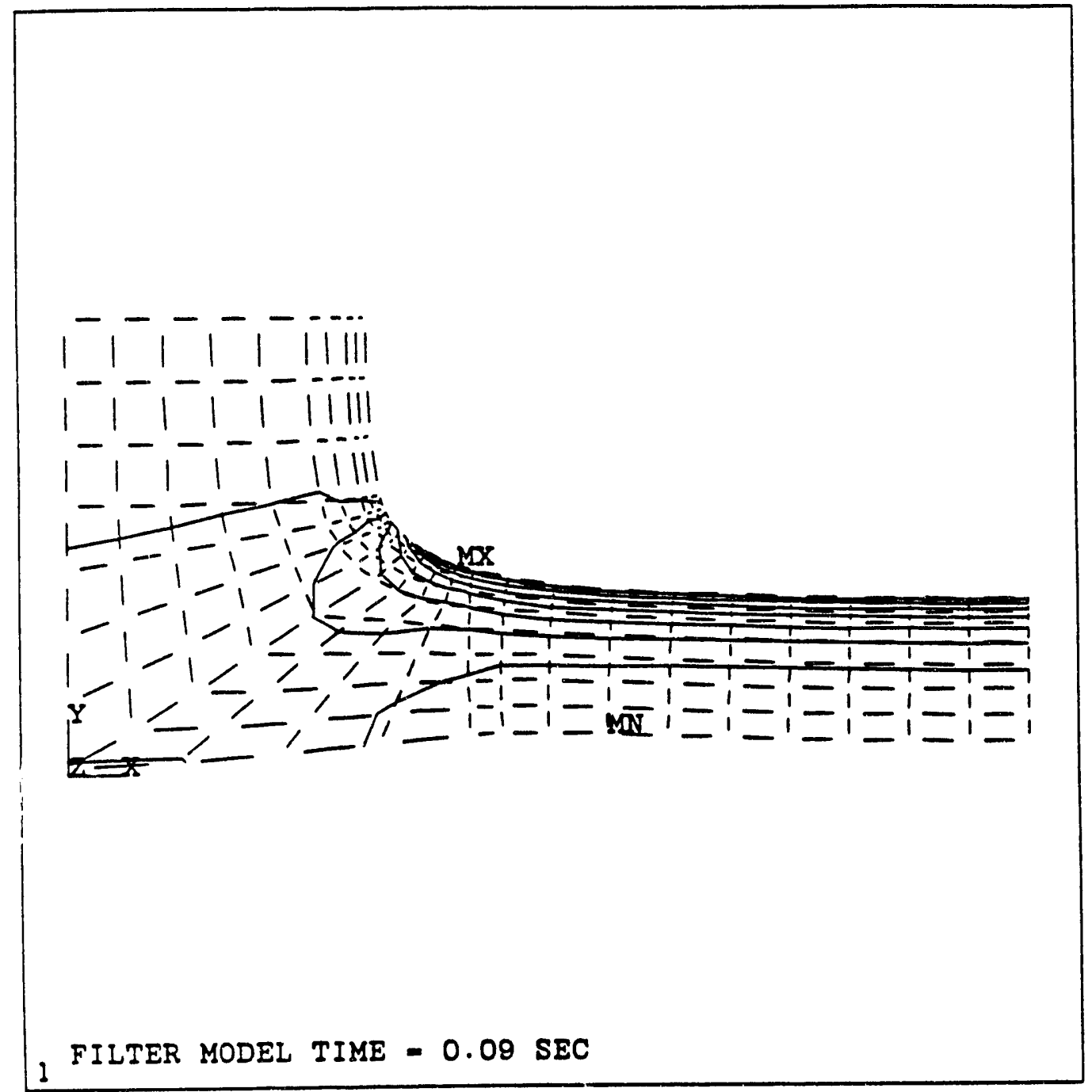

ANSYS 4.3

JUN 131989

$15: 30: 45$

PLOT NO. 4

POSTI STRESS

STEP $=1$

ITER-1

SIGI (AVG)

ZV-1

DIST- .16

$X F=.145$

$Y F=.0675$

IXX-3278

$M N=2.61$

NCON-9

VMIN-328

VINC $=328$

Figure 2-25. Floor model, time $=0.09 \mathrm{~s}$, air temperature $=475^{\circ} \mathrm{F}$ 


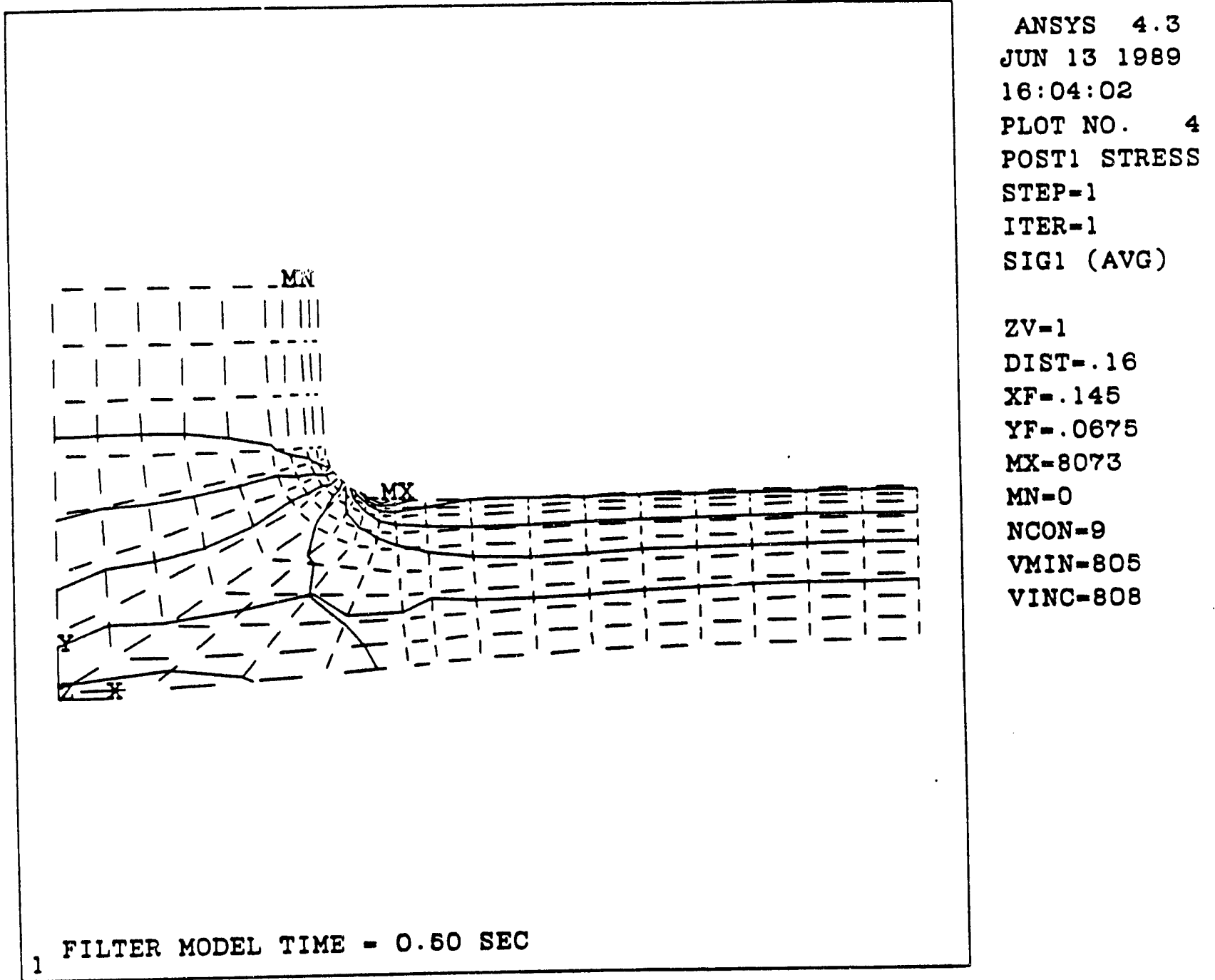

Figure 2-26. Floor model, time $=0.50 \mathrm{~s}$, air temperature $=475^{\circ} \mathrm{F}$ 


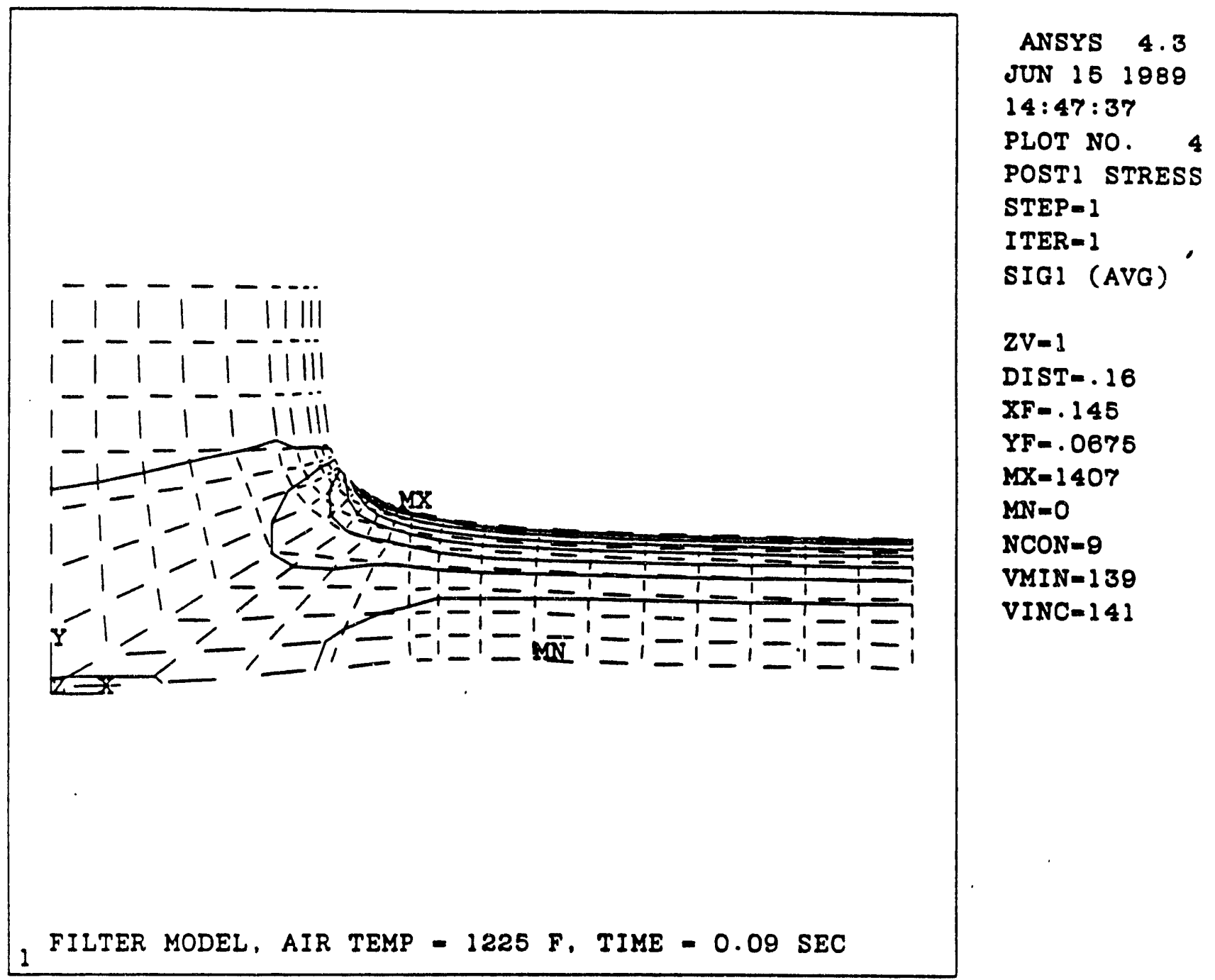

Figure 2-27. Floor model, time $=0.09 \mathrm{~s}$, air temperature $=1225^{\circ} \mathrm{F}$ 


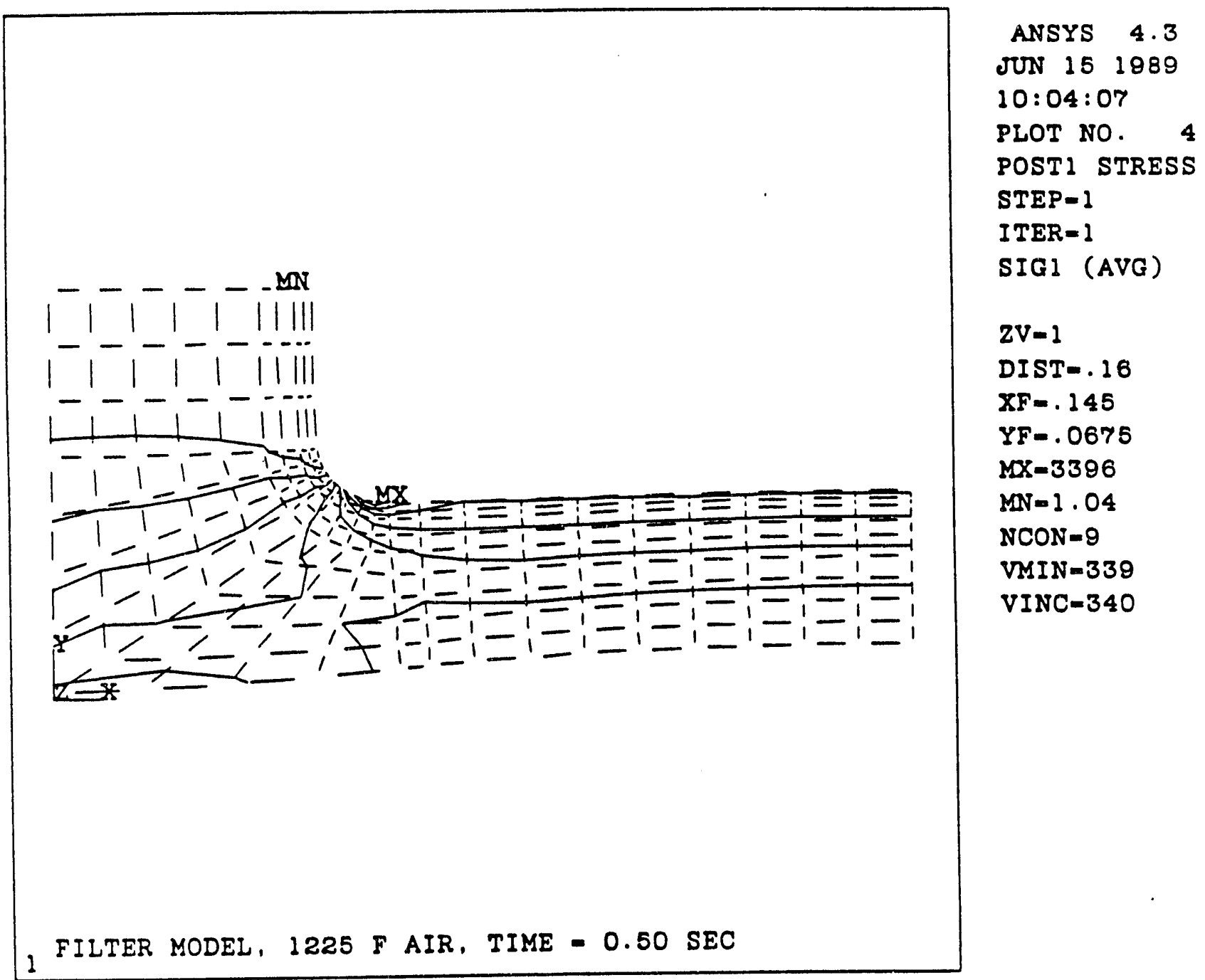

Figure 2-28. Floor model, time $=0.50 \mathrm{~s}$, air temperature $=1225^{\circ} \mathrm{F}$ 
Finally, the stress contour plots from the back wall analysis are shown in Figures 2-29 and 2-30 for the two purge times of interest. Again the maximum stress occurs in the sharp corner, but the magnitude is lower than the floor results. This is due to the back wall itself acting as a heat sink, which reduces the thermal gradient in the corner.

\subsubsection{Comparison with Spatially Uniform Method}

As a second check, the floor section was modeled again using a method developed by Westinghouse (Reference 8). This method utilizes a major simplifying assumption. Since the filter membrane is thin and cooled by transpiration, it is assumed that the porous membrane cools in a spatially uniform manner. It is also assumed that the gas exits at a temperature in equilibrium with the porous solid. A simple heat balance for this condition can be written as:

$$
\dot{m} C_{p_{1} s}\left(T_{f}(\theta)-T_{p}\right)=\frac{d}{d \theta}\left[m_{f} C_{p, f}\left(T_{f}(\theta)-T_{\text {ref }}\right)\right]
$$

This equation can be solved to give the temperature of the filtering membrane as a function of time.

$$
T_{f}(\theta)=T_{p}+\left(T_{f}(0)-T_{p}\right) e^{-\varepsilon \theta}
$$

where:

$$
\alpha=\frac{\dot{m}_{p} C_{p, g}}{A_{f} t_{f} p_{f} C_{p, f}}
$$

where:

$$
\begin{aligned}
T_{f}(\theta) & =\text { Filter membrane temperature (a function of time) } \\
t_{p} & =\text { Inlet pulse gas temperature } \\
\theta & =\text { Time } \\
\dot{m} & =\text { Mass flow of pulse to filter }
\end{aligned}
$$




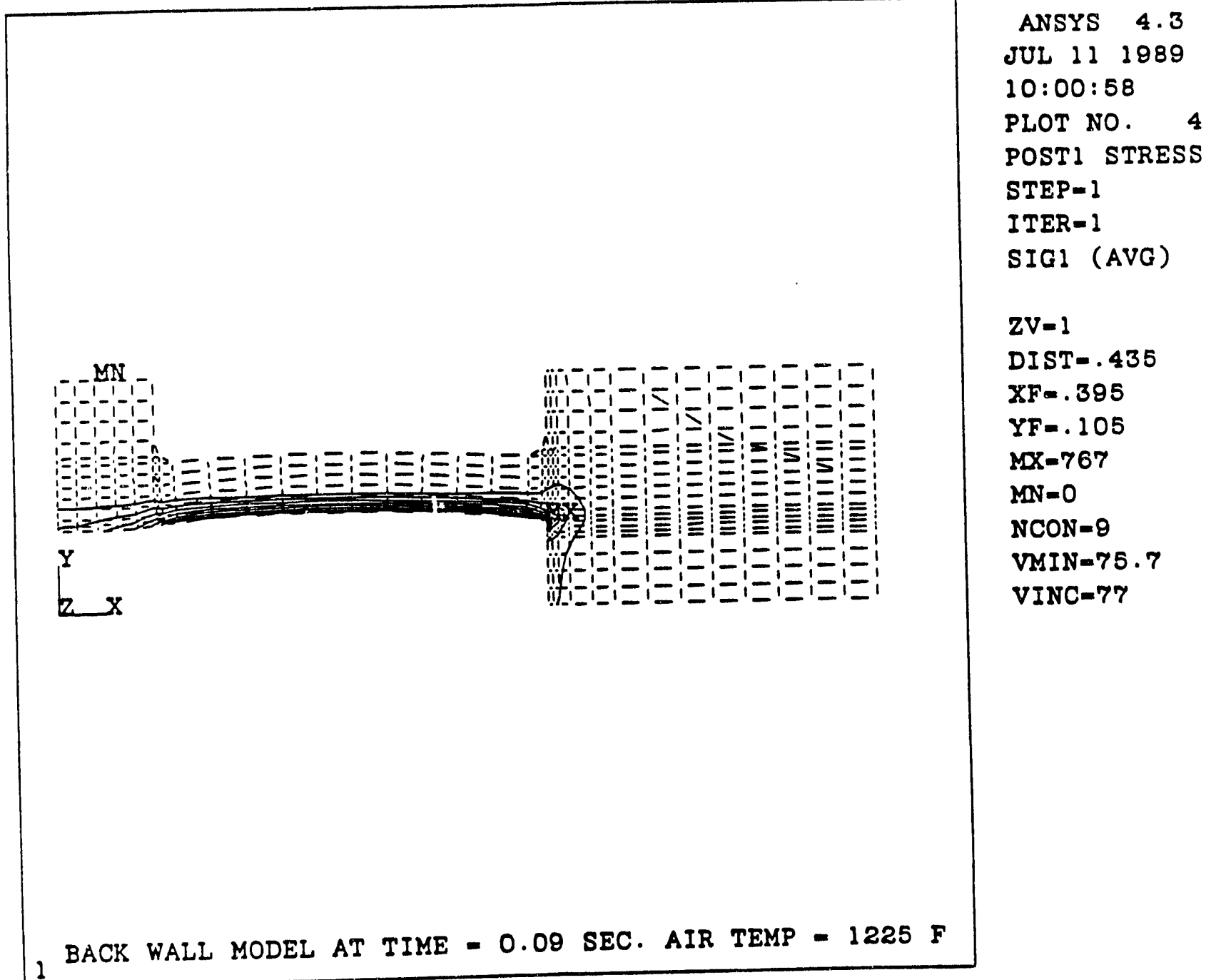

Figure 2-29. Back wall model, time $=0.09 \mathrm{~s}$, air temperature $=1225^{\circ} \mathrm{F}$ 


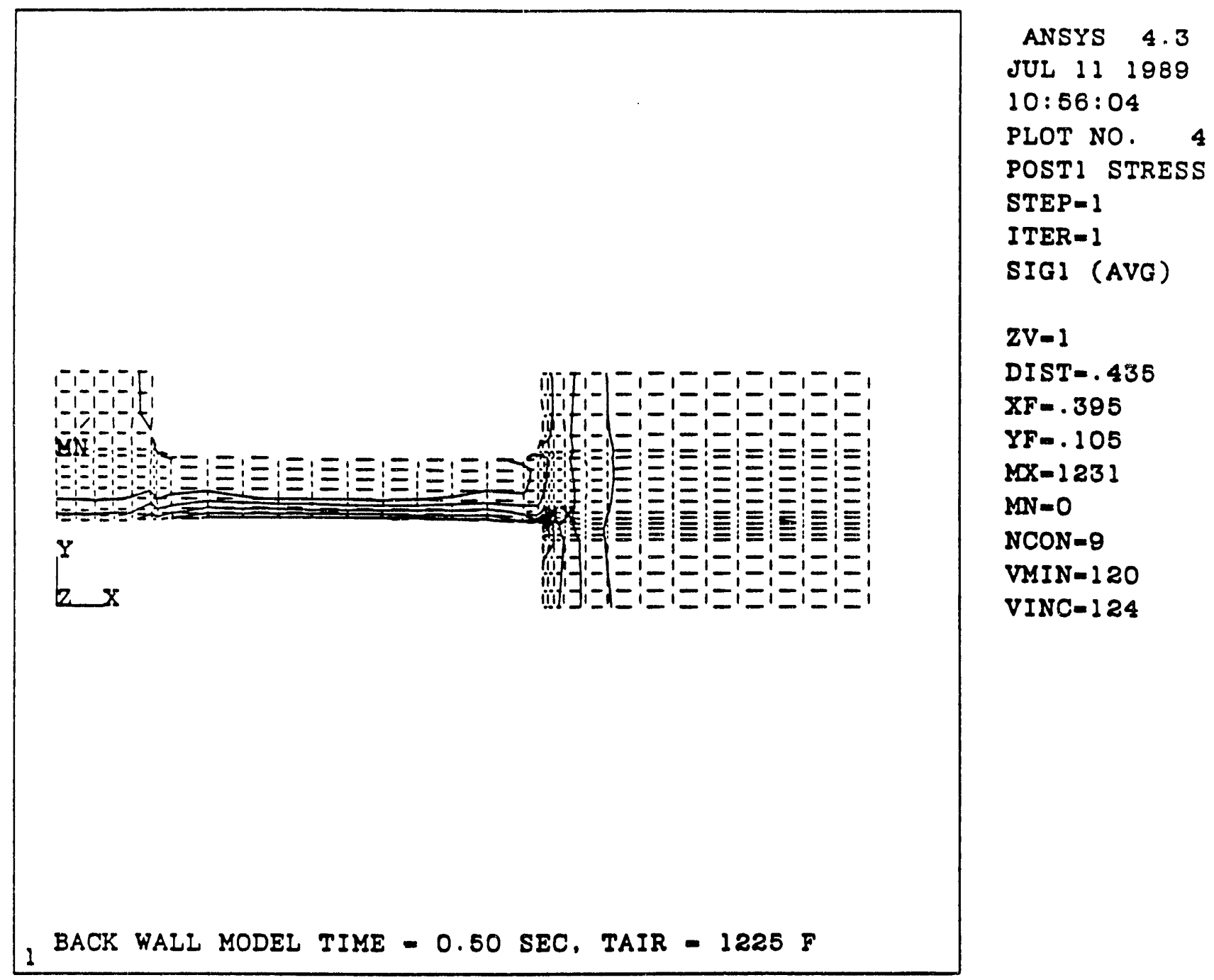

Figure 2-30. Back wall model, time $=0.50 \mathrm{~s}$, air temperature $=1225^{\circ} \mathrm{F}$ 
$C_{p, 8}=$ Constant pressure heat capacity of pulse gas

$A_{t} \quad=$ Actual filter membrane surface area

$t_{f}=$ Thickness of membrane

$\rho_{\mathrm{f}}=$ Bulk density of membrane

$C_{p f}=$ Constant pressure heat capacity of filter media

The filtering membrane is treated as a single node with a specified, time-dependent temperature. All other boundary conditions were kept the same as in the previous analysis. Figure 2-31 shows the grid and boundary conditions used in the analysis. Note that all nodes for the porous membrane have been combined into a single node. All other nodes are the same as in the previous analysis.

Temperature predictions using the spatially uniform method are shown in Figure 2-32. Figure 2-32 shows the results of the axial distribution model for comparison. In the axial distribution model, the porous membrane is divided into numerous nodes. Figure 2-32 shows the temperature of four of these nodes in the porous membrane, nodes $1,11,271$, and 281 . The spatially uniform model treats all of these nodes as a single node with a specified temperature, as shown in Figure 2-32.

The nodes representing the porous membrane in the axial distribution analysis span a range of 1498 to $1563^{\circ} \mathrm{F}(1088$ to $1124 \mathrm{~K}$ ) at $0.5 \mathrm{~s}$. The spatially uniform method utilizes a single node with a temperature of $1520^{\circ} \mathrm{F}(1100 \mathrm{~K})$ for the same time value. Stresses calculated based on the temperatures predicted by the axial distribution method should be more accurate, and more conservative than those calculated using the spatially uniform method. The axial distribution method is more accurate and more conservative because the analysis takes into account the temperature variation through the thickness of the filter membrane and across its length. Treating the filter membrane as a single node has the effect of reducing the local thermal stresses due to the large area over which the temperature remains spatially constant. Comparison of the nodal 


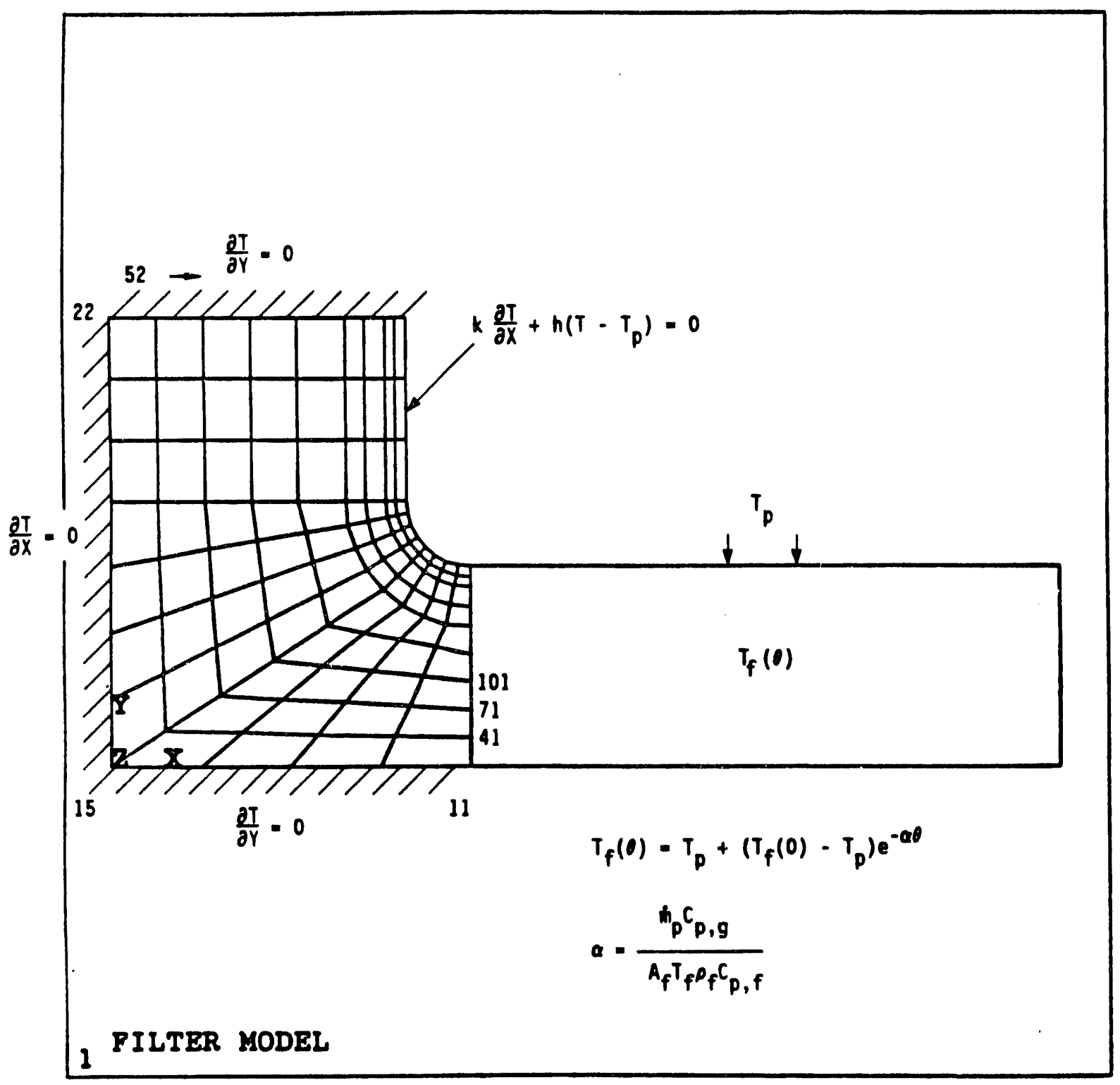

Figure 2-31. Grid structure used in the spatially uniform method 


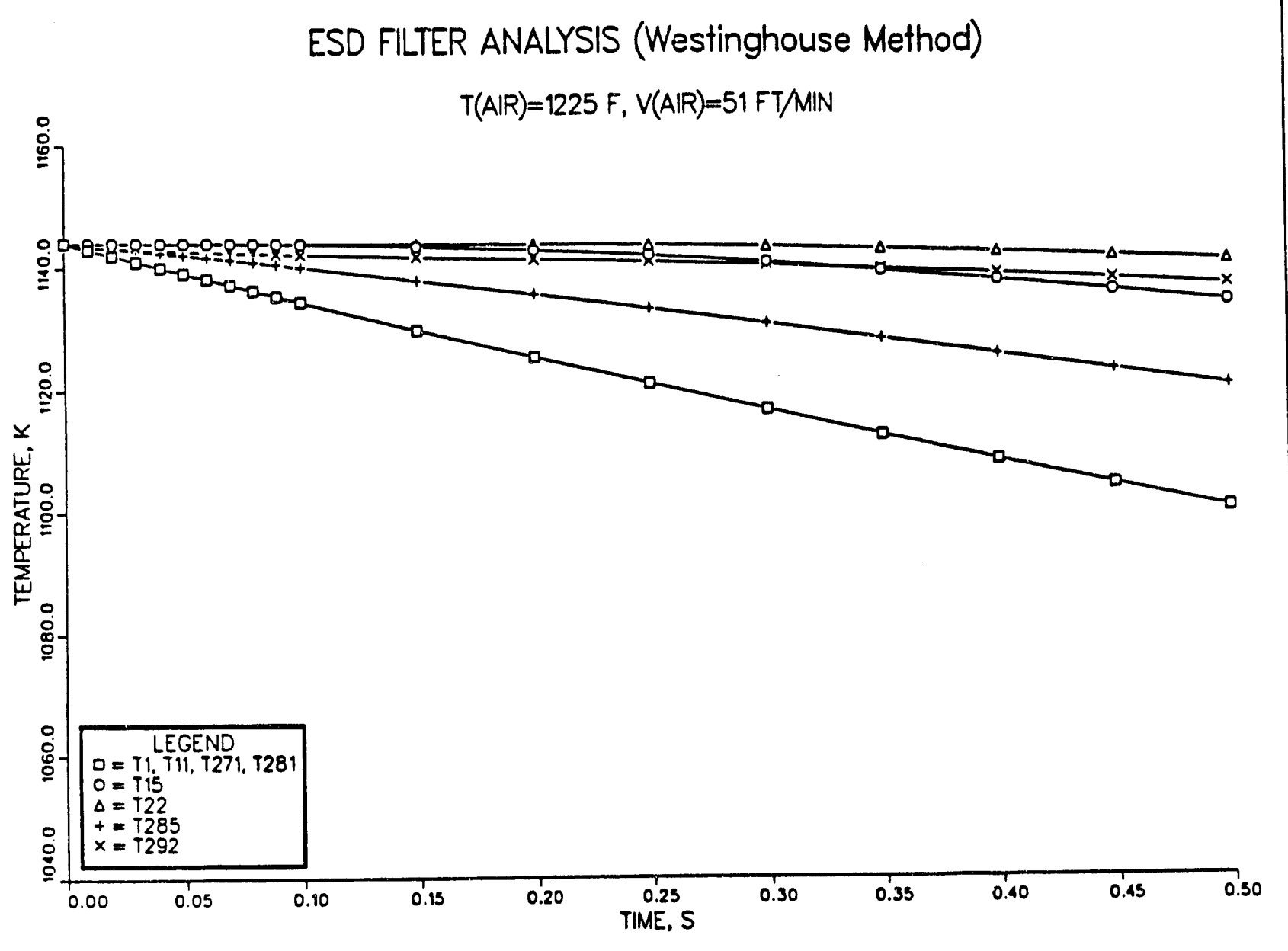

Figure 2-32. Temperature prediction using the spatially uniform method 
temperatures for nodes 1, 11, 271, and 281 in Figures 2-22 and 2-32 shows the differences in the temperatures.

Stress contour plots for the purge gas temperature condition of $475^{\circ} \mathrm{F}$ are shown in Figures 2-33 and 2-34. The maximum stress at $0.50 \mathrm{~s}$ is $6283 \mathrm{psi}$.

\subsubsection{Summary and Conclusions}

The maximum tensile stresses obtained from the various analyses are summarized in Table 2-5. As expected, the analysis using the spatially uniform method predicts lower stresses when compared with the axial distribution analysis. For the floor model with a $475^{\circ} \mathrm{F}$ purge gas, the maximum stress at $0.09 \mathrm{~s}$ is 3278 psi versus $1252 \mathrm{psi}$ for the axial distribution and spacially uniform models, respectively. At $0.50 \mathrm{~s}$, the stresses are 8073 psi versus 6283 psi for the axial distribution and spacially uniform models, respectively. The single-node assumption used for the porous membrane in the spacially uniform method causes lower prediction of the maximum stiess in the filter. This is caused by the lack of a thermal gradient and, therefore, lack of thermally induced stresses over the area covered by the single node of the filter membrane.

The thermal stress levels calculated are directly proportional to the coefficient of thermal expansion. In addition, they are affected by Poisson's Ratio and Youngs Modulus. For the latter two parameters, the measured material values differed from those assumed in the stress analysis. The corrected thermal stresses are shown in Table 2-5. The thermal stress varies with Poisson's ratio by the following ratio:

$$
\text { Thermal Stress } \propto \frac{1}{1-v}
$$

where

$$
v=\text { Poisson's ratio }
$$

$a_{2} \ldots$ is directly proportional to Young's Modulus. The measured values (shown in Appendix F) were used to calculate the corrected thermal stresses. The assumed measured values are compared in Table 2-6. 


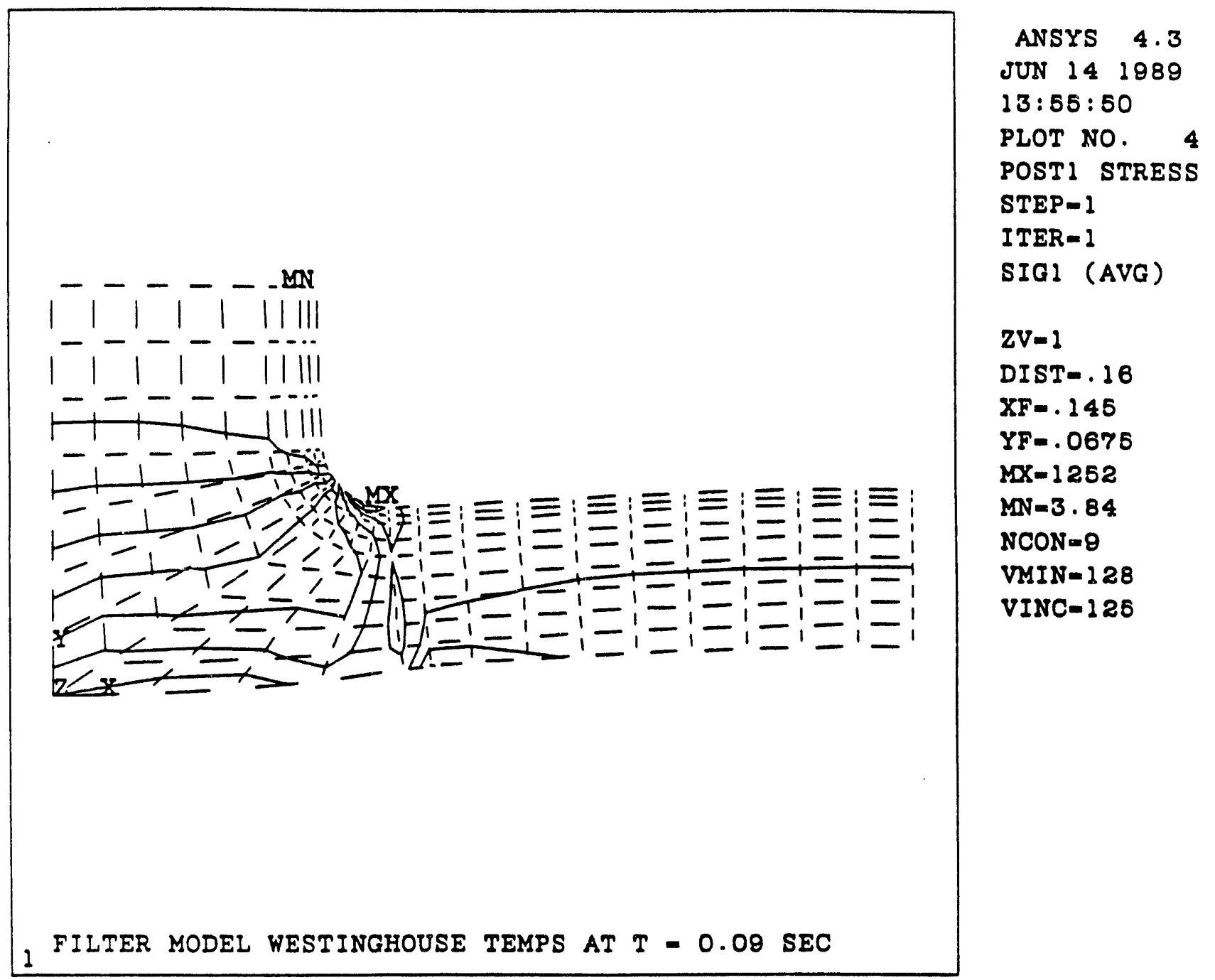

Figure 2-33. Floor model, time $=0.09 \mathrm{~s}$, air temperature $=475^{\circ} \mathrm{F}$, spatially uniform method 


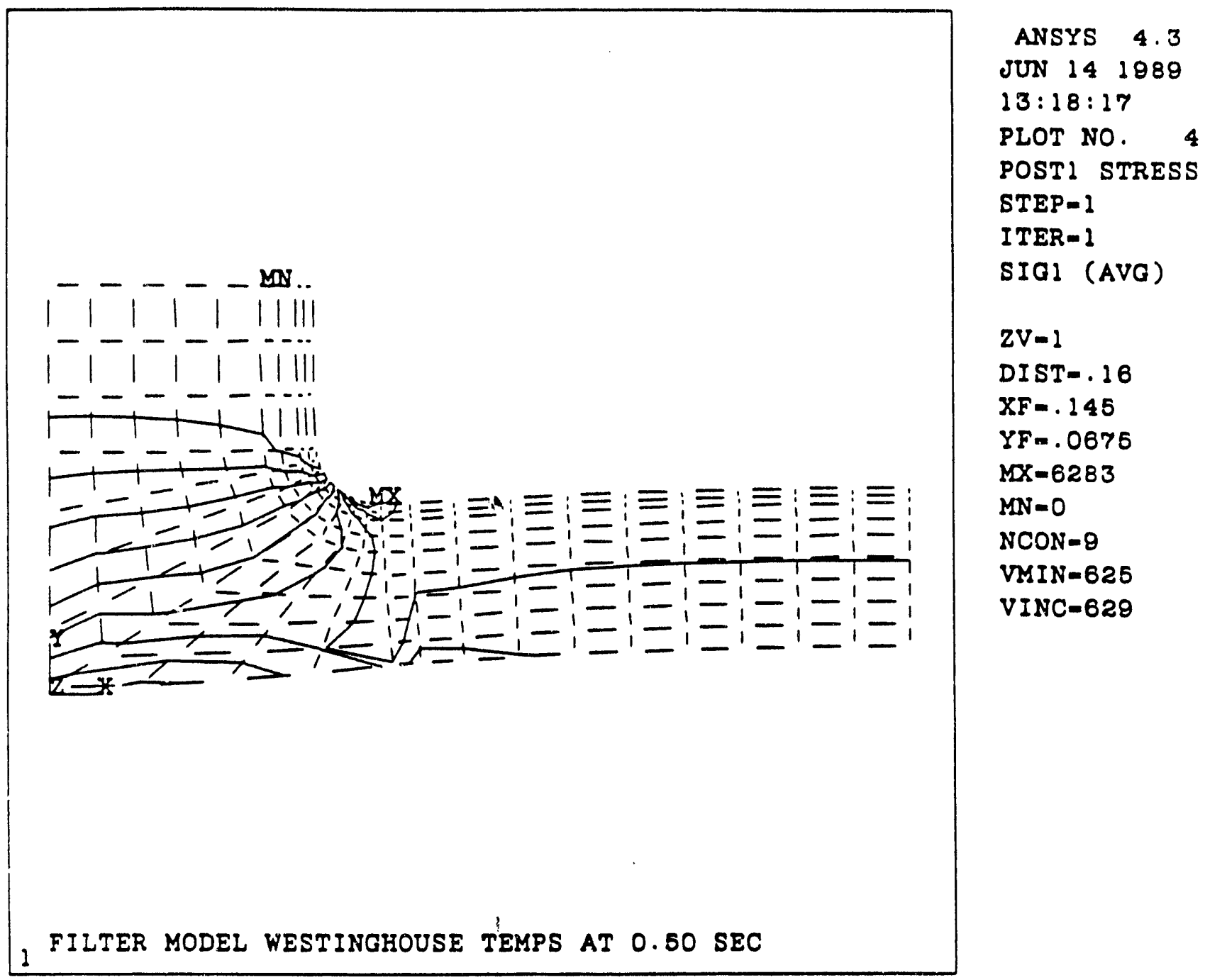

Figure 2-34. Floor model, time $=0.50 \mathrm{~s}$, air temperature $=475^{\circ} \mathrm{F}$, spatially uniform method 
Table 2-5. Maximum principal tensile stress

\begin{tabular}{|l|c|c|c|}
\hline $\begin{array}{c}\text { Purge Pressure Results } \\
\text { (10 psi Flow Pressure) }\end{array}$ & $\begin{array}{c}\text { Time } \\
(\mathbf{s})\end{array}$ & $\begin{array}{c}\text { Maximum Stress } \\
\text { (psi) }\end{array}$ & $\begin{array}{c}\text { Corrected } \\
\text { Maximum Stress } \\
\text { (psi) }\end{array}$ \\
\hline Floor & - & 307 & \\
Backwall & - & 325 & \\
Thermal Boundary Condition (Airflow) & & & \\
Floor $-475^{\circ} \mathrm{F}$ (axial distribution) & 0.01 & 1043 & 397 \\
& 0.05 & 2441 & 939 \\
& 0.09 & 3278 & 1247 \\
Floor $-475^{\circ} \mathrm{F}$ (spatially uniform) & 0.50 & 8073 & 3072 \\
& 0.09 & 1252 & 476 \\
Floor $-1225^{\circ} \mathrm{F}$ (axial distribution) & 0.50 & 6283 & 2391 \\
& 0.09 & 1407 & 535 \\
Backwall $-1225^{\circ} \mathrm{F}$ (axial distribution) & 0.50 & 3396 & 1292 \\
& 0.09 & 767 & 292 \\
& & 1231 & 468 \\
\hline
\end{tabular}

Table 2-6. Comparisons of assumed and measured values of Young's Modulus and Poisson's Ratio

\begin{tabular}{|l|c|c|}
\hline & Poisson's Ratio & $\begin{array}{c}\text { Young's Modulus } \\
(\mathbf{x ~ 1 0} \text { }\end{array}$ \\
\hline Assi) \\
Measured & 0.2 & 15.6 \\
\hline
\end{tabular}




\subsection{CONCLUSIONS}

Figure 2-35 shows the overall detailed design of the crossflow filter and mount. This design meets the requirements of permeability and surface area as established by DOE, while also providing advantages in mounting and manufacturing.

The most unique feature of this design, other than the material used for the crossflow filter, is the mount design. The mount is designed such that a flangeless crossflow filter is used. GTE indicates that attachment of the crossflow filter flange and meeting flatness requirements have caused them problems. Elimination of the crossflow flange therefore eases the manufacturing of the crossflow. In addition, recent tests of the crossflow have shown cracking emanating from the flange into the crossflow filter. Again, elimination of the flange may reduce the tendency for crossflow filler cracking.

The mount is also designed such that the unit can be factory-assembled and shipped as a unit. This approach eliminates the need for field assembly of the crossflow. With this design, the assembly crew would bolt the unit to a flange on the manifold. The unit would be pretorqued for compressive preload of the crossflow filtur.

In addition, the selection of the mount materials eliminates dimensional changes with temperature. The materials selected have differing coefficients of thermal expansion that, with this design, essentially eliminate expansion of the mounting geometry over the temperature range of room temperature to $1600^{\circ} \mathrm{F}$. Therefore, the compressive preload on the filter can be maintained jy the mount. 


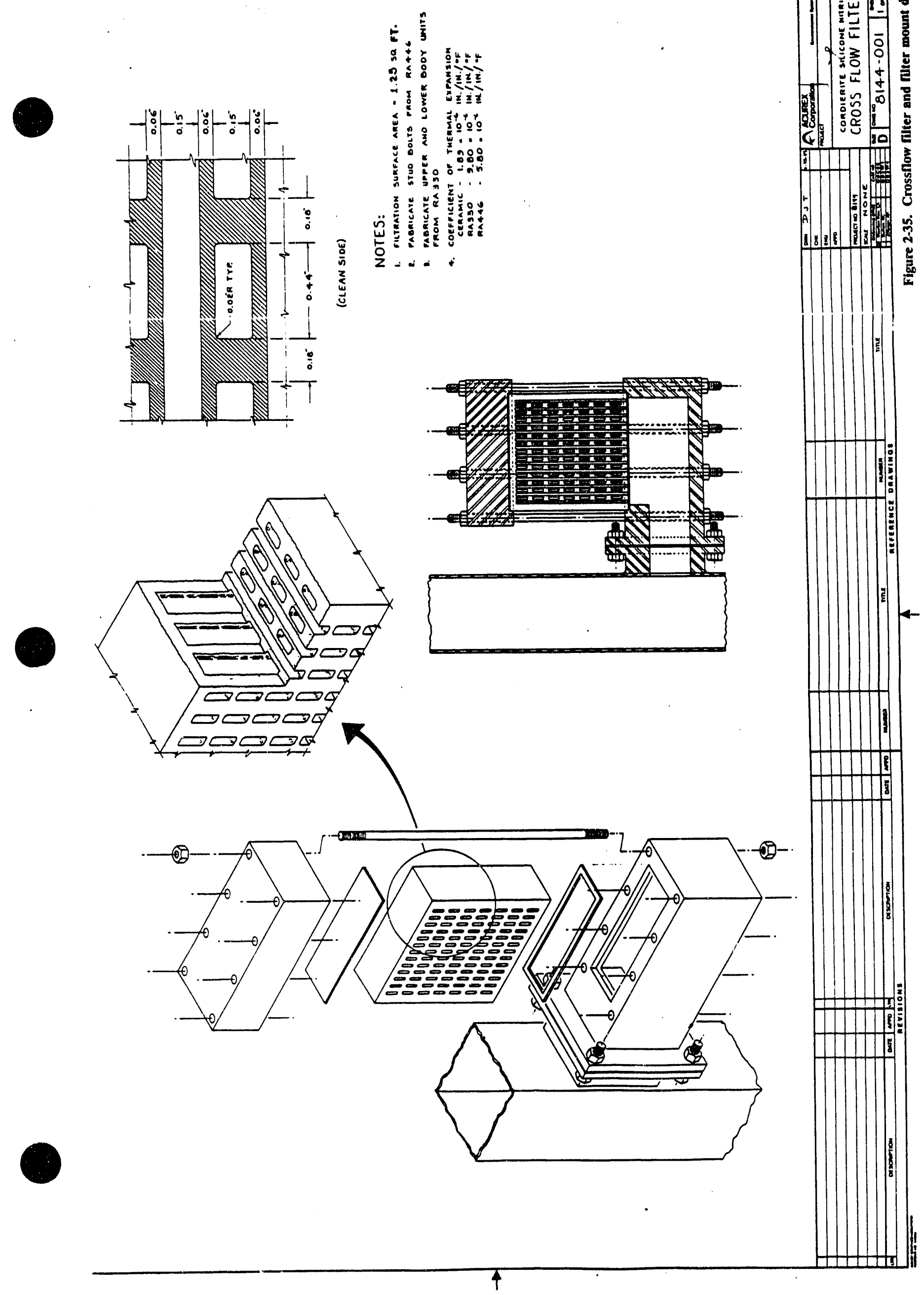




\section{SECTION 3}

\section{FILTER PROPERTY OPTIMIZATION}

\subsection{TARGET VALUES}

\subsubsection{Permeability}

DOE established a permeability guideline of 5 in w.c. at $10 \mathrm{ft} / \mathrm{min}$ face velocity at standard temperature and pressure. Darcy's Law was used to determine the permeability versus thickness relationship required to meet the requirement established by DOE. A discussion of Darcy's law is presented in Appendix D.

Using Darcy's law, Figure 3-1 presents the required permeability at each thickness that is required to meet the DOE requirement. Any points below and to the right of the line exceed the DOE requirement, whereas the points above and to the left of the line do not meet the DOE requirement. This guideline was given to GTE as the permeability requirement for the crossflow filter material.

\subsubsection{Material Strength}

From previous work, it was estimated that the stresses imposed during the pulse cleaning transient were approximately 2000 psi. These stresses are a combination of thermal and pressure stresses with the stress load approximately half thermal and half pressure. Based on this analysis, it was estimated that the required strength to provide an adequate safety factor for the pulse cleaning transient was approximately 4000 psi. Based on our measurements, the material strength is approximately 5300 psi. 


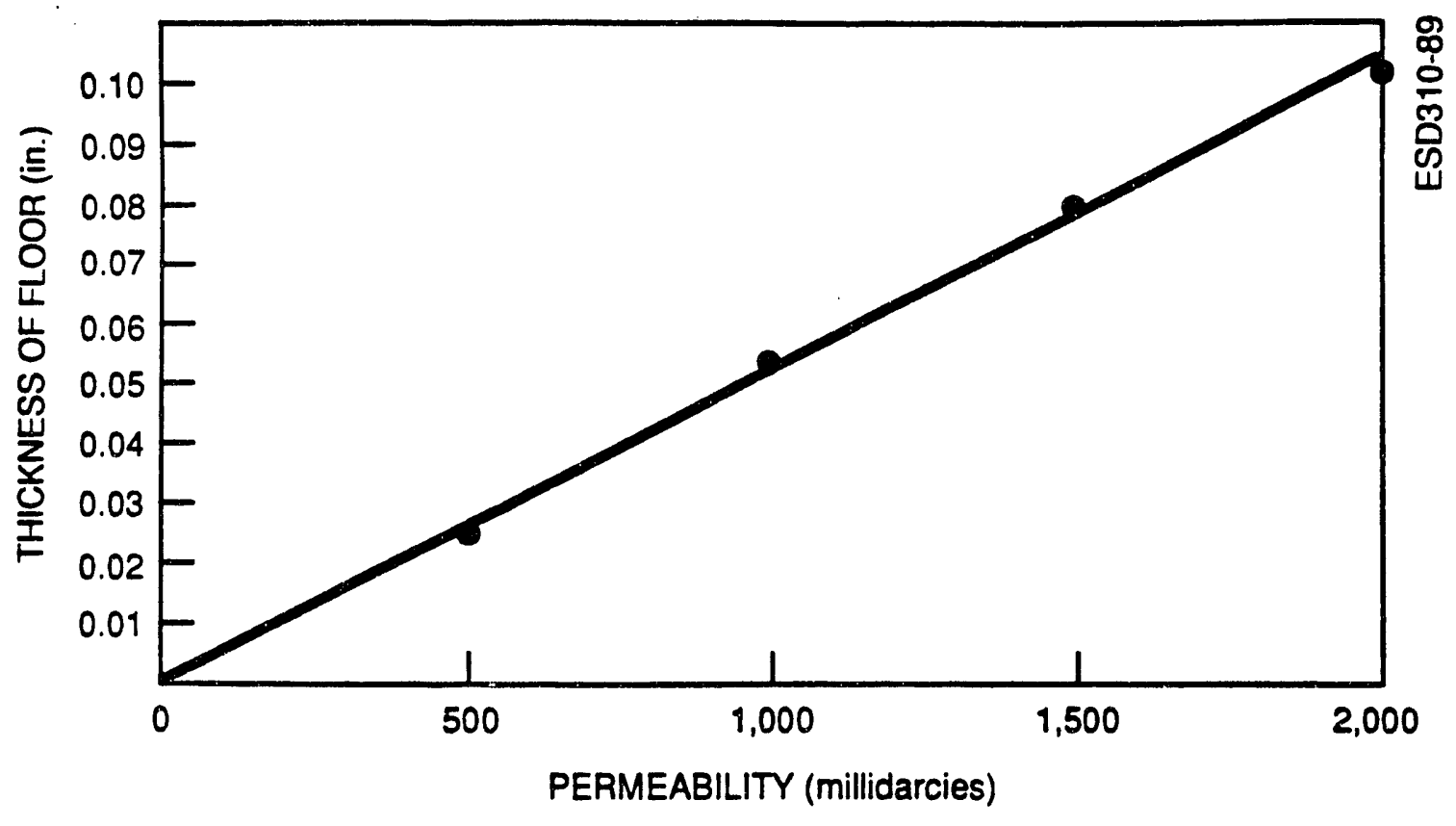

Figure 3-1. Permeability versus floor thickness required to meet 5 in water $\Delta P 10 \mathrm{ft} / \mathrm{min}$ face velocity

\section{MANUFACTURING TECHNIQUES}

\subsubsection{Description}

The use of walnut shells and wood flour as a filler material combination was developed during the cordierite filter program. The walnut shells and wood flour filler combination was determined to give improved permeability characteristics to the cordierite material. The walnut shell material initially used for cordierite was 325-mesh. The wood flour was 80-mesh. (See Appendix $\mathrm{C}$ for mesh versus physical size.) The different characteristics of the walnut shell and wood flour materials are shown in Figures 3-2 through 3-5.

The walnut shells are essentially spherical in nature, while the wood flour has a fibrous or anisotropic character. Therefore a combination would produce a large pore structure (walnut shells) with good interconnectivity (wood flour). 


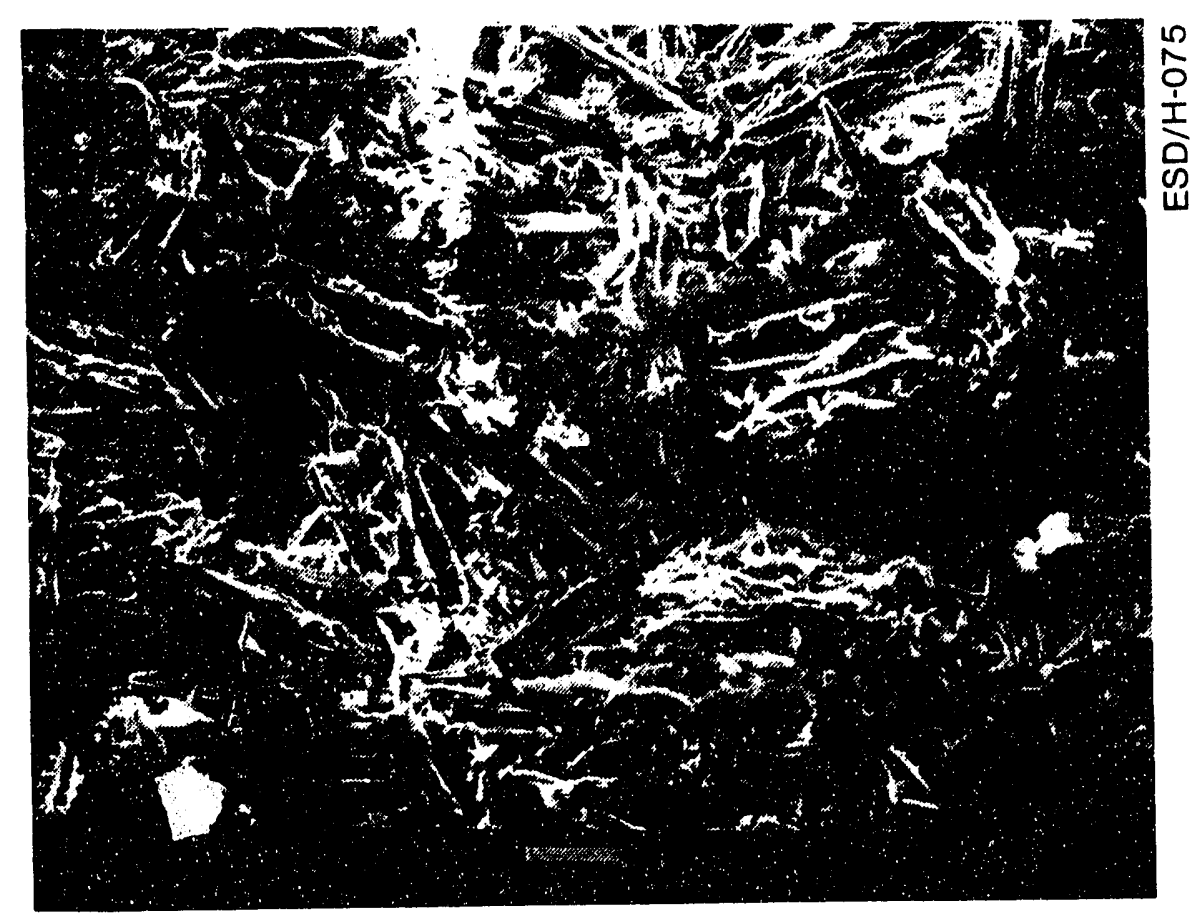

Figure 3-2. 100x scanning electron micrograph of 80-mesh wood flour

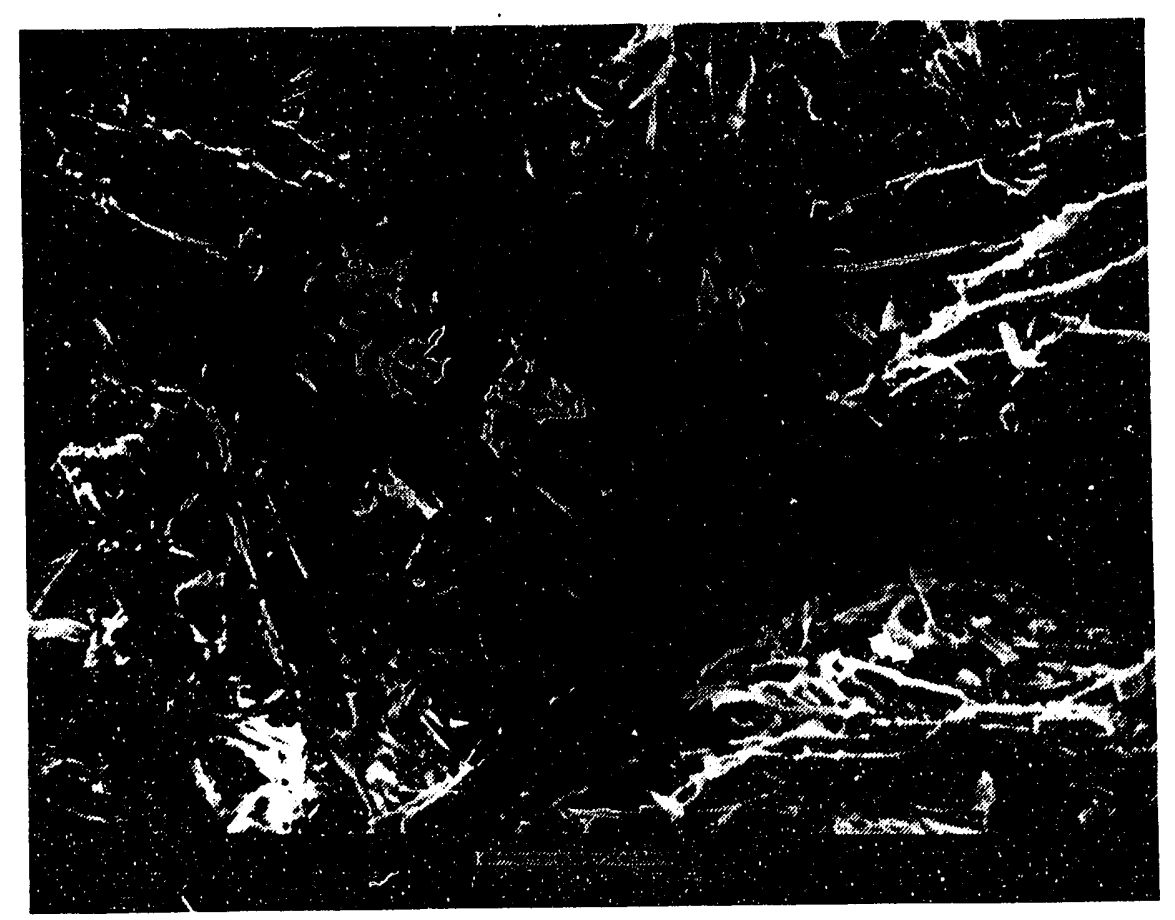

Figure 3-3. 200x scanning electron micrograph of 80-mesh wood flour 


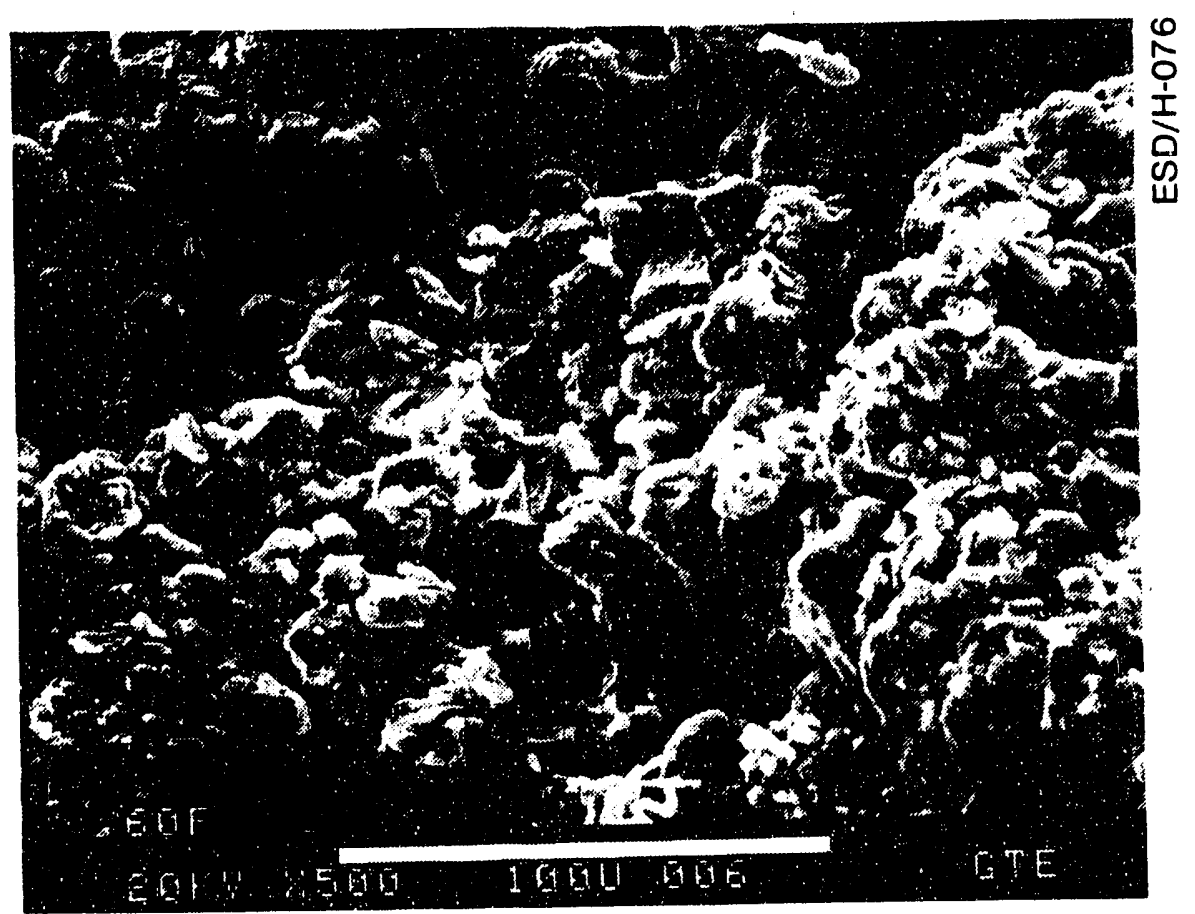

Figure 3-4. 500x scanning electron micrograph of 325-mesh walnut shells

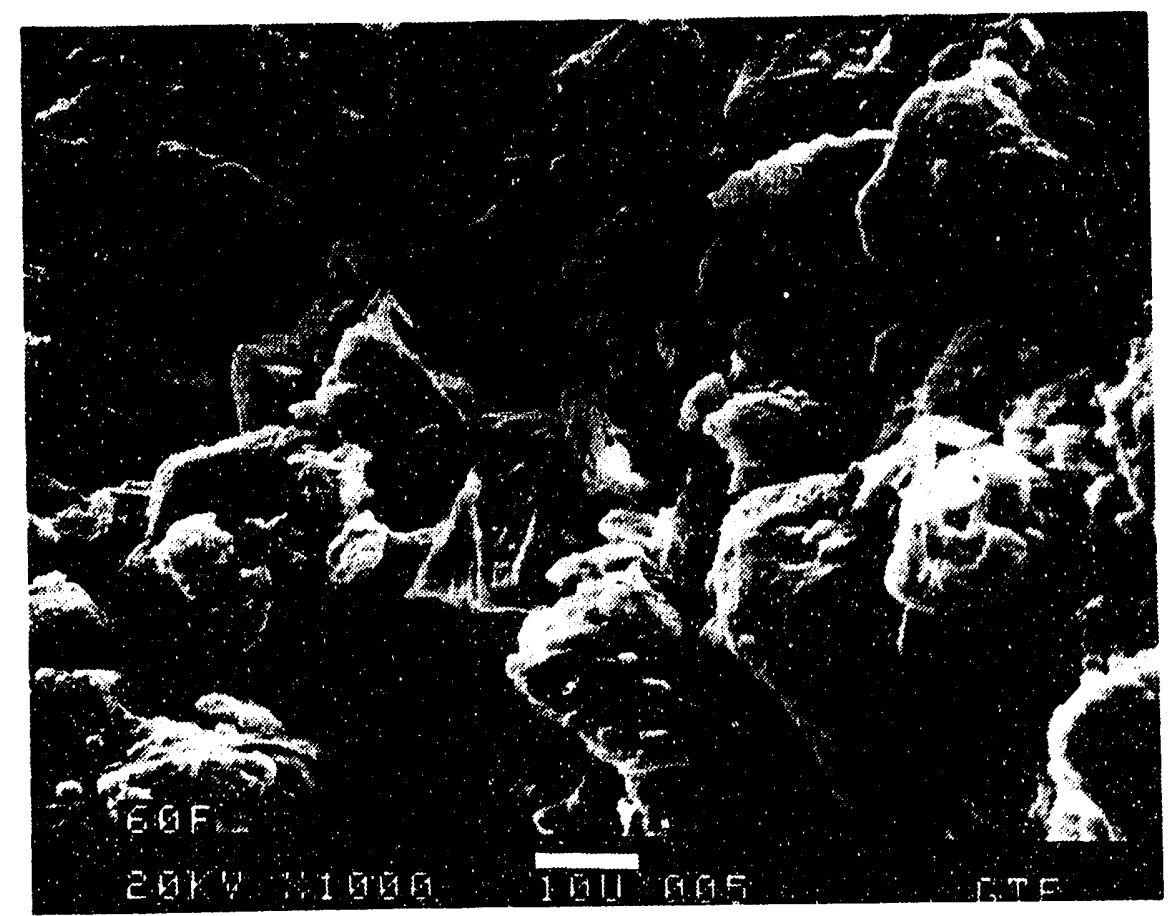

Figure 3-5. 1000x scanning electron micrograph of 325-mesh walnut shells 
It was determined very early in the present work that the duplication of the permeabilities and face velocities by direct substitution of filler materials used in the cordierite program could not be accomplished. The addition of the same filler amounts and filler material yielded much lower permeabilities in the CSN25 material. For this reason, an effort was undertaken to determine the effects of different filler particle size and particle size distribution. Because the wood flour was fairly large in size and uniform in its distribution, as seen in the SEM photographs, the tests were conducted on variations of the walnut shell filler material.

\subsubsection{Walnut shell}

\section{Description}

The walnut shell material is commercially available from several sources. In general, the finer-size material is used for filler and is sold as a 325 -mesh grade and a 200 -mesh grade. The 325-mesh material was the type used in the cordierite research and the initial tests of the CSN25 project. For the CSN25 work, the 200-mesh grade was purchased to give a larger particle size variability. SEMs of the as-received 325-mesh and 200-mesh walnut shell material are shown in Figures 3-6 through 3-9. When initial tests showed that the permeability was much lower than expected, the walnut shells were screened to determine the effects of a more uniform and larger filler size. Because there was no coarser walnut shell material on hand, the 200-mesh material was used for the screening tests. Initial wet screening tests showed that approximately 10 percent of the screened material did not pass through a 270-mesh screen. The screen used was a standard 270-mesh stainless steel screen. The 270-mesh screen was used because it would allow materials under $53 \mu \mathrm{m}$ to pass through and, therefore, allow the use of filler at least $53 \mu \mathrm{m}$ and larger.

The fraction that remained on the screen was screened through a 120 -mesh screen to remove any coarse material. This portior: of screened material was labeled $-120+270$, which indicated that the material was screened to keep only the walnut shell particles that were between 53 and $125 \mu \mathrm{m}$. The SEMs of these materials are shown in Figures 3-10 and 3-11. 


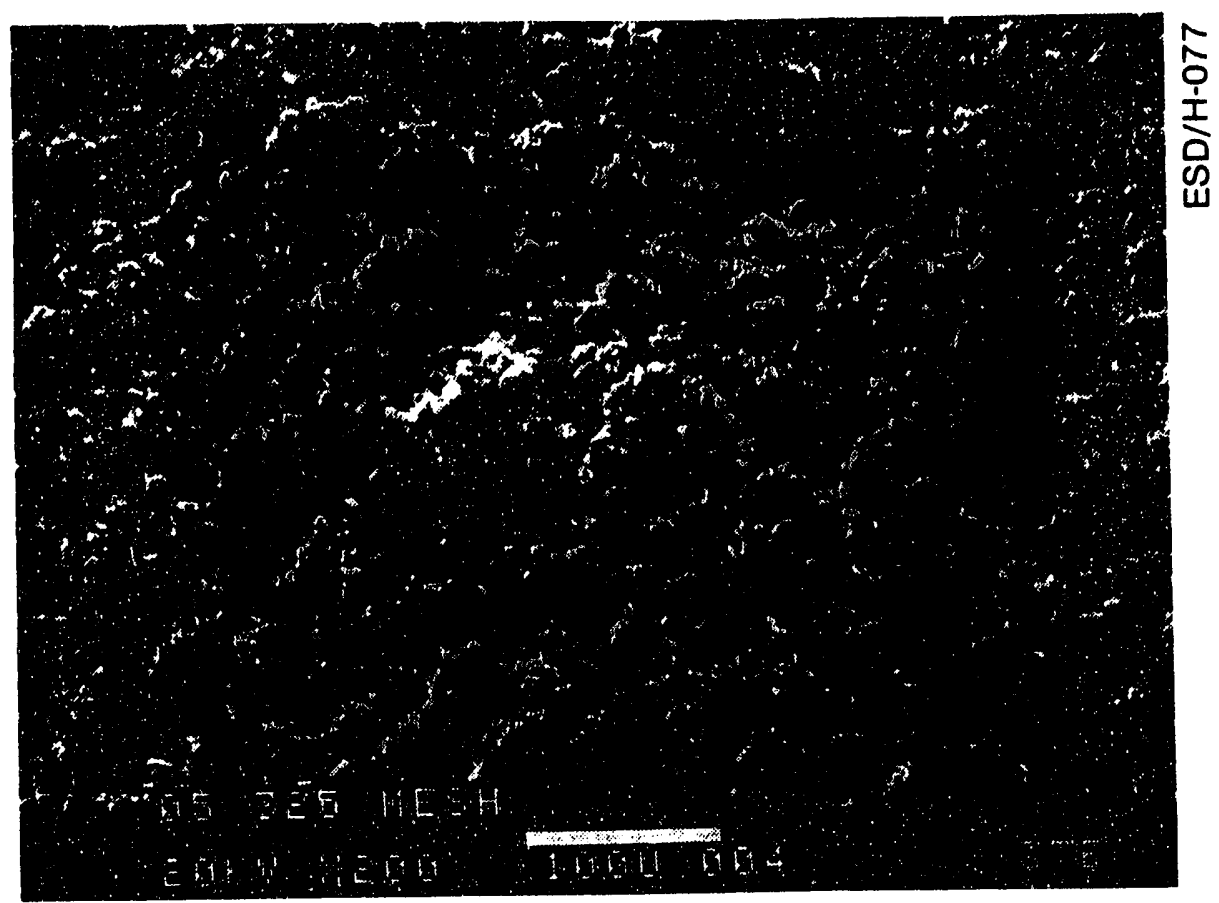

Figure 3-6. 200x scanning eleitron micrograph of 325-mesh walnut shells

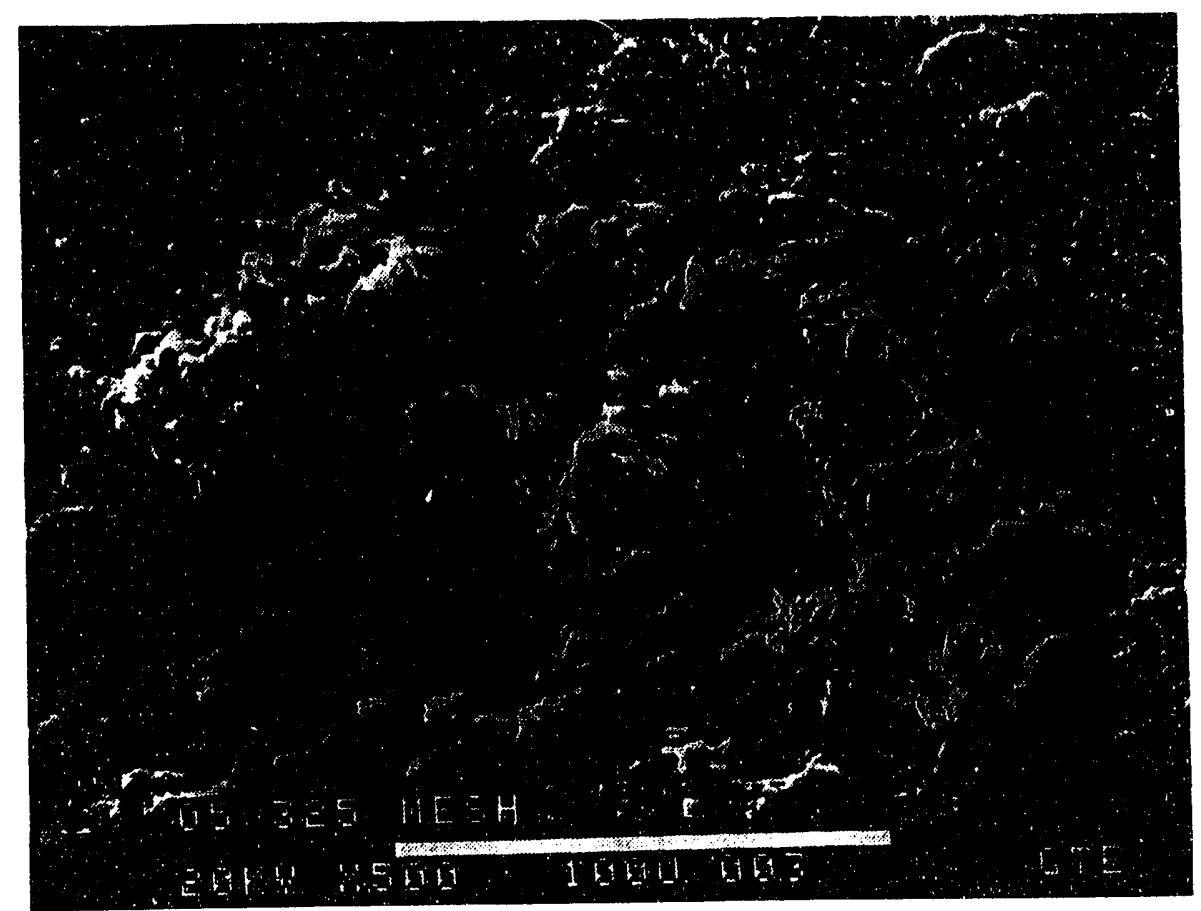

Figure 3-7. 500x scanning electron micrograph of 325-mesh walnut shells 


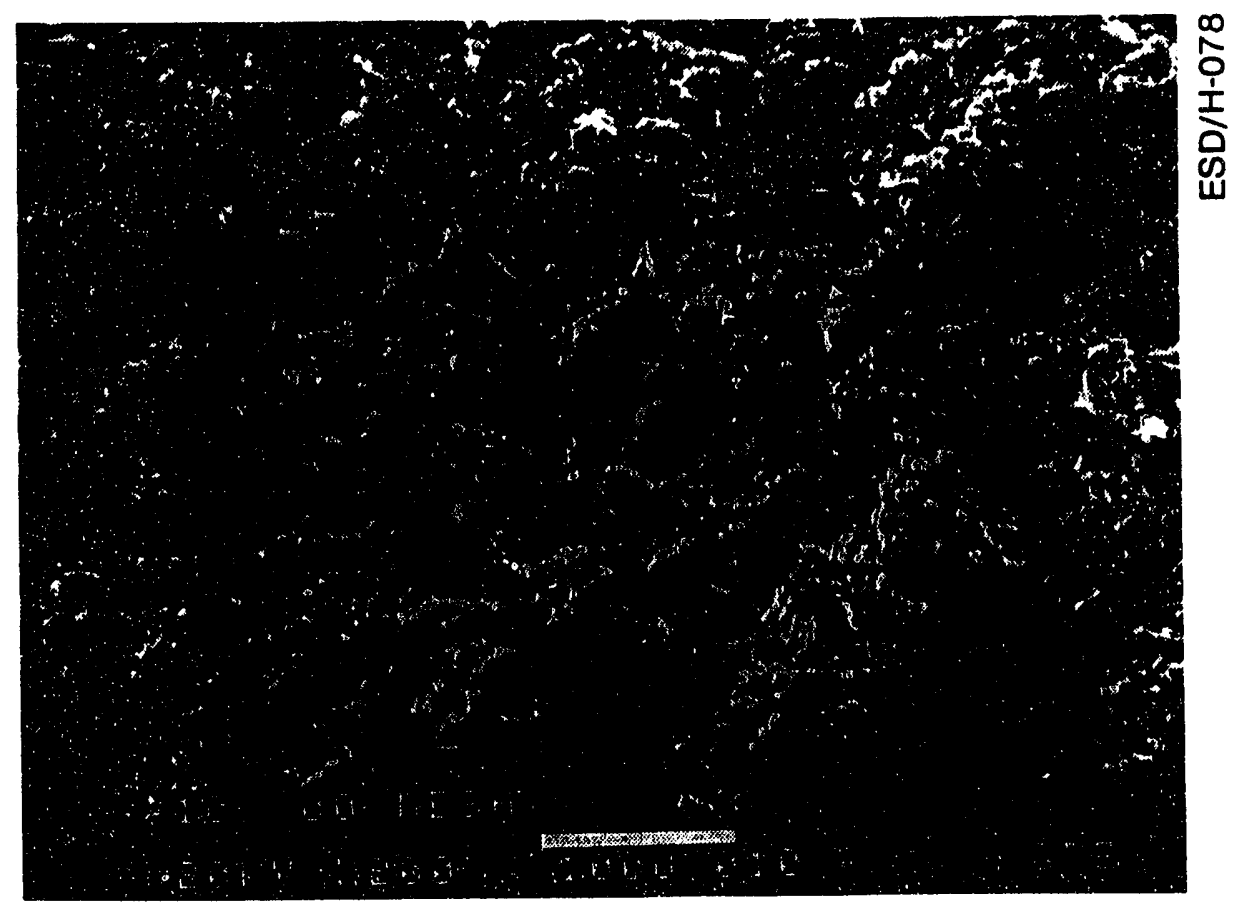

Figure 3-8. 200x scanning electron micrograph of 200-mesh walnut shells

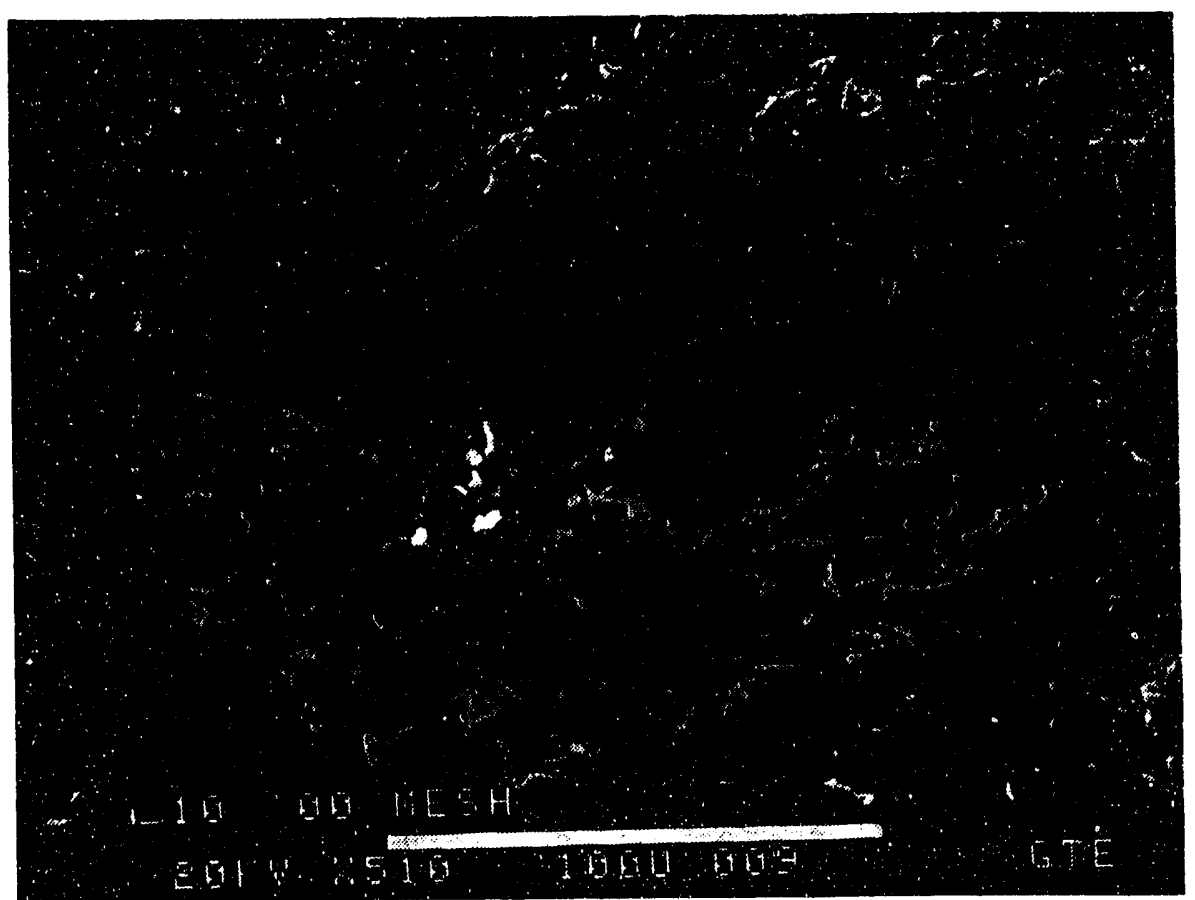

Figure 3-9. 500x scanning electron micrograph of 200-mesh walnut shells 


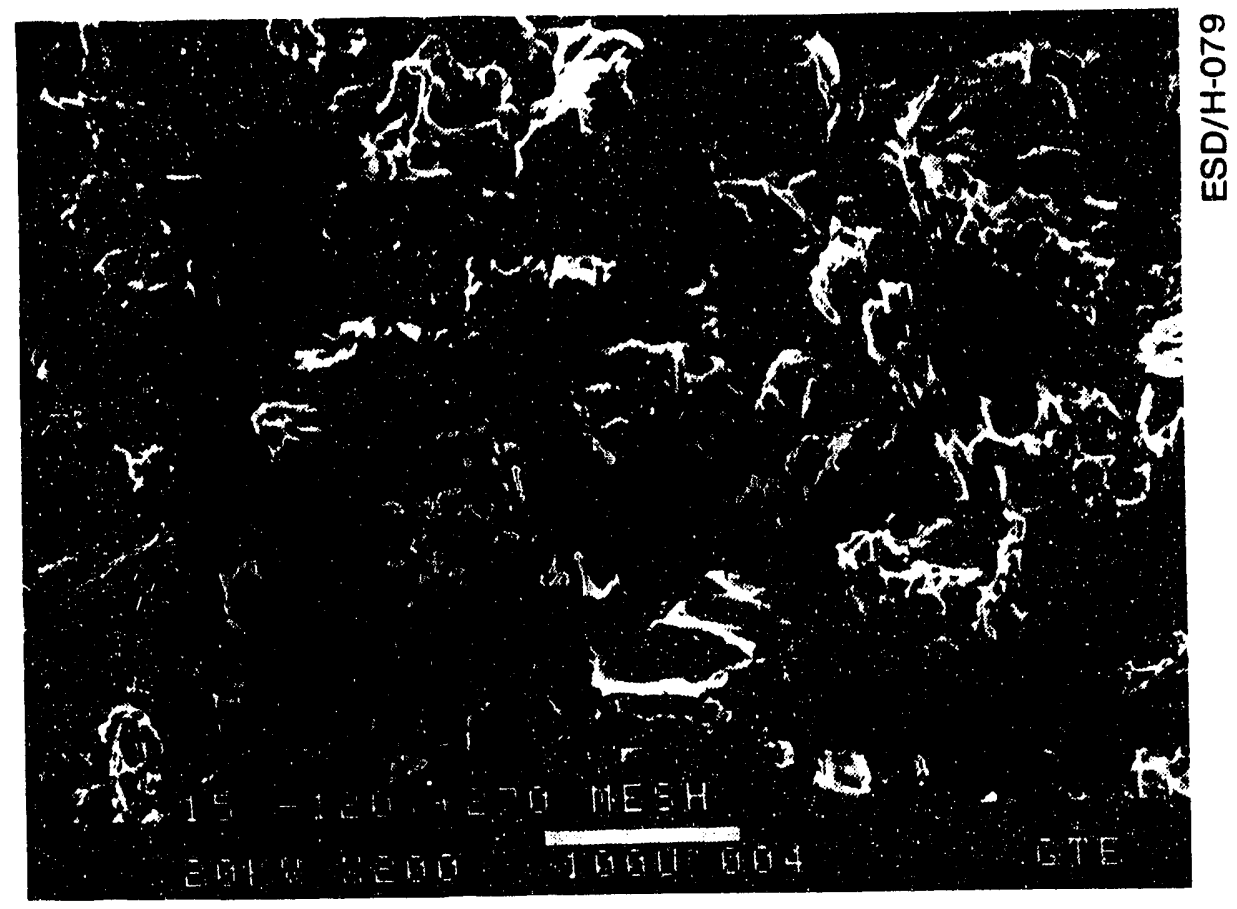

Figure 3-10. 200x scanning electron micrograph of $-120+270$ mesh walnut shells

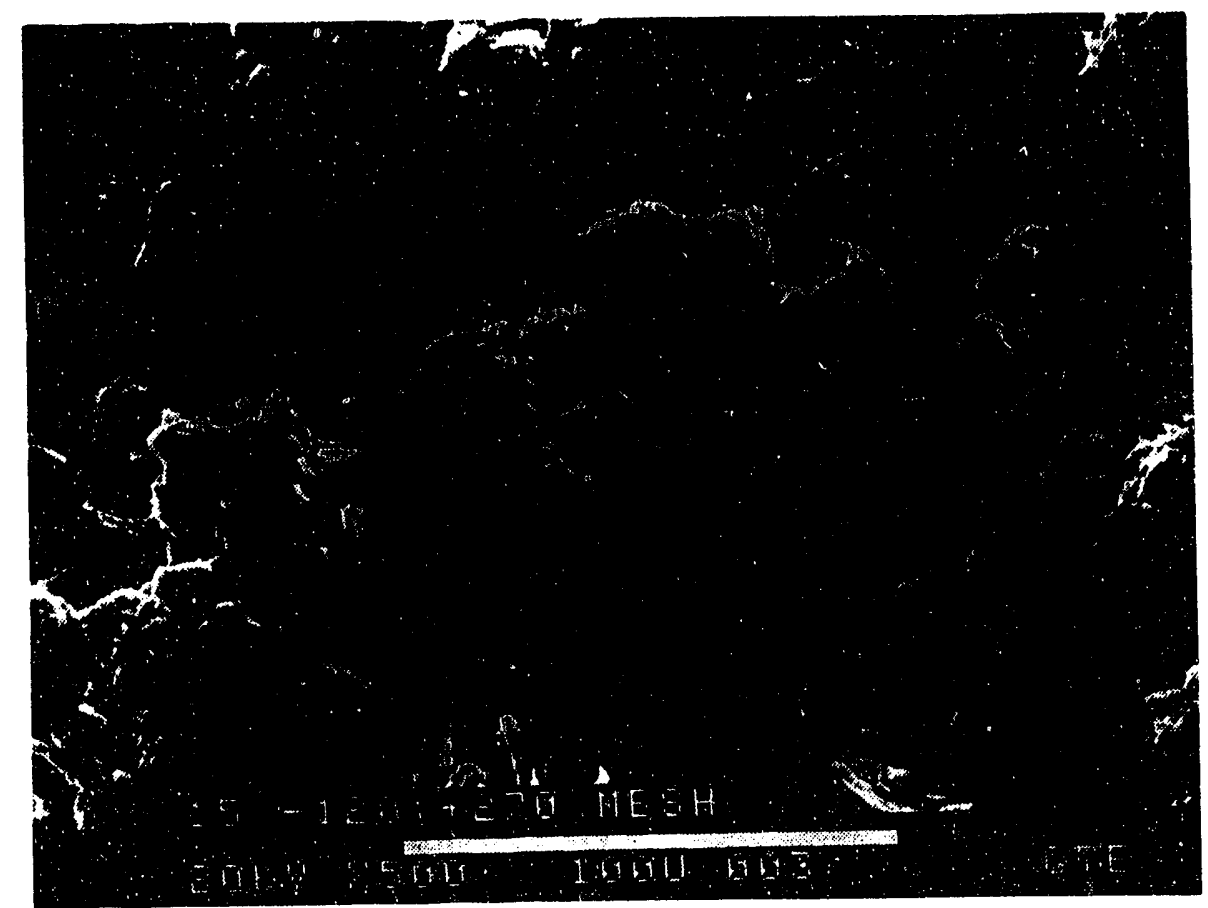

Figure 3-11. 500x scanning electron micrograph of $-120+270$ mesh walnut shells 
The remaining 200-mesh walnut shell material was then processed through 120 - and 270 -mesh screens to obtain enough material for the extruding of samples. Because of the 10 percent yield, the screening process was very slow. The samples were evaluated for particle size distribution using a micromerograph technique. The micromerograph data are shown in Figure 3-12.

The data showed that care had to be taken to assure that all the fines were washed through the screen. Permeability and face velocity tests of samples made with this screen fraction showed improvement in permeability, but not enough to meet permeability requirements. Because of the need for a filler with a larger particle size, material of coarser fraction was sought and purchased.

The coarser material is used for cleaning and polishing parts and is readily available. This material was purchased in two sizes, a 40- through 100-mesh cut and a 60- through 200-mesh cut. To further classify the material, the 60 to 200 -mesh material was screened through a 70 -mesh screen, giving a fairly narrow range of walnut shells in the $212-$ to $250-\mu \mathrm{m}$ range. Another cut was taken from the 40 to 100 material using the 70 -mesh screen which gave a range of walnut shells in the 212- to 425- $\mu \mathrm{m}$ range. Test extrusions of the materials showed increased difficulty in extruding the 212- to $425-\mu \mathrm{m}$ walnut shell material. Although the samples have been extruded, fired, and tested for permeability, SEMs of the coarser walnut shell material and the micromerographs for particle size distribution have not yet been received. The wet screening of these two coarser materials proceeds quite easily, and this larger-particle-size material could probably be dry screened with ease. The dry screening tests were not conducted because of lack of time. All the wet-screened materials were dried in an air drying oven at $250^{\circ} \mathrm{F}$ overnight.

\subsubsection{Materials Mixing}

The screened walnut shells and the wood flour are weighed and added to the CSN25 powder in the desired amounts. This blend makes up a $1000 \mathrm{~g}$ batch which is the minimum-size batch that can be confidently blended in the Simpson mix muller used to extrude the test batches. This mixer is illustrated in Figure 3-13 and shows the muller with the damp granular mix described below. The 
Micromerograph Data

Sample Identification: A 200 mesh walnut shells machine screened wet through $-120+270$ mesh screen

\begin{tabular}{|c|c|c|c|}
\hline \multicolumn{2}{|c|}{$\frac{\text { Slae Ranre }}{\text { (microns) }}$} & requency & Cummulat \\
\hline $\begin{array}{l}3.0 \\
4.0 \\
5.0 \\
10.0 \\
15.0 \\
20.0 \\
30.0 \\
40.0 \\
50.0 \\
70.0 \\
80.0 \\
100.0\end{array}$ & $\begin{array}{l}3.0 \\
4.0 \\
5.0 \\
10.0 \\
15.0 \\
20.0 \\
30.0 \\
10.0 \\
50.0 \\
70.0 \\
80.0 \\
100.0 \\
120.0\end{array}$ & $\begin{array}{l}0.000 \\
0.002 \\
0.003 \\
0.022 \\
0.073 \\
0.073 \\
0.151 \\
0.117 \\
0.089 \\
0.034 \\
0.190 \\
0.190 \\
0.056\end{array}$ & $\begin{array}{l}0.000 \\
0.002 \\
0.005 \\
0.028 \\
0.101 \\
0.173 \\
0.324 \\
0.141 \\
0.531 \\
0.564 \\
0.754 \\
0.844 \\
1.000\end{array}$ \\
\hline
\end{tabular}

Sample Identlficat1on: B 200 mesh walnut shells machine screened wet through $-120+270$ mesh screen

\begin{tabular}{|c|c|c|c|}
\hline \multicolumn{2}{|c|}{$\begin{array}{l}\text { Stre Bance } \\
\text { (microns) }\end{array}$} & ouency & 13mmidat \\
\hline $\begin{array}{l}3.0 \\
4.0 \\
5.0 \\
10.0 \\
15.0 \\
20.0 \\
30.0 \\
40.0 \\
50.0 \\
70.0 \\
80.0 \\
100.0\end{array}$ & $\begin{array}{l}3.0 \\
4.0 \\
5.0 \\
10.0 \\
15.0 \\
20.0 \\
30.0 \\
40.0 \\
50.0 \\
70.0 \\
80.0 \\
100.0 \\
120.0\end{array}$ & $\begin{array}{l}0.000 \\
0.002 \\
0.003 \\
0.010 \\
0.036 \\
0.050 \\
0.088 \\
0.100 \\
0.122 \\
0.070 \\
0.409 \\
0.099 \\
0.010\end{array}$ & $\begin{array}{l}0.000 \\
0.002 \\
0.005 \\
0.016 \\
0.052 \\
0.102 \\
0.190 \\
0.290 \\
0.411 \\
0.181 \\
0.891 \\
0.890 \\
1.000\end{array}$ \\
\hline
\end{tabular}

Sample Ident1flcation: C 200 sesh walnut shells hand screened wet throuch $-120+270$ mesh screen.

Stre Ranre

(microns)

3.0

4.0

5.0

10.0

15.0

20.0

30.0

40.0

50.0

70.0

80.0

100.0

3.0
4.0
5.0
10.0
15.0
20.0
30.0
10.0
50.0
70.0
00.0
100.0
120.0

3.0

5.0

10.0

30.0

0.0

30.0

70.0

100.0

120.0

Ireauenay

$$
\begin{aligned}
& 0.000 \\
& 0.007 \\
& 0.005 \\
& 0.004 \\
& 0.024 \\
& 0.013 \\
& 0.067 \\
& 0.027 \\
& 0.067 \\
& 0.027 \\
& 0.227 \\
& 0.260
\end{aligned}
$$$$
0.273
$$

Cummulative

$$
\begin{aligned}
& 0.000 \\
& 0.007 \\
& 0.012 \\
& 0.016 \\
& 0.040 \\
& 0.053 \\
& 0.120 \\
& 0.147 \\
& 0.213 \\
& 0.240 \\
& 0.167 \\
& 0.727
\end{aligned}
$$

1.000

Figure 3-12. Data sheet of micromerograph results 


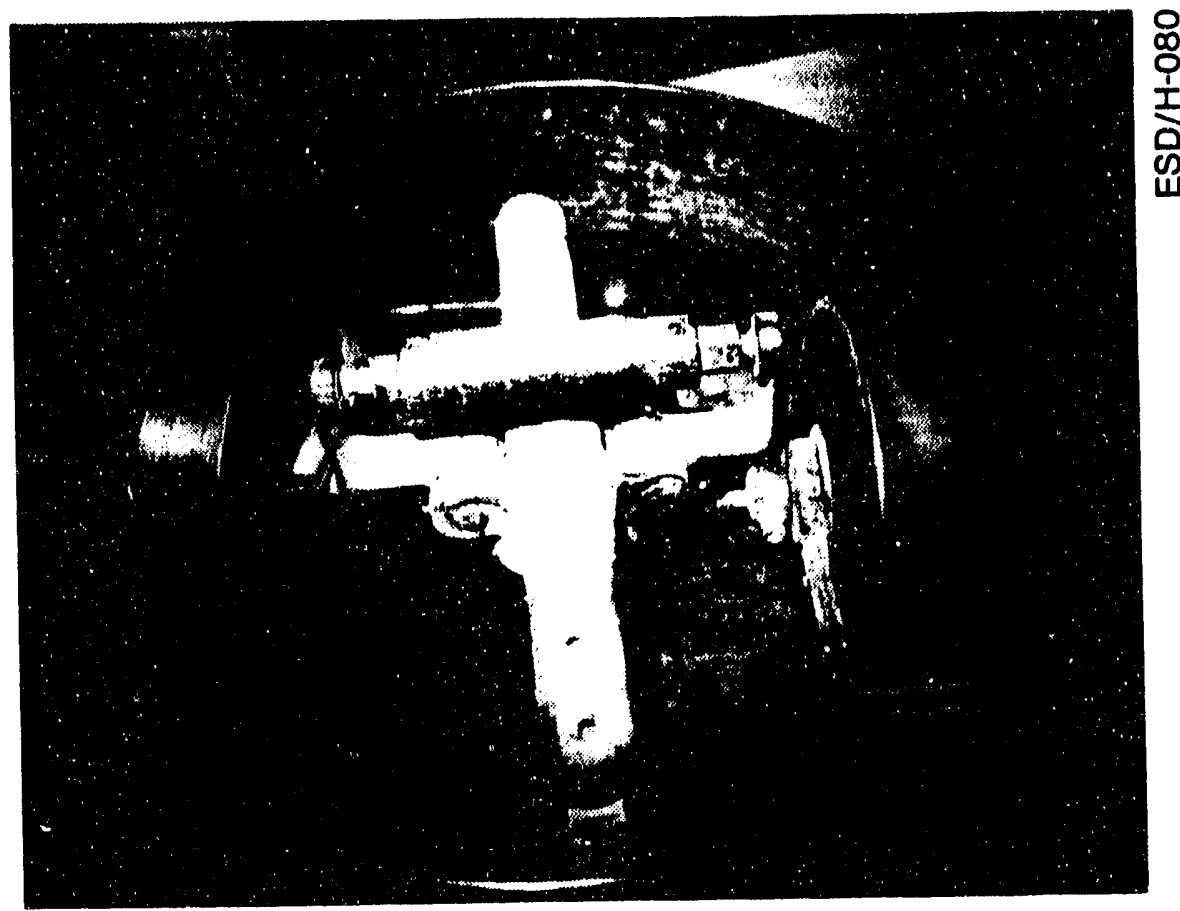

Figure 3-13. Simpson mix muller with material in initial mixing stage

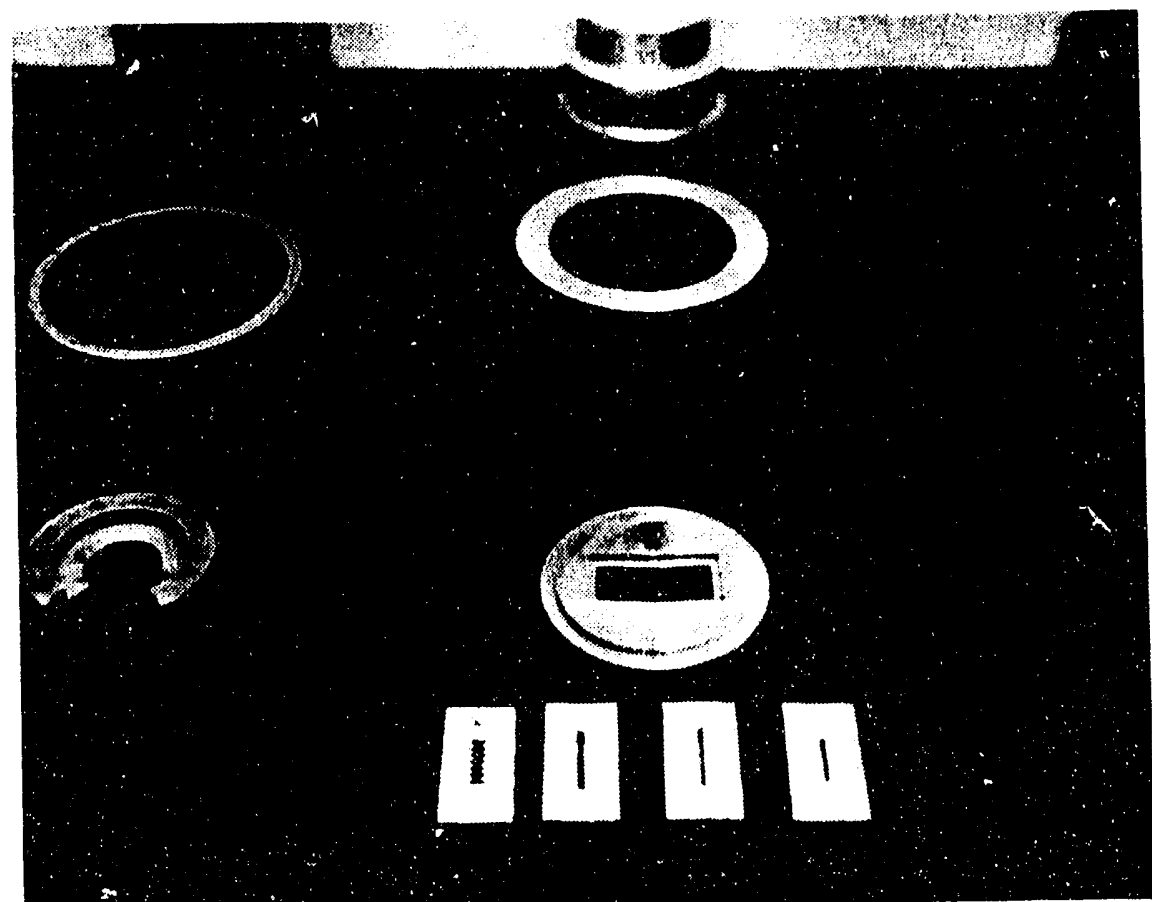

Figure 3-14. Sections of extrusion die with various sizes of die inserts 
CSN25 with walnut shells and wood flour material is allowed to blend dry in the mix muller with the dust lid on for 30 min to facilitate good mixing of the dry ingredients.

The wet binder system is then added in two stages. Approximately 75 percent of the desired amount is added to the mixer and allowed to $\mathrm{mix}$ for another $15 \mathrm{~min}$. This blends the material into a damp granular mix. The remaining wet binder is added to the mix and mulled for another $15 \mathrm{~min}$. At the end of this mixing period, the extrusion mix has the consistency of clay and is ready for extrusion.

\subsubsection{Extrusion}

The strusion mix is taken from the mix muller and placed in a plastic bag to prevent drying before extrusion. A small sample is taken from the bag and placed into the extrusion die. The sample size is about $100 \mathrm{~g}$. The die is assembled and placed in the press. The extrusion die is shown in Figures 3-14 through 3-16. The material is extruded into lengths of about $3 \mathrm{ft}$.

The extrusion pressure is kept in the range of 15,000 to $20,000 \mathrm{lb}$. If the material does not extrude at $20,000-\mathrm{lb}$ pressure, it is returned to the mix muller and mulled for another $15 \mathrm{~min}$ with additional wet binder. If the material extrudes below $15,000 \mathrm{lb}$, the material is returned to the mix muller and mulled for another $15 \mathrm{~min}$ with additional dry CSN25 with walnut shell and wood flour filler. Each composition of material varies in the amount of wet binder necessary for extrusion. In general, it appears that as the amount of filler in the composition increases, the amount of wet binder needed to extrude between 15,000 to $20,000 \mathrm{lb}$ pressure increases. The increased particle size of the walnut shells requires less wet binder. The weight percent of wet binder to dry material varies between 22 to 28 percent depending on the composition.

The extrusion die is a four-part die that is shown in detail in Figure 3-14. The chamber is about 3 in diameter by 4 in deep. The die itself fits into an end cap that is mace to set into the chamber. The die is 1 in by 2 in and is removable to allow the use of various extrusion test shapes. 


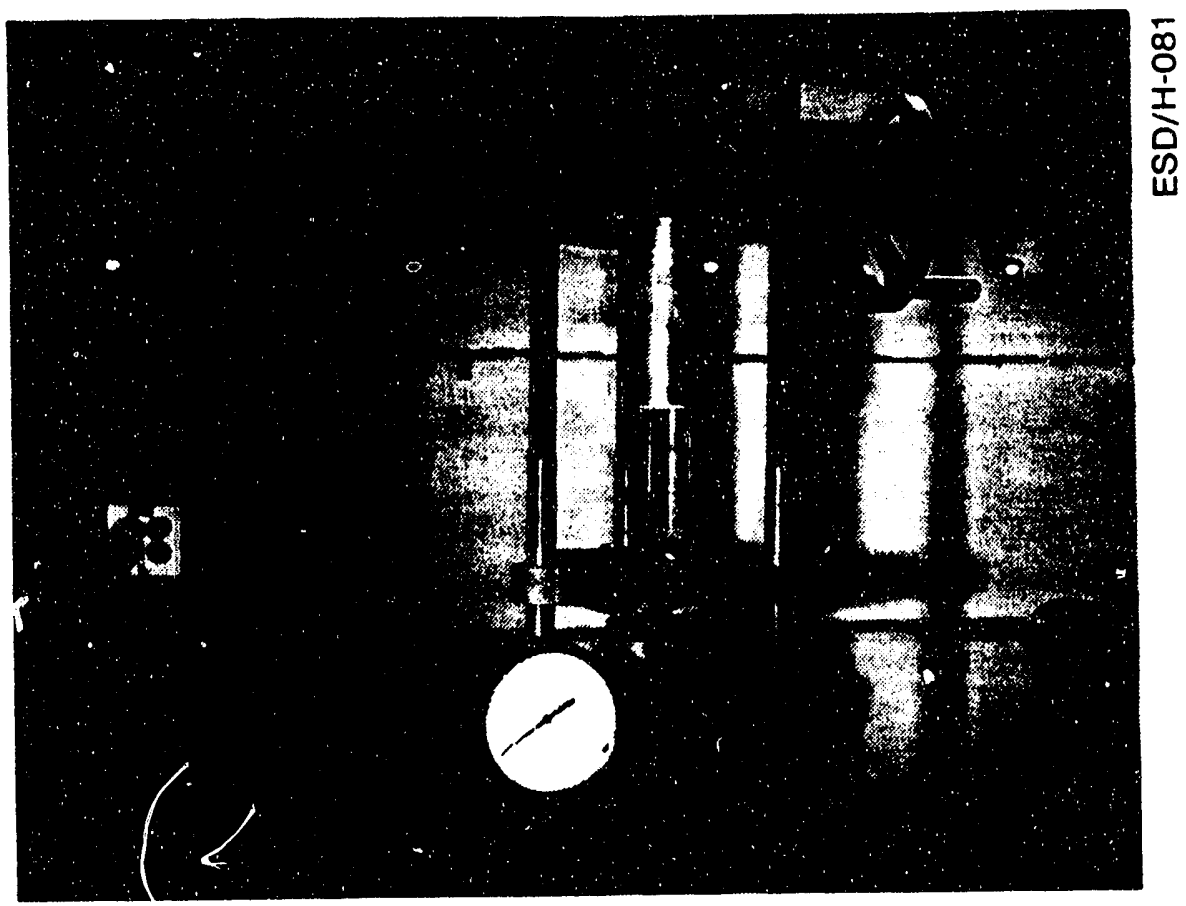

Figure 3-15. Press with assembled extrusion die

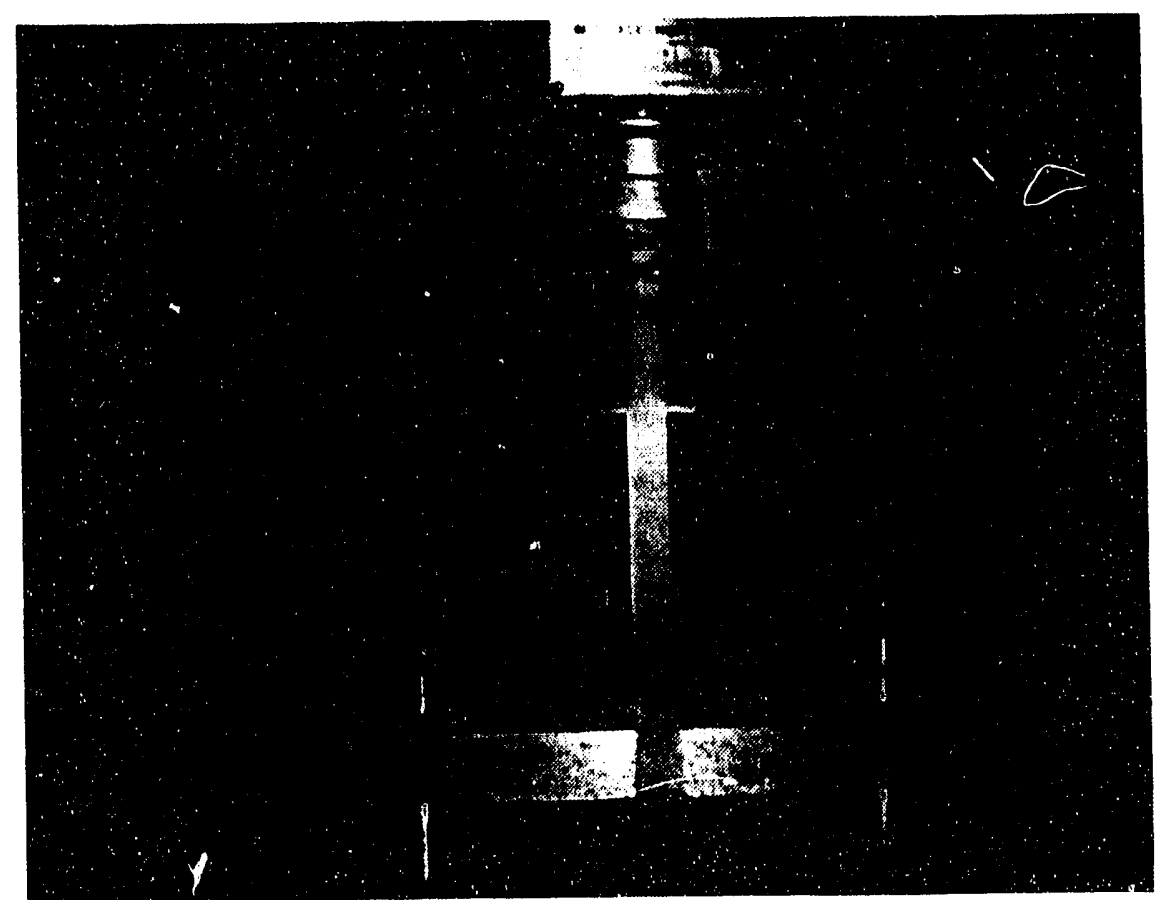

Figure 3-16. Material being extruded in extrusion rig 
The die sizes for this test program were 1.0 in by 0.100 in and 1.0 in by 0.075 in. A 0.75 -in by 0.075-in die from the cordierite program was used until the new die inserts could be manufactured.

After the material is extruded into 3-ft lengths, it is placed on corrugated plastic and placed in an air dryer overnight to remove the moisture from the extrusion. Once air-dried, the extruded material has excellent green strength and can be handled without warping. This dried extrusion is stored until the samples are ready for binder burnout.

In an effort to simulate a process to manufacture a filter as closely as possible, and to check the effect that stacking or pressing an extruded piece might have, samples of an extruded material were also placed between two metal plates and pressed in a direction perpendicular to the direction of the extrusion. These samples were then placed on the plastic racks and dried in the same fashion as the others. These samples and the other extruded samples are shown in Figures 3-17 and 3-18.

\subsubsection{Binder Burnout}

The binder burnout of the extruded material and the filler burnout was performed in air in a single burnout procedure. Initial attempts to burn out the material in air resulted in the ignition of the samples with a corresponding "fireplace $\log ^{n}$ type of combustion. Because of the concerns over oxidation of the silicon nitride and the thermal shock damage that this type of combustion would have on a large filter, the binder burnout technique was modified to control the combustion. The extruded material was buried in alumina sand to limit the diffusion of air into the sample. This technique resulted in a uniform binder burnout that had no large spikes in temperature. The extruded material was placed in a furnace at $325^{\circ} \mathrm{C}$ overnight to allow for complete oxidation of the binder and filler material. Examination of the material under an optical microscope showed no residual carbon, and an x-ray of the sintered CSN25 showed no formation of silicon carbide (Figure 3-19). 


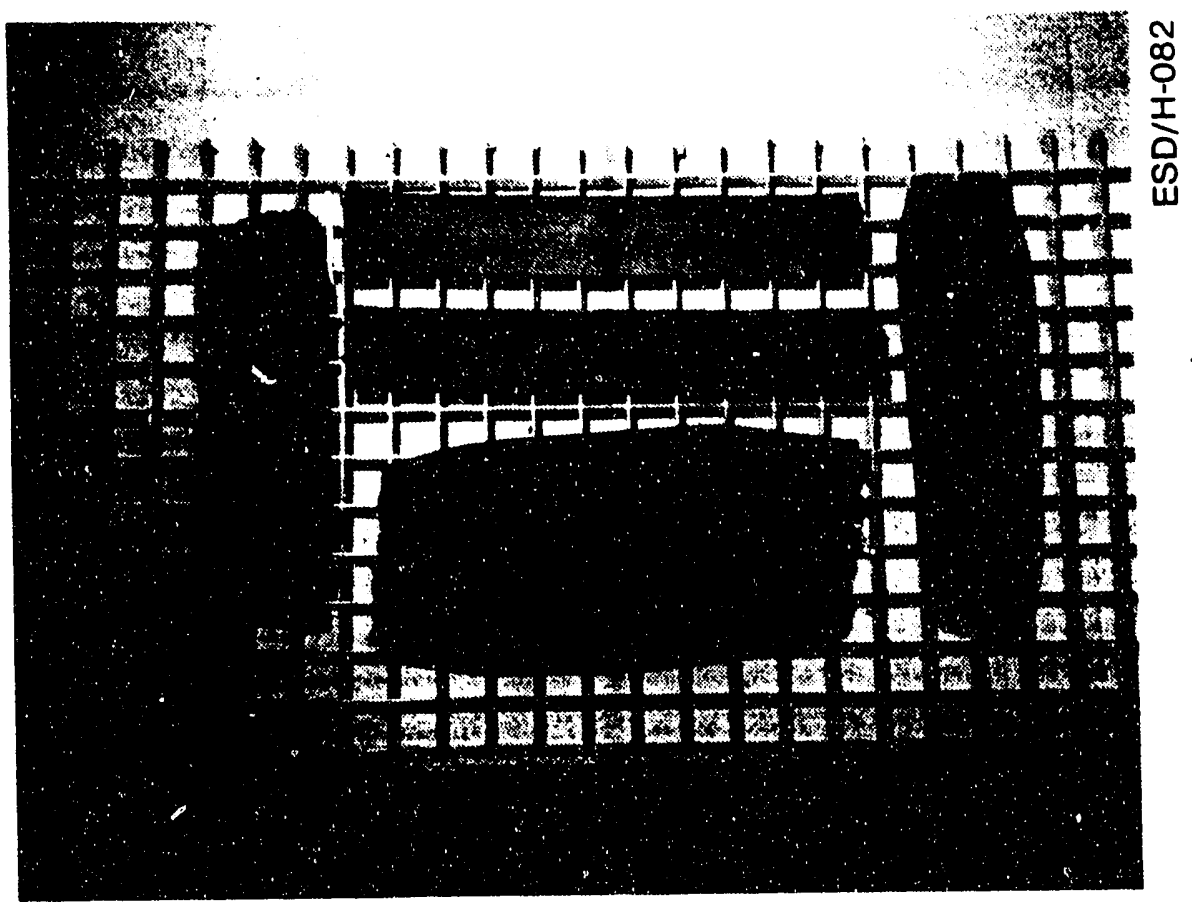

Figure 3-17. Samples of extruded pieces pressed together

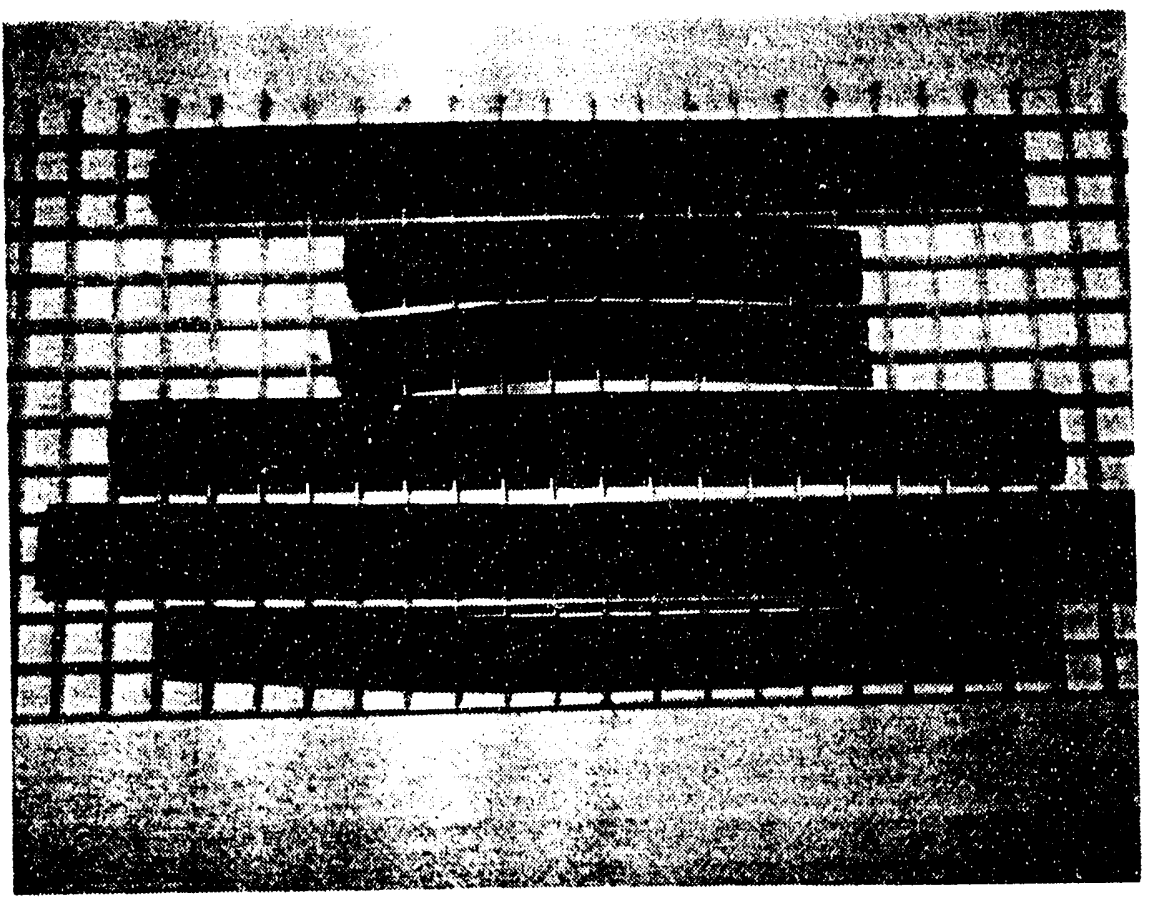

Figure 3-18. Samples of material extruded with various die inserts 


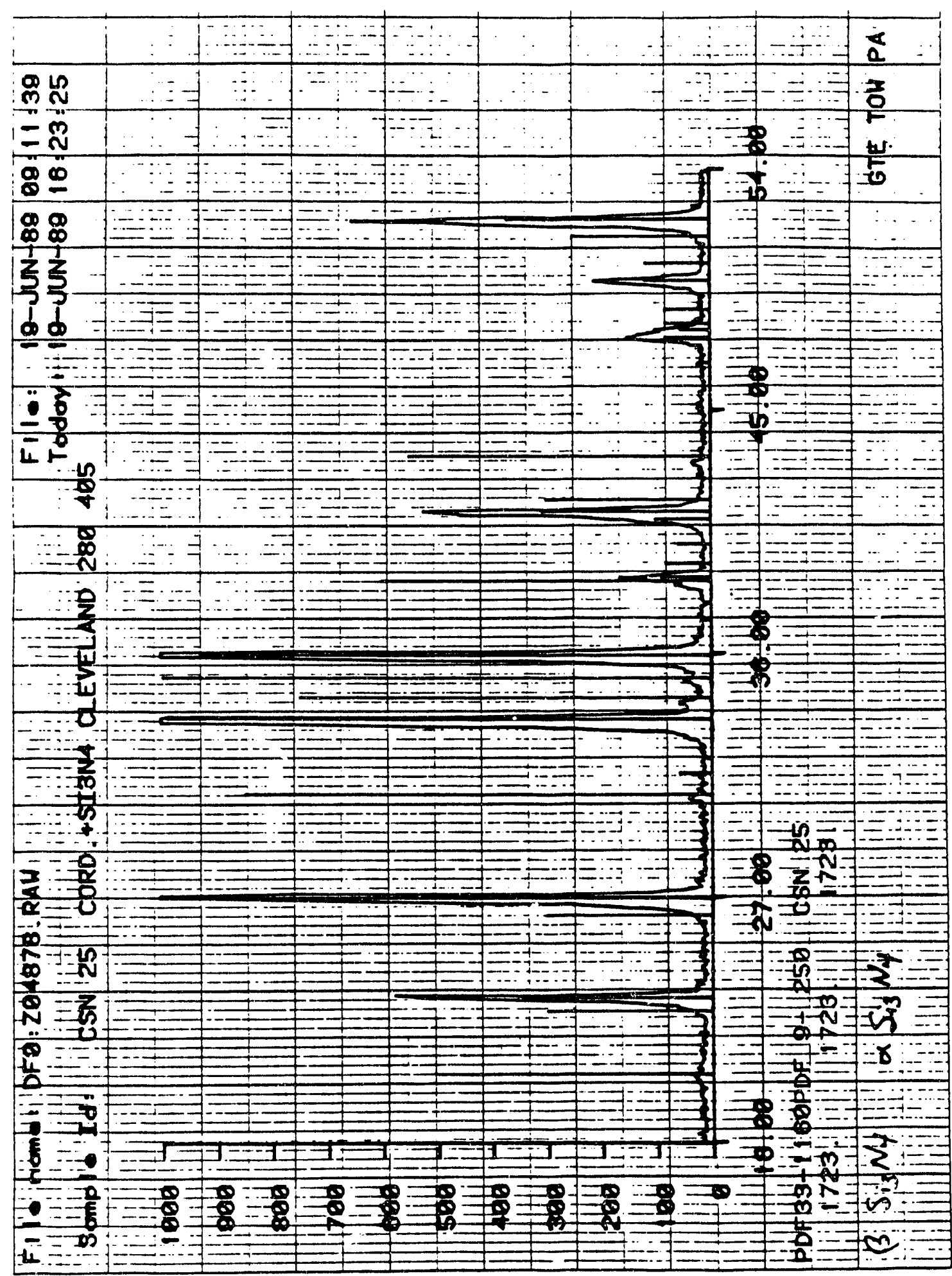

है

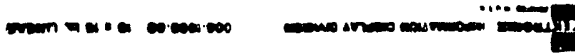




\subsubsection{Sintering}

The sintering of the CSN25 material after binder burnout was done in a nitrogen atmosphere at atmospheric pressure. The material was placed in graphite boats that had been prefired at least once in nitrogen at the sintering temperature of $1700^{\circ} \mathrm{C}$. The material was taken immediately from the binder burnout step, and placed in the graphite boats on a layer of boron nitride powder to prevent contact of the CSN25 with the graphite and therefore prevent the formation of silicon carbide at the contact point.

The transfer from the binder burnout step to the sintering step was done as rapidly as possible to minimize the condensation of moisture in the very porous CSN25 material. The CSN25 material was sintered at $1700^{\circ} \mathrm{C}$. The furnace was evacuated and backfilled with nitrogen twice to assure the removal of oxygen in the sintering atmosphere. The furnace was ramped to $1700^{\circ} \mathrm{C}$ at a constant ramp rate going from room temperature to $500^{\circ} \mathrm{C}$ in vacuum; then the furnace was backfilled with nitrogen to atmospheric pressure between $500^{\circ}$ and $800^{\circ} \mathrm{C}$. After $1 \mathrm{hr}$ at $1700^{\circ} \mathrm{C}$, the furnace was cooled using the standard CSN25 cooling procedure.

\subsection{RESULTS}

\subsubsection{Alignment During Extrusion}

There is always the concern that extrusion of a particular material might cause alignment, especially in the case of a thin-walled extrusion. The use of a walnut shell that is quite spherical was used during this work to minimize this effect. To try to identify potential differences, SEMs of sintered sample fracture surfaces were taken parallel and perpendicular to the direction of the extruded sample. These SEMs are shown in Figures 3-20 through 3-23. The SEMs do not show evidence of anisotropy in the microstructure due to extrusion. Permeability measurements of samples extruded at 0.075 -in and 0.100 -in thicknesses show higher permeabilities in the thicker samples. This seems to indicate there is some type of extrusion effect taking place. 


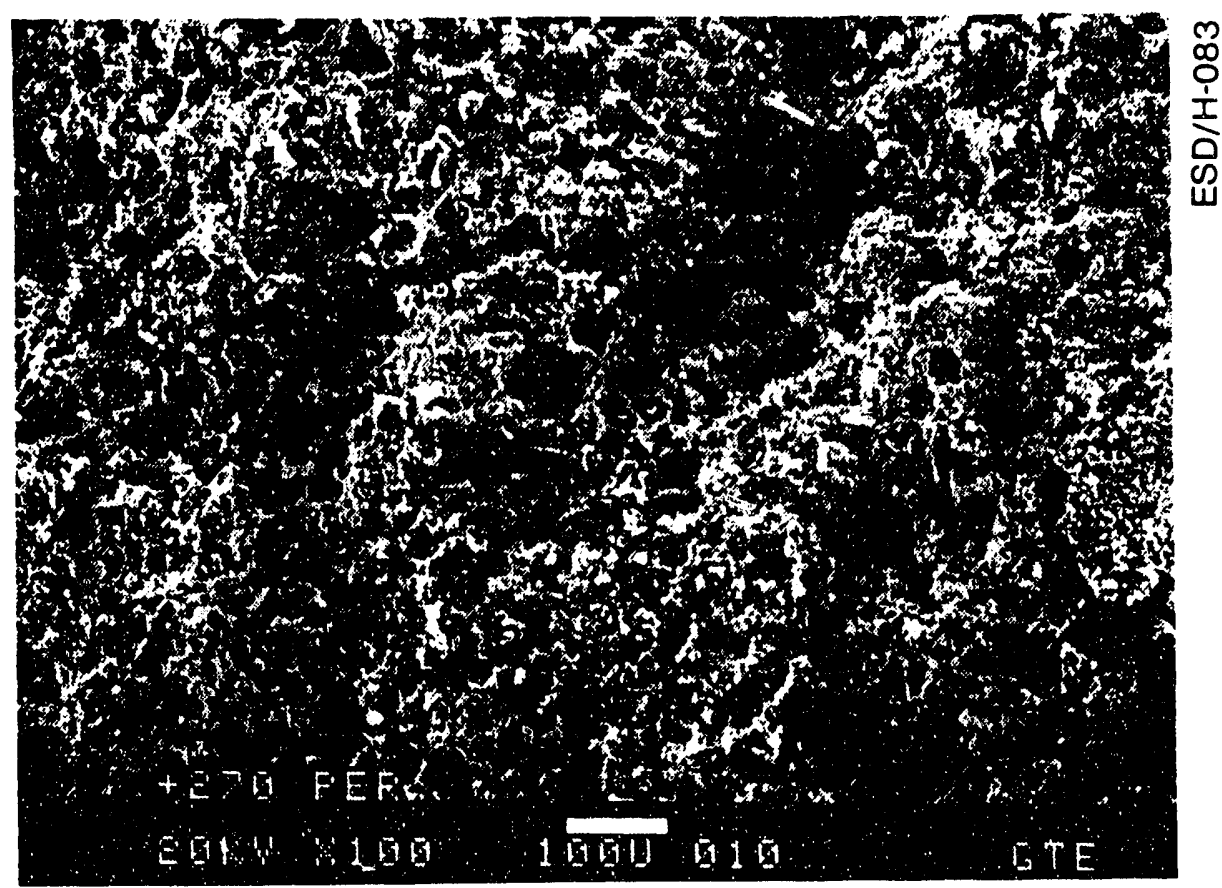

Figure 3-20. 100x scanning electron micrograph of fracture surface of sample with $-120+270$ mesh walnut shell filler. Fracture taken perpendicular to direction of extrusion.

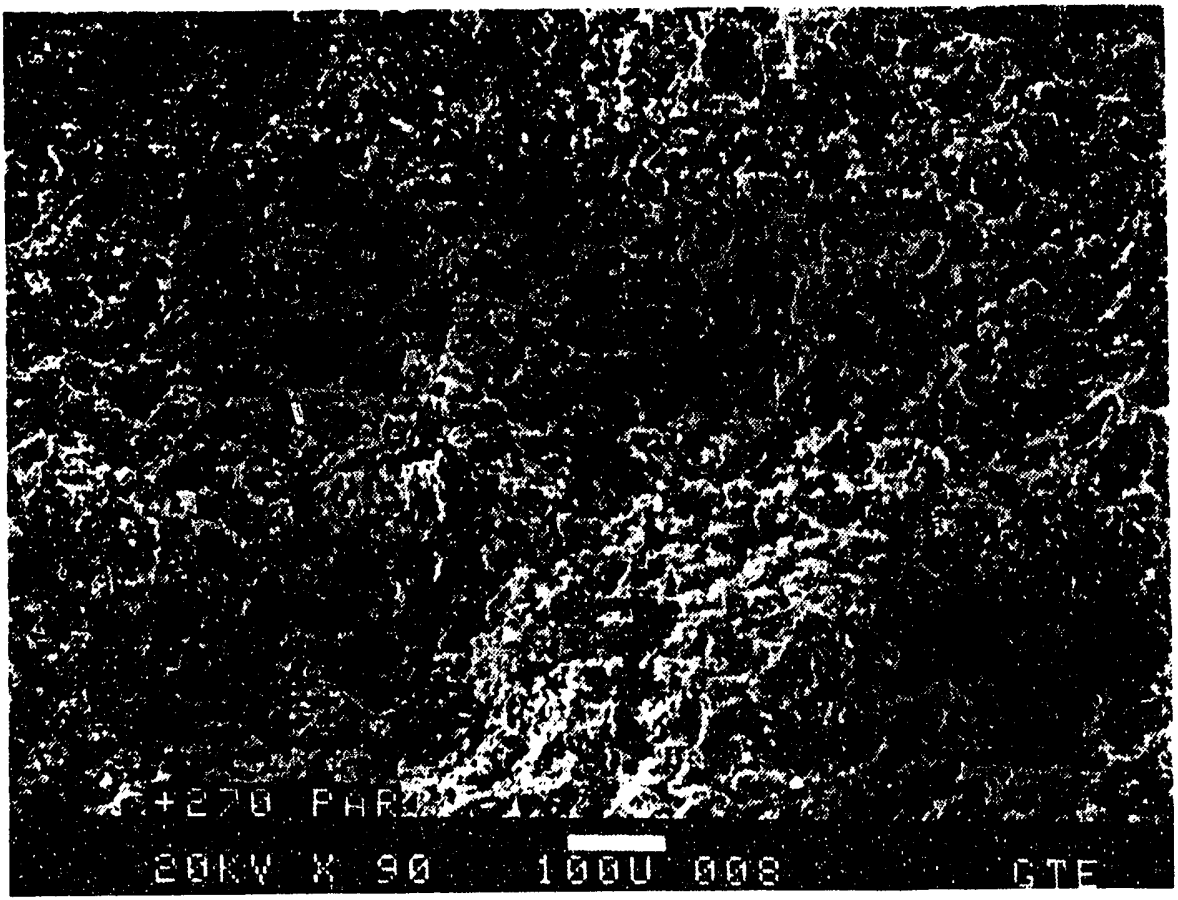

Figure 3-21. 100x scanning electron micrograph of fracture surface of sample with $-120+270$ mesh walnut shell filler. Fracture taken parallel to direction of extrusion. 


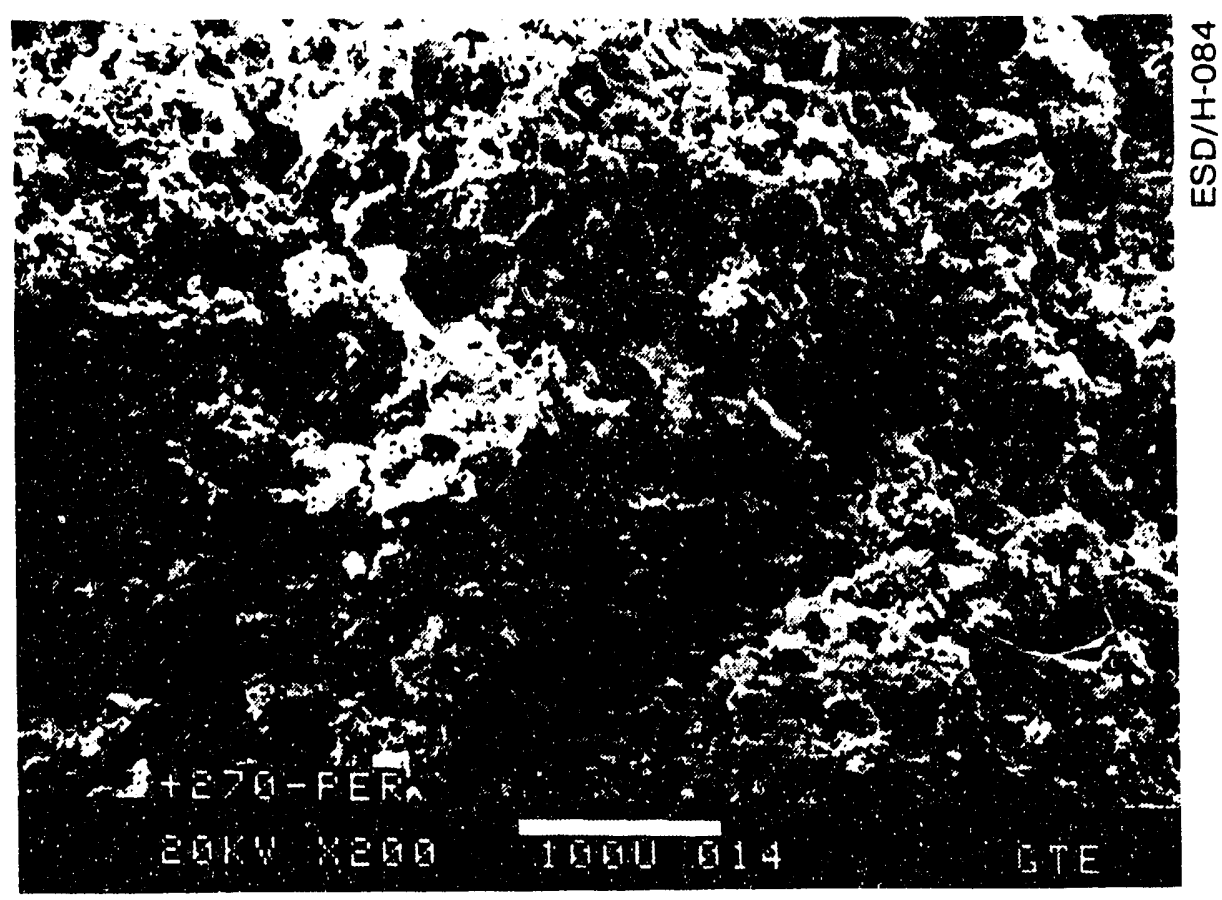

Figure 3-2:2. Perpendicular fracture at 200x

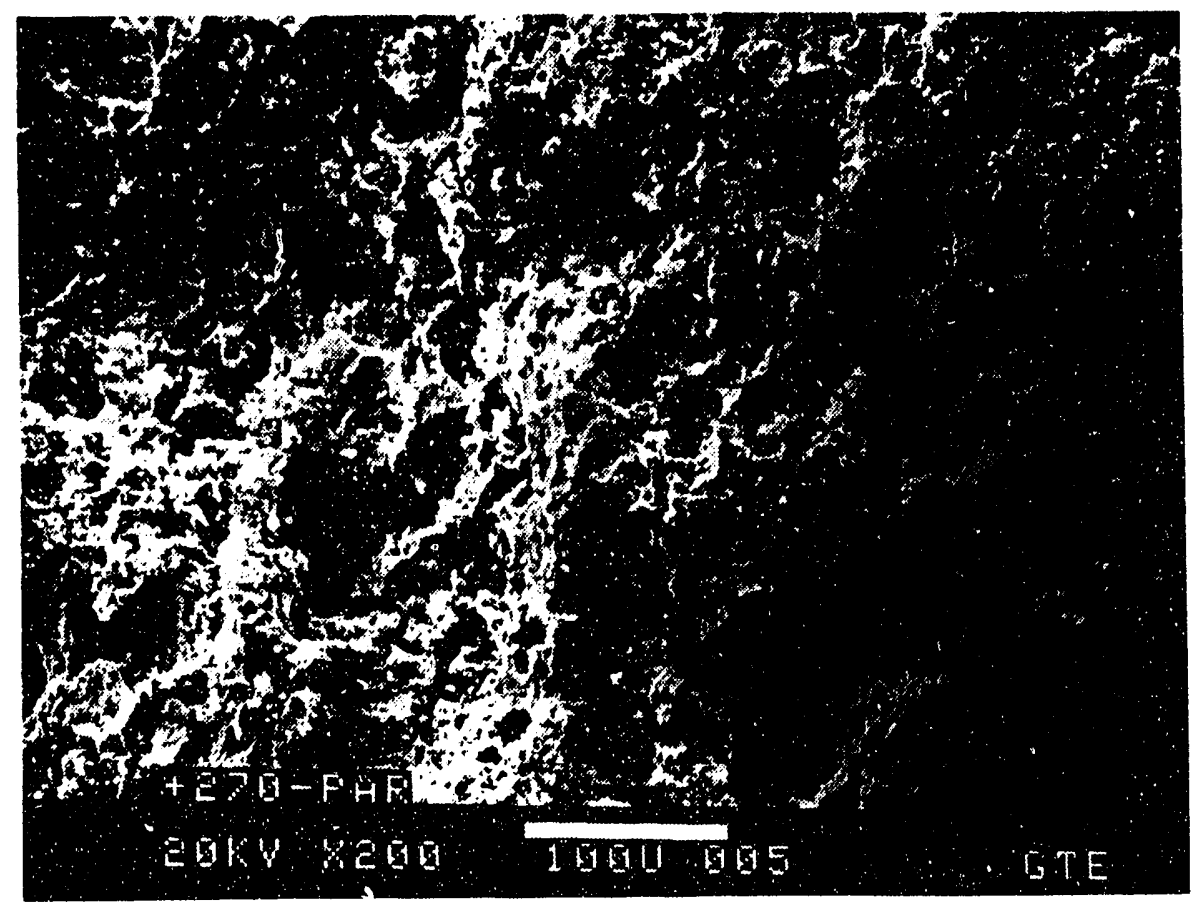

Figure 3-23. Parallel fracture at $200 x$ 


\subsubsection{Permeability Versus Composition}

In general, it appears that permeability is influenced by:

- Extrusion thickness

- Amount of filler

- Particle size of walnut shells

- Particle size distribution

- Walnut shell to wood flour ratio

- Surface roughness of the extrusion

The permeability measurement technique is described in Appendix D.

\subsubsection{Extrusion Thickness}

The effect of extrusion thickness is shown in the extrusions of samples that are from the same compounded batch and are different only in the thickness of the extrusion die. The materials are binder-fired and sintered in the same runs. The samples are shown in Figure 3-24. In every case, the permeability of the thicker sample is higher. This may be due to a surface roughness effect that increases the permeability because of the larger filler particles, or it may be because of the alignment effects of the extrusion process.

\subsubsection{Amount of Filler}

The effect of the amount of filler is shown dramatically in Figure 3-25. The face velocities of the samples that have the coarse walnut shells are shown. The walnut shells are wet-screened to a screen fraction of $-60+70$ which is a particle size range of between 212 and $250 \mu \mathrm{m}$. After extrusion, all the samples are binder-fired and sintered in the same runs. The samples that have 60 and 50 percent fillers have high permeabilities and face velocities at 5 in of $\mathrm{H}_{2} \mathrm{O}$. The samples with 40 percent filler have very low permeabilities, indicating very low interconnecting porosity. 


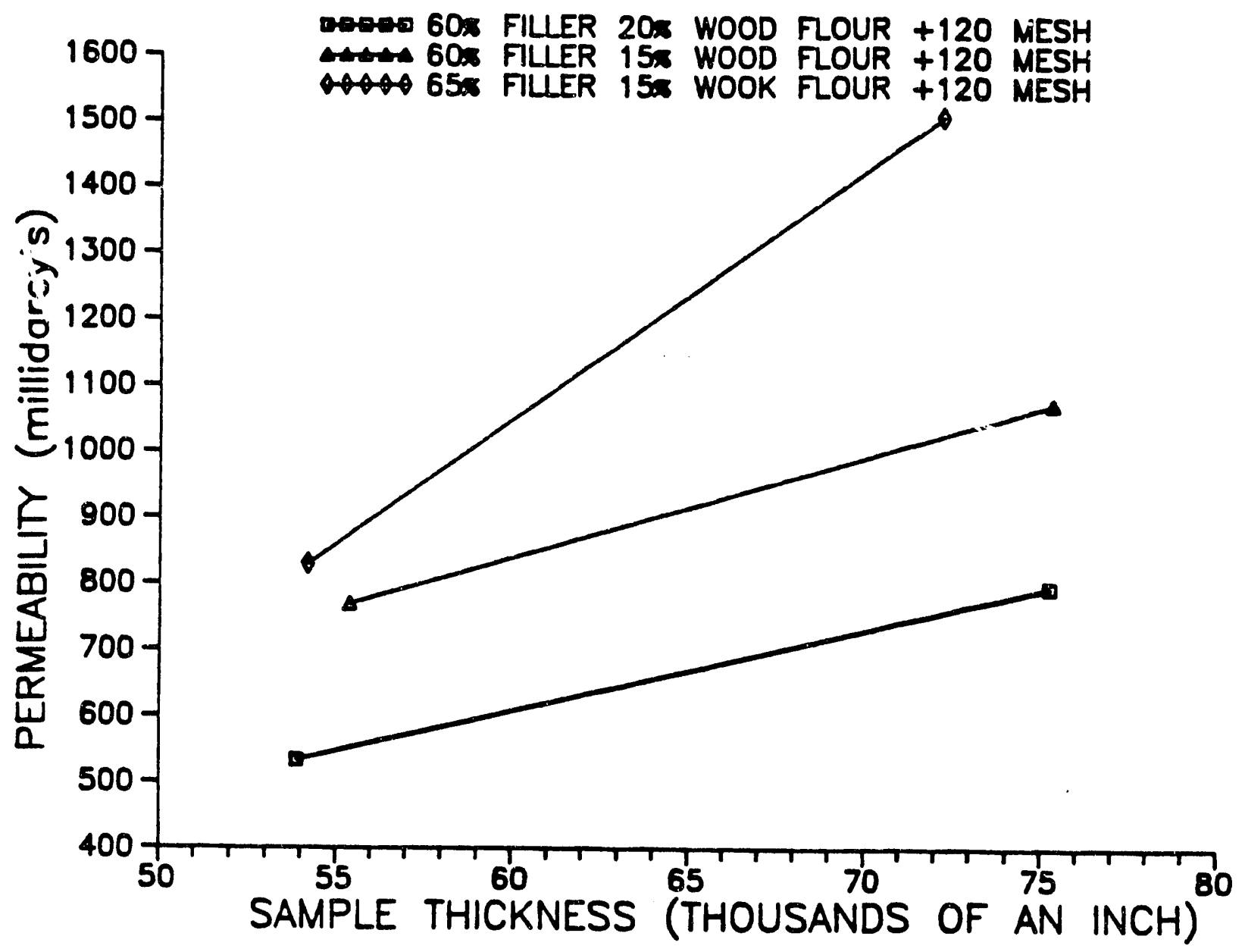

Figure 3-24. Variation of permeability with extruded sample thickness 


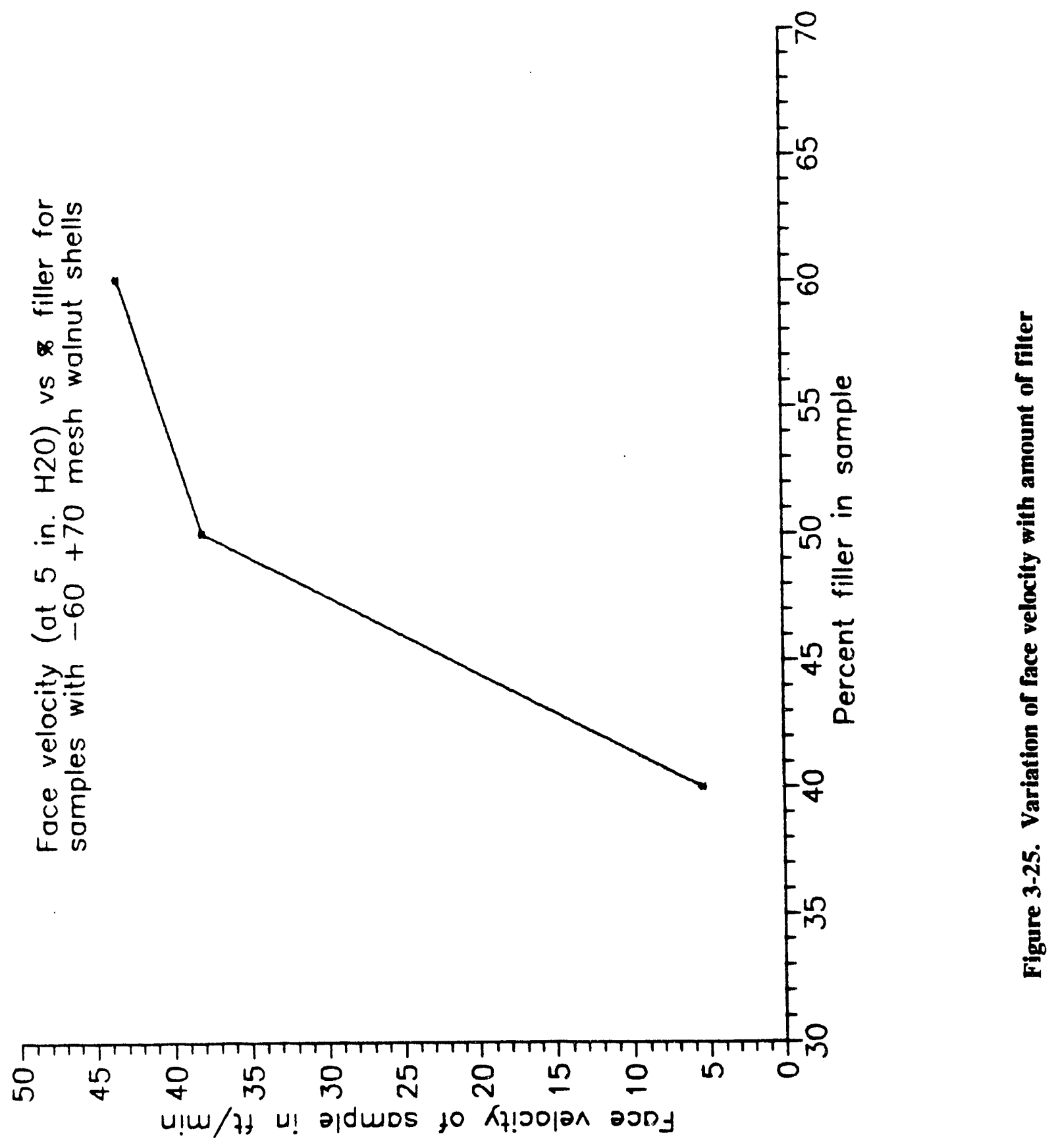




\subsubsection{Particle Size of Walnut Shells}

The most dramatic effect of filler additions is the particle size of the walnut shells. The permeability and face velocity remained below the desired levels; and though variations in processing conditions improved the permeability and face velocity somewhat, the levels were only about half those required. The use of the coarser filler material increased the permeability and face velocity to more than twice the desired levels at the same filler concentration and allowed the filler to be lowered 10 percent while still maintaining a suitable face velocity.

\subsubsection{Particle Size Distribution of Walnut Shells}

Because the particle size of the walnut shells plays such an important role in the permeability and face velocity of the samples, it is important not only to control the screen fraction of the filler, but to make sure that the particle size distribution in the screen fraction is uniform. A distribution of three wet-screened samples is shown in Figures 3-26 and 3-27. The samples are walnut shells wet-screened to $-120+270$ mesh.

\subsubsection{Walnut Shell to Wood Flour Ratio}

In the samples made with a $-120+270$ screen fraction of walnut shells, it was shown that there is an optimum ratio of wood flour to walnut shells. The percentage of wood flour was kept between 5 and $20 \mathrm{wt} \%$ for all the different walnut shell sizes. Although the wood flour size would probably also have an effect on the optimum ratio, it was kept at an 80-mesh size during the course of these tests.

\subsubsection{Surface Roughness of the Extrusion}

The effect of surface roughness is shown in Figure 3-28. The samples of material compounded with a walnut shell screen fraction of $-60+70$ mesh were extruded at a thickness of $0.100 \mathrm{in}$. Some of the extruded material from filler amounts of 60,50 , and 40 percent were pressed between two steel plates to compress it and remove the roughness of the material caused by the extrusion. These pressed samples are coded with a $P$ in the sample code in the data shown in Figure 3-29. In each case, the permeability of the samples was lowered. Mercury porosimeter 


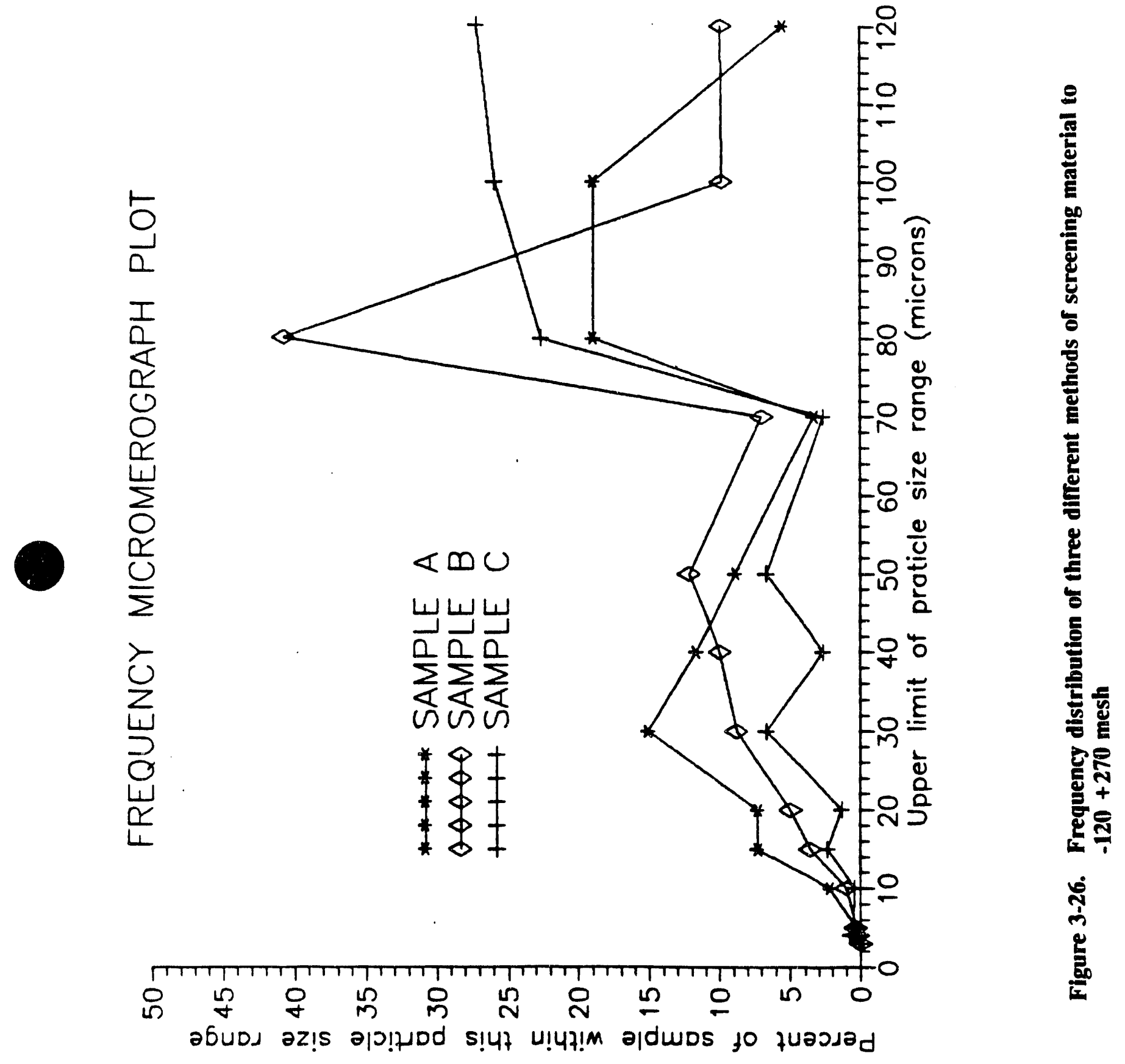



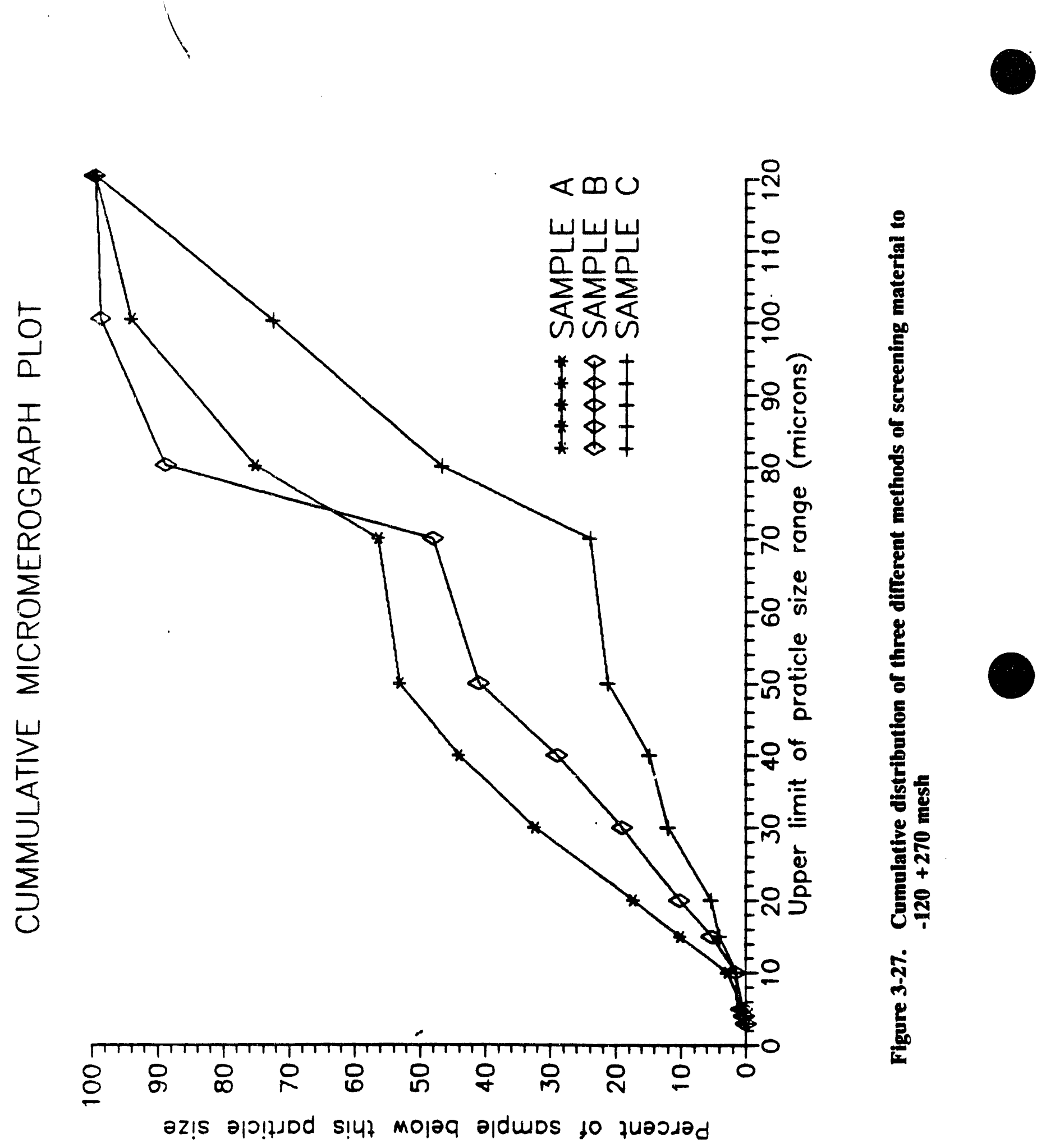


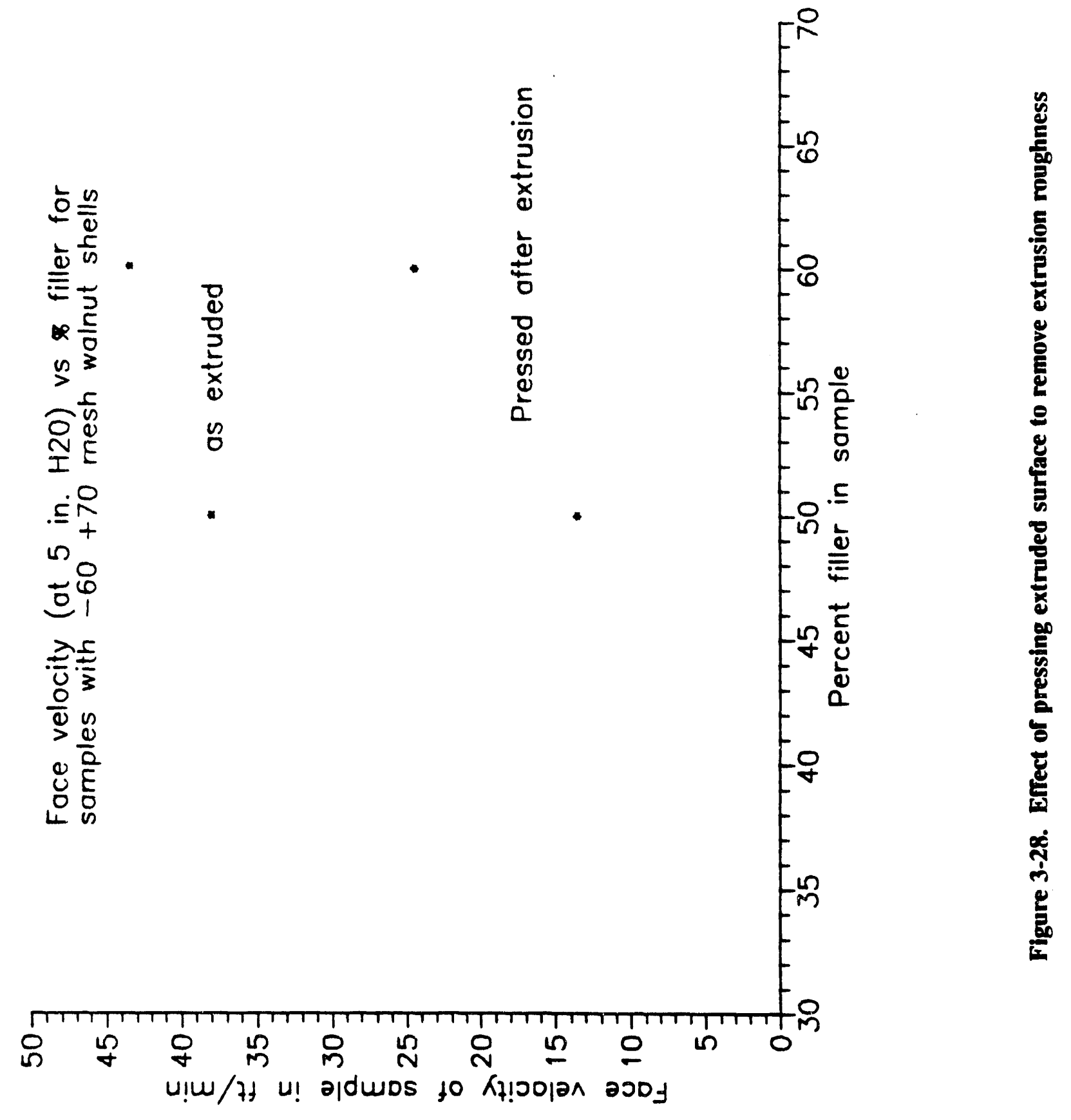




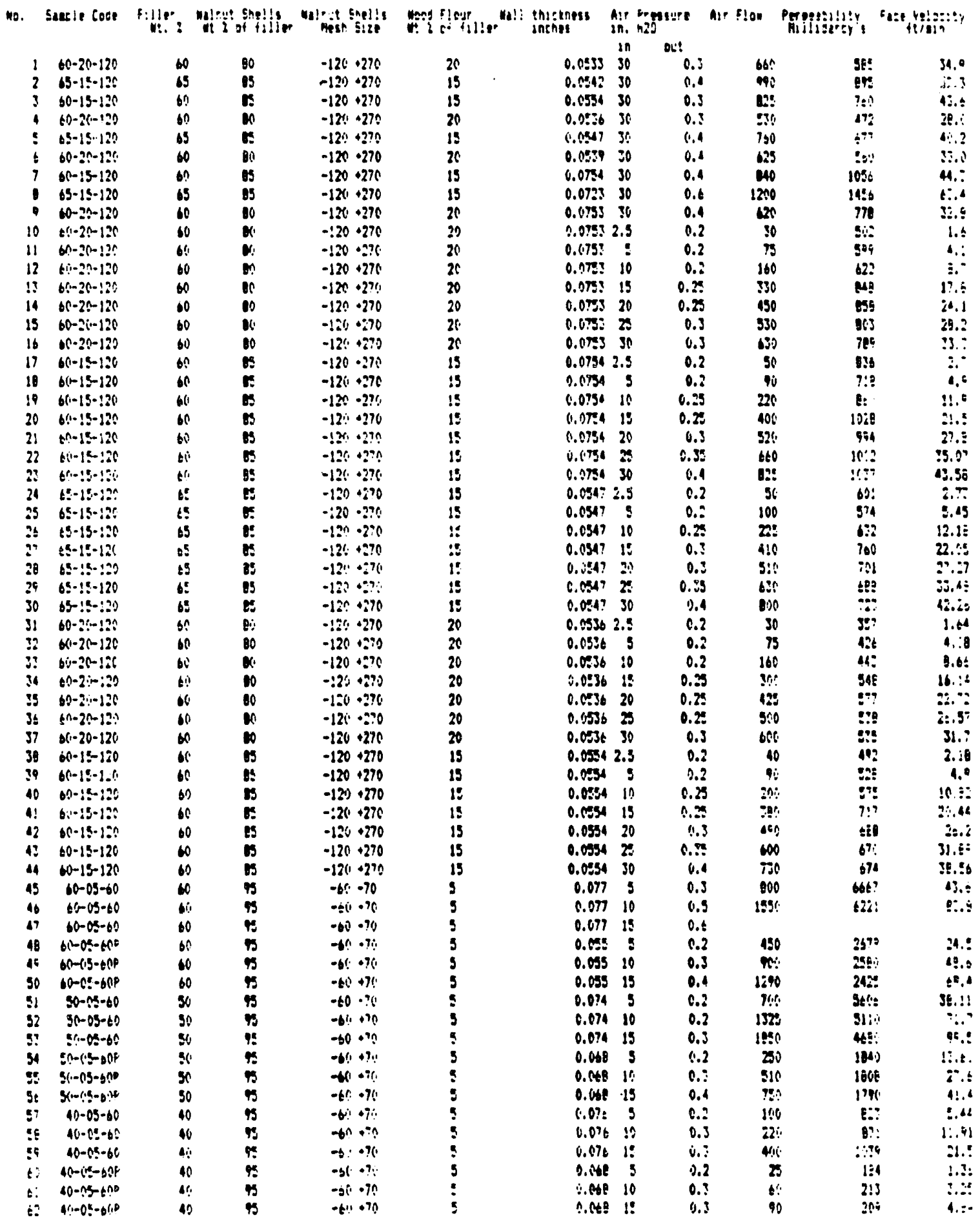

Figure 3-29. Data page of permeability and face velocity testing results 
tests of the samples are shown in Figures 3-30 and 3-31, and show that the porosity size and distribution in the material is also influenced.

\subsubsection{Variability of Testing Procedure}

The amount of variability in the samples made from the same composition are shown in Figure 3-32. Three samples were each tested three different times to determine the amount of error in the testing procedure.

\subsection{CONCLUSIONS}

GTE has developed material suitable to be manufactured into crossflow filters. The permeability of the material meets the requirements established by DOE. Extensive work has been done in investigating the effect on permeability of composition, size of filler, extrusion size, and extrusion postprocessing (pressing). This information can be used to fine-tune the permeability, if required.

This material is CSN25 ( 25 percent cordierite) with 50 percent filler. The filler is 95 percent walnut shells screened at $-60+70$ mesh and 5 percent wood flour. The permeability obtained with this composition is approximatsly 1800 millidarcies for a sample 0.06 in thick. This material thickness corresponds to that developed for the crossflow design (see Section 2). With the work in Task 3 completed, fabrication of the actual filter elements began. This work is described in Section 4. 


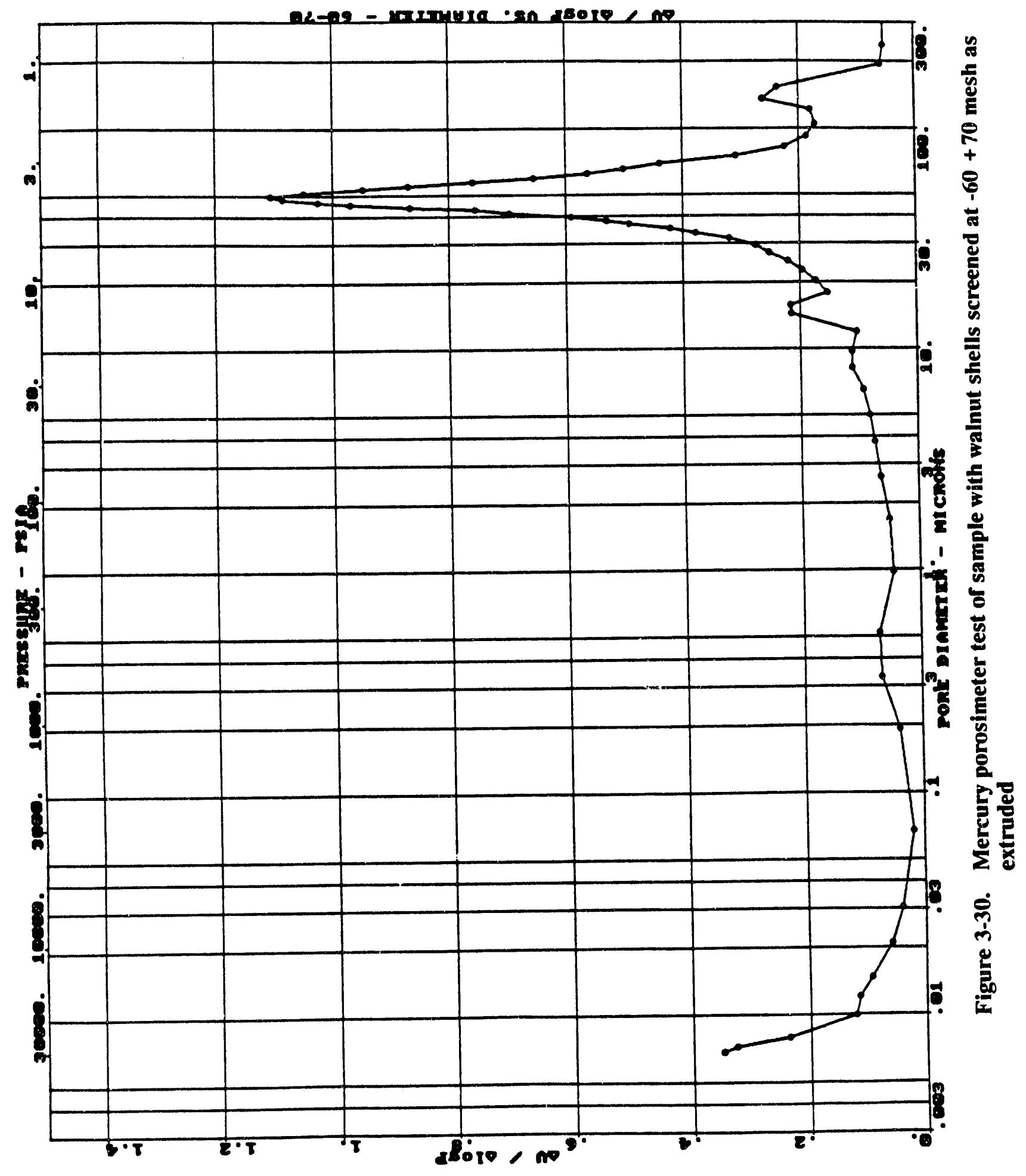









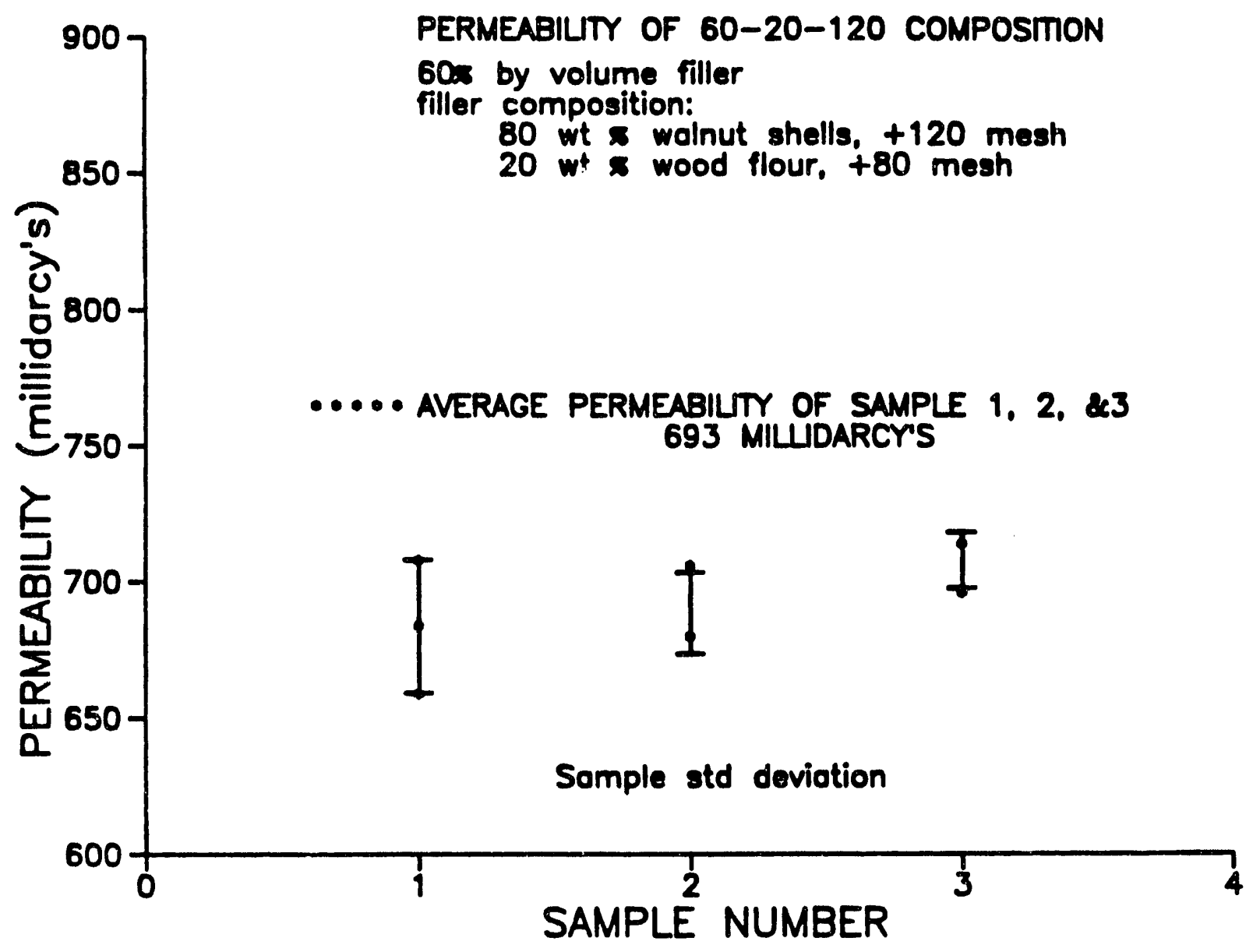

Figure 3-32. Variation of permeability testing technique 


\section{SECTION 4}

\section{FILTER MANUFACTURE}

The objective of this task was to develop the filter manufacturing technique. The filter manufacturing technique was developed by making small-scale $(2.75$-in by 2.75 -in by 1.75 -in) filters for testing at Acurex. The information and techniques developed for testing at Acurex were then used to scaleup half-scale (6-in by 6 -in by 2 -in) filters for manufacturing.

The small-scale filters were manufactured for two reasons: (1) to be tested in the benchscale filter test facility at Acurex, and (2) to develop and test the filter manufacturing technique. After perfecting the manufacturing technique on the small-scale filters, scaleup of the manufacturing techniques to the half-scale filters was easier.

The following sections detail the manufacturing technique developed by GTE and the testing done at GTE and Acurex.

\subsection{MANUFACTURE FILTERS}

\subsubsection{Introduction}

The primary goal of the filter manufacturing effort was to adhere to the material composition and the Acurex filter design. The present process being used at GTE for crossflow recuperator production and crossflow filter development uses a glue bonding procedure. This procedure results in a channel that has a fillet radius on only two of the four corners of the channel. To adhere to the Acurex filter design, a process modification was developed to allow each of the four corners of the filter channel to have a fillet radius. Moreover, during the glue bonding process there is a tendency for the crossflow filter to delaminate along the bonded section of the filter. Therefore, the process modification was also designed to address this delamination problem. 
The Phase 2 manufacturing effort consisted of adhering to the material composition developed in Phase 1 of the Acurex design for:

- Extruding

- Press bonding

- Drying

- Binder/filler removal

- Bisque firing

- Sintering

- Machining

The development areas to be addressed were scaleup and testing of the press bonding process, binder and filler burnout of the 50-volume percent filler composition, the weakness uf the filter after binder/filler burnout, and the shrinkage of the crossflow filter during sintering.

\subsubsection{Press Bonding}

The press bonding technique was developed to address the need for a fillet radius on all four corners of the crossflow filter channels, and to eliminate the delamination problems that plague the glue-bonded filters. The basic effort involved extruding a ribbed sheet in the required configuration, placing a nondeformable blank in the channel formed by the extrusion, layering these extruded preforms to the desired height, placing the stacked preforms in a pressing assembly, and pressing to a pressure suitable to form the extruded preforms into a nonlaminated filter. The nondeformable blanks were then removed from the filter, and the filter dried, the filter binder was removed, and the material sintered.

The intent at start of this project was to use a glue bonding technique. The plan included extruding the necessary material for the filters in the production press used for forming the crossflow heat recuperators. Because of the amount of material required for an extrusion run in the production extruder, and the necessity for the press bonding process to use freshly extruded material, the use of the production press was ruled out for the manufacturing of the press-bonded 
crossflow filter. The extrusion system was designed for use in the hand press that was used in Phase 1 of the contract. The press is shown in Figure 4-1. In order to implement the construction of the test samples for Acurex testing as fast as possible, a small extrusion system was built first that would allow the extrusion of the clean and dirty channels of the small test filter. This system was also to be used for the extrusion of the clean side channels of the filter to be made for testing at Westinghouse. Manufacture of the small Acurex test filters required the manufacture of two extrusion dies that are shown in Figures 4-2 and 4-3. Figure 4-2 shows the clean channel extrusion die design and Figure 4-3 shows the die design for the dirty channel extrusinn.

The extrusion system is shown disassembled in Figure 4-4, and in the hand press in Figure 4-5. Figure 4-6 shows a length of material that has been extruded from the system. A larger pressing system had to be manufactured for the extrusion of the dirty channel side of the 6-in by 6-in by 2 -in filters to be tested at Westinghouse. The die design for the dirty channel side of these filters is shown in Figure 4-7, and the design for the clean side extrusion die is shown in Figure 4-8. The larger pressing system is shown disassembled in Figure 4-9, and is shown in the hand press in Figure 4-10. A sample of the dirty side extrusion blank is shown in Figure 4-11.

Initially, sanded wood dowels in the approximate shape of the desired channels were used in pressing. When this technique was shown to be feasible and the shrinkages had been determined, the necessary nondeformable blanks were machined from aluminum flat sheets and the four edges of the aluminum blanks were given a radius of 0.040 in. This radius was used to give a filleted radius of between 0.030 and 0.040 in to the channels of the sintered crossflow filter. For the Acurex test filter, 44 press bonding rods of two sizes were used. For the 6 -in by 6 -in by 2 -in filters to be tested at Westinghouse, 196 press bonding rods of two sizes were used.

The cross section of the press bonding rods is shown in Figure 4-12. Initial press bonding tests with the rods showed that a method would have to be used to prevent sticking of the extruded composition to the rods. A water insoluble light oil was used to coat the rods, effectively eliminating the rod sticking problem. The press bonding jig was built to press both the Acurex test 


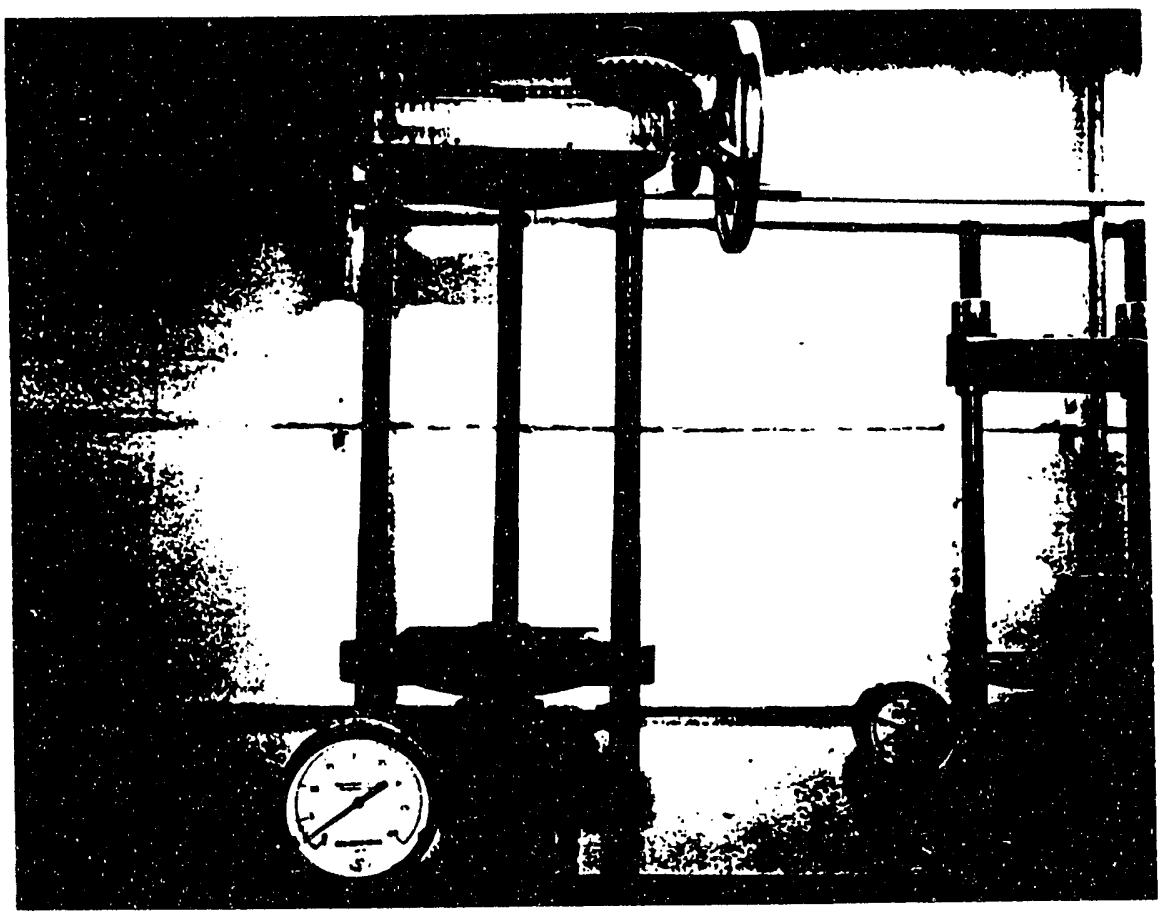

Figure 4-1. Hand press for extrusion apparatus 


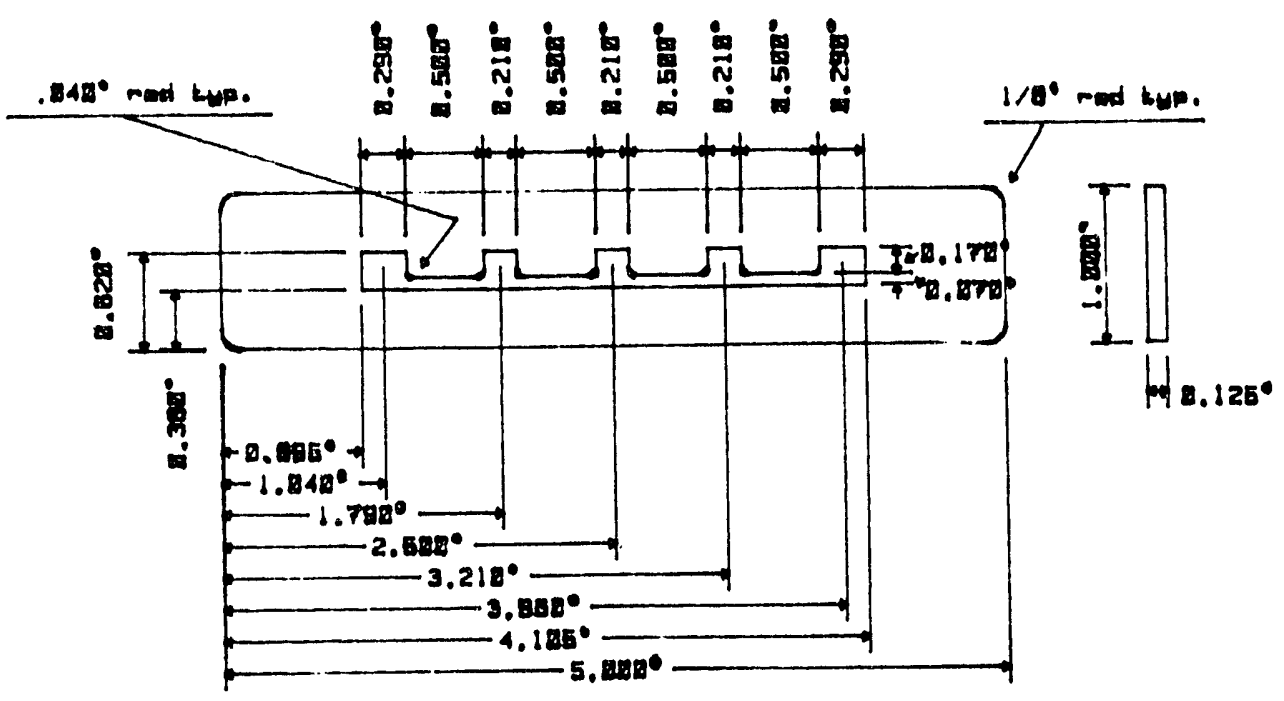

Figure 4-2. Acurex clean-channel test filter extrusion die

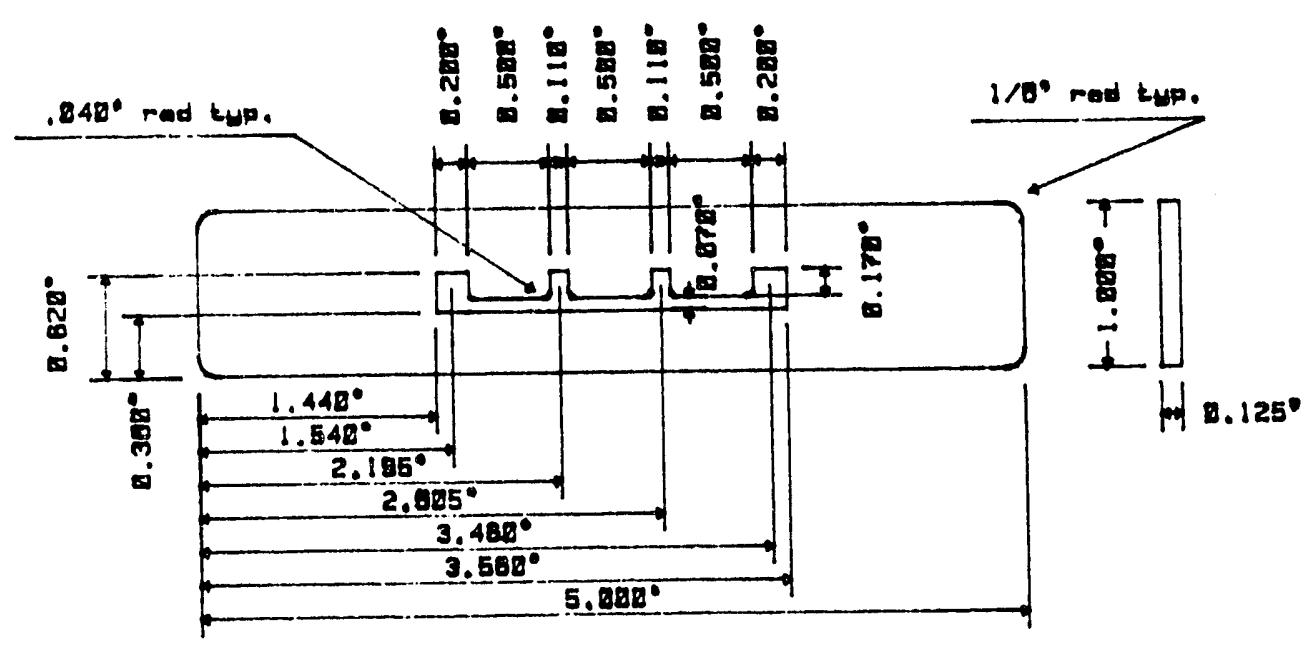

Figure 4-3. Acurex dirty-channel test filter extrusion die 


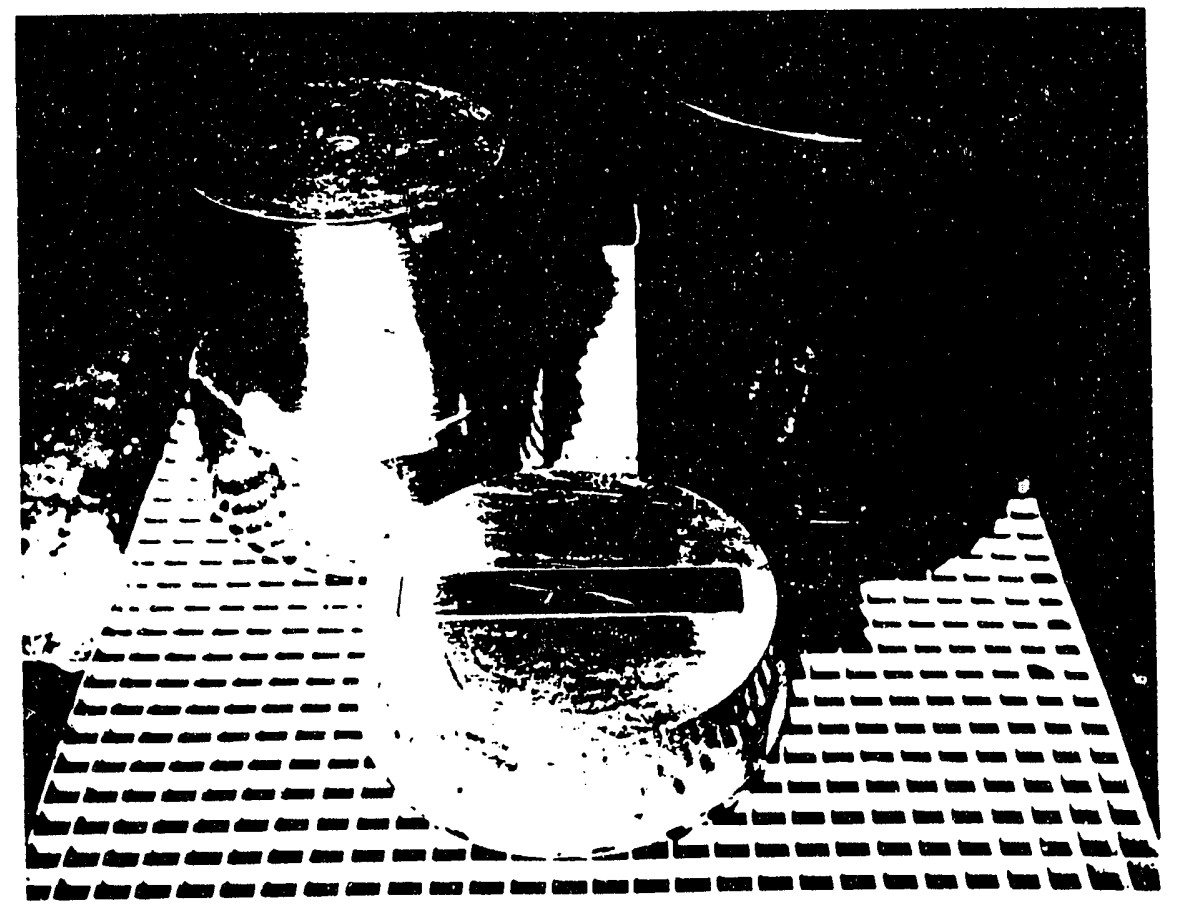

Figure 4-4. Narrow-width extrusion apparatus for hand press

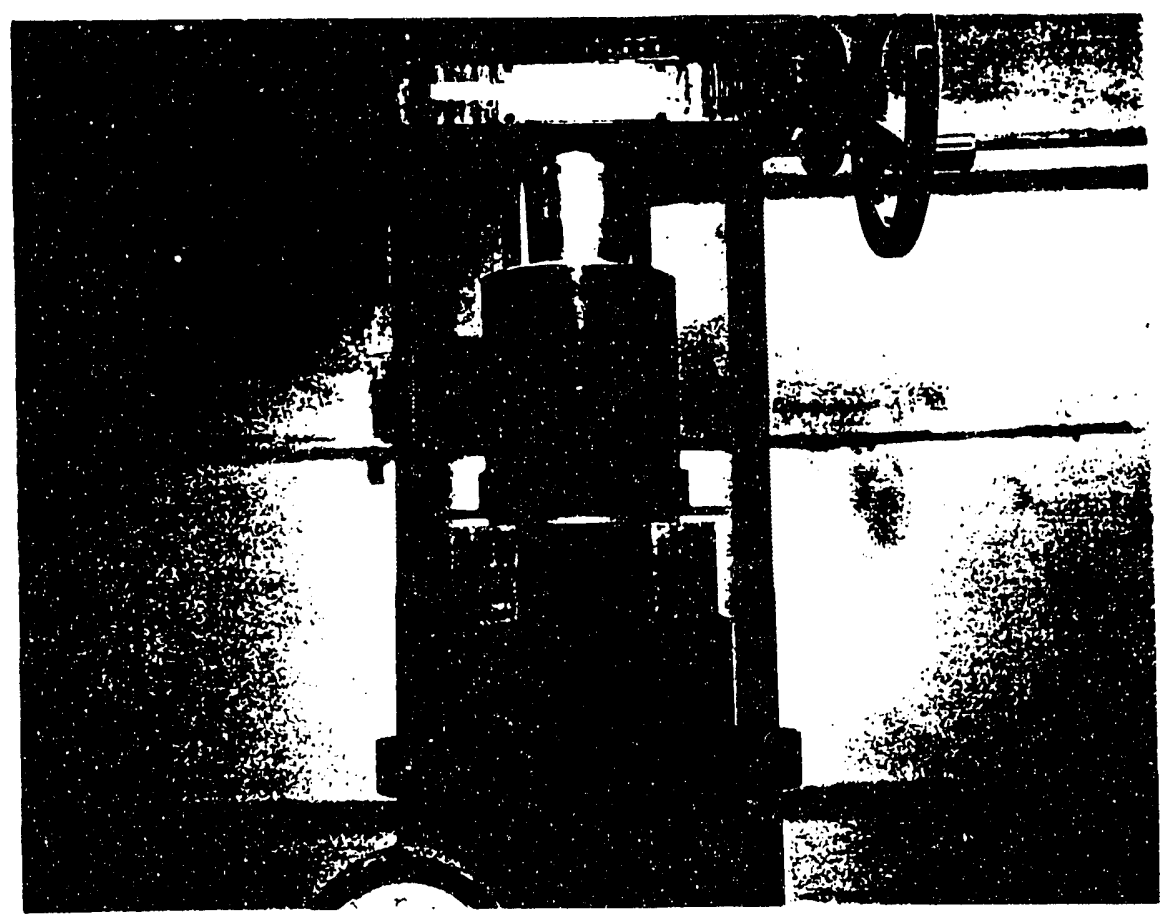

Figure 4-5. Narrow-width extrusion apparatus assembled and mounted in hand press 


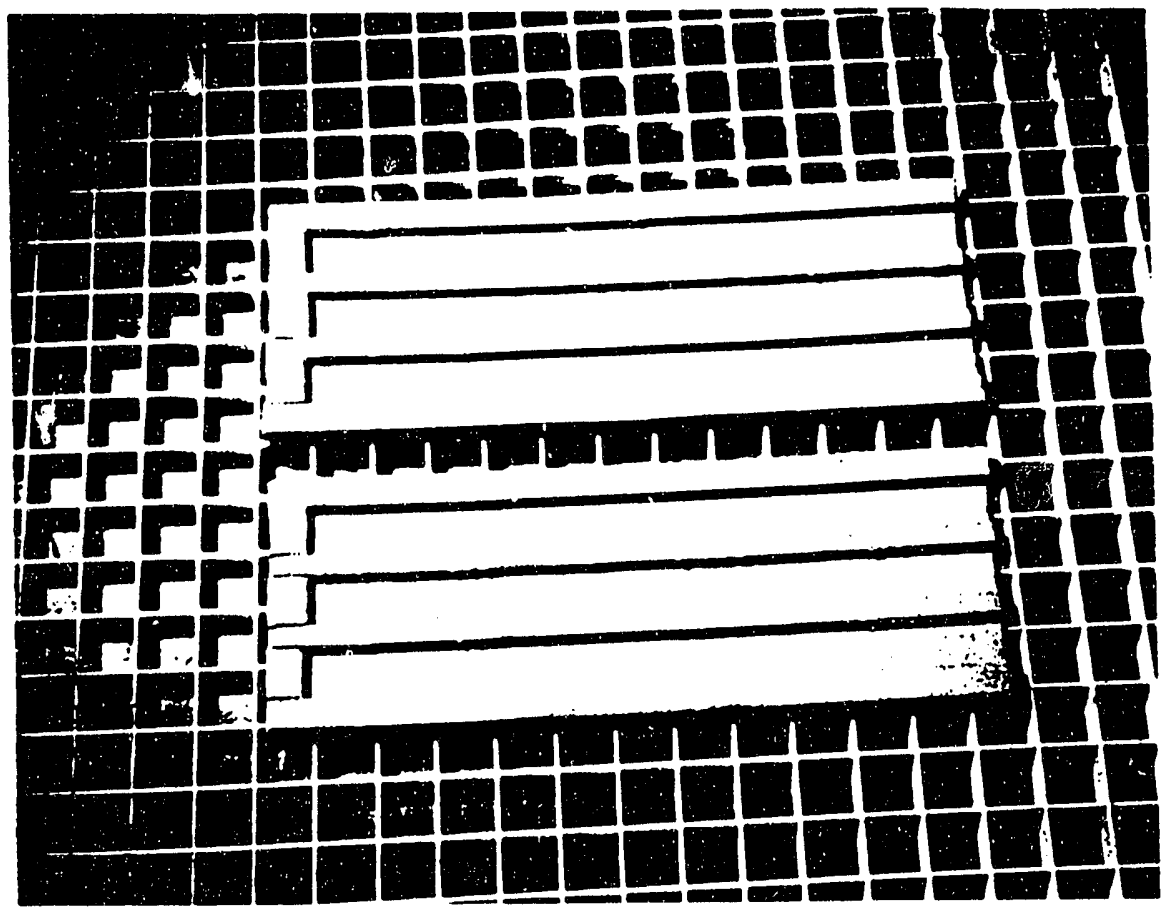

Figure 4-6. 6-in by 6 -in by 2 -in filter clean side extrusion from the narrow widith extrusion apparatus with end plugs inserted 


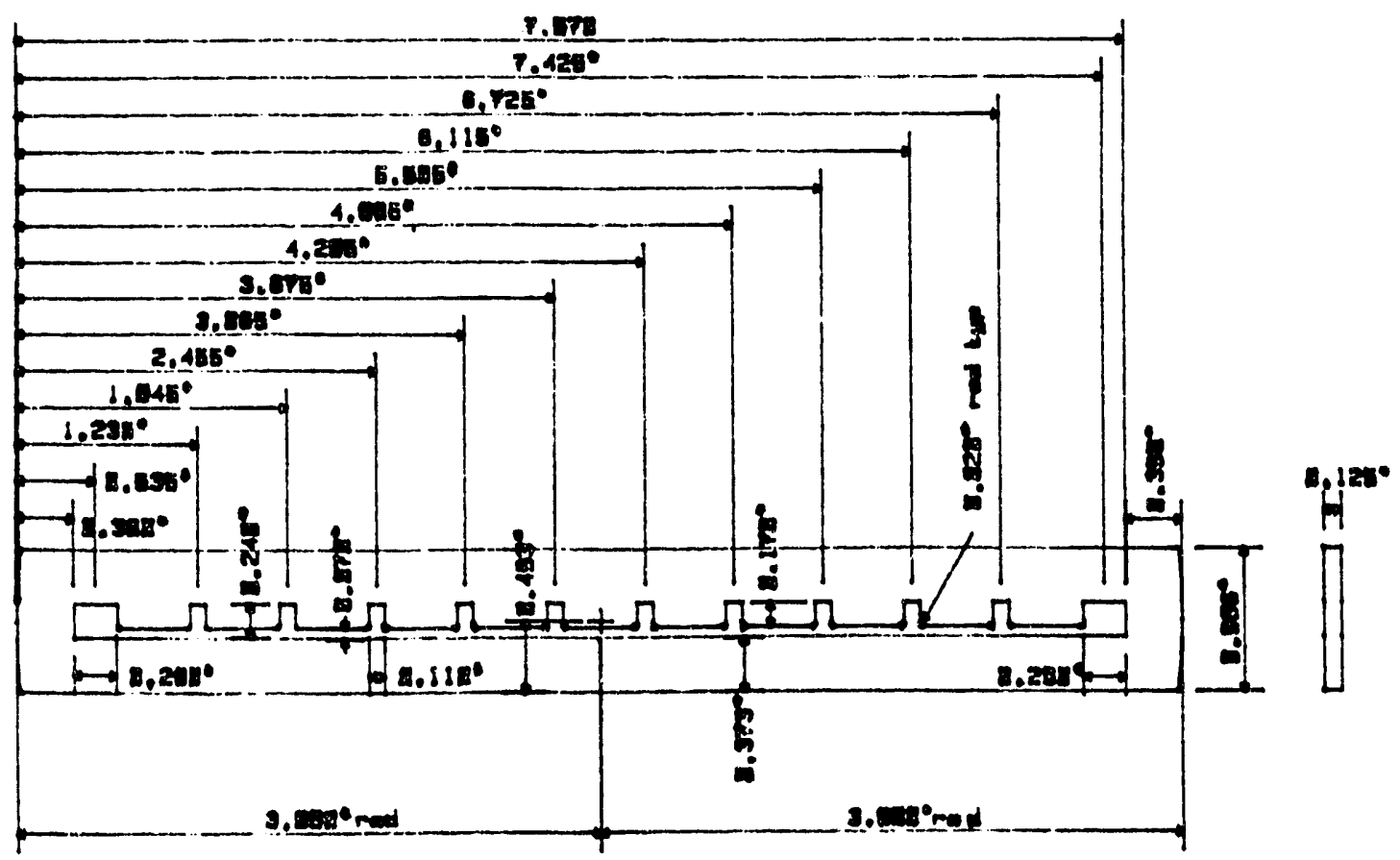

Figure 4-7. 6-in by 6-in by 2-in filter dirty-channel extrusion die design

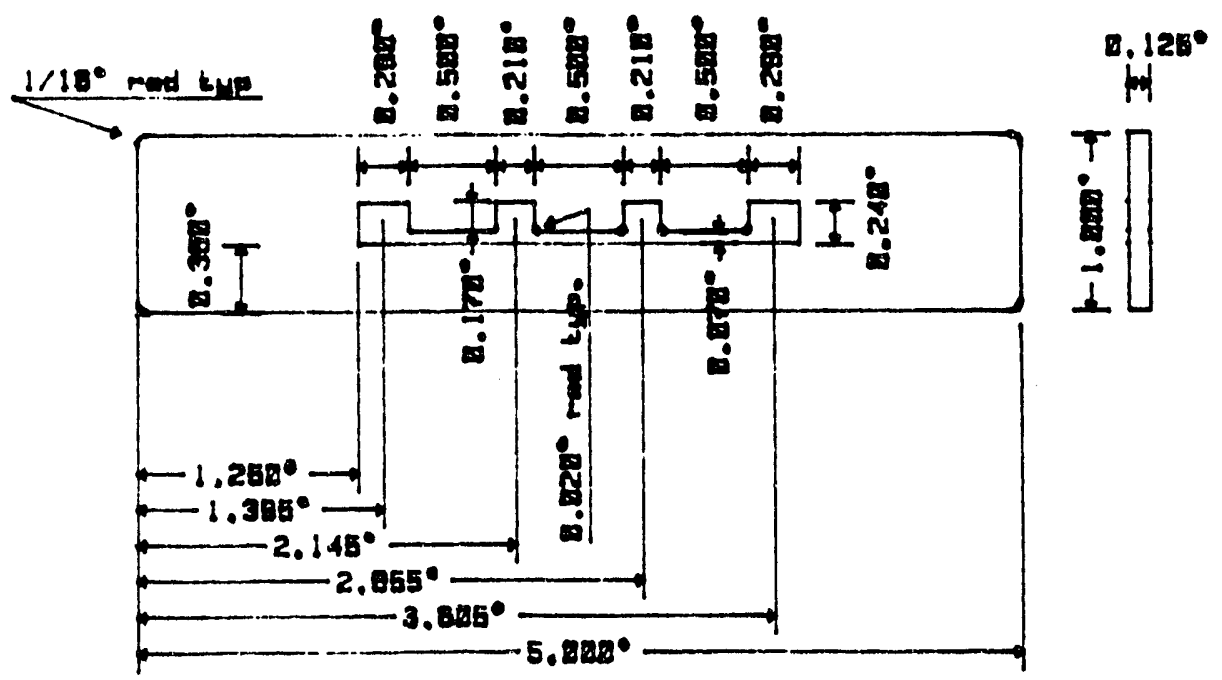

Figure 4-8. 6-in by 6-in by 2 -in filter clean-channel die design 


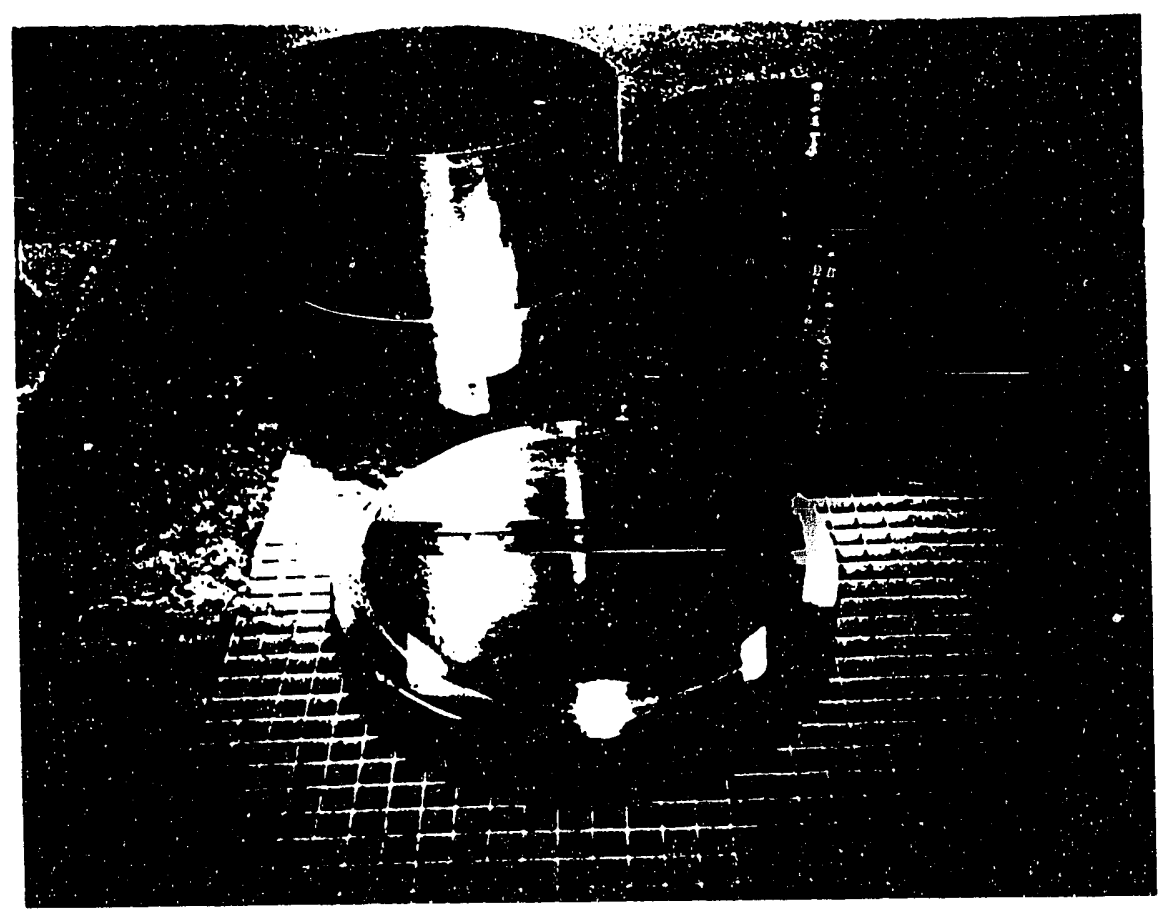

Figure 4-9. Wide extrusion apparatus for hand press

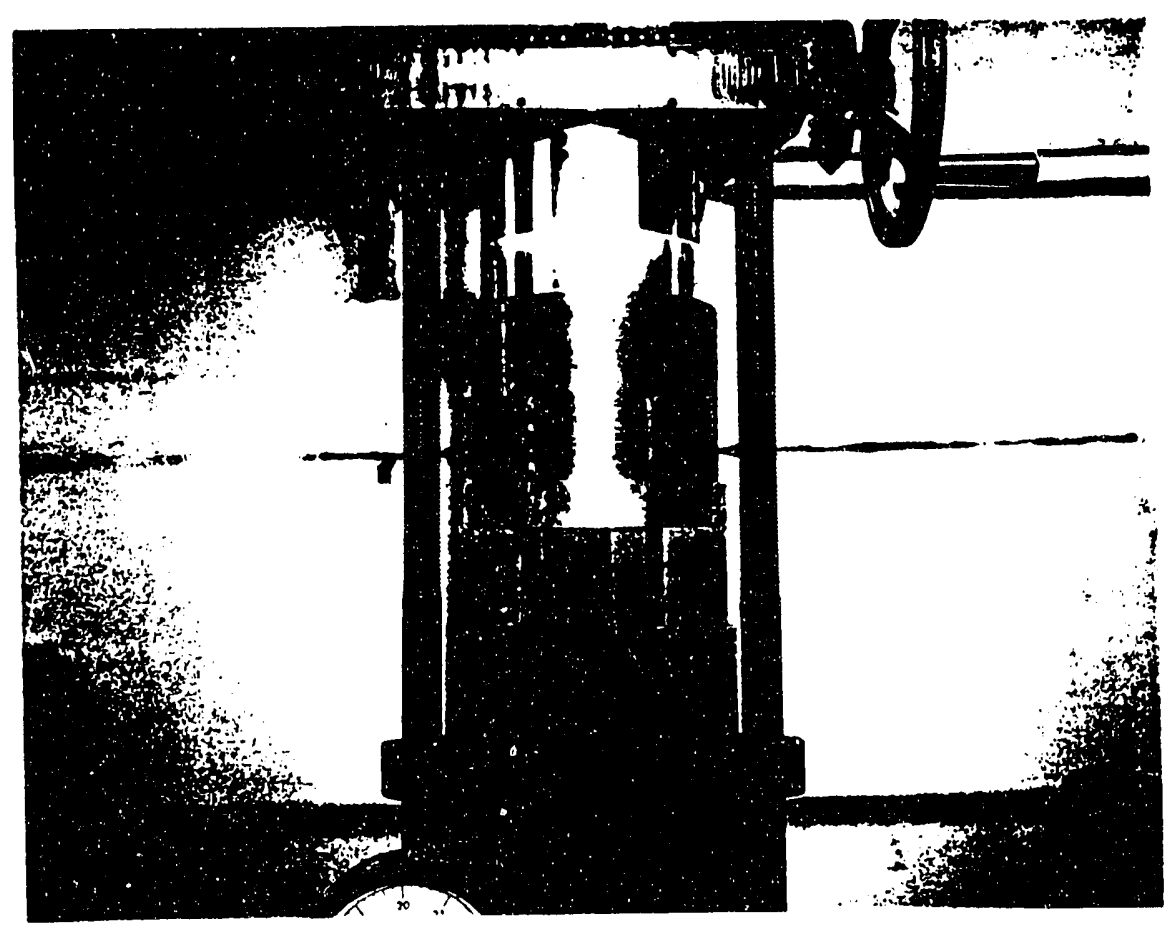

Figure 4-10. Wide extrusion apparatus assembled and mounted in hand press 


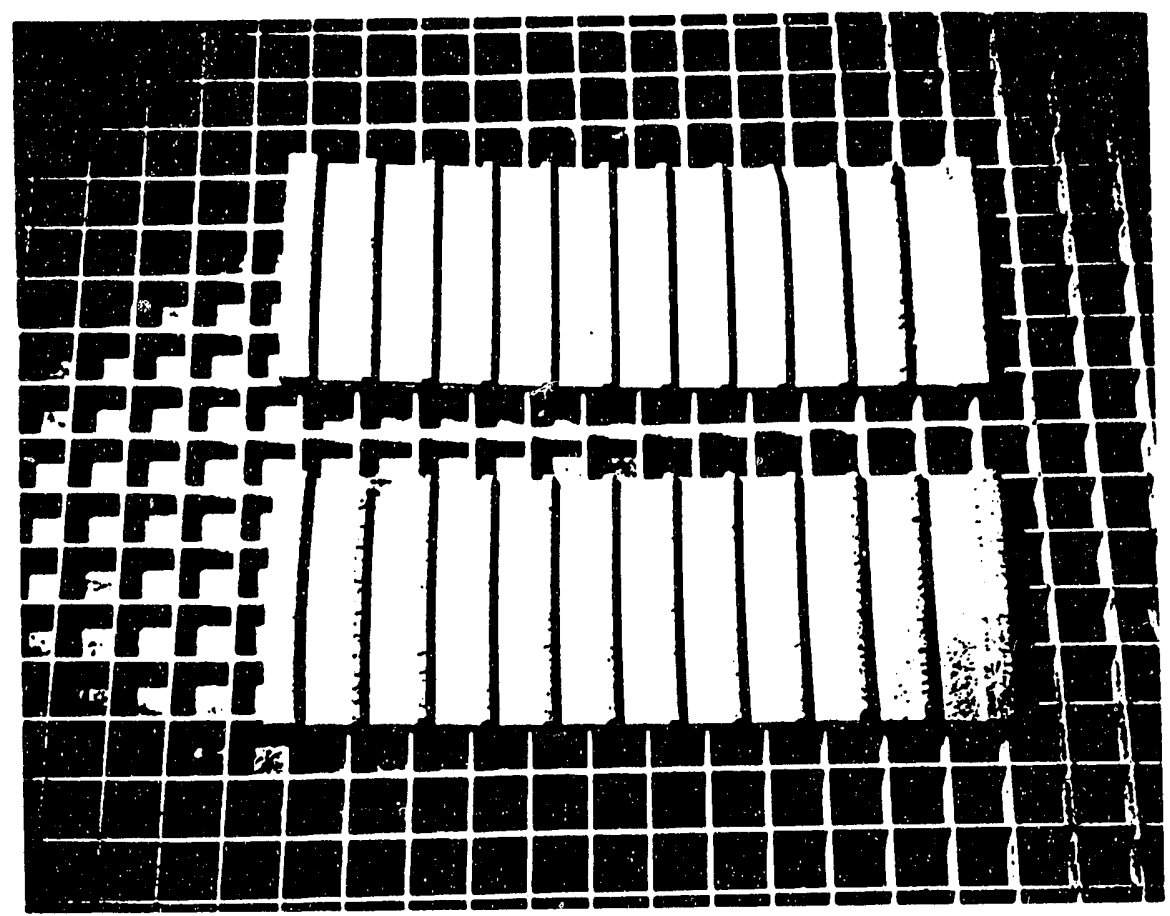

Figure 4-11. 6-in by 6-in by 2-in filter dirty-side extrusion from the wide extrusion apparatus 

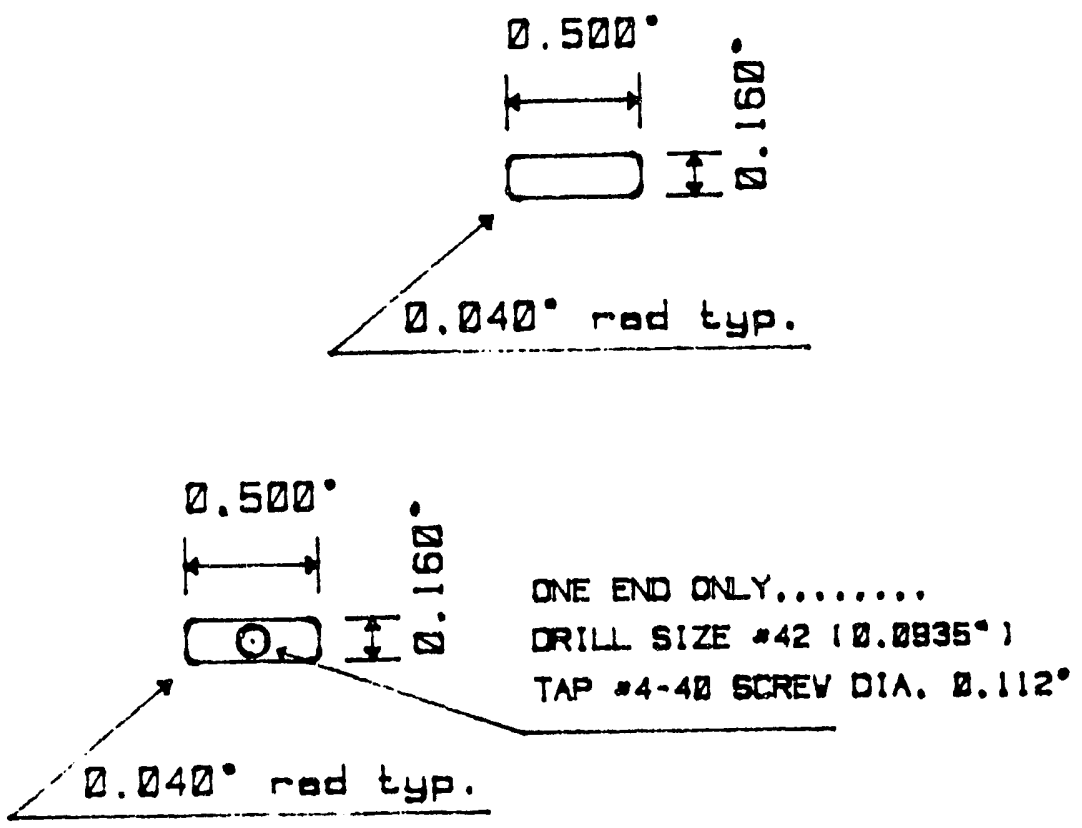

Figure 4-12. Cross section of press bonding rod design 
filters and the 6 -in by 6 -in by 2 -in filters to be tested at Westinghouse. The press bonding jig is shown in Figure 4-13. The Acurex press bonded test filter is shown in Figure 4-14.

The press bonding jig worked well for the Acurex test filter. The extruded material with the aluminum rods in place was stacked in the jig. The jig was assembled and placed in the hand press. The jig was pressurized to between 1600 and 2000 psi by pressing from the top of the pressing jig with a pressing plate. The assembled pressing jig in place in the hand press is shown in Figure 4-15. The jig was dissembled after pressing and the rods were removed from the pressed filter. Care had to be taken during the removal of the rods so the vacuum created in the closed channels did not collapse the cell walls. These filters had very good bonding and showed a very smooth uniform surface.

Press bonding the 6-in by 6 -in by 2 -in filters was done in much the same way as the Acurex test filters. The larger number of rods and the increased number of extruded sheets lengthened assembly time so that care had to be taken to prevent premature drying of the extruded material. To minimize the premature drying, the extruded sheets were stored in plastic bags until they were assembled into the pressing jig. The larger pressing jig assembly is shown in Figure 4-16. Figure 4-16 shows the increas span of the assembled jig. The jig did not have enough strength to prevent bulging of the side during the press bonding step. A series of plates were welded to the longer span of the pressing jig in an attempt to reduce the distortion during the pressing operation. Although somewhat helpful, it did not eliminate the problem. As a result of the pressing distortion, the 6-in by 6 -in by 2 -in filters could not be pressed above 1100 psi. The pressing pressure was typically about 1000 psi. Distortion of jig also was a concern because of the potertial tearing of the pressed filters bonded ribs due to spring back when the pressure was released. To try to accommodate a lower allowable pressing pressure, the material was extruded at a higher water content. The higher water content material improved the ability to press bond at a lower pressure, but it decreased filter permeability. 


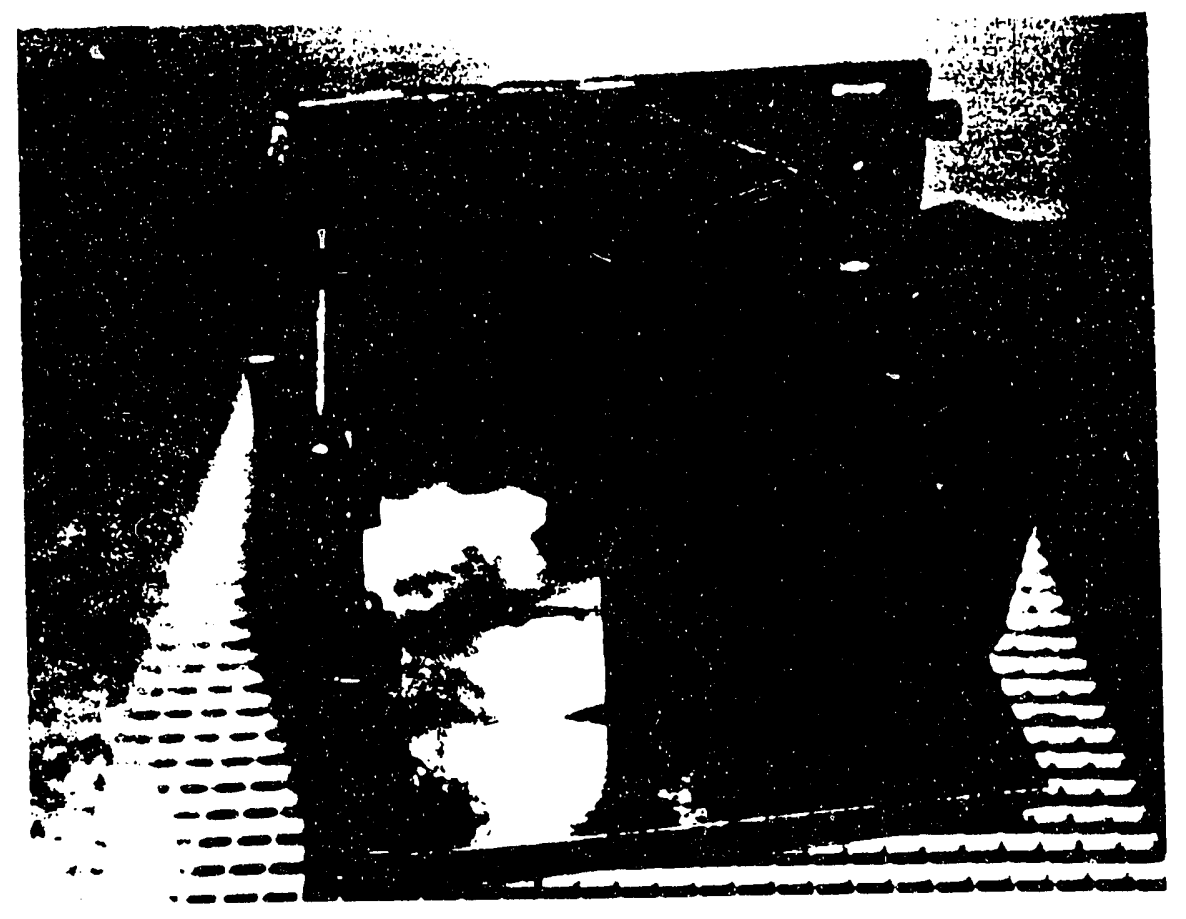

Figure 4-13. Press bonding jig with Acurex test filter section

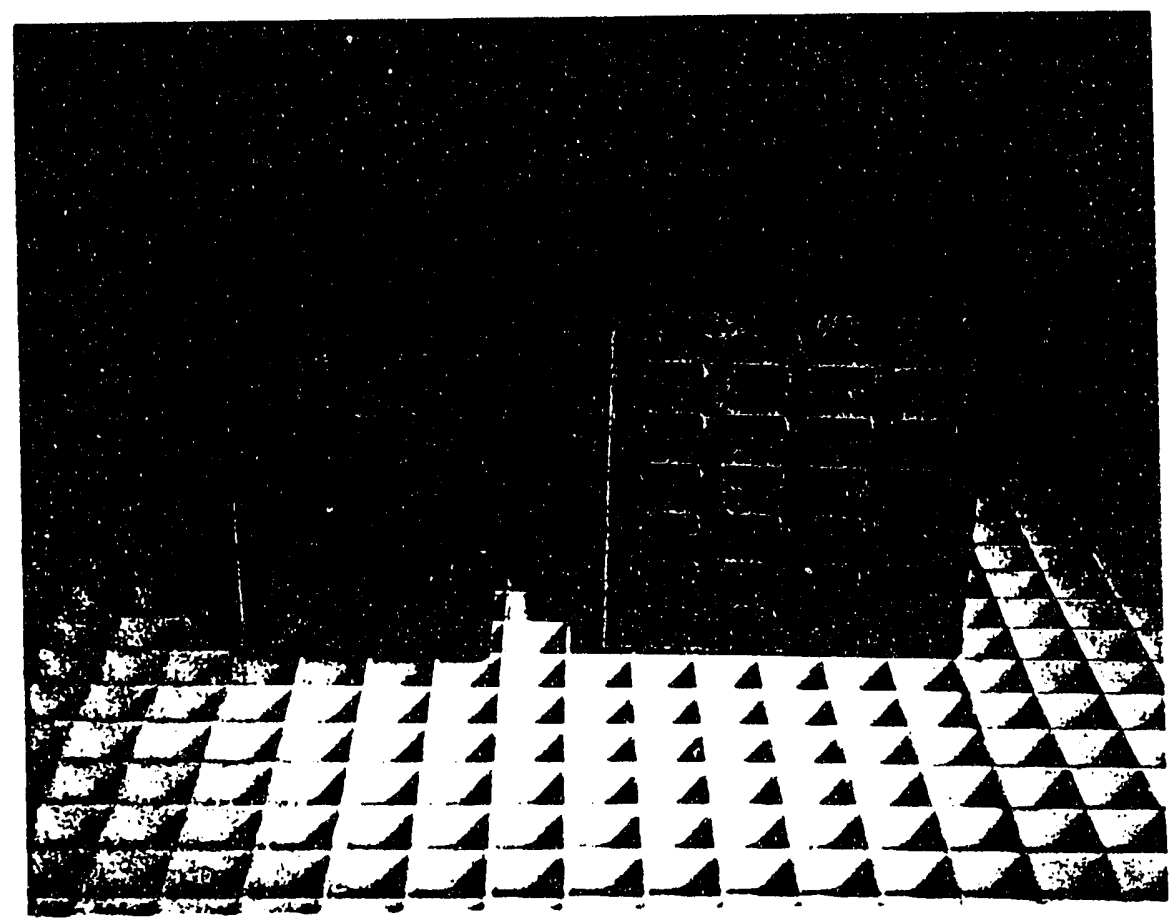

Figure 4-14. Clean side face (left) and dirty side face of Acurex test filter 


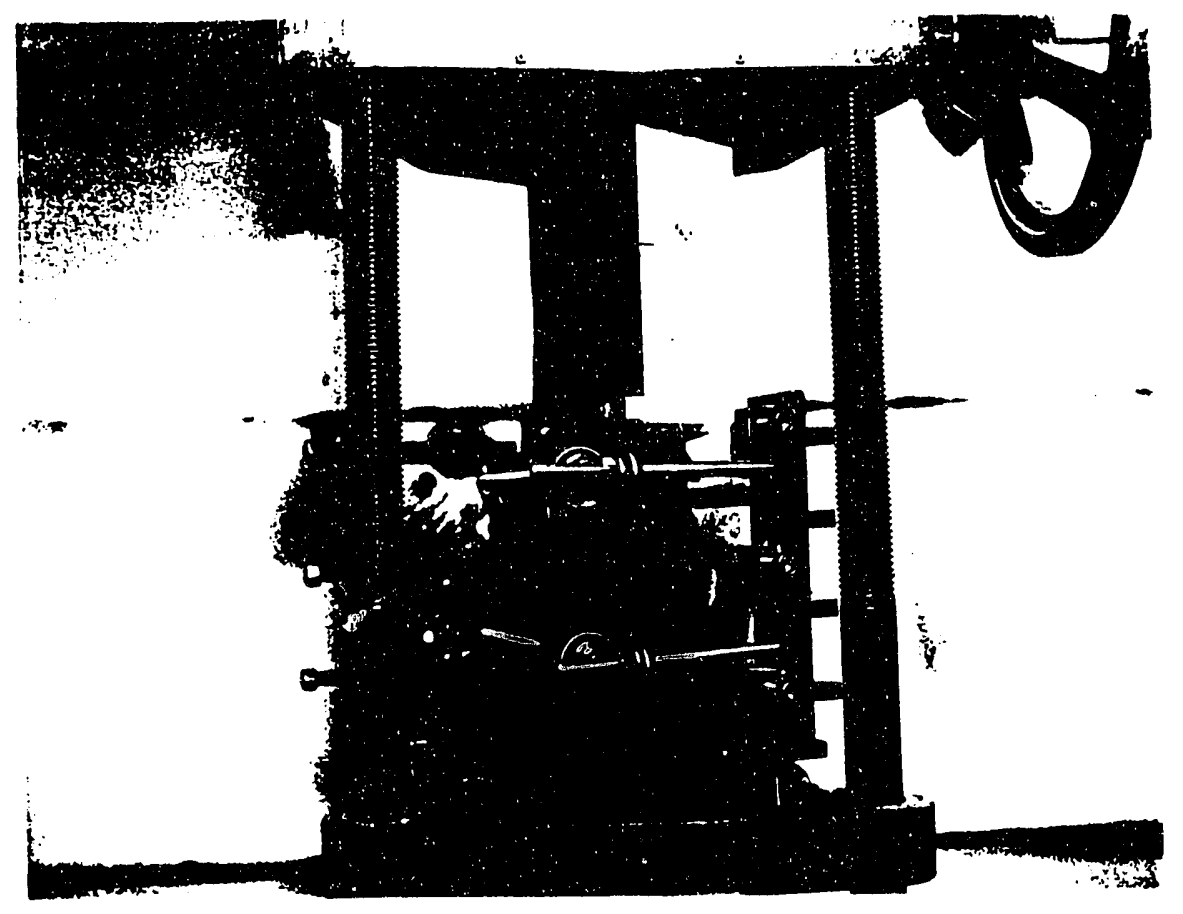

Figure 4-15. Pressing jig with 6-in by 6 -in by 2 -in filter section in place in the hand press

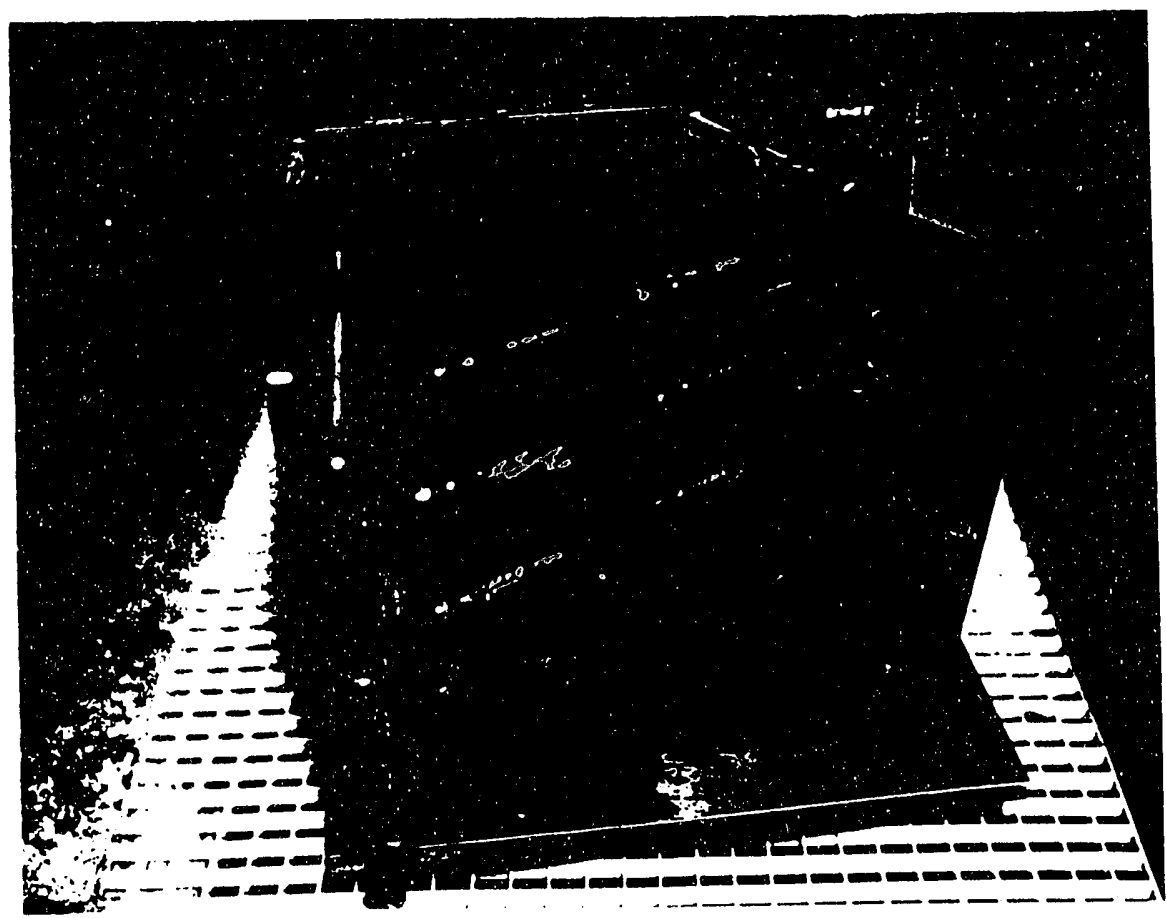

Figure 4-16. 6-in by 6-in by 2 -in pressing jig assembly showing reinforcing plates for the 6 -in by 6 -in by 2 -in filter 


\subsubsection{Drying}

The pressed filters were air dried after the pins were removed. The drying procedure was the same process used in drying previously extruded filter sheets. Filters were placed in a room temperature drying chamber that had air circulated with a series of fans. Cross sections of the filter have shown that the thicker edges of the filter develop internal cracks because of this drying technique. Sereral attempts were made to modify the process by slowing down the drying and using a heating schedule. The efforts were unsuccessful, and to minimize the number of variables in the manufacture of the filters, the original drying procedure was used throughout the 6 -in by 6 -in by 2 -in filter manufacture. The filters were dried for $24 \mathrm{hr}$ in the room temperature air dryer.

\subsubsection{Binder and Filler Burnout}

Binder and filler burnout required a process modification because of the organic content of the crossflow filter material. Initial attempts to burn the binder organic material from the filter resulted in the destruction of the filters because of the ignition of the organic and the rapid temperature rise caused by the combustion of the organic. In order to burn the binder out in air and to control the oxidation rate of the binder and filler, a localized atmosphere control system was used.

The filters were housed or covered with a material that would allow air and oxidation products to diffuse through the cover, but at a rate slow enough to prevent rapid combustion at the surface of the filter. The most effective cover was a 1-in-high temperature insulating fiberboard cover that was built to allow about 1 in of space between the edge of the filter and the inside surface of the fiberboard cover. The cover was constructed by cutting the fiberboard to size and bonding the cut pieces together with a high-temperature fiber bonding material. The filters were placed in an air oven and treated at $400^{\circ} \mathrm{C}$ for $12 \mathrm{hr}$ using an 8-hr linear ramp from room temperature to $400^{\circ} \mathrm{C}$, a $12-\mathrm{hr}$ soak, and an oven limited cooling rate. When the filters had cooled to room temperature, they were removed from the oven and placed in an oven that was controlled at a constant $100^{\circ} \mathrm{C}$ to prevent moisture adsorption while waiting to be sintered. The filters were 
very easily damaged during this part of the processing because of their high porosity and had to be handled very carefully. Initial attempts to sinter the 6 -in by 6 -in by 2 -in filters resulted in damage to the filters during the process of preparing the filters for firing in the sintering furnace.

\subsubsection{Bisque Firing}

The 6-in by 6 -in by 2 -in filters were bisque fired to $1200^{\circ} \mathrm{C}$ to give the filters more strength for handling and sintering. The filters were bisque fired on the same setter that they were binder fired on, to minimize handling. After bisque firing at $1200^{\circ} \mathrm{C}$, the filters were strong enough to handle.

\subsubsection{Sintering}

The filters were fired in nitrogen atmosphere at $1700^{\circ} \mathrm{C}$ for $2 \mathrm{hr}$ and then soaked at a temperature below the melting temperature of cordierite to crystallize any cordierite glass that had formed during the sintering process.

The primary concern in the sintering of the 6-in by 6-in by 2 -in filters was the porosity of the filters and the amount of shrinkage during sintering. The shrinkage during sintering was about 13 percent and the open and porous nature of filter was expected to put a large amount of drag stress on the filter material. To help alleviate these stresses, the filter was sintered on shrink plates that were formed from the same material as the filter. The shrinkage and the shrinkage rate at a given temperature would then be essentially the same.

The filter was sintered by setting it on one of its 6 -in by 6-in faces. This was done because initially the weight of the filter caused slumping at the lower portion of the filter when the filter was sintered on one of its 2-in by 6-in faces. Figure 4-17 shows a bisque-fired filter, a sintered filter, and a filter that has been sintered and machined. The first several sintering runs resulted in filters that were dish shaped because of temperature variations between the top and bottom of the filter during sintering. Setter plates were also placed on top of the filter to equalize the heating rate of the filter during sintering. These plates were effective in reducing the dishing of the filter during sintering. 


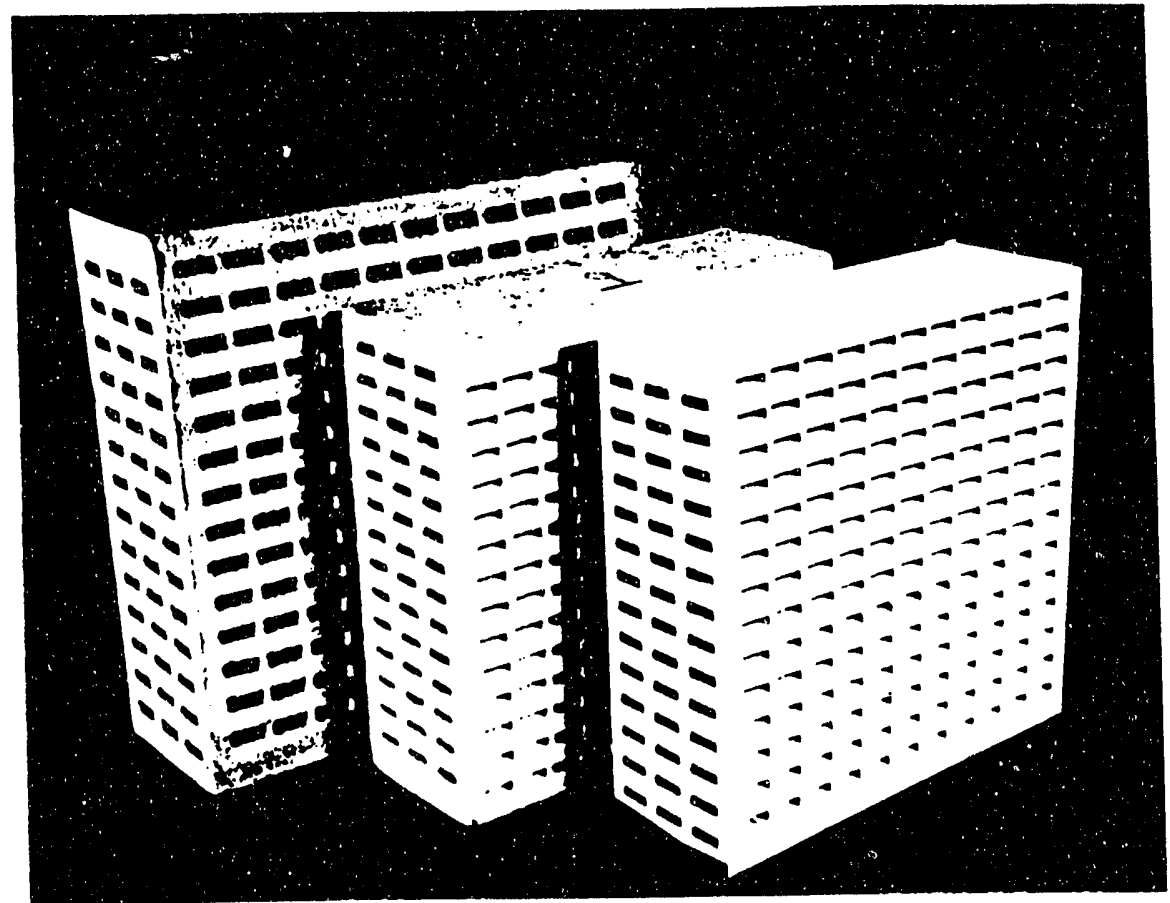

Figure 4-17. Bisque-fired 6-in by 6-in by 2 -in filter (left), sintered filter (center), and machined filter (right) 


\subsection{FILTER QUALIFICATION}

\subsubsection{Process Inspection}

Visual inspection during the manufacture of the filter was the primary process qualification procedure. Typical practice was used during the weighing and measuring of raw materials. The blending and mulling of the material for extrusion were kept constant with the procedure in Phase 1 of the contract. The primary difference in processing was the additional amount of water added to increase the ability of the extruded material to deform under the lower pressure that was necessary for the press bonding of the 6-in by 6 -in by 2 -in filters. The increased amount of water allowed the material to bond at the lower pressure, but also caused the permeability to be lower by making a smoother surface on the face of the extrusion. The CSN25 material sinters to density and the porosity is dependent on the filler and the extrusion process to create the voids necessary for high permeability. Photomicrographs of an extruded sheet that has been sintered are shown in Figure 4-18. The rough surface created by the coarse filler during extrusion is clearly shown. Figure 4-19 shows photomicrographs of an extruded sheet that has been pressed between two metal plates to simulate the press bonding technique. The surface has been flattened considerably and shows clearly the dense surface layer of CSN25. The next set of photomicrographs in Figure 4-20 shows the surface of a section of a press bonded filter. This surface is very similar to the surface of the sample shown in Figure 4-19.

The photomicrographs in Figure 4-21 show the results of an effort to increase the surface roughness of the press bonded filters. The technique involved coating the pressing rods with a layer of coarse filler material during assembly. The technique raises the permeability of the material, but Figures 4-18 through 4-21 show the sensitivity of the surface of the channel to the processing parameters in the press bonding method.

\subsubsection{Physical Testing}

Fracture surface: A sintered filter test sample that had been press bonded was scribed around its surface with a diamond saw and fractured to create a fracture surface of a cross section 

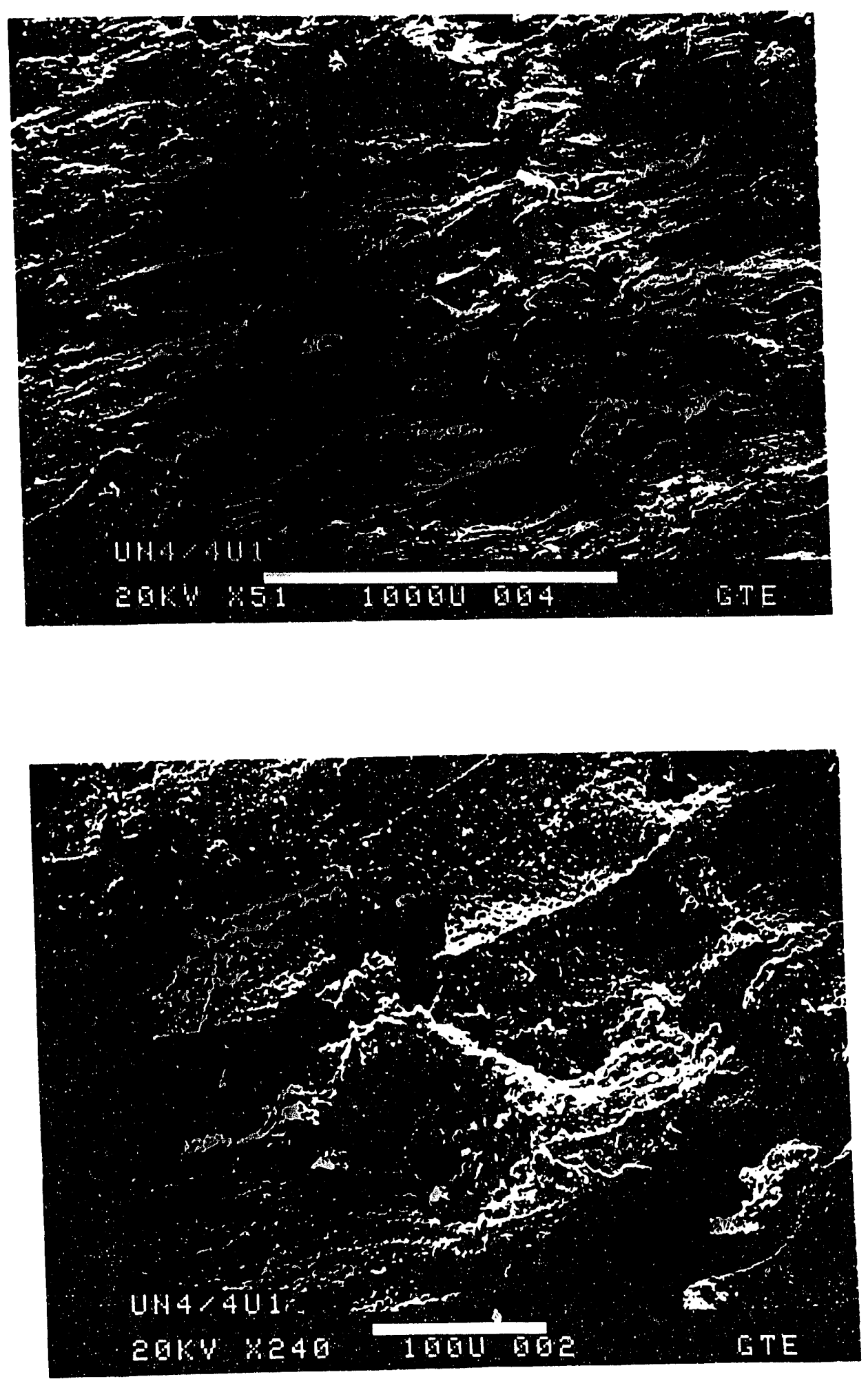

Figure 4-18. Photomicrographs of sintered surface of an extruded sheet of CSN25 porous material 

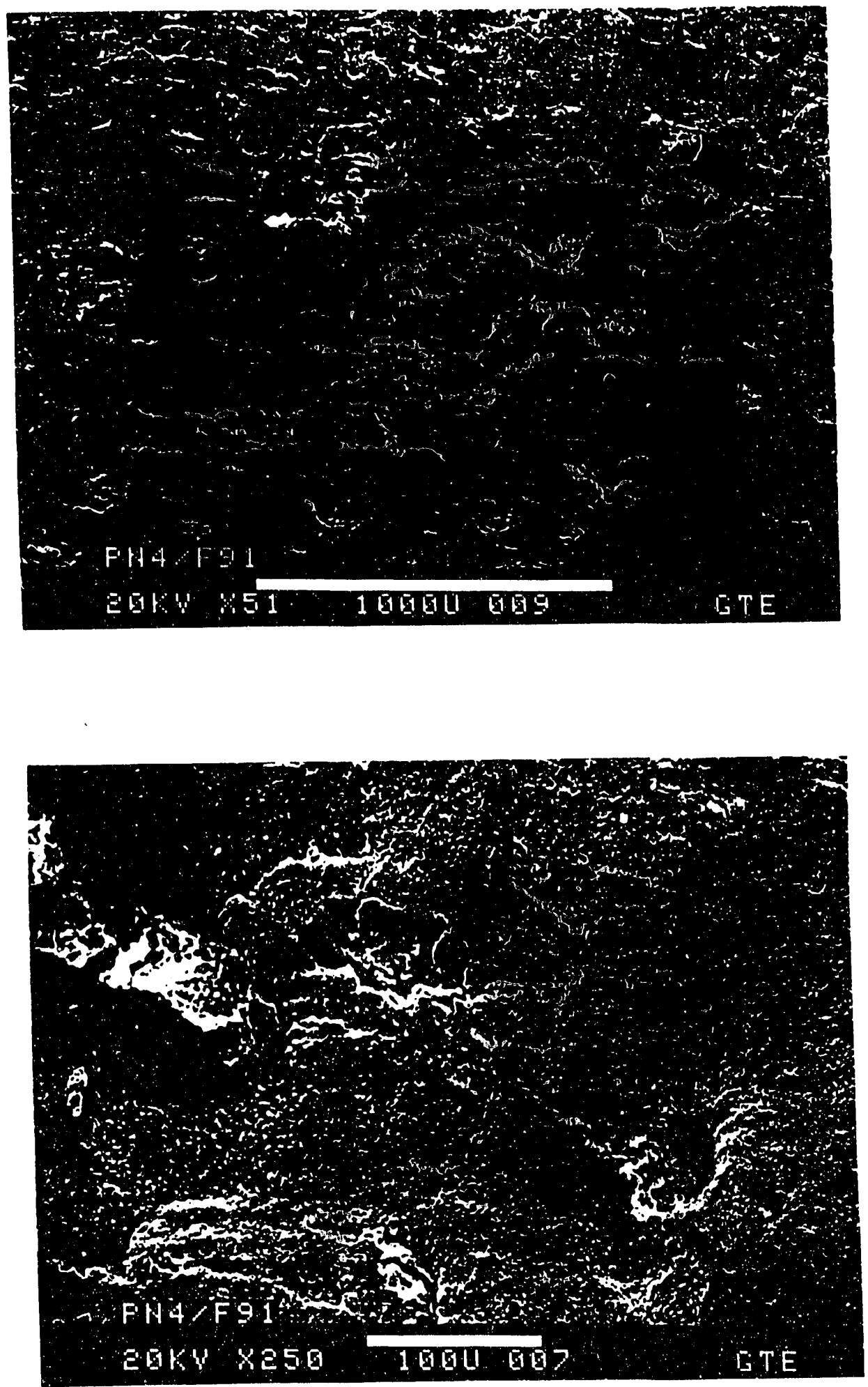

Figure 4-19. Photomicrographs of sintered surface of extruded porous CSN25 pressed between two metal plates 

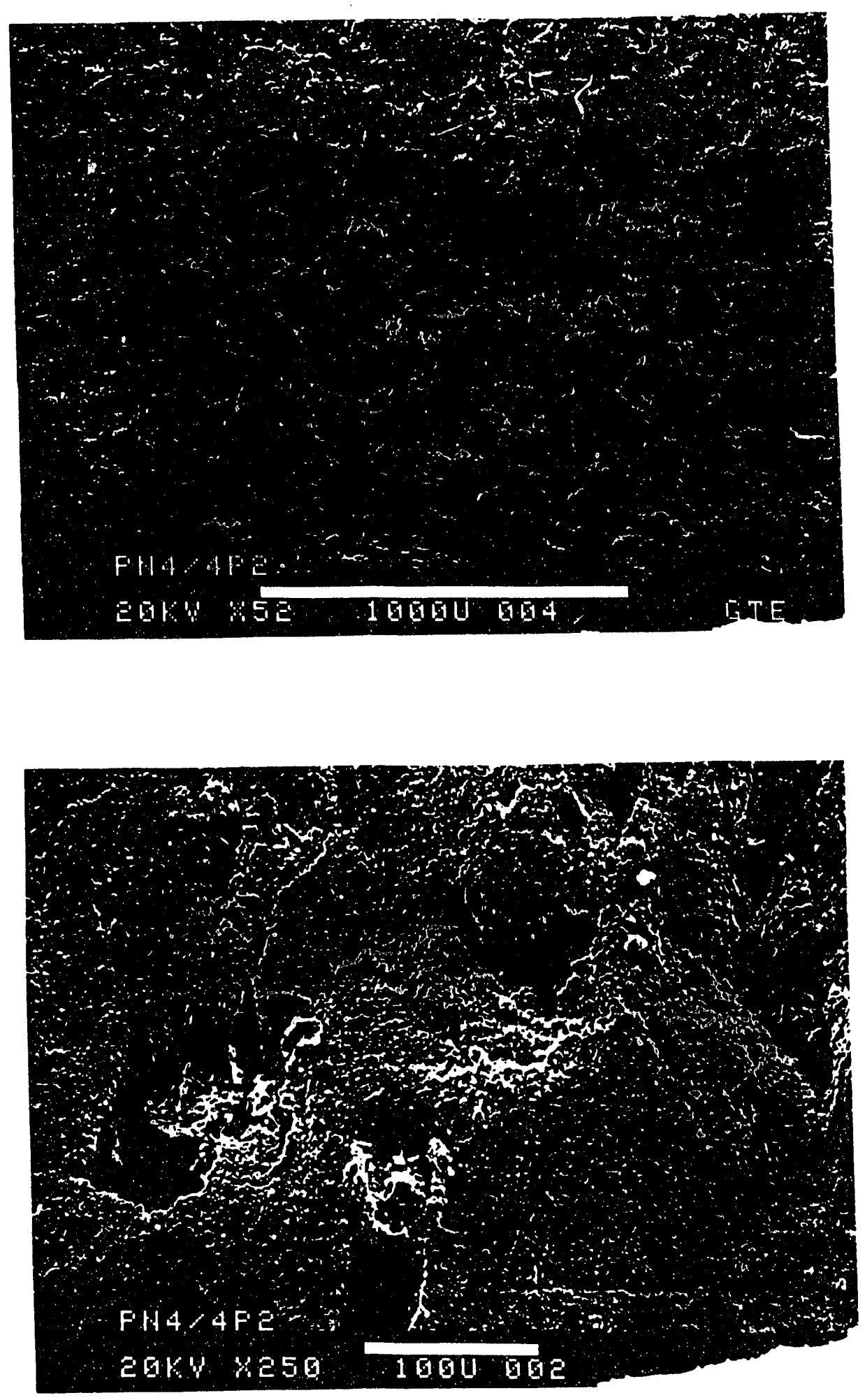

Figure 4-20. Photomicrographs of sintered CSN25 press-bonded crossflow filter surface 

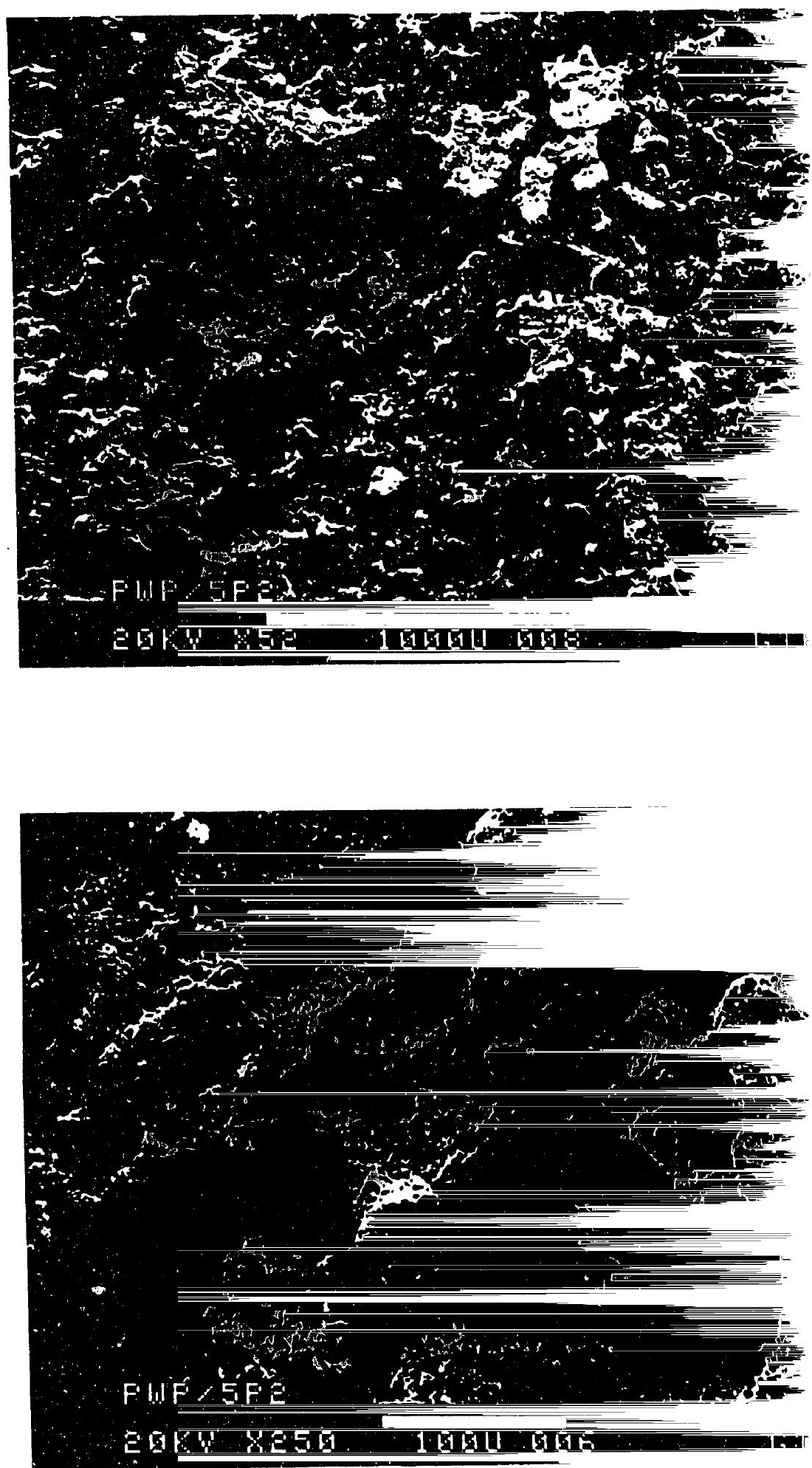

Figure 4-21. Photomicrographs of sintered CSN25 crossflow surface pressed bonded with filler coated rods 
of a press bonded filter. The fracture surface is shown in Figure 4-22. The fracture surface shows the radius on all four corners of the filter, the porous nature of the material, and the lack of a glue area in the press bonding technique.

Bend strength: The bend strength of the material was measured on samples that were made by layering 0.060 -in extruded sheets of material and press bonding the sheets between two metal plates. This technique was used to simulate the filter as closely as possible as bend strength samples of any size are difficult to cut from the filter itself. The average bend strength of five samples is 5349 psi with a standard deviation of 637 psi. The test results are shown in Appendix A.

Elastic modulus: Attempts to measure elastic modulus using a sonic technique were unsuccessful because of the high porosity of the sample material. Samples were made and sent to Dr. Richard Tressler at Pennsylvania State University. The elastic modulus of the samples was measured from room temperature to $1000^{\circ} \mathrm{C}$. The test results of the elastic modulus are shown in Appendix B.

Porosimetry analysis: The porosimetry analysis was done by Porous Materials, Inc., Analytical Services Division, Cornell Industry Research Park, Ithaca, New York. The graphical data is shown in Appendix C.

Burst test: Pressure testing to destruction was done on one of the Acurex test filters and on one of the 6-in by 6 -in by 2 -in filters to be tested at Westinghouse. The burst test apparatus consisted of a metal block machined to allow a manifold to cover one set of clean side channels. This manifold was gasketed and clamped over one set of clean side channels. The manifold was attached to a high volume water line and the water was slowly turned on and the water pressure measured. The water pressure was raised to the maximum pressure that could be achieved when testing the Acurex test samples. The maximum pressure was $60 \mathrm{psi}$. The Acurex samples did not burst at this pressure. The 6-in by 6-in by 2 -in filter showed several channels that burst at pressures of about 39 to 40 psi. Other channels did not burst at the maximum test pressure of 60 psi. 

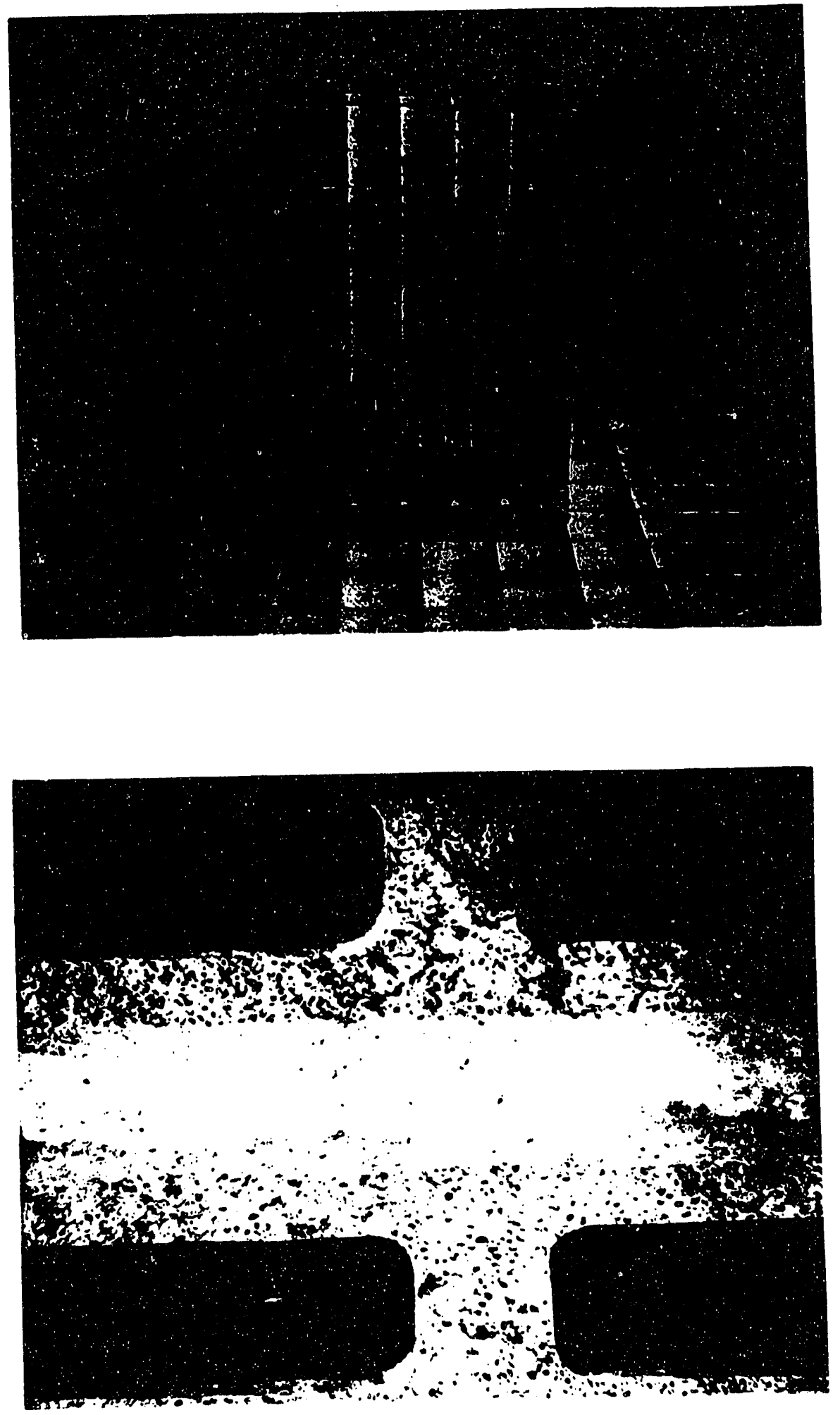

Figure 4-22. Fracture-surface photomicrographs of press-bonded CSN25 test filter 
Since a new filter mounting technique was being used, as well as a new filter manufacturing technique, we defined a series of tests to determine the filter durability under a variety of conditions. These tests were:

- Filter mounting

- Pulse cleaning

\subsubsection{Filter Mounting}

Acurex designed a smaller version of the filter mount design conceived earlier in the program. Machine drawings were produced and material procured, and the mount was manufactured. Once the mount was completed, we tested the filter and mount thermally and mechanically.

\subsubsection{Mount Design}

Figure 4-23 shows the small-filter mount design. Table 4-1 is the parts list. The mount is made from Rolled Alloys RA 33019 gage sheet. After receiving the mount, we verified the small filter for fit. We received two types of small filters from GTE: as-sintered and machined. On the as-sintered filters, only each filter's clean face was machined (to provide a better mounting surface). On the machined filters, all six sides of each filter were machined. The mount was designed for the machined filter only. The as-sintered filter was too large to fit.

\subsubsection{Mount Testing}

The first step in this testing was to thermally cycle the filter, to verify material dimensional stability and attempt to find the maximum heat rate the filter could withstand. Initially we heated the filter at $200^{\circ} \mathrm{F} / \mathrm{hr}$, with no indication of cracking or thermal stress. Next, we heated the filter at $400^{\circ} \mathrm{F} / \mathrm{hr}$, with the same result. Following this test, we checked the filter for dimensional stability. Figure 4-24 shows the measurement locations on the filters. Table 4-2 presents the measurement results. As can be seen, the material is dimensionally stable, with only slight 

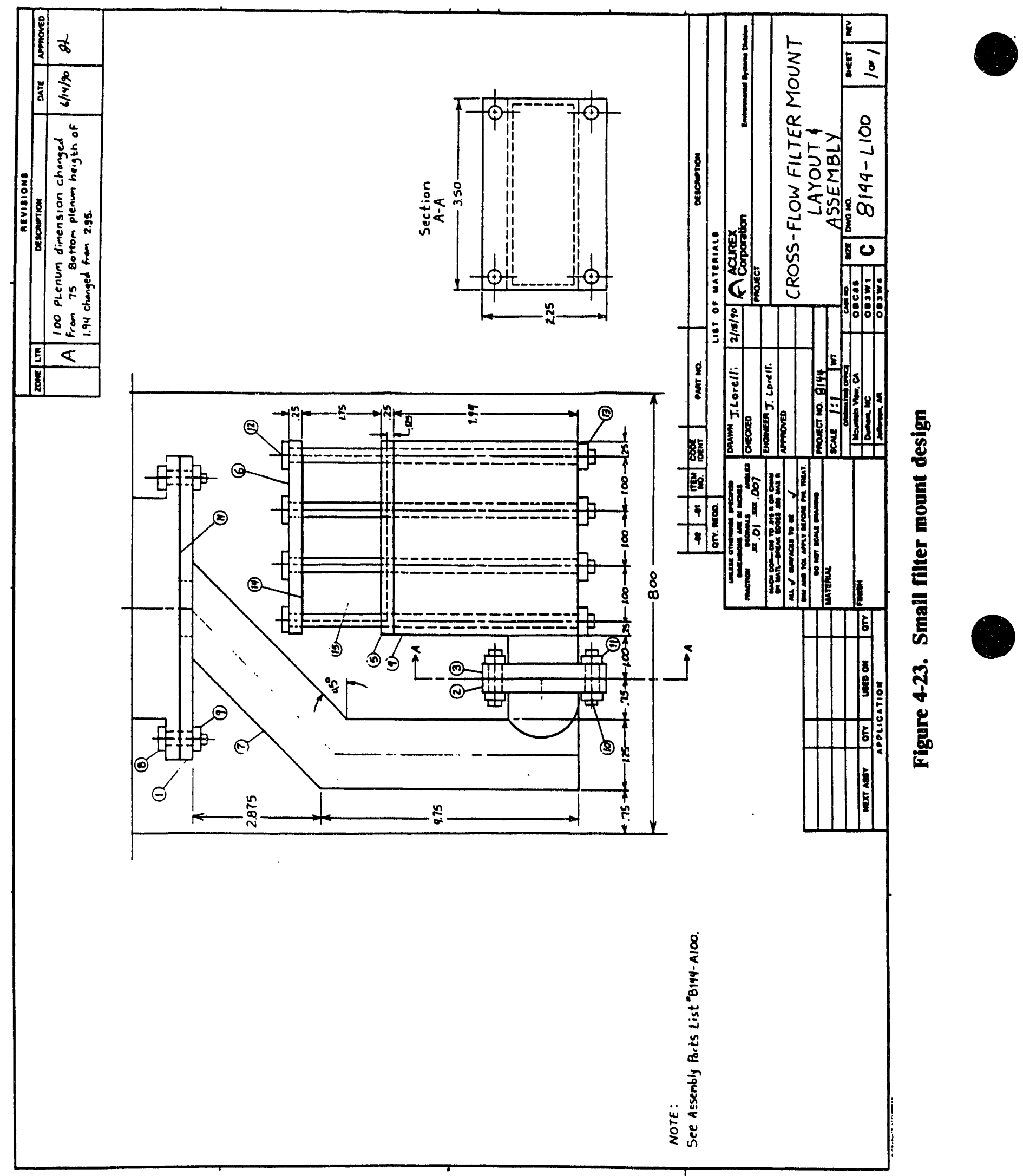
Table 4-1. Crossflow filter mount

\begin{tabular}{|c|l|l|c|}
\hline \multicolumn{3}{|c|}{ Assembly parts list No. 8144-A100 } & Qty \\
\hline Item & \multicolumn{1}{|c|}{ Part No. } & \multicolumn{1}{|c|}{ Description } & 1 \\
\hline 1 & $8144-\mathrm{D} 100$ & Flange Mount & 1 \\
3 & $8144-\mathrm{D} 300-1$ & Plenum Flange & 1 \\
4 & $8144-\mathrm{D} 300-2$ & Filter Plenum Flange & 1 \\
5 & $8144-\mathrm{L} 100$ & Filter Plenum, 3.5 in x 2.2 in, 19 Ga. & 1 \\
6 & $8144-\mathrm{D} 200-1$ & Filter Flange (Lower) & 1 \\
7 & $8144-\mathrm{D} 200-2$ & Filter Flange (Upper) & 1 \\
8 & $1 / 4$ in-20 x 1 in & RA 300 Bolts & 6 \\
9 & $1 / 4$ in-20 & RA 300 Nuts & 6 \\
10 & $1 / 4$ in-20 x 1 in & RA 330 Bolts & 4 \\
11 & $1 / 4$ in-20 & RA 330 Nuts & 4 \\
12 & $1 / 4$ in-20 x 15 in & SS 416 Bolts & 8 \\
13 & $1 / 4$ in-20 & RA 330 Nuts & 8 \\
14 & & Interam Gasket & As needed \\
\hline
\end{tabular}



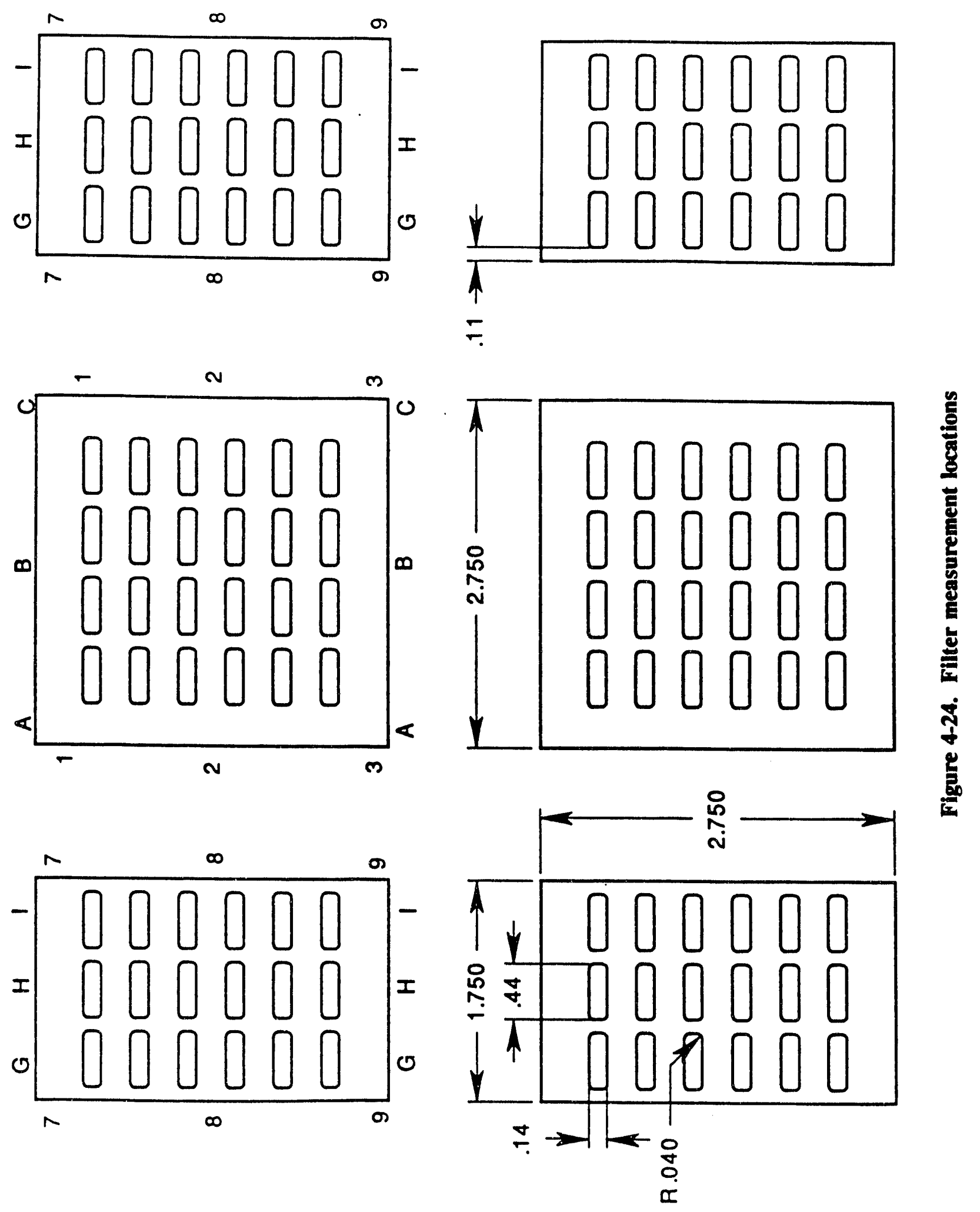
Table 4-2. Crossflow filter dimensions

\begin{tabular}{|c|c|c|c|c|c|}
\hline \multicolumn{2}{|c|}{ Left side } & \multicolumn{2}{|r|}{ Front } & \multicolumn{2}{|c|}{ Right side } \\
\hline \multicolumn{6}{|c|}{ Sample 1: As pressed and sintered-as received } \\
\hline $\begin{array}{l}\text { G-G } \\
H-H \\
I-I \\
7-7 \\
8-8 \\
9-9\end{array}$ & $\begin{array}{l}2.749 \\
2.780 \\
2.761 \\
1.863 \\
1.856 \\
1.860\end{array}$ & $\begin{array}{l}\text { A-A } \\
\text { B-B } \\
\text { C-C } \\
1-1 \\
2-2 \\
3-3\end{array}$ & $\begin{array}{l}2.882 \\
2.882 \\
2.882 \\
2.825 \\
2.794 \\
2.819 \\
\end{array}$ & $\begin{array}{l}\text { D-D } \\
\text { E-E } \\
\text { F-F } \\
4-4 \\
5-5 \\
6-6 \\
\end{array}$ & $\begin{array}{l}2.761 \\
2.770 \\
2.785 \\
1.891 \\
1.861 \\
1.862 \\
\end{array}$ \\
\hline \multicolumn{6}{|c|}{ Sample 1, Run 1: As pressed and sintered-1600 $\mathrm{F} @ 200^{\circ} \mathrm{F} / \mathrm{hr}$} \\
\hline $\begin{array}{l}\text { G-G } \\
\text { H-H } \\
\mathrm{I}-\mathrm{I} \\
7-7 \\
8-8 \\
9-9 \\
\end{array}$ & $\begin{array}{l}2.790 \\
2.780 \\
2.765 \\
1.862 \\
1.855 \\
1.860 \\
\end{array}$ & $\begin{array}{l}\text { A-A } \\
\text { B-B } \\
\text { C-C } \\
1-1 \\
2-2 \\
3-3 \\
\end{array}$ & $\begin{array}{l}2.785 \\
2.783 \\
2.778 \\
2.812 \\
2.791 \\
2.801 \\
\end{array}$ & $\begin{array}{l}\text { D-D } \\
\text { E-E } \\
\text { F-F } \\
4-4 \\
5-5 \\
6-6 \\
\end{array}$ & $\begin{array}{l}2.762 \\
2.775 \\
2.785 \\
1.901 \\
1.870 \\
1.865 \\
\end{array}$ \\
\hline \multicolumn{6}{|c|}{ Sample 1, Run 2: As pressed and sintered-1600 ${ }^{\circ} \mathrm{F} @ 400^{\circ} \mathrm{F} / \mathrm{hr}$} \\
\hline $\begin{array}{l}\text { G-G } \\
\text { H-H } \\
\text { I-I } \\
7-7 \\
8-8 \\
9-9 \\
\end{array}$ & $\begin{array}{l}2.789 \\
2.781 \\
2.766 \\
1.862 \\
1.856 \\
1.861 \\
\end{array}$ & $\begin{array}{l}\text { A-A } \\
\text { B-B } \\
\text { C-C } \\
1-1 \\
2-2 \\
3-3 \\
\end{array}$ & $\begin{array}{l}2.786 \\
2.788 \\
2.779 \\
2.815 \\
2.795 \\
2.802 \\
\end{array}$ & $\begin{array}{l}\text { D-D } \\
\text { E-E } \\
\text { F-F } \\
4-4 \\
5-5 \\
6-6 \\
\end{array}$ & $\begin{array}{l}2.764 \\
2.776 \\
2.784 \\
1.899 \\
1.872 \\
1.864 \\
\end{array}$ \\
\hline \multicolumn{6}{|c|}{$\begin{array}{l}\text { Sample 1, Run 3: As pressed and sintered-after mounting and } \\
\text { ramping to } 1600^{\circ} \mathrm{F} \text { twice }\end{array}$} \\
\hline $\begin{array}{l}\text { G-G } \\
\text { H-H } \\
\text { I-I } \\
\end{array}$ & $\begin{array}{l}2.787 \\
2.780 \\
2.758 \\
\end{array}$ & & & & \\
\hline \multicolumn{6}{|c|}{ Sample 2: Machined and air fired-as received } \\
\hline $\begin{array}{l}\text { G-G } \\
\text { H-H } \\
\text { I-I } \\
7-7 \\
8-8 \\
9-9 \\
\end{array}$ & $\begin{array}{l}2.736 \\
2.736 \\
2.731 \\
1.747 \\
1.735 \\
1.730 \\
\end{array}$ & $\begin{array}{l}A-A \\
B-B \\
C-C \\
1-1 \\
2-2 \\
3-3 \\
\end{array}$ & $\begin{array}{l}2.745 \\
2.74 \\
2.74\end{array}$ & $\begin{array}{l}\text { D-D } \\
\text { E-E } \\
\text { F-F } \\
4-4 \\
5-5 \\
6-6 \\
\end{array}$ & $\begin{array}{l}2.740 \\
2.740 \\
2.745 \\
1.746 \\
1.740 \\
1.735 \\
\end{array}$ \\
\hline \multicolumn{6}{|c|}{ Sample 2, Run 1: Machined and air fired-1600 $\mathrm{F} @ 200^{\circ} \mathrm{F} / \mathrm{hr}$} \\
\hline $\begin{array}{l}\text { G-G } \\
H-H \\
I-I \\
7-7 \\
8-8 \\
9-9 \\
\end{array}$ & $\begin{array}{l}2.762 \\
2.748 \\
2.750 \\
1.740 \\
1.734 \\
1.742 \\
\end{array}$ & $\begin{array}{l}\mathbf{A}-\mathbf{A} \\
\mathbf{B}-\mathbf{B} \\
\mathbf{C}-\mathbf{C} \\
1-1 \\
2-2 \\
3-3 \\
\end{array}$ & $\begin{array}{l}2.741 \\
2.738 \\
2.735 \\
2.738 \\
2.741 \\
2.742 \\
\end{array}$ & $\begin{array}{l}\text { D-D } \\
\text { E-E } \\
\text { F-F } \\
4-4 \\
5-5 \\
6-6 \\
\end{array}$ & $\begin{array}{l}2.735 \\
2.732 \\
2.730 \\
1.740 \\
1.740 \\
1.731 \\
\end{array}$ \\
\hline \multicolumn{6}{|c|}{ Sample 2, Run 2: Machined and air fired-1600 F @ 400 F/hr } \\
\hline $\begin{array}{l}\text { G-G } \\
H-H \\
\mathrm{I}-\mathrm{I} \\
7-7 \\
8-8 \\
9-9 \\
\end{array}$ & $\begin{array}{l}2.740 \\
2.741 \\
2.745 \\
1.742 \\
1.738 \\
1.730 \\
\end{array}$ & $\begin{array}{l}\text { A-A } \\
\text { B-B } \\
C-C \\
1-1 \\
2-2 \\
3-3 \\
\end{array}$ & $\begin{array}{l}2.743 \\
2.740 \\
2.738 \\
2.740 \\
2.741 \\
2.743 \\
\end{array}$ & $\begin{array}{l}\text { D-D } \\
\text { E-E } \\
\text { F-F } \\
4-4 \\
5-5 \\
6-6 \\
\end{array}$ & $\begin{array}{l}1.742 \\
1.738 \\
1.730 \\
\end{array}$ \\
\hline \multicolumn{6}{|c|}{ Sample 2, Run 2: Machined and air fired-recheck } \\
\hline $\begin{array}{l}\text { G-G } \\
\text { H-H } \\
\text { I-I }\end{array}$ & $\begin{array}{l}2.745 \\
2.742 \\
2.748 \\
\end{array}$ & & & & \\
\hline
\end{tabular}


differences between as-received and thermally-cycled dimensions. These differences are attributable to normal variations in measurement.

After verifying the filter materials dimensional stability, we determined that the filter fit the mount, and performed a series of tests to test the thermal and mechanical response of the filter/mount system. These tests included thermal cycling and strain gage testing.

The first step in determining the testing conditions for the filter/mount system was to determine the bolt preload for mounting the filter. Based on our knowledge of working and allowable stresses in the crossflow filter, we needed to establish an acceptable level of (compressive) stress in the filter caused by bolt loading. The filter is mounted in such a way that bolt loading should be minimized to avoid crushing, yet this loading must be large enough to offset any loosening of the filter in the mount during pulse cleaning.

\section{Mode 1: Crushing Along Bottom Perimeter of Mount}

The total amount of load in the filter is concentrated along the bottom mount perimeter. If the bolt load is large enough, crushing may occur along the edge of the filter. Thus, we used both the gasket area and the total force caused by bolt loading to calculate the stress level in the filter. We then calculated bolt torques by assuming a friction coefficient of 0.14 (light-oiled bolt).

\section{Mode 2: Channel Floor Buckling}

If the bolt pre-load is large enough, the channel floor may be crushed because it is oriented parallel to the mount plates. Consequently, we used the total area of these channel floors to calculate stresses for different mount forces. A bolt load of $10 \mathrm{lb}$ produces a stress of 151 psi, which we considered too large. We found 30 psi to be an acceptable stress level for a bolt load of $2 \mathrm{lb}$.

\section{Mode 3: Mount Loosening Due to Pulse Cleaning}

The bolt load needs to be large enough to offset the force caused by the mount plates being spread apart from pulse cleaning. Based on a pulse pressure of $10 \mathrm{psi}$ and a total dirty side channel area of $1.48 \mathrm{in}^{2}$, we found a bolt force of $1.85 \mathrm{lb}$. Therefore, a bolt pre-load greater than this 
amount was needed, so we decided to use a bolt load of $3 \mathrm{lb}$, which would cause a channel floor stress of 45 psi and a bottom mount stress of 79.2 psi.

After determining the bolt torque for filter mounting, we wanted to verify that the mount did not place undue stress on the filter. For this testing, we mounted strain gages on two filters. Initially, we had to experiment with the strain gages to determine an attachment technique. The results of the strain gage testing are summarized below.

\section{Strain Gage Testing-Room Temperature}

We devised a clamping arrangement to place stress on a filter with a strain gage mounted. The force was placed on the top of the filter and directly over the channels where the strain gage was located. We made an adapter so we could use a torque wrench to determine the applied force (the torque reading (in-lb) was multiplied by the lever arm (in) to obtain force). To increase the strain gages' strain sensitivity, we energized each strain gage to $5 \mathrm{~V}$. The results are shown in Table 4-3. Two sets of plots, showing torque versus voltage, and applied force versus strain, are shown in Figures 4-25 and 4-26 of the two test runs. As can be seen, voltage caused by the torque was less than $1 \mathrm{mV}$ for the undamaged filter. The maximum working stress for the filter was -3844.82 psi. A compressive force of $104.5 \mathrm{lb}$ caused cracking in the filter. The resulting extrapolated stress is approximately $-4655.88 \mathrm{psi}$. Stresses were calculated by multiplying the strain times the modulus of elasticity (4.59 EE6 psi).

Measured Modulus of Rupture (MOR) values are approximately 5350 psi for this material. The stress that caused cracking was somewhat less than the MOR value. Because the filter cracked by separating where the rib joins the floor, this gives an indication of the rib-floor bend strength.

\section{High-Temperature Measurements}

Current results of the strain gage testing are inconclusive. It appears that both gages behaved linearly and had similar temperature drifts. In the first test run, we used $8 \mathrm{in}-\mathrm{lb}$ torque on the mount. We noted no significant differences between the mounted and unmounted gages. Before the second test run, we increased the mount torque to $60 \mathrm{in}-\mathrm{lb}$; no voltage at the bridge 


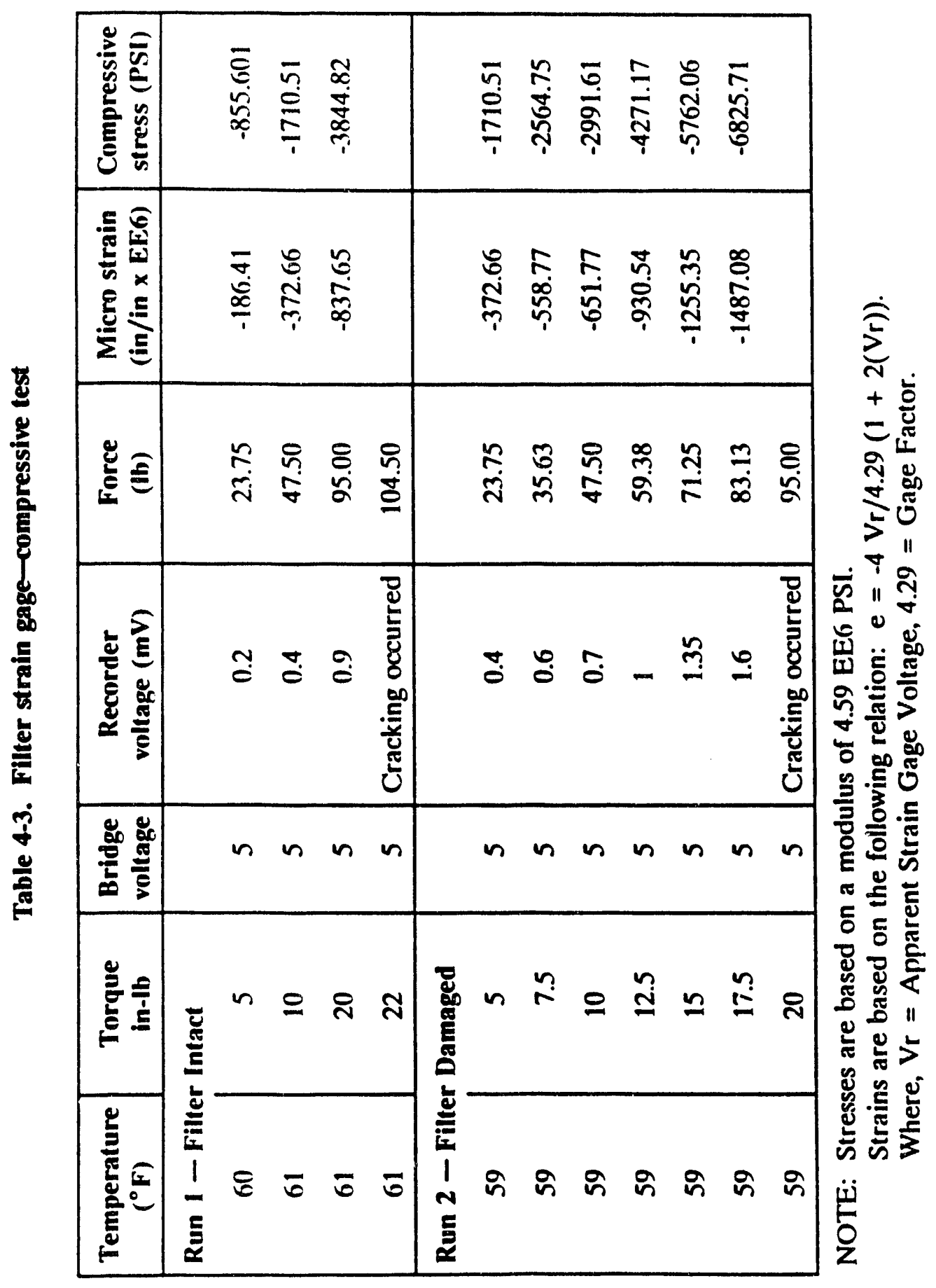



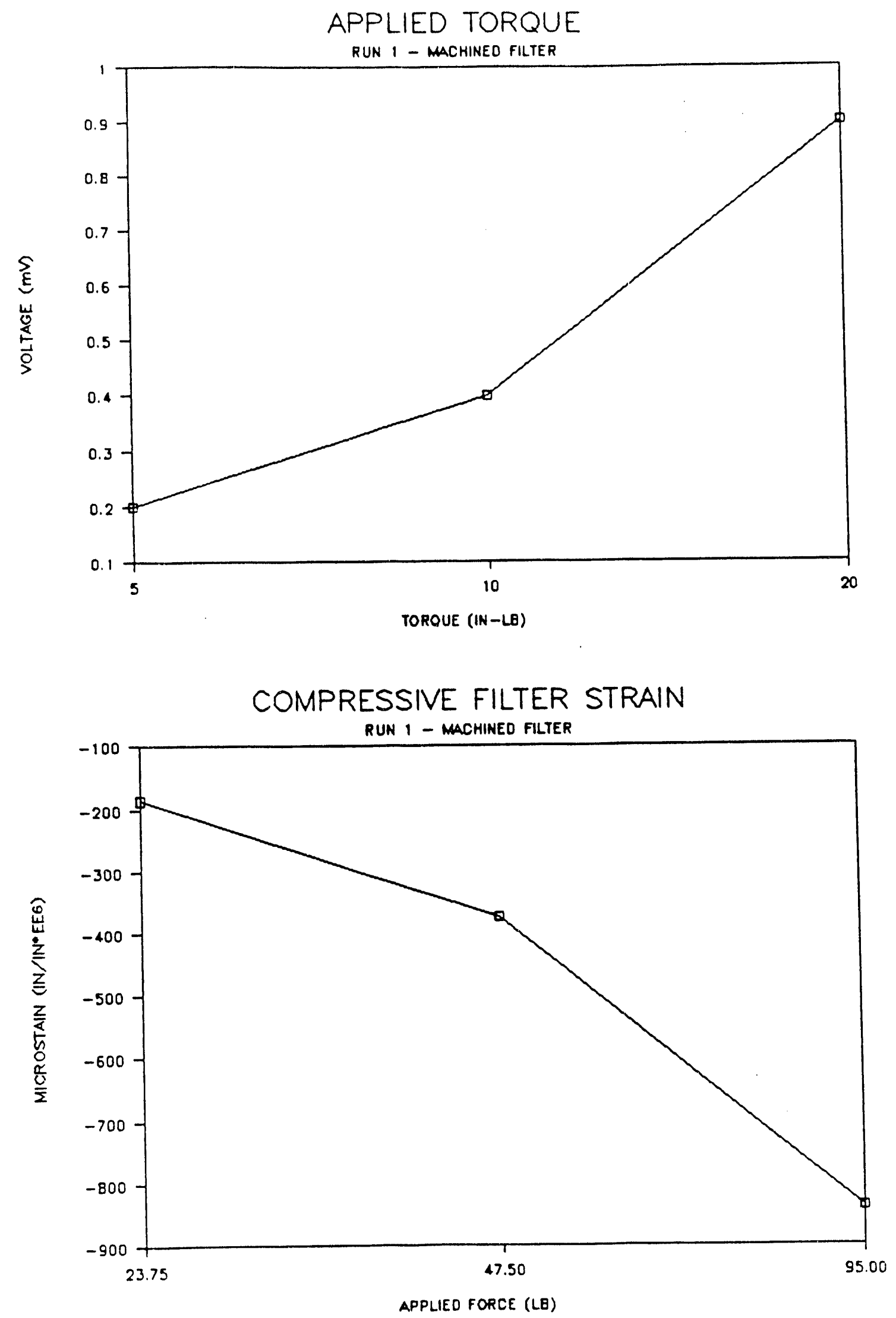

Figure 4-25. Strain gage test, run 1 

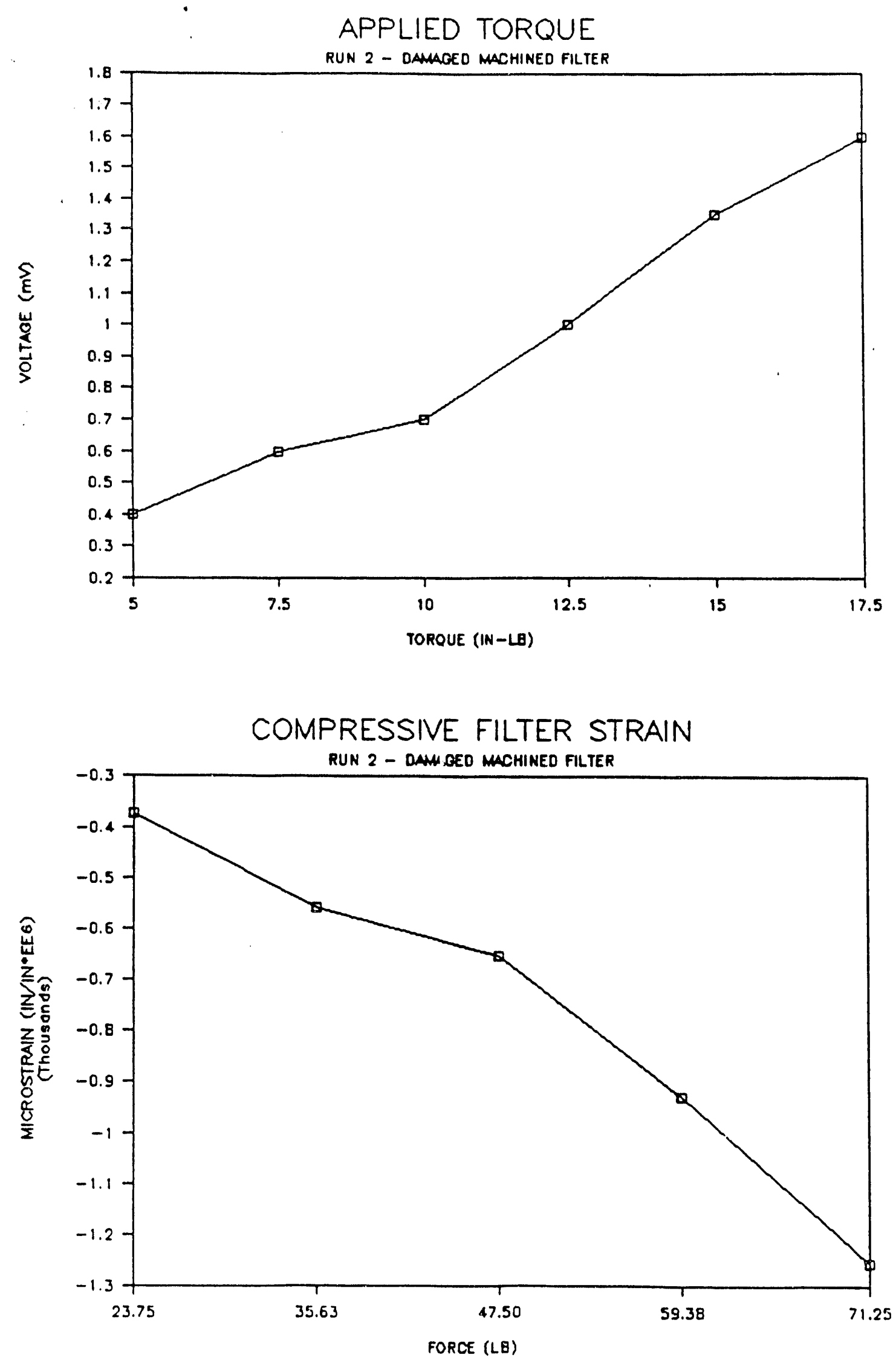

Figure 4-26. Strain gage test, run 2 
output was evident. The test was continued to $1500^{\circ} \mathrm{F}$; once again, no voltage change between the mounted and unmounted gages was apparent. We therefore can make the following conclusion:

Based on a bolt of $60 \mathrm{in}-\mathrm{lb}, 1714 \mathrm{lbf} /$ bolt $=13,714 \mathrm{lbf}$ total would have been applied. Assuming a filter element area of $2.24 \mathrm{in}^{2}$, this yields a stress of $6122 \mathrm{psi}$. The Modulus of Elasticity as determined by Pennsylvania State University is $4.59 \times 10^{6} \mathrm{psi}$. The expected strain would then be: $6122 \div\left(4.59 \times 10^{6}\right)=1.33 \times 10^{-3}$ in/in $=1330 \mu$ strain. Based on a bridge sensitivity of $0.75 \mathrm{mV} / 1000 \mu$ strain, the expected voltage would be $0.75(1.33)=0.9975 \mathrm{mV}$. The large temperature-induced voltages (over $60 \mathrm{mV}$ at $1500^{\circ} \mathrm{F}$ ) would not allow detection of such a small voltage change caused by the applied load.

These results neither verify nor refute the concept of the low-expanding filter mount. However, the filter survived with $60 \mathrm{in}-\mathrm{lb}$ of mount torque at $1500^{\circ} \mathrm{F}$ with no visible damage. In practice, this is much more bolt torque that would be required to achieve a gasket seal on the mount. Therefore, it is highly likely that the mount is not imposing significant stress on the filter due to thermal expansion. The Pennsylvania State University study performed measurements for Young's Modulus to $1000^{\circ} \mathrm{F}$ and found little variance with room temperature values. Therefore, if the mount is not imposing appreciable strain on the filter due to expansion, we can assume that room temperature strain will remain constant at high temperature.

\subsubsection{Pulse Cleaning}

The pulse cleaning test parameters were:

$\begin{array}{ll}\text { Number of pulses: } & 5000 \\ \text { Pulse duration } & 0.5 \mathrm{~s} \\ \text { Time between pulses: } & 30 \mathrm{~s} \\ \text { Operating temperature } & 1600^{\circ} \mathrm{F} \\ \text { Pulse pressure: } & 80 \mathrm{psig}\end{array}$

To complete this testing, we installed a small filter (see Figure 4-27) in the bench-scale filter test facility, heated the vessel, and performed the testing. After 5000 pulses, we removed and 


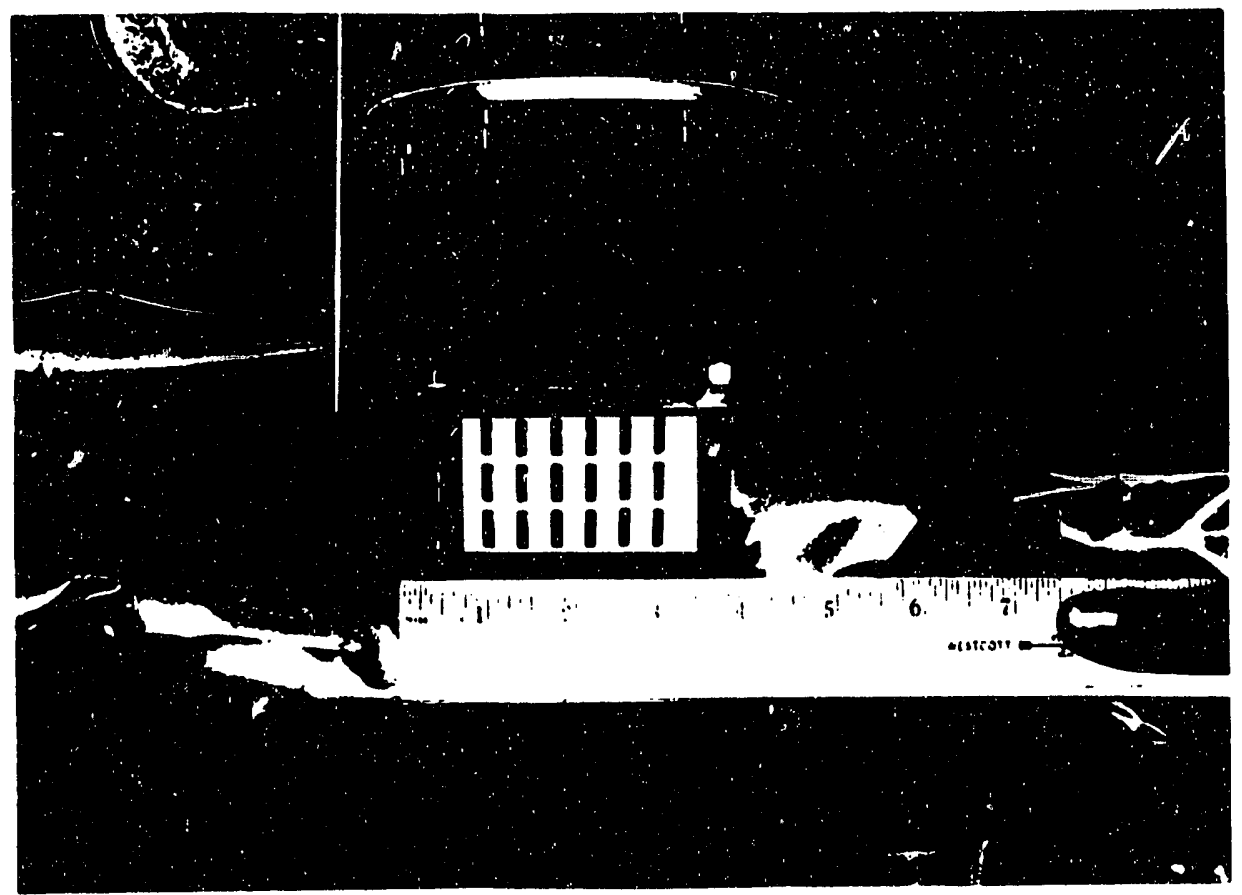

Figure 4-27. Small filter mounted for pulse cleaning tests 
examined the filter. A small crack that existed on the side of the filter had widened. However, the filter did not delaminate.

The crack on the side of the filter had been discovered when the filter was machined. This crack was attributed to the drying technique used during manufacture. Based on our observation of this crack, we decided that the half-scale filters would not be machined. 


\section{SECTION 5}

\section{FILTER TESTING}

The objective of this effort was to test the manufactured filters under simulated operating conditions for a total of 100 hours. This testing took place at the Westinghouse Science and Technology Center.

\subsection{FILTER TESTING}

Acurex defined a test plan as shown in Table 5-1. However, after discussions with Westinghouse upon delivering the filter for testing, the test plan was amended to that shown in Table 5-2. Testing at the lower face velocities was eliminated because the flowrates for these test conditions was below the Westinghouse operating envelope.

The test plan shown in Table 5-2 provides for longer test periods at each face velocity. The dust loading was to be maintained at $6000 \mathrm{ppm}$. However, at the higher face velocities, this dust load required too frequent pulse cleaning ( $<3 \mathrm{~min}$ cycle time), and the dustload was lowered to 2000 ppm.

\subsubsection{Proof Testing}

During testing, the new test plan was revised further. The actual test plan is shown in Table 5-3. The test plan was revised because upon testing at $15 \mathrm{fpm}$ face velocity, the pressure drop was quite high ( $\sim 135$ in. w.c.) and the cleaning cycle was less than 5 minutes. Therefore, it was decided to terminate testing at $15 \mathrm{fpm}$. It was decided to finish the test matrix at $7 \mathrm{fpm}$ to obtain information on steady-state flow operation of the filter. 
Table 5-1. Proof testing conditions

\begin{tabular}{|l|c|c|c|c|c|}
\hline & Startup & Baseline & Low & Medium & High \\
\hline Time (hr) & 20 & 5 & 25 & 25 & 25 \\
Temperature ( $\left.{ }^{\circ} \mathrm{F}\right)$ & 1600 & 1600 & 1600 & 1600 & 1600 \\
Pressure (atm) & 10 & 10 & 10 & 10 & 10 \\
Face velocity (ft/min) & 5 & $5,10,15$ & 5 & 10 & 15 \\
Dust loading (ppm) & 0 & 0 & 6000 & 6000 & 6000 \\
\hline Remarks & \multicolumn{6}{|c|}{$\Delta$ P clean versus flowrate } \\
\hline
\end{tabular}

Table 5-2. New test plan

\begin{tabular}{|l|l|l|l|}
\hline Temperature & $1600^{\circ} \mathrm{F}$ & $1600^{\circ} \mathrm{F}$ & $1600^{\circ} \mathrm{F}$ \\
Pressure & $150 \mathrm{psig}$ & $150 \mathrm{psig}$ & $150 \mathrm{psig}$ \\
Face velocity & $12 \mathrm{fpm}$ & $15 \mathrm{fpm}$ & $20 \mathrm{fpm}$ \\
Dust loading & $6000 \mathrm{ppm}$ & $6000 \mathrm{ppm}$ & $6000 \mathrm{ppm}$ \\
Time & $33 \mathrm{hr}$ & $33 \mathrm{hr}$ & $34 \mathrm{hr}$ \\
\hline
\end{tabular}

Table 5-3. Actual test plan

\begin{tabular}{|l|l|l|l|}
\hline Temperature & $1600^{\circ} \mathrm{F}$ & $1600^{\circ} \mathrm{F}$ & $1600^{\circ} \mathrm{F}$ \\
Pressure & $150 \mathrm{psig}$ & $150 \mathrm{psig}$ & $150 \mathrm{psig}$ \\
Face velocity & $12 \mathrm{fpm}$ & $15 \mathrm{fpm}$ & $7 \mathrm{fpm}$ \\
Dust loading & $6000 \mathrm{ppm}$ & $6000 \mathrm{ppm}$ & $6000 \mathrm{ppm}$ \\
Time & $30 \mathrm{hr}$ & $4 \mathrm{hr}$ & $42 \mathrm{hr}$ \\
\hline
\end{tabular}


Therefore, filter operation at three face velocities was tested: 7,12 , and $15 \mathrm{fpm}$. Test conditions were chosen to simulate operation of a filter on a PFBC. Test pressure was 150 psig, and test temperature ranged from $1000^{\circ} \mathrm{F}$ to $1550^{\circ} \mathrm{F}$. Dust inlet concentration ranged from 3000 to $6000 \mathrm{ppm}_{\mathrm{w}}$.

Testing was performed in an oxidizing atmosphere. There was some discussion early in the program as to whether to test in a reducing or oxidizing atmosphere. Since most test facilities are currently oxidizing atmospheres, the decision was made to test in an oxidizing atmosphere. The material should also be tested in a reducing atmosphere, after further development work.

\subsection{TEST RESULTS}

Two filters were tested at Westinghouse STC. The first filter was tested at face velocities of 12 and $15 \mathrm{fpm}$, and the second was tested at $7 \mathrm{fpm}$. Both filters were manufactured in the same manner, so there was very little difference in the filter characteristics. Table 5-4 summarizes the test times for each filter.

The first filter was tested for 32 hours and the second for 42 hours. The first filter was removed from testing after a corner of the filter broke off during unit cooldown. It was theorized that dust had trapped between the edge of the mount and the filter. As the mount contracted during cooling, the trapped dust broke the filter. Examination of the filter strongly indicated that the filter had not failed in service as the break surface was clean and there was no scouring of the break surface by dust at high velocity. If rigid ceramic filters break in service, they show abrasion

Table 5-4. Filter test summary

\begin{tabular}{|l|c|c|c|}
\hline & $\begin{array}{c}\text { Exposure Time } \\
\text { (hr) }\end{array}$ & $\begin{array}{c}\text { Test Time } \\
\text { (hp) }\end{array}$ & Cleaning Pulses \\
\hline Filter 1 & 89.8 & 32.5 & 260 \\
Filter 2 & 96.4 & 42.3 & 125 \\
Total & 186.2 & 74.8 & 383 \\
\hline
\end{tabular}


markings around the break surface. The second filter was installed in the test facility and testing was restarted.

\subsection{Collection Efriciency}

Collection efficiency (See Figure 5-1) during the testing ranged from a low of 98.5 percent to a high of 99.99 percent. In general, collection efficiency should be $\geq 99.5$ percent, however, there were several gasket and sampling system failures which affected the collection efficiency.

The gasket failures were attributed to a variety of problems including:

- too little weight on the filter

- gasket mounting surface too small

Acurex used an existing filter mount at Westinghouse which was not of the design developed in Task 2 of this project. To secure the filter into the existing mount, weights were stacked on the filter. At the beginning of testing, 25 pounds were stacked onto the filter. Over the first 30 hours of testing, the weight was gradually increased to 55 pounds. The combination of increasing the weight and changing the gasket design allowed normal operation of the filter.

It should be pointed out that this approach would not be used in normal operation. The mount designed for the filter would be fabricated. However, due to budget and time constraints, the existing mount was used.

In addition, testing pointed out that the gasketing surface on the half-scale filter was too small. This surface needs to be increased to accommodate the pressure drop experienced.

The last several days of testing, the sampling system appears to have been leaking, skewing the collection efficiency data. The sampling system was fixed and the collection efficiency on the last day of testing increased to 99.99 percent.

The raw test data summary is shown in Appendix H. The pressure drop plots for individual test days are shown in Appendix I. 


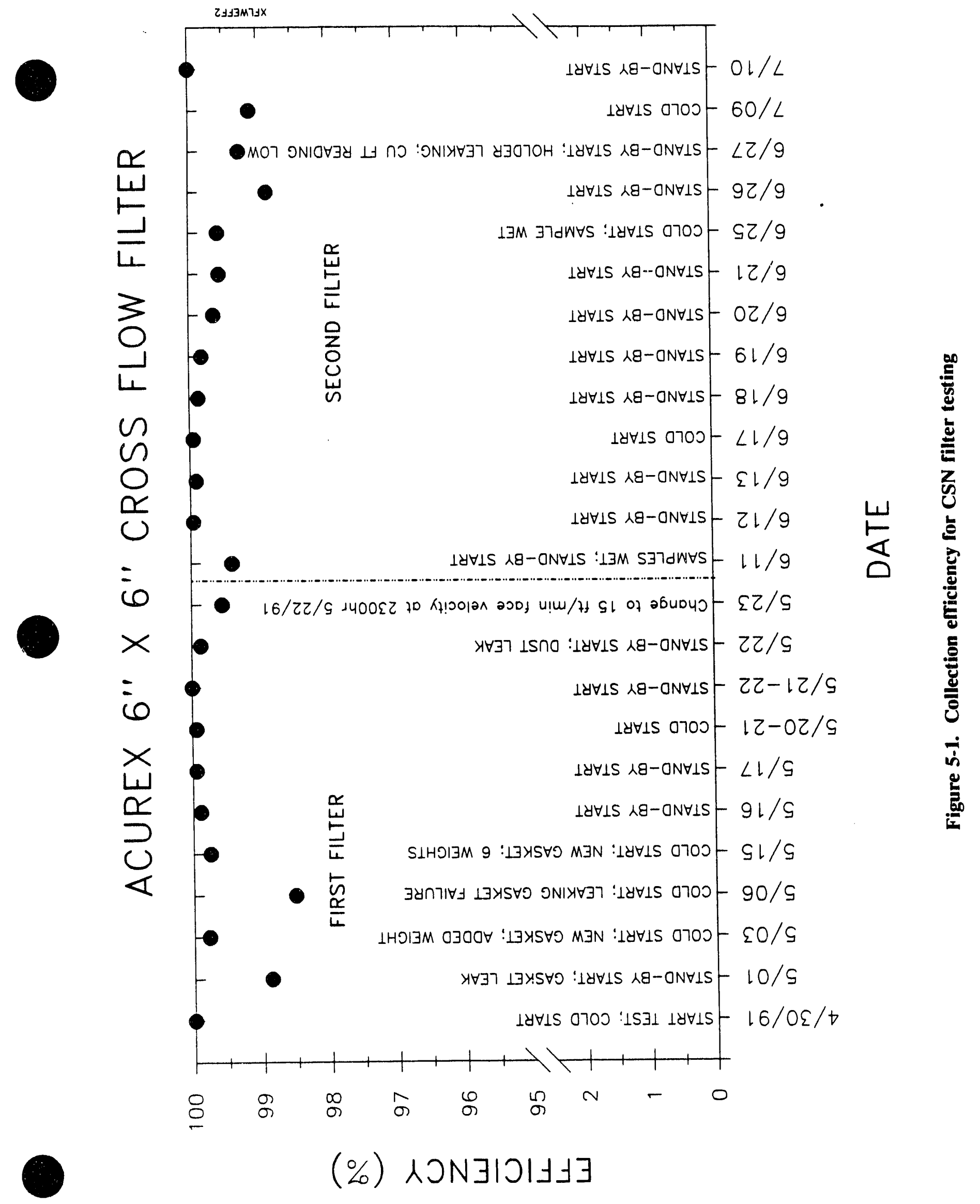




\subsubsection{Permeability}

As discussed in Section 3, the CSN material has a permeability of approximately 1800 millidarcies. However, after press-bonding, the surface permeability is closed off, reducing the permeability by approximately 60 percent. Therefore, the filter permeability was approximately 600 to 700 millidarcies. This led to higher filter pressure drop than expected. However, the operating pressure drop was only slightly above average for the range of face velocities tested.

As with all barrier filters, filter permeability decreased over the test period. Figure 5-2 shows the permeability for filter 1 . As can be seen, the permeability appears to be asymptotically declining to approximately half the unused filter value. For comparison, The permeability of the candle filters tested at the Grimethorpe PFBC decreased approximately 70 percent during the first 100 hours of testing.

Permeability of the second filter (See Figure 5-3) decreased approximately 35 percent during testing. This filter was not tested at the higher face velocities $(12,15 \mathrm{fpm})$, and therefore was not pulse cleaned as often. The second filter experienced 125 cleaning cycles whereas the first filter experienced 265. The combination of higher face velocity operation and larger number of cleaning cycles probably decreased permeability of the first filter faster than the permeability of the second filter.

\subsubsection{Filter Cleaning}

At the beginning of testing, pulse pressure was purposefully kept low to make sure that the filter was not overcleaned while it was at its most permeable state. However, as can be seen in Figure 5-4, the pulse pressure was quickly raised over the course of the early testing.

This figure also shows that the first filter never reached steady-state operation. It appears that the filter was about to equilibrate when the face velocity was raised.

Therefore, the second filter was operated at only one face velocity so that steady state filter operation could be obtained. The second half of Figure 5-4 shows that the pulse cleaning pressure was very close to equilibrating when testing was stopped. Examination of the last several test days 


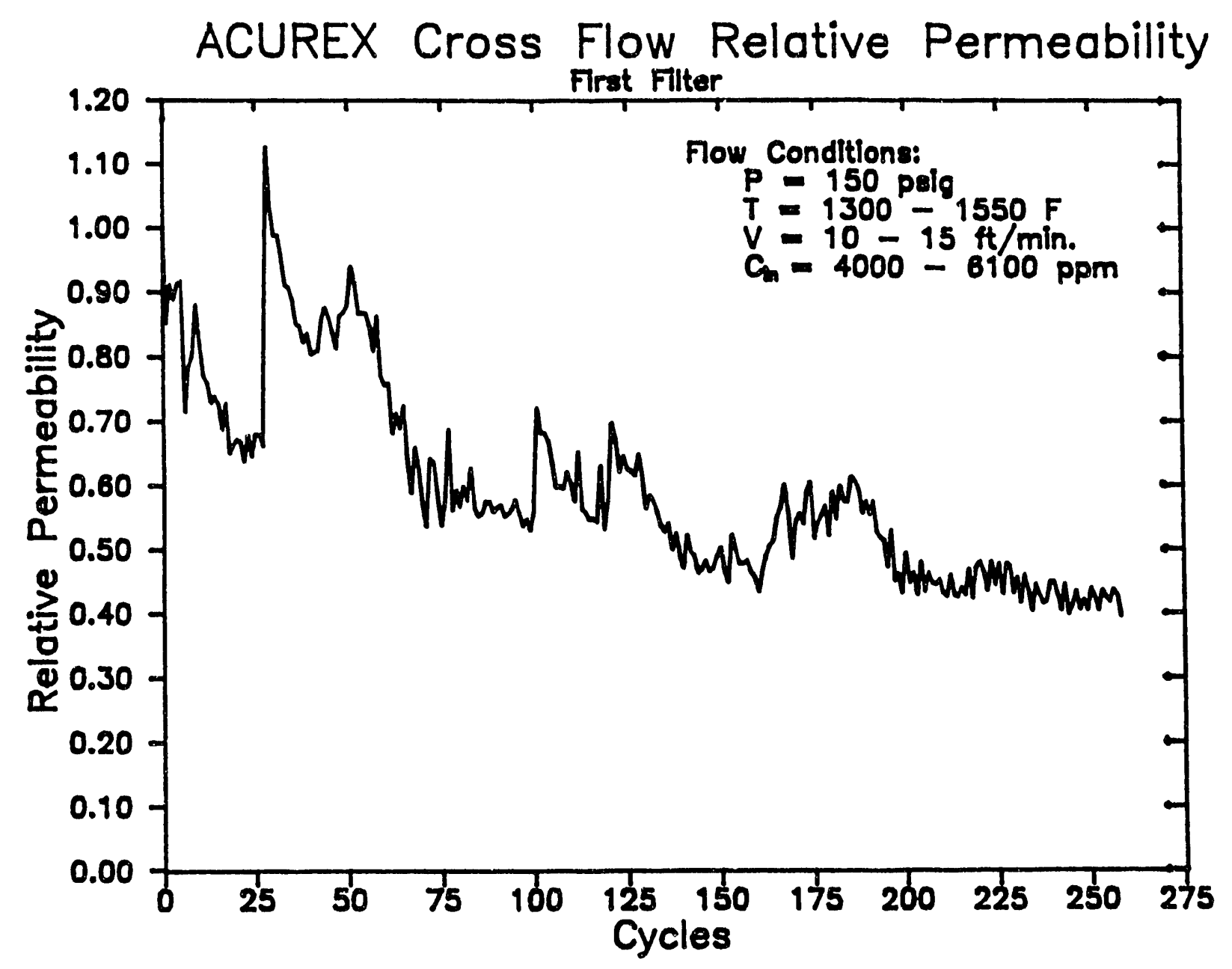

Figure 5-2. Permeability during testing for first test filter 


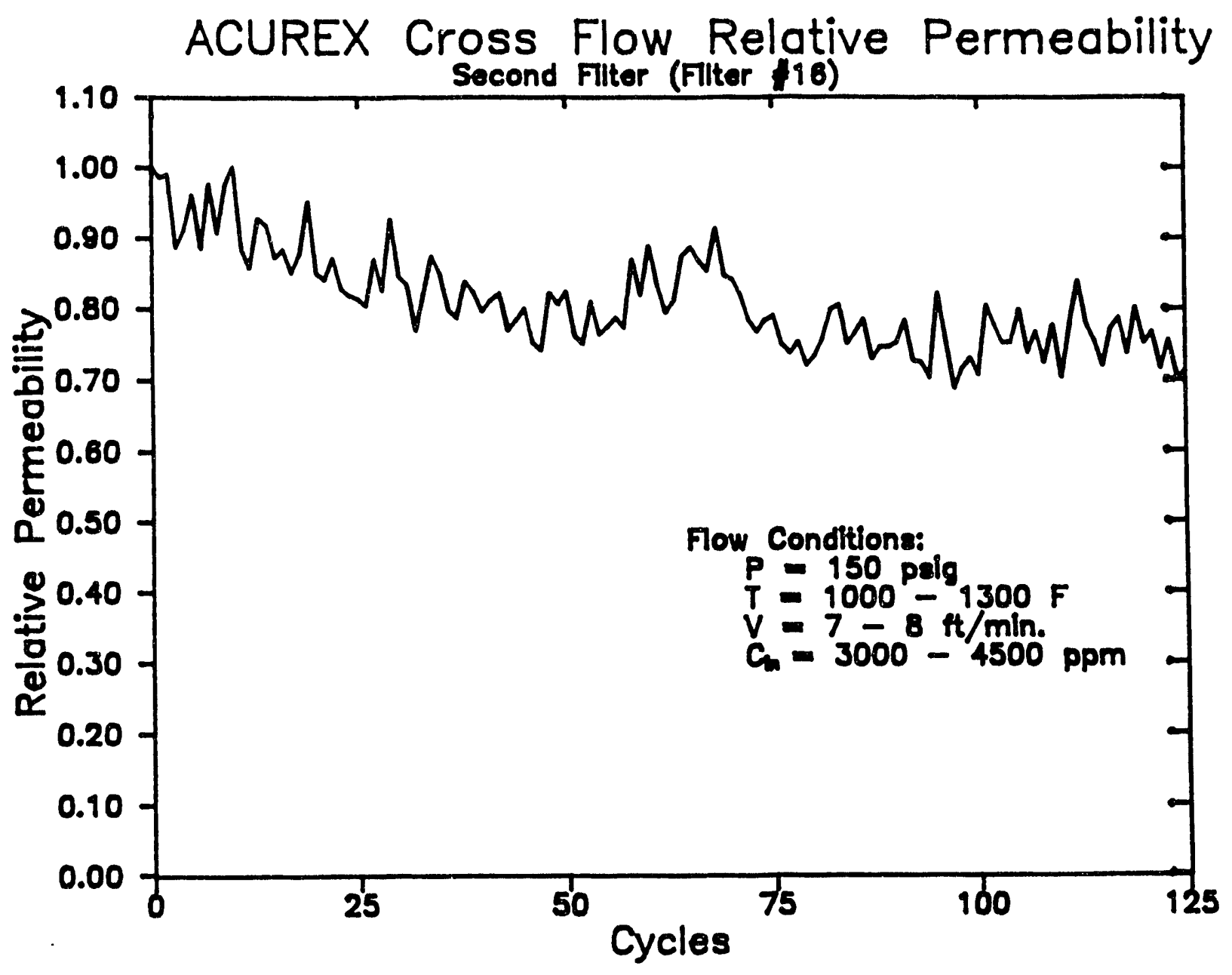

Figure 5-3. Permeability during testing for second test filter 


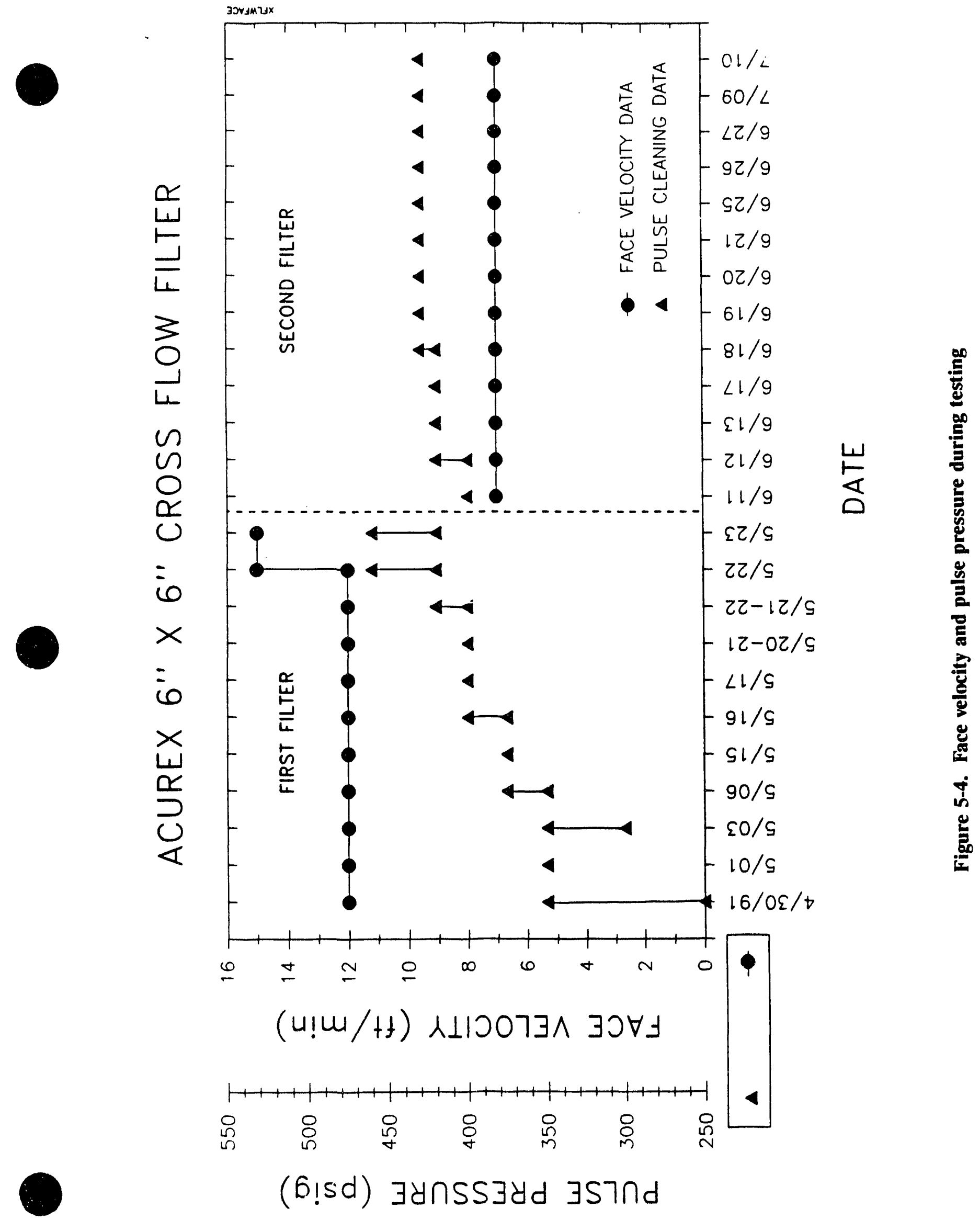


results (Appendix I) shows that the filter was operating fairly steadily with even cleaning cycles, and relatively constant clean filter pressure drop. 


\section{SECTION 6}

\section{SUMMARY OF RESULTS AND RECOMMENDATIONS}

\subsection{SUMMARY OF RESULTS}

Cordierite silicon nitride (CSN) material has been developed into material suitable to be manufactured into crossflow filters. The CSN material that is undergoing development is CSN25, or 25 percent cordierite with silicon nitride. GTE of Towanda, Pennsylvania, developed the material and manufacturing facili nd Acurex Corporation designed the crossflow filter.

\subsubsection{Material Development}

DOE established material permeability guidelines of 5 in water pressure drop for a clean filter at $10 \mathrm{ft} / \mathrm{min}$ pressure drop at standard temperature and pressure. GTE has developed a material that meets these permeability requirements. The material is 50 percent filler with the filler being 95 percent walnut shells and 5 percent wood flour. The walnut shells have been screened to 60 to 70 mesh. This material has a permeability of 1800 millidarcies at a thickness of 0.06 in.

To develop the material, GTE examined the effect of filler content on CSN25. The maximum filler content that can be extruded and fired with this material is 65 percent. If the percentage of filler is increased to over 65 percent, the green strength of the material is very low, meaning that it is too fragile to handle for sintering. However, if the filler content is less than 65 percent the material green strength is sufficient for handling.

In addition, GTE investigated the effect of filler size on permeability. The original investigations were made with filler sizes of approximately 200 mesh. The maximum permeability for this material was approximately 600 millidarcies. Also, the material had a pore size of 
approximately $40 \mu \mathrm{m}$. Examinations of mixed oxide crossflow filters have shown pore sizes of 100 to $120 \mu \mathrm{m}$. GTE therefore began to investigate increasing the pore size with the assumption that the permeability would increase.

GTE ordered filler in the 40 to 120 mesh range and screened it into two fractions: 60 to 70 mesh and 40 to 100 mesh. Material samples were made using filler of each size. The 40 to 120 mesh filler was found to be too coarse to extrude, whereas the 60 to 70 mesh material extruded without difficulty. As a result, 60 to 70 mesh filler was selected as the final filler size.

Once the filler size was determined, GTE reexamined the effect of filler content on permeability. Three samples were made at filler contents of 60 percent, 50 percent, and 40 percent, and the permeability of each was checked. The permeability of the material was about 200 millidarcies at 40 percent filler, 1800 millidarcies at 50 percent filler, and 2700 millidarcies at 60 percent filler. The target value for permeability was 1500 millidarcies. Since 50 percent filler met the target value, and since it was felt that this composition would be stronger than the 60 percent filler composition, the 50 percent filler composition material was selected as the final filter material composition.

\subsubsection{Filter Design}

The filter design was accomplished using two methods. First, a filter geometry was calculated based on the material thickness produced by GTE and allowable stresses calculated using concentrated loads. Second, this geometry was analyzed for thermal and structural stresses using a finite element analysis. Two parts of the filter were analyzed: the porous floor and rib and the backwall where the clean channel ends. The stress analysis was centered around analysis of a pulse cleaning transient.

\subsubsection{Macroscopic Design}

To design the filter, concentrated loads were assumed for the filter porous floor. Then, a floor thickness was assumed and the channel width and rib thickness were calculated based on a 
calculated allowable stress. The stress was calculated based on stress derating factors, safety factors, and the assumed tensile strength of the CSN material.

Initially, a floor thickness of 0.09 in was assumed; however, GTE was manufacturing samples thinner than this dimension. Therefore, the design was amended to assume a floor thickness of 0.06 in. However, manual stress calculations were carried out for a range of floor thicknesses to determine the effect of floor thickness on stress. It was found that bending stress was inversely proportional to the square of the floor thickness.

Once the floor thickness was set, the channel width was determined. Bending stress is inversely proportional to the square of the channel width. The channel width was set to meet the allowable stress for the 0.06 -in floor thickness.

Calculations revealed the stress in the rib to be minimal, so the rib sizing was selected to provide an integral number of channels. Channel height was selected based on the design of previous crossflow filters. Channel height inversely affects the surface height of the filter and directly affects the cleanability of the filter. Decreasing the channel height increases the filter surface area, but may make the filter difficult to clean since the dust cannot exit the dirty channels during pulse cleaning. Consequently, we examined other crossflow filters to determine the channel heights that have been previously used, and selected a midrange value.

Acurex developed a unique design for mounting the crossflow filter during this effort. Because of the difficulty experienced by manufacturers in making and attaching a mounting flange to the crossflow filter, Acurex designed a mount that does not require a flanged crossflow. (See Figure 2-35 in Section 2.4). The approach to this mount is to provide a means for factory assembly of a unit that has been preloaded into the mount. The entire mount is then shipped to the site and mounied onto the manifold. In addition, the mount material selection and design provides for a mount that has essentially zero thermal expansion over the expected operating temperature range. This approach should offer significant advantages over the shipment of unmounted crossflow filters. 


\subsubsection{Stress Analysis}

Two finite element stress analyses were completed on selected parts of the filter. The two sections of the filter are shown in Figure 2-13 in Section 2.3. The porous floor and backwall were analyzed to determine the stress due to the thermal effects of pulse cleaning.

A model was developed for caci section of the filter. The thermal part of the model was based on axial temperature distribution calculations for flow through porous media. The porous media relationship was used to calculate the temperature distribution in the porous floor during a pulse cleaning transient. The temperature distribution was then combined with the material properties to determine the thermal stresses, and the locations of maximum and minimum stress.

For the porous floor, the area of maximum stress was calculated to be the fillet radius where the porous floor meets the rib. The maximum stress in the backwall analysis occurs at the $90^{\circ}$ angle formed by the intersection of the clean channel wall and the backwall.

The maximum stress level was found to be quite sensitive to the temperature of the pulse gas and the flow of pulse gas through the porous media. Two pulse gas temperatures were investigated: $475^{\circ} \mathrm{F}$ and $1225^{\circ} \mathrm{F}$. These numbers were calculated based on assumed manifold sizes, number of filters on a manifold, pulse nozzle size, and pulse pressure. The flow of gas through the porous floor was calculated using Darcys Law. The results of the thermal stress are presented in Table 2-5 in Section 2.3.

With a pulse gas temperature of $475^{\circ} \mathrm{F}$, the stress at the fillet radius in the porous floor model for a $0.01 \mathrm{~s}$ pulse was $397 \mathrm{psi}$. As the pulse length increased to $0.5 \mathrm{~s}$, the stress increased to 3072 psi. The stress calculated by this model was compared to the stress calculated by the spatially uniform thermal model. These results are also shown in Table 2.5. The pulse temperature was increased to $1225^{\circ} \mathrm{F}$ and the stresses recalculated. The stresses were significantly reduced, as expected.

The backwall stress calculations were run only for the case where the pulse gas temperature was $1225^{\circ} \mathrm{F}$. These stresses ranged from $292 \mathrm{psi}$ with an $0.09-\mathrm{s}$ pulse to 463 psi with an $0.5-\mathrm{s}$ pulse. 


\subsubsection{Filter Manufacturing}

GTE developed a filter manufacturing technique that produces a monolithic filter. The filter is press bonded in the green state, fired to burn out the organic material, then bisque fired to give strength for handling, and sintered to full strength. In addition, the sintering process includes a step to crystallize the cordierite glass in the filter.

The first step in developing the filter manufacturing technique was production of small-scale filters for Acurex. These 2.75 -in by 2.75 -in by 1.75 -in filters were used to perfect the manufacturing technique so that GTE could scale up to the required 6-in by 6-in by 2 -in size required for testing at Westinghouse. The first step was verification of the layup procedure. Tiles of the proper shape were extruded and the filter was assembled. The unique aspect of this process was that channel formers (rods machined in the proper shape) were inserted when assembling the filter. The whole assembly was then press bonded in a mold. The rods were removed and the filter dried.

After drying the filter was sintered. With the larger filters (6-in by 6 -in by 2 -in) the filter was bisque fired after drying. Bisque firing provides some material strength so that the filter material will be durable enough for handling. The filter was sintered after bisque firing.

\subsubsection{Filter Qualification}

A series of tests were defined which would qualify the 6-in by 6-in by 2 -in filters for testing at Westinghouse. These tests are discussed in Section 4.3. A filter was thermally cycled to determine heatup and cooldown rates. The maximum rate we could produce was $400^{\circ} \mathrm{F} / \mathrm{hr}$. The filter showed no degradation from thermal ramping at this rate.

In addition, the same filter was pulse cleaned 5000 times with no evidence of cracking or delamination. The filter integrity was tested at the beginning and end of testing by bubble point analysis.

The mount designed in Task 2 was manufactured for the small filter to be tested at Acurex. A variety of tests were completed to test the mount filter system. Mount testing concentrated on 
determination of the effect of heating and cooling on the mount/filter system. Initially, the filter and mount were assembled, placed in an oven and heated to $1600^{\circ} \mathrm{F}$. There was no observed effect on the filter from the mount. Additionally, strain gages were placed on a mounted filter and unmounted filter. Both filters were heated to $1600^{\circ} \mathrm{F}$, while strain measurements were compared. There was no discernible difference in the strain measurements.

Based on these observations, we concluded that the filter was not highly susceptible to delamination from pulse cleaning, and that the mount assembly fulfilled its function of securing the filter without imparting additional strain on the filter during heatup, cooldown and operation.

\subsubsection{Filter Testing}

Almost 200 total hours of exposure including 75 total hours of dust feeding were completed separately on two crossflow filters. Examination of both filters showed that the filters dic $x t$ delaminate or crack due to operating conditions. One filter did fail as a result of trapped dust cracking a corner off the filter as the filter mount contracted during cooldown.

The filters showed high collection efficiency during steady state opration. However, testing showed that the filter gasket surface area needs to be increased as the mount gasket failed several times during testing. However, when the gasket problems were solved, the filters generally had collection efficiencies between 99.5 percent and 99.99 percent.

Filter operating characteristics were within the range of typical operation. Filter face velocity ranged from 7 to $15 \mathrm{fpm}$ and maximum pressure drop at those conditions ranged from 35 to 135 in. w.c.

The second filter was operated at $7 \mathrm{fpm}$ only, so that the steady-state operation characteristics of the filter could be determined. The filter appeared to be fairly close to conditioned at the end of testing, with the result that the permeability had dropped approximately 25 percent from unused condition.

Stable pulse pressure, cleaning cycle interval and clean filter pressure drop were obtained during testing of the second filter. At $7 \mathrm{fpm}$, the maximum pulse pressure was $430 \mathrm{psig}$, and pulse 
cleaning occurred approximately every 30 minutes. Clean filter pressure drop was approximately 20 in. w.c.

\subsection{RECOMMENDATIONS}

The results of this project show that cordierite silicon nitride is an attractive candidate material for crossflow filters. The design of the crossflow filter was changed to reflect some of the continuing problems which plague other crossflow filter materials, primarily flange breakage and delamination, and to take advantage of CSN's material properties.

Corrosion resistance of the CSN material is yet to be determined. However, since material strength for the CSN material is approximately twice that of other crossflow filter materials, it may be better able to withstand the effects of corrosion than other materials.

Even though, the developed material looks promising for this application, the real accomplishment of this project was development of the press-bonding manufacturing technique. All testing indicates that this technique produces a monolithic ceramic upon sintering. In addition, this technique is applicable to other materials.

Based on the information developed during this project, the following conclusions can be drawn.

\subsubsection{Conclusions}

The conclusions are separated into three areas:

- Filter design

- Filter manufacturing

- Filter testing

\subsubsection{Filter Design}

1. A crossflow filter design has been developed which meets the requirements established by the DOE for size and surface area. The design is focused on minimizing the thermal and mechanical stresses to which the filter is subject. 
2. The filter design incorporates a flangeless mounting system since stress analyses have shown that the flange area is subject to the highest stresses. Because of the flangeless filter design, a new filter mount design was developed. With this design, the differing thermal expansion properties of material are used to produce a filter mount whose mounting faces expand at the same rate as the filter material.

3. Stress analysis of the filter design showed that the calculated stresses are highly sensitive to the inputs, particularly pulse gas temperature and flow velocity of gas through the filter wall.

4. During filter testing, continued problems with gasket failure indicated that the filter gasket surface was not of sufficient size.

\subsubsection{Filter Manufacturing}

1. The sintered material has high permeability ( $>1200$ millidarcies), and high strength ( $\approx$ $5300 \mathrm{psi})$.

2. The press-bonding manufacturing technique produces a monolithic material upon sintering.

3. Sintering causes approximately 15 percent material shrinkage. Therefore, care must be taken during the sintering process to account for the shrinkage. This is accomplished through the use of shrink plates and setting powders.

4. One problem with the press-bonding technique as currently practiced is that the surface permeability of the material is closed off during the pressing operation.

\subsubsection{Filter Testing}

1. Testing at Acurex showed that the CSN crossflow withstood pulse cleaning five thousand times at operating temperature $\left(1600^{\circ} \mathrm{F}\right)$ without failure or delamination.

2. Water overpressure testing at GTE showed that the filters withstood pressure greater than three times that experienced during normal operation without failure. 
3. Strain gage testing at Acurex showed that the mount did not create any thermal expansion mismatch stresses in the crossflow filter material.

4. During testing at the Westinghouse Science and Technology Center, the filter performed quite well, with collection efficiencies as high as 99.99 percent during normal operation.

5. The filters successfully completed testing at the Westinghouse Science and Technology Center without delamination.

6. The first filter tested at Westinghouse failed when one of the mounting corners of the filter broke during cooldown of the test facility. The conclusion was reached that the corner was broken off by dust trapped between the mount and the filter as the mount contracted during cooldown.

7. During testing, several gasket failures occurred, which was attributed to the small mounting filter mounting surface.

8. During testing the filter pressure drop could be controlled and cycle time was fairly constant.

9. During normal operation, filter outlet concentrations varied from $0.65 \mathrm{ppm}$ to $7.5 \mathrm{ppm}$. Higher outlet dust loadings were generally attributed to gasket failure or sampling system failure.

\subsubsection{Recommendations}

This project has allowed a significant portion of the development of this product to a commercial filter. The material and manufacturing technique have shown a great deal of promise. However, the filter design and manufacturing technique must be refined to permit ease of manufacture and to improve filter operability.

Based on the examination of the conclusions, the following recommendations can be made:

1. The CSN filter has shown significant promise both from a material and manufacturing standpoint. Further development is warranted. 
2. Changes need to be incorporated into the filter design to increase the filter/ mount interface surface area. This would alleviate gasket failure problems experienced at Westinghouse. Also, increasing dirty channel dimensions may reduce the cleaning energy requirement.

3. Changes to the press-bonding technique need to be incorporated so that the reduction of filter permeability is minimized.

4. Other techniques of material sintering (microwave sintering, etc.) need to be investigated. These approaches may reduce material shrinkage during sintering, and therefore simplify the sintering process.

5. Better definition of the thermal stress model input parameters is needed. Significant emphasis is placed on the thermal model results, however, the input parameters (pulse gas temperature, in-filter pressure, gas velocity through the filter) are ill-defined, but have a significant effect on the stress analysis results.

6. After design and manufacturing are refined, scale-up of the filter to full-size, with demonstration testing of the full-scale filter is warranted. 


\section{REFERENCES}

1. Sawyer, J. W., "Assessment of the Causes of Failure of Ceramic Filters for Hot-Gas Cleanup in Fossil Energy Systems and Determination of Materials Research and Development Needs," ONRL/Sub/86-57964/01, Acurex Final Report, Acurex Corporation, Mountain View, California, for Oak Ridge National Laboratory, Oak Ridge, Tennessee, January 1989.

2. "High-Temperature High-Pressure Gas Cleanup with Ceramic Bag Filters," DOE DE-AC0180ET17092, Acurex Corporation, Mountain View, California, December 1982.

3. "Economic Studies of Coal Gasification Combined-Cycle Systems for Electric Power Generation," EPRI AF-642, Fluor Engineers, Inc., January 1978.

4. "Cost and Performance of Kellog Rust Westinghouse-Based Gasification-Combined-Cycle Plants," EPRI AP-4018, Fluor Engineers, Inc., June 1985.

5. "Economic Assessment Cost of the Impact of Plant Size on Coal Gasification-CombinedCycle Plants," EPRI AP-3084, Fluor Engineers, Inc., May 1983.

6. Roberts, P. B., "Solar's Advancec' Coal-Fired Industrial Cogeneration Gas Turbine System-A Status Report," Solar Turbine, Inc., July 1988.

7. Cleveland, J., "CSN Filter Material Properties," Memorandum, GTE Products Corporation, Towanda, Pennsylvania, 1989.

8. "A Mechanical Analysis of a Ceramic Cross Flow Filter," Internal Report, Westinghouse Electric Corporation, Contract DE-AC21-86MC23252, October 1987 through April 1988.

9. Peterson, R. E., "Stress Concentration Factors," Wiley \& Sons, 1974.

10. Jorgensen, Robert, Ed., "Fan Engineering," Seventh Edition, Buffalo Forge Company, Buffalo, New York, 1970.

11. Tassicker, O., "Thermal Cycling Effects in the Pulse Manifolds and Ceramic," Grimethorpe PFBC Gas Filter Project, Technology Transfer Workshop, Palo Alto, California, May 1988.

12. DeSalvo, G. J., and R. W. Gorman, "ANSYS Engineering Analysis System User's Manual," Swanson Analysis Systems, Inc., Houston, Pennsylvania, June 1, 1987.

13. SINDA85/FLUINT, Systems Improved Numerical Differencing Analyzer and Fluid Integrator, User's Manual, Version 2.2," Cosmic Program No. MSC-21528. 


\begin{abstract}
APPENDIX A
DOE PERFORMANCE AND DESIGN GUIDELINES AND RECOMMENDATIONS FOR CROSSFLOW FILTERS
\end{abstract}


The proposed silicon nitride cross-flow filter will be able to perform as follows:

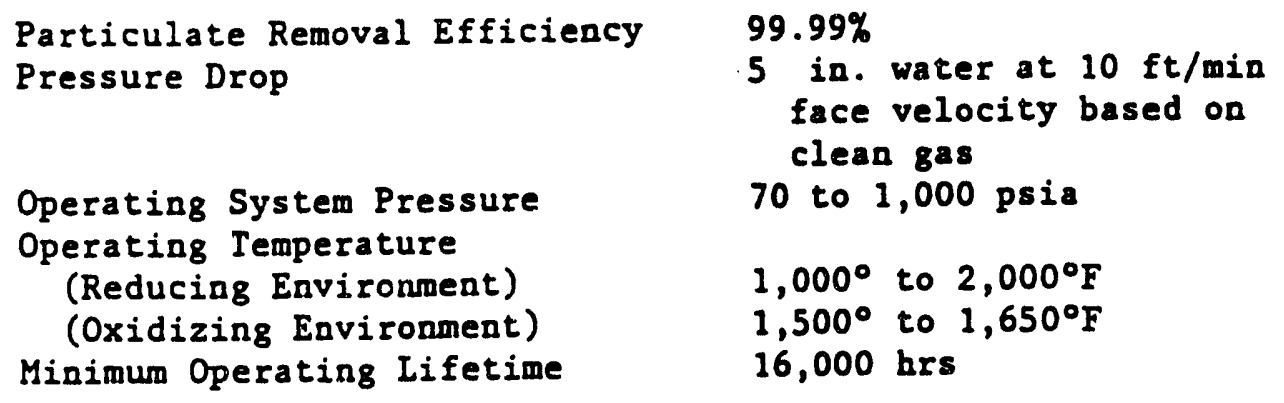

Element Height $(H)$ Element Width $(W)$ Element Length (I) Flange Width (FW) Flange Length (FI) Flange Thickness (FT) Minimum Surface Area

6 inches
2 inches
6 inches
3 inches $(W+1$ inch $)$
7 inches $(L+1$ inch $)$
0.5 inches
1.25 square feet

12 inches

4 inches

12 inches

5 inches $(W+1$ inch)

13 inches ( $L+1$ inch)

0.5 inches

10 square feet 


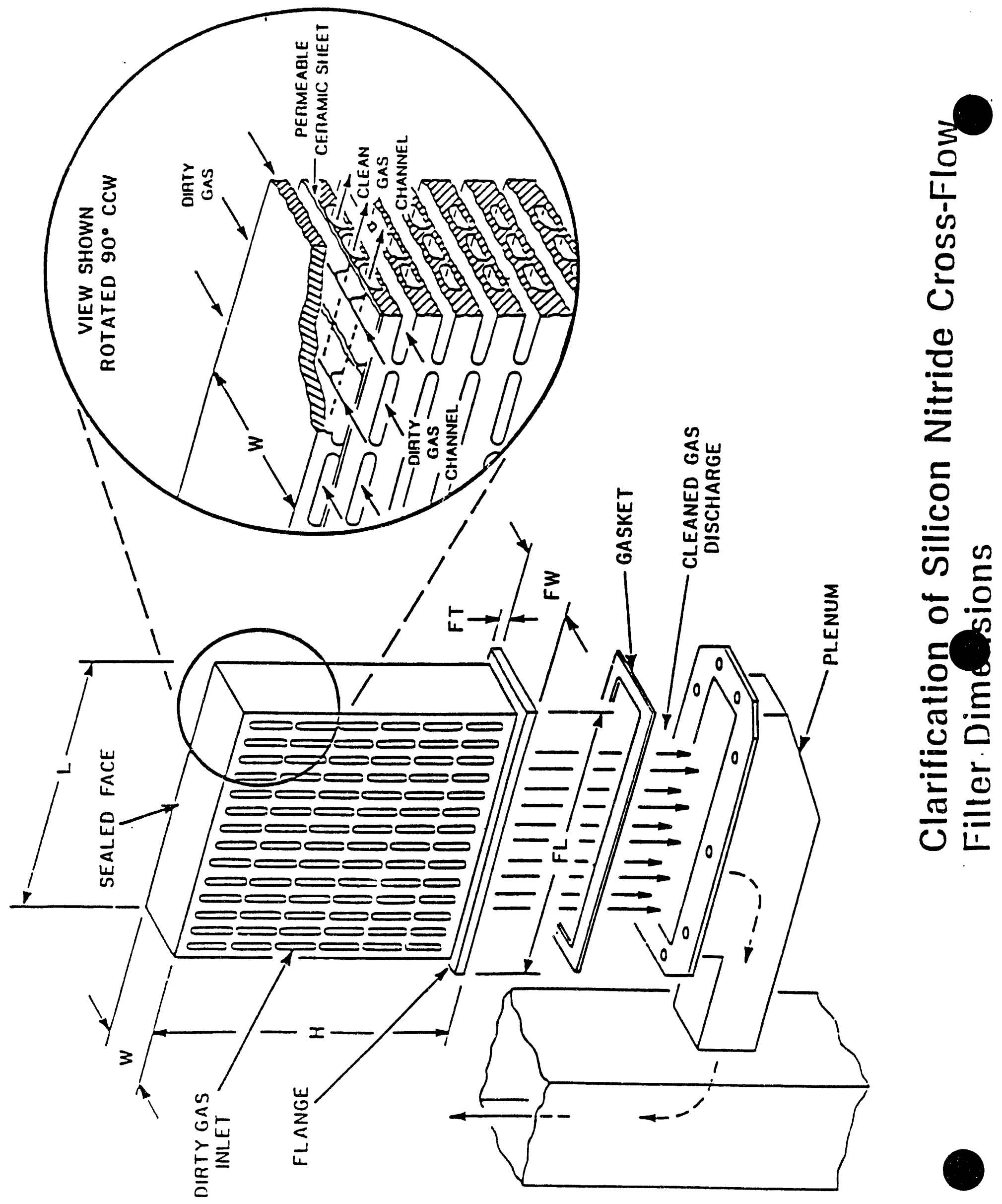


GENERAL PARAMETERS FOR ALUMINA OXIDE CROSS-FLOW FILTERS

\section{Cross-Flow Filter Element Dimensions}

The primary consideration in determining the overall filter element dimensions is the maximization of actual filtration area per element. This minimizes the number of individual filter elements to be mounted inside a pressure vessel. This maximization of actual filtration area per element reduces total system cost, increases the compact nature of the installation, and minimizes the chance for sealing leaks. Offsetting these considerations is the fact that the filter is cleaned by a pulse jet, which will probably limit the total size of the filter element since the amount of pulse cleaning gas is currently limited by valve technology. An additional consideration in the total size of the filter element is the fact that dust collected in the filter channels must be easily blown out of the channels during the pulse cleaning. This limits the aspect ratio of the filter channel opening to the channel length in the proper proportion that the accumulated dust can easily escape out the filter channel opening.

Mounting and sealing the filter element has to date required a ceramic flange. This flange must have sufficient strength to withstand clamping forces as well forces caused by the pulse cleaning described in the Mechanical Stability section. The mounting and clamping forces are difficult to define; thus, a general flange thickness is specified. The flange must not be connected to the main filter element body using a sharp corner, instead, a gradually curved surface is required to minimize stress gradients. The following overall cross-flow filter element dimensions are given for a half-scale filter and a full-scale filter. It should be particularly noted though that the filter dimensions and channel dimensions are not optimized values. This is the reason for greater than ( $>$ ) and less than (<) signs. Obviously, filter area per element would increase as filter size increases; however, it is not known at this time whether larger size filters are practical. Additionally, by reducing the channel heights, more filter surface can be put into the same height filter element with the drawback that the smaller channel openings could hinder the removal of dust from the interior of the channel during the pulse cleaning.

\begin{tabular}{lll}
\hline & Half-Scale Filter & Full-Scale Filter \\
\hline & $>=6$ inches & $>=12$ inches \\
Element Height (H) & $>=2$ inches & $>=4$ inches \\
Element Width (W) & $>=6$ inches & $>=12$ inches \\
Element Length (L) & 3 inches $(W+1$ inch) & 5 inches $(W+1$ inch) \\
Flange Width (FW) & 7 inches $(L+1$ inch) & 13 inches $(L+1$ inch) \\
Flange Length (FL) & $>0.5$ inches & $>0.5$ inches \\
Flange Thickness (FT) & 1.25 square feet & 10 square feet \\
Minimuin Surface Area & &
\end{tabular}


Channel Dimensions

The channel sizes in general should be as wide and long as possible, with the shortest possible height dimension to maximize the amount of actual filtering surface. However, as discussed above the dirty side channels must be large enough for easy exiting of the collected dust cake during pulse cleaning. Additionally, the inside clean side channels must be large enough to keep the flow-related pressure drop of the cleaned gas during the filtering cycle relatively small when compared to the pressure drop through the filter media. The clean side channel also must not hinder backflow of gas during the pulse cleaning cycle. The spacing of the ribs that compose each channel's wall must be sufficient to provide enough structural strength for the filter element and to withstand the force caused by the filtration and cleaning cycles across the ce:amic filter surface. There is no appreciable difference between the channel dimensions of half-scale and full-scale filters; thus, the following nonoptimized channel dimensions have been incorporated in previous cross-flow filters. It should be noted that these two parameters are variable, and dramatically affect several other parameters such as cleanability and total surface area; thus, the specifications below should be considered only as general guidance.

$\begin{array}{ll}\text { Channel Width }(\mathrm{CW}) & >=0.375 \text { inches } \\ \text { Channel Height }(\mathrm{CH}) & <=0.25 \text { inches }\end{array}$

\section{Backwall Properties}

The filter backwall is defined as the porous section of each filter plate that separates the dirty side of the filter from the clean side. The backwall is the active filter area of each backwall section through which the hot gas must pass. The active filter area is defined as the filtering surface that is not resting on or beneath any of the support ribs, as it is assumed that no gas passes through the area where a rib is connected to the filter backwall. To keep pressure drop low, the active filter area of the filter backwall should be as thin as possible yet still retain enough strength to prevent failures due to pressure and thermal forces.

Pore size and porosity should be as large as possible to minimize pressure drop; however, material strength and dust penetration are offsetting conside:ations. Dorosity can be measured by simple dry versus saturated weight measi:ements. Oore size can be estimated by measuring the air pressure requirec to initiate bubble formation in a submerged section of the porous media. Generally, different combinations of thickness, porosity, and pore size that give clean pressure drops of less than 5 inches $H_{g}$ at a face velocity of 10 feet per minute are appropriate. Face velocity is defined as the actual cubic teet of gas per minute passing through the filter divided by that total amount of active filter area expressed in cubic feet. 


\author{
Backwall Thickness (BT) \\ Backwall Porosity (BP) \\ Backwall Pore Diameter (PD) \\ Clean Pressure Drop \\ $0.03<\mathrm{BT}<0.10$ inches
$45 \%<\mathrm{BP}<55 \%$ porosity
$<=100$ microns
$<=5$ inches $\mathrm{H}_{2} \mathrm{O}$ at $10 \mathrm{ft} / \mathrm{min}$
}

Chemical and Mechanical Stability

The cross-flow filter is intended for use in a wide range of advanced coal conversion technologies and, therefore, must be able to withstand a wide range of harsh thermal and chemical environments. In general the applications can be divided into oxidizing and reducing environments. The pressurized fluidizedbed combustion condition shown in Append2x B is typical of oxidizing condi$t$ ions. The gasification conditions shown in Appendix B is typical of reducing conditions. In addition to bring resistant to the hot, high-temperature gases that necessarily pass through the filter, the filter material wust also be resistant to contact with the solid particulate matter being filtered. This particulate matter ranges between 100 to 10,000 ppm concentration expressed as weight of particulate per unit weight of gas fllow. Typical components in the particulate are:

$$
\begin{array}{ll}
\text { Oxidizing Applications } & 3 \mathrm{Al}_{2} \mathrm{O}_{3} * 2 \mathrm{SiO}_{2}, \mathrm{CaSO}_{4}, \mathrm{CaO}, \mathrm{Fe}_{2} \mathrm{O}_{3}, \mathrm{NaSO}_{4} \\
\text { Reducing Applications } & \mathrm{C}, \mathrm{SiO}_{2}, \mathrm{FeS}, \mathrm{CaS}, \mathrm{Na}, \mathrm{NaCl}, \mathrm{NaCO}, \mathrm{NaS}, \\
& \mathrm{CaO}_{2} \mathrm{Al}_{2} \mathrm{O}_{3} \neq 2 \mathrm{SiO}_{2}
\end{array}
$$

Mechanical stability of the cross-flow filter requires that the filter element be able to tolerate the mounting and clamping forces required to seat and seal the filter as well as being able to withstand the internal pressurization required for pulse jet cleaning. During pulse jet cleaning, internal pressures of up to 10 psi will be generated. This internal force will tend to cause the filter elemen: to delaminate; thus, the filter backwall media must be capable of surviving the stresses induced by this degree of internal pressurization. An important point that must not be overlooked in the pulse cleaning is the temperature differential between the pulse cleaning gas and the filter's operating remperature. Currently, there is no satisfactory method of producing a pulse gas temperature much greater than $300^{\circ} \mathrm{F}$; principally, because of valve technology. Therefore, the mass flow of relatively cold pulse gas will cause a rapid temperature drop in a filter that is operating in a $1,200^{\circ}$ to $1,800^{\circ} \mathrm{F}$ system. The mechanical stability requires that the filter withstand these magnitudes of thermal stresses:

Internal Pressure Rise

Cleaning Pulse Duration

Cleaning Gas Temperature
10 psi

$0.1 \mathrm{sec}<t<1.0 \mathrm{sec}$

$300^{\circ} \mathrm{F}<\mathrm{T}<900^{\circ} \mathrm{F}$ 


\section{APPENDIX B \\ CSN TECHNICAL REPORT \\ THERMAL MODEL APPROACH FOR CROSSFLOW FILTER}

Two 2-dimensional thermal models were developed under the Preliminary Filter Design task: one to analyze the porous floor, and one to analyze the backwall of the clean channel. These models were used to analyze thermal stresses that occur within the filter during pulse cleaning. The approach for model development is discussed below.

\section{B.1 GEOMETRY SELECTION}

The simplest symmetrical geometry was chosen for each model. Wherever possible, symmetrical boundaries within the filter walls were identified. For example, boundaries were drawn at half the rib height and half the rib thickness. However, each geometry contained the entire thickness of the floor of a filter element. The temperature in the floor is expected to vary with the thickness of the floor since flow is unidirectional. Furthermore, for the 2-dimensional backwall model, the entire backwall was incorporated into the geometry since the temperature in the backwall is expected to vary with the thickness.

\section{B2 THERMAL MODEL EQUATION}

The unsteady-state equation for the conduction of heat was the basis for these thermal models. This equation is shown in Figure B-1. Conduction was the dominant mechanism of heat transfer in this analysis. Convection was also included at wall boundaries and within the filter floor. For heat transfer within the filter floor, effective conductivities were developed to account for axial dispersion within the floor. Axial dispersion is significant in thin porous structures (50 to $100 \mu \mathrm{m}$ ) less than 0.2 inches thick (Reference B-1). Radiation was considered an insignificant mechanism of heat transfer for the crossflow filter. 


$$
\begin{aligned}
& \epsilon_{\mathrm{f}} \mathrm{C}_{\rho} \frac{\partial \mathrm{T}}{\partial \theta}=\frac{\partial}{\partial \mathrm{x}}\left(\mathrm{K}_{\mathrm{x}} \frac{\partial \mathrm{T}}{\partial \mathrm{x}}\right)+\frac{\partial}{\partial \mathrm{y}}\left(\mathrm{K}_{\mathrm{y}} \frac{\partial \mathrm{T}}{\partial \mathrm{y}}\right)+\frac{\partial}{\partial z} \mathrm{~K}_{\mathrm{z}} \frac{\partial \mathrm{T}}{\partial \mathrm{z}} \\
& \text { Parameters: } \quad \epsilon_{\mathrm{f}}=\text { Density of filter } \\
& C_{\rho}=\text { Heat capacity, filter } \\
& \mathrm{K}_{x}, \mathrm{~K}_{\mathrm{y}}, \mathrm{K}_{\mathrm{z}}=\text { Directional thermal conductivities, filter } \\
& \mathrm{T}=\text { Temperature } \\
& x, y, z=\text { Dimensions } \\
& \theta=\text { Time }
\end{aligned}
$$

Figure B-1. Unsteady-state equation for heat conduction

\section{B.3 INITIAL CONDITION}

At time zero, the filter was presumed to have a uniform temperature of $1600^{\circ} \mathrm{F}$.

\section{B.4 BOUNDARY CONDITIONS}

Three types of boundary conditions were used in this analysis: zero flux boundaries, a convective wall flux correlation, and an axial dispersion analysis. For symmetrical boundaries within the filter, the heat flux across these boundaries is zero. No driving force for heat transfer exists in either direction across the boundary.

Wall face boundaries were described with a heat convection equation. The heat transfer coefficient for this equation was determined from Leva's correlation for fixed-beds during cooling (Reference B-2). Both equations are presented in Figure B-2.

Filter floor boundaries were also described with a heat conduction equation. The heat transfer coefficient was determined from Leva's correlation for fixed beds (see Figure B-2). Effective thermal conductivities were developed to account for axial dispersion within the porous filter floor (Reference B-2). Effective thermal conductivities are arithmetic sums of the thermal conductivity of the void space and the solid filter. 
Boundary condition:

$$
-K_{x} \frac{\partial T}{\partial X}=h_{w}\left(T_{w}-T_{b}\right)
$$

$$
\text { For } \begin{aligned}
h_{w} & =\text { Wall heat transfer coefficient } \\
T_{w} & =\text { Wall temperature } \\
T_{b} & =\text { Bulk gas temperature }
\end{aligned}
$$

Leva's correlation for $h_{w}$ :

$$
\frac{h_{w} d}{K}=3.50\left(\frac{d_{p} G}{\mu}\right)^{0.7} \in-4.6 \frac{d_{p}}{d}
$$

$$
\text { For } \begin{aligned}
d & =\text { Diameter of floor (or equivalent) } \\
d_{p} & =\text { Particle diameter of filter } \\
G & =\text { Mass velocity of gas } \\
\mu & =\text { Viscosity of gas }
\end{aligned}
$$

Figure B-2. Boundary conditions for wall faces 


\section{REFERENCES}

\section{APPENDIX B}

B-1. Carberry and Wendel, "A Computer Model of the Fixed-Bed Catalytic Reactor: the Adiabatic and Quasi-Adiabatic Cases," AIChE Journal, Vol. 9, No. 1, p. 129, January 1963.

B-2. Smith, J. M., "Chemical Engineering Kinetics," 2nd. ed., McGraw Hill, p. 512, 1970. 
APPENDIX C

CORRESPONDENCE BETWEEN MESH SIZE AND PHYSICAL SIZE

$\begin{array}{lll}\text { Mesh } & \text { Micron } & \text { Inches } \\ 325 & 45 & 0.0017 \\ 270 & 53 & 0.0021 \\ 230 & 63 & 0.0025 \\ 200 & 75 & 0.0029 \\ 170 & 90 & 0.0035 \\ 140 & 106 & 0.0041 \\ 120 & 125 & 0.0049 \\ 100 & 150 & 0.0059 \\ 80 & 180 & 0.0070 \\ 70 & 212 & 0.0083 \\ 60 & 250 & 0.0098 \\ 50 & 300 & 0.0117 \\ 45 & 355 & 0.0138 \\ 40 & 425 & 0.0165 \\ 35 & 500 & 0.0197 \\ 30 & 600 & 0.0234 \\ 25 & 710 & 0.0278 \\ 20 & 850 & 0.0331\end{array}$

C-1 


\section{APPENDIX D \\ PERMEABILITY MEASUREMENT}

Permeability is that property of a potential filter material determined by the flow rate of a fluid (typically air) through a specified area of known thickness at some pressure drop. Also, a highly permeable material may be a poor filter if the pore size is too large, thus some measure of maximum pore diameter is also required to determine the suitability of a material as a filter. Figure D-1 shows the device used to measure the permeability of test samples. Air enters at the inlet, flowing through the portion of the sample not covered by the gaskets, to the outlet. The gaskets are very soft, typically with a Shore A Durometer of 5 to 10. The high-pressure side (inlet), typically 20 to 30 inches of water (in WC) and the low-pressure side (outlet), typically 0.2 to 1.0 in WC, are each connected to manometers. The outlet side is also connected to a flowmeter. The "O"-ring prevents edge flow. By using the inlet and outlet pressures, the air flow rate, the sample thickness, and the masked area, the permeability can be calculated. A discussion and sample calculation of the Darcy unit of permeability are presented in this appendix. The same device is used to measure the largest pore diameter by measuring the pressure required to produce the first air bubble through a water-saturated sample. The outlet is positioned to face upward and is filled with water. A manometer and flowmeter are not connected to the outlet for this test. The pressure at the inlet is slowly increased until the first bubble appears at the outlet. This pressure is used to calculate the largest pore diameter (ASTM E128). 


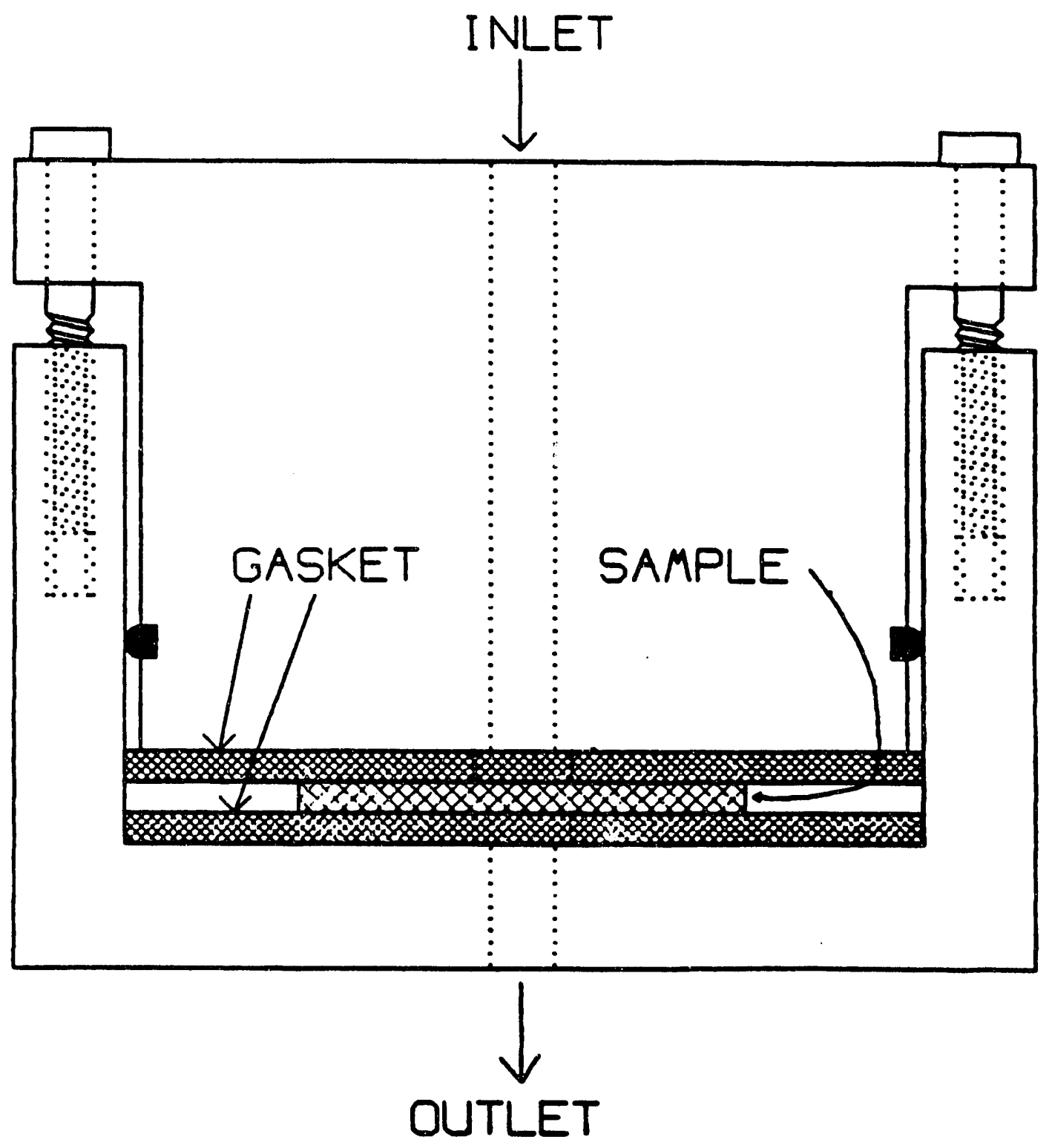

Figure D-1. Device used to measure the permeability of test samples D-2 
The formula for permeability in Darcy is:

$$
K=\frac{\mathbf{u} \mathbf{Q} \mathbf{L}}{A\left(P_{\text {in }}-P_{\text {out }}\right)}
$$

where

$$
\begin{aligned}
& \mathbf{K}=\text { permeability in Darcy } \\
& \mathbf{u}=\text { viscosity of fluid in centipoise } \\
& \mathbf{Q}=\text { volume flow rate in mi/sec } \\
& \mathbf{L}=\text { length or thickness of sample in } \mathrm{cm}^{2} \\
& \mathbf{A}=\text { cross-sectional area of sample in } \mathrm{cm}^{2} \\
& \mathbf{P}_{\mathbf{1 n}}=\text { inlet pressure in atmosphere } \\
& \mathbf{P}_{\text {out }}=\text { outlet pressure in atmosphere }
\end{aligned}
$$

Also

$$
Q=Q 1 \frac{P}{\frac{P_{\text {In }}+P_{\text {out }}}{2}}
$$

where

$$
\begin{aligned}
& \mathbf{Q 1}=\text { actual flow rate at } P, \mathrm{ml} / \mathrm{sec} \\
& \mathbf{P}=\text { pressure at which } Q 1 \text { is measured, atmosphere }
\end{aligned}
$$

Substituting (2) in (1) gives:

$$
K=\frac{2 u Q 1 P L}{A\left(P_{\text {in }}^{2} \cdot P_{\text {out }}^{2}\right)}
$$

Units of the Darcy are:

$$
\text { cp } \mathrm{cm}^{3} \mathrm{sec}^{-1} \text { atm } \mathrm{cm} \mathrm{cm}^{-2} \mathrm{~atm}^{-2}
$$

Since

$$
\mathrm{cp}=0.01 \mathrm{gm} \mathrm{cm}^{-1} \mathrm{sec}^{-1}
$$

and

$$
\text { atm }=1.013 \times 10^{6} \mathrm{gm} \mathrm{cm}^{-1} \mathrm{sec}^{-2}
$$


Then $\quad \frac{\mathrm{cp} \mathrm{cm}}{2}=9.869 \times 10^{-9} \mathrm{~cm}^{2}$

Example: Calculate the permeability for the following conditions -

$$
\begin{aligned}
& \mathrm{u}=0.0178 \mathrm{cp} \\
& \mathrm{Q} 1=15.167 \mathrm{ml} / \mathrm{sec} \\
& \mathrm{L}=0.106 \mathrm{~cm} \\
& \mathrm{~A}=0.5987 \mathrm{~cm} \\
& \mathrm{P}=1 \mathrm{~atm} \\
& \mathrm{P}_{\text {out }}=1.049 \mathrm{~atm} \\
& \mathrm{P}_{\mathrm{in}}=1.001 \mathrm{~atm}
\end{aligned}
$$

Substituting in (3) gives

$$
\begin{aligned}
& K=\frac{(2)(.0178 \mathrm{cp})(15.167 \mathrm{ml} / \mathrm{sec})(1 \mathrm{~atm})(.106 \mathrm{~cm})}{\left(.5987 \mathrm{~cm}^{2}\right)\left[(1.049 \mathrm{~atm})^{2}-(1.001 \mathrm{~atm})^{2}\right]} \\
& K=0.972 \text { Darcy }=972 \mathrm{mDarcy}
\end{aligned}
$$




\section{APPENDIX E}

MODULUS OF RUPTURE DATA

E-1 


\section{Modulus of Rupture Test}

\section{CSN -25}

\begin{tabular}{|c|c|c|c|c|c|c|}
\hline Number & Di. & D & $\begin{array}{l}\text { sions } \\
\text { hes }\end{array}$ & $\begin{array}{c}\text { Area } \\
\text { sq. In. }\end{array}$ & $\begin{array}{l}\text { Load } \\
\text { Founds }\end{array}$ & $\begin{array}{l}\text { MOR } \\
\text { PSI }\end{array}$ \\
\hline $\begin{array}{l}1 \\
2 \\
3 \\
4 \\
5\end{array}$ & $\begin{array}{l}.193125 \\
.192891 \\
.192500 \\
.192969 \\
.193203\end{array}$ & $\begin{array}{l}x \\
x \\
x \\
x \\
x\end{array}$ & $\begin{array}{r}143203 \\
.141211 \\
.141772 \\
.146172 \\
.143086\end{array}$ & $\begin{array}{l}.028 \\
.027 \\
.027 \\
.028 \\
.028\end{array}$ & $\begin{array}{l}23.4 \\
28.3 \\
30.3 \\
32.7 \\
26.3\end{array}$ & $\begin{array}{l}4431.33 \\
5518.23 \\
5871.38 \\
5939.23 \\
4986.65\end{array}$ \\
\hline & Mean & & 5349. & & & \\
\hline
\end{tabular}




\section{APPENDIX F}

MEASURING SHEAR AND YOUNG'S MODULUS AND POISSON'S RATIO 


\section{Experimental Procedure:}

A small notch was cut at each corner of the specimen as illustrated in figure 1 . The specimens were suspended in a furnace via sapphire rods (20 mil) which were beaded at the ends. The sapphire was used as both the driver and signal pickup. After the first measurement at room temperature, the furnace was ramped at $20^{\circ} \mathrm{C} / \mathrm{min}$ to each test temperature $\left(200,400,600,800\right.$, and $\left.1000^{\circ} \mathrm{C}\right)$ with a five minute dwell. Data was collected at each temperature at the end of the soak. Three samples were tested. A fourth sample was provided, however, one corner broke off when the notch was being cut and so was not tested. 


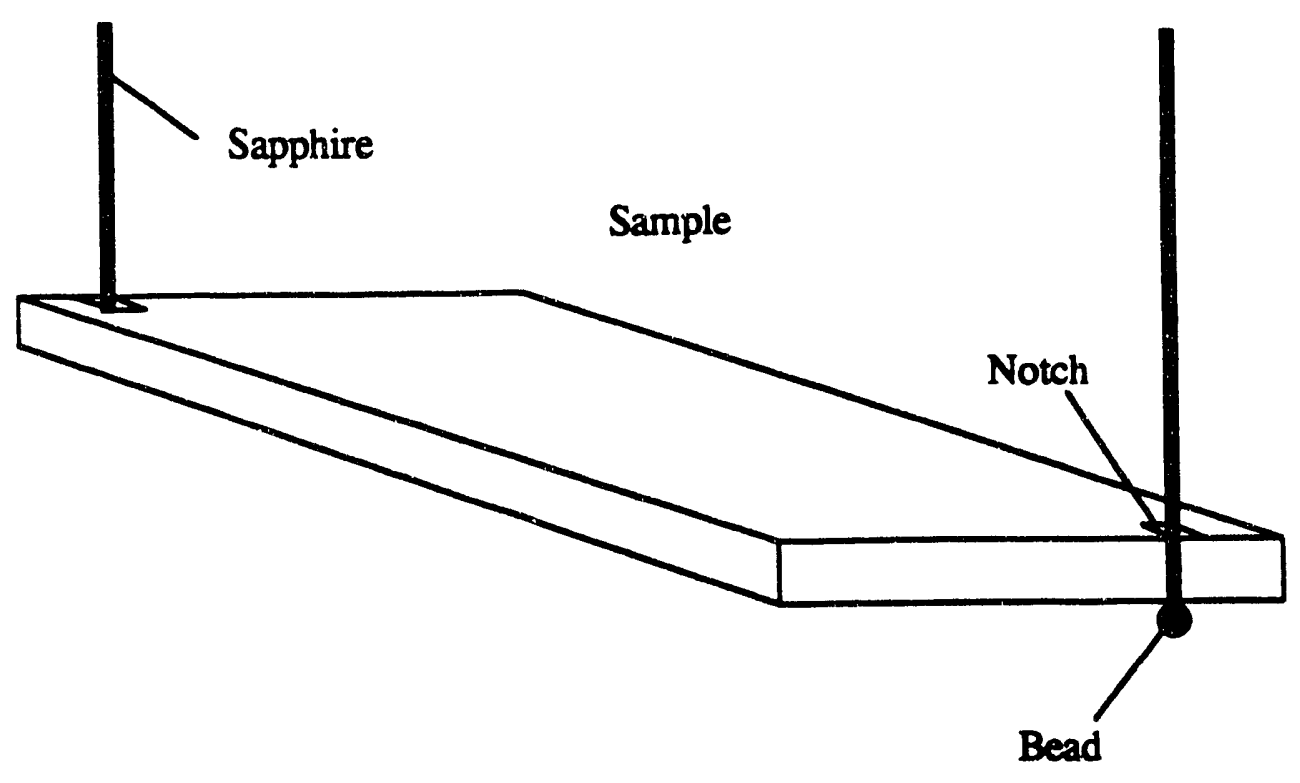

Figure 1: Schematic of Technique for Measuring Moduli 

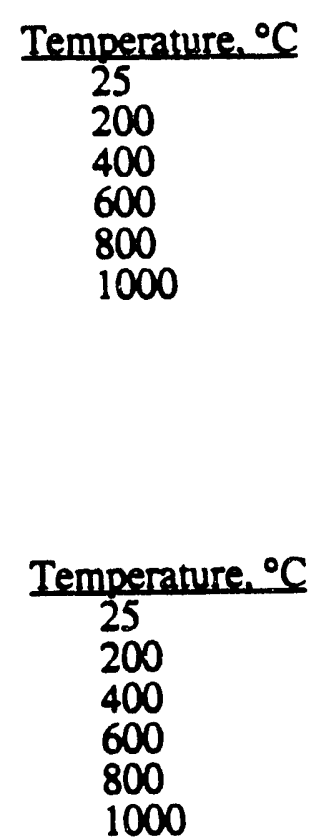
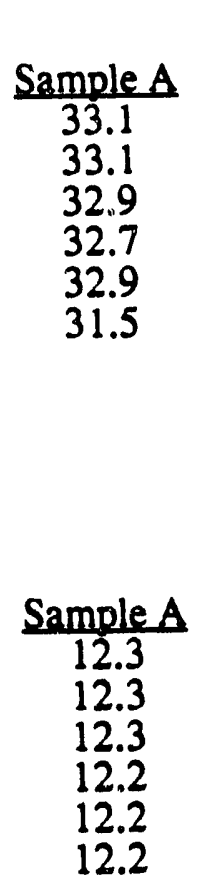

\begin{tabular}{c} 
Sample A \\
\hline .35 \\
.35 \\
.35 \\
.34 \\
.35 \\
.29
\end{tabular}

\begin{tabular}{cc}
$\begin{array}{c}\text { Young's Modulus, GPa } \\
\text { Sample B }\end{array}$ & Sample C \\
\hline 30.1 & 31.8 \\
30.1 & 31.8 \\
30.1 & 31.8 \\
30.2 & 31.7 \\
30.2 & 31.7 \\
30.1 & 30.2
\end{tabular}

\begin{tabular}{cc}
$\begin{array}{c}\text { Shear Modulus, GPa } \\
\text { Sample B }\end{array}$ & Sample C \\
\hline 15.3 & 11.3 \\
15.3 & 11.3 \\
15.3 & 11.3 \\
15.3 & 11.3 \\
15.3 & 11.3 \\
15.3 & 11.3
\end{tabular}

Poisson's Ratio

\begin{tabular}{cc} 
Sample B & Sample C \\
\cline { 1 - 2 } .02 & .41 \\
-.02 & .41 \\
-.02 & .41 \\
-.01 & .40 \\
-.01 & .40 \\
-.02 & .34
\end{tabular}




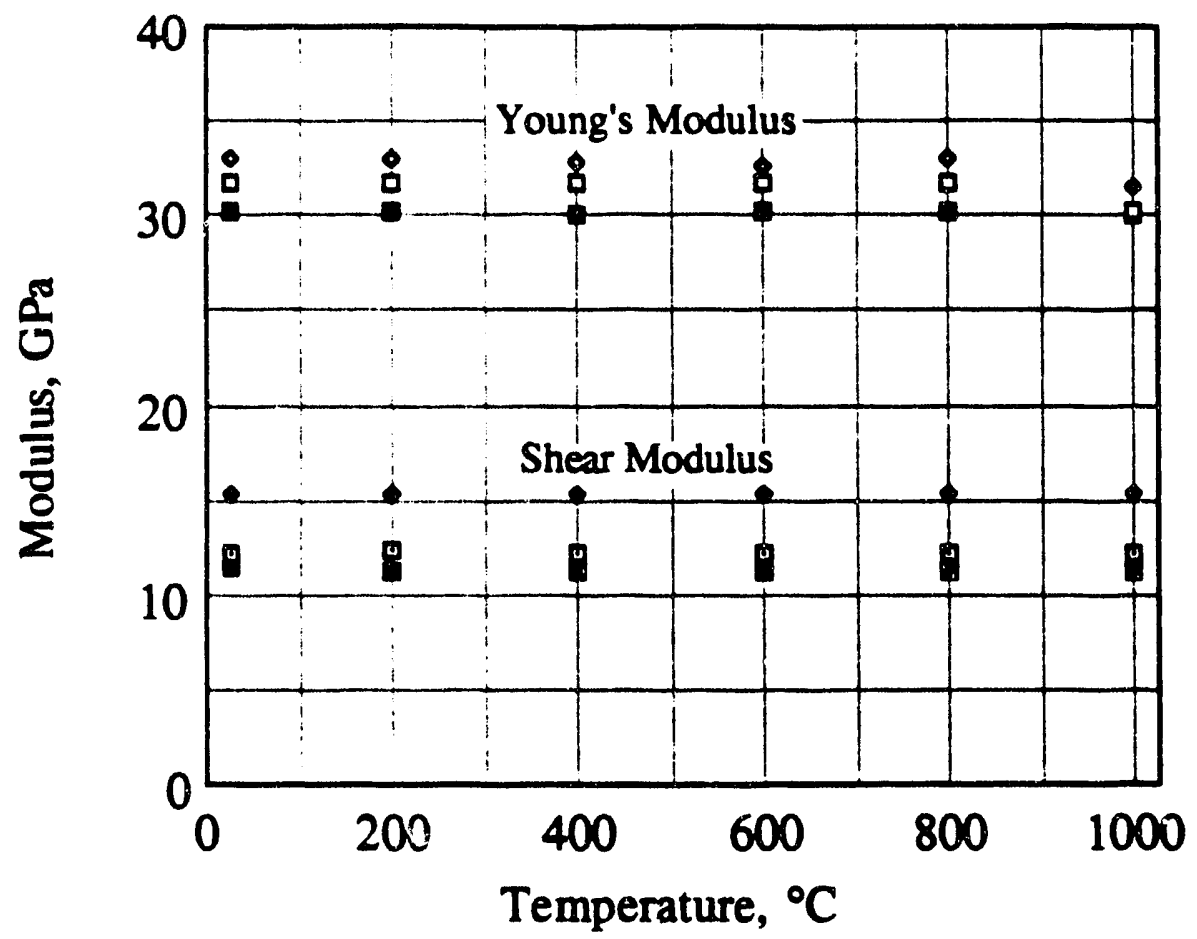




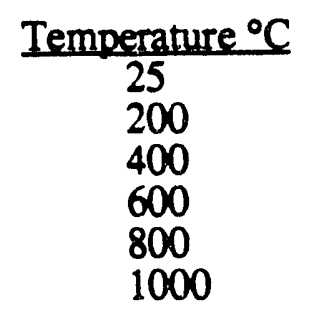

\begin{tabular}{cc} 
Young's \pm Std. Dev.(GPa) & Shear \pm Std. Dev.(GPa) \\
\hline $31.7 \pm 1.5$ & $13.0 \pm 2.1$ \\
$31.7 \pm 1.5$ & $13.0 \pm 2.1$ \\
$31.6 \pm 1.4$ & $13.0 \pm 2.1$ \\
$31.5 \pm 1.3$ & $12.9 \pm 2.1$ \\
$31.6 \pm 1.4$ & $12.9 \pm 2.1$ \\
$30.6 \pm 0.8$ & $12.9 \pm 2.1$
\end{tabular}

F-7 
APPENDIX G

POROSIMETRY DATA

G-1 


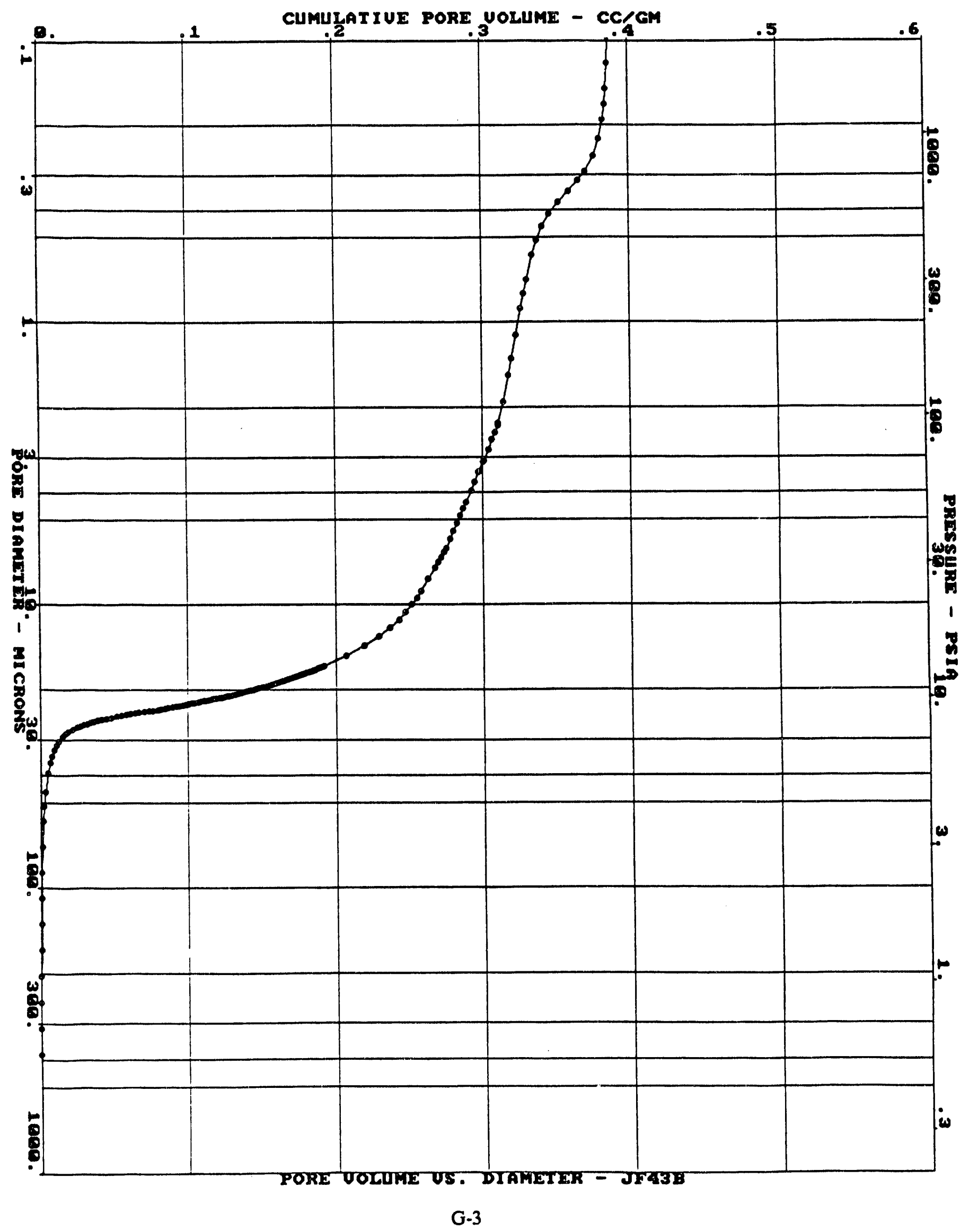




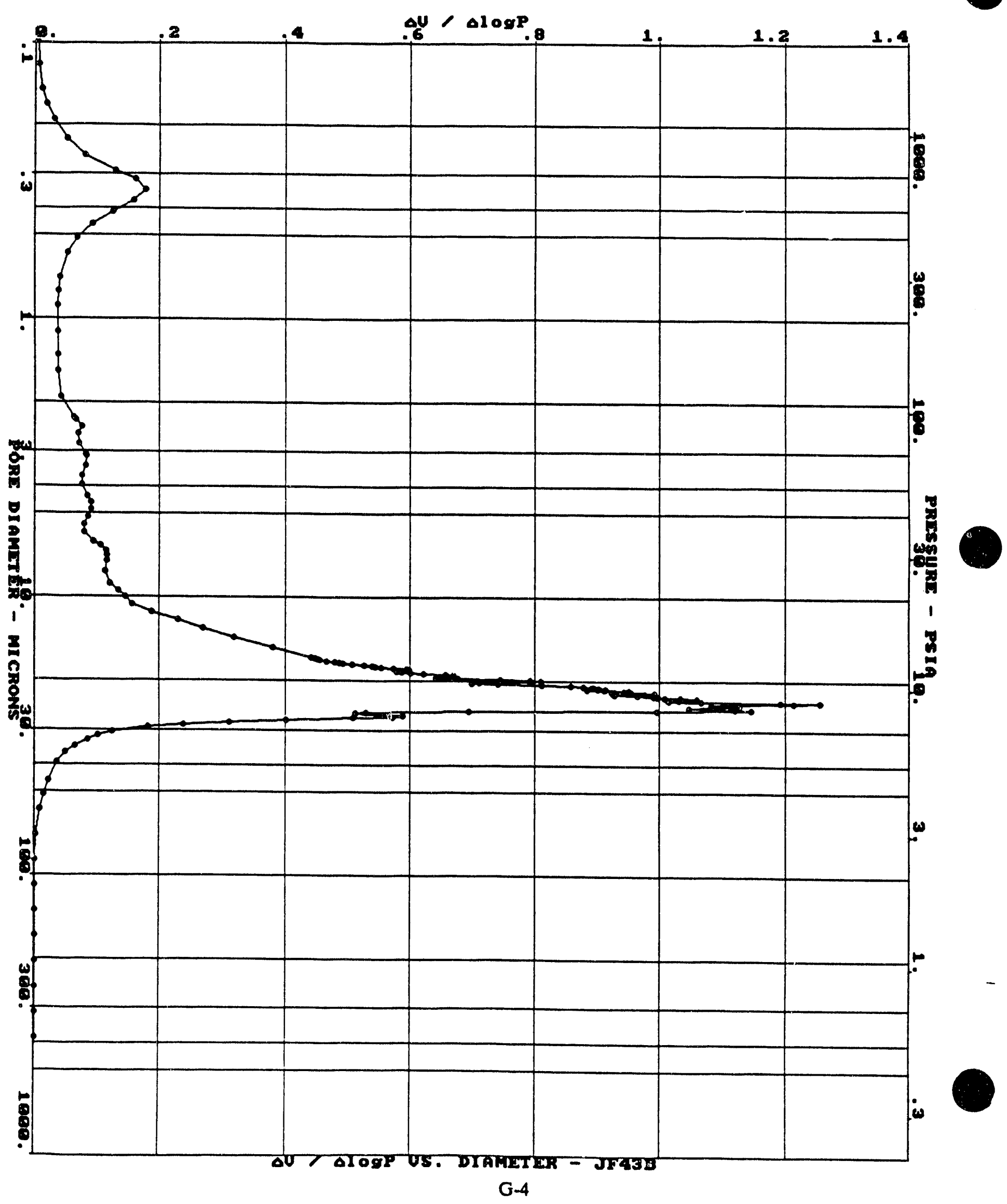




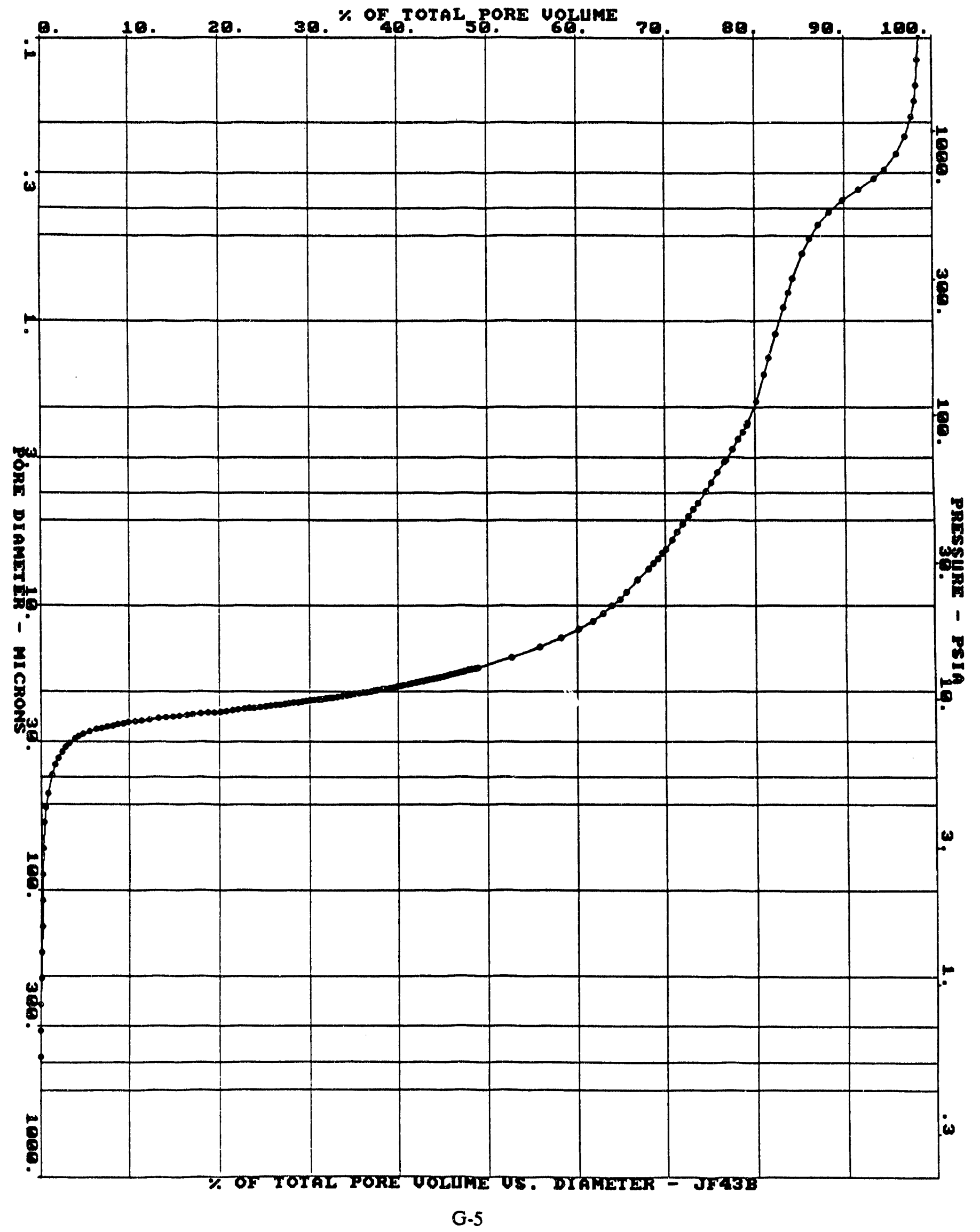




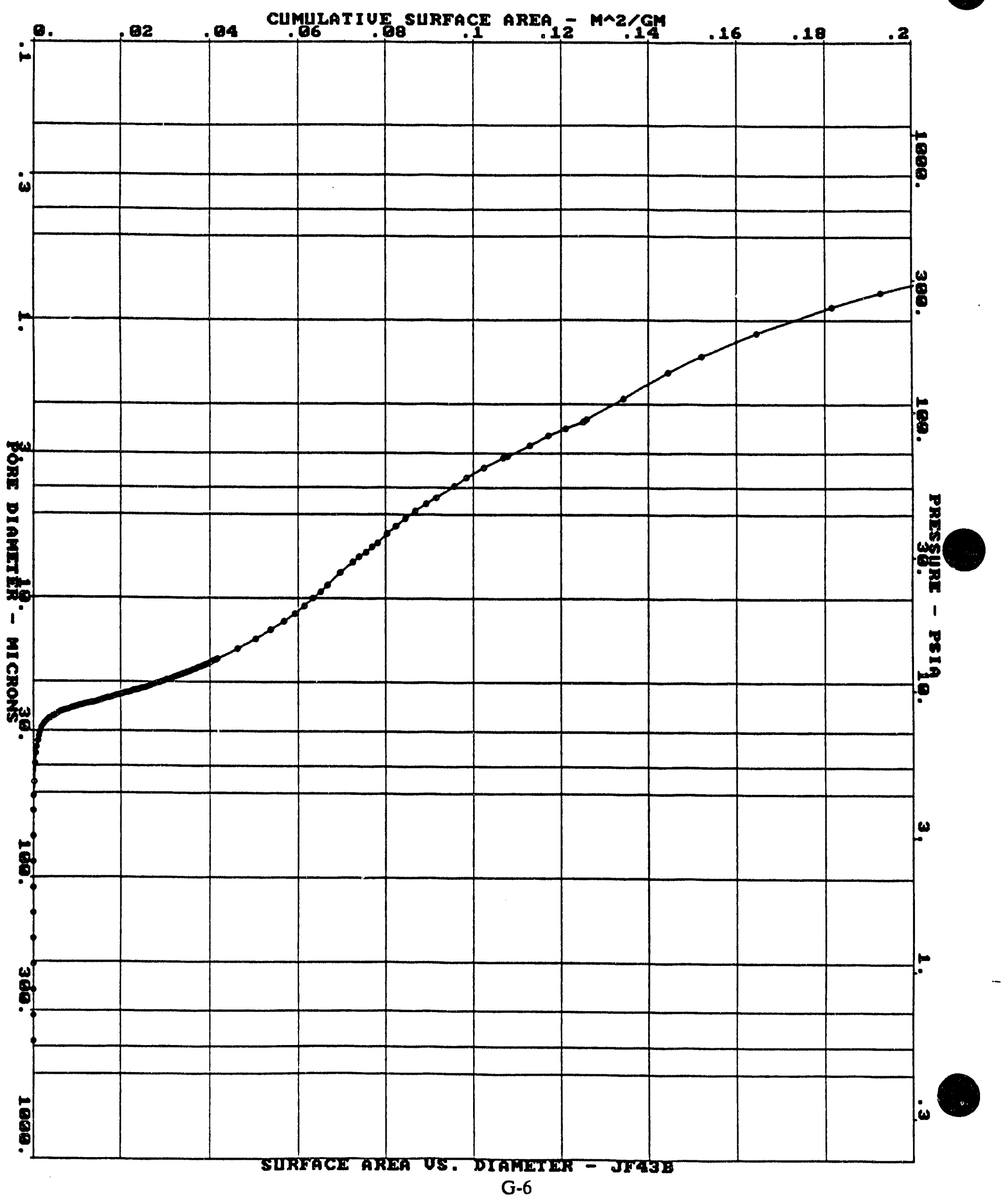


APPENDIX H

SUMMARY OF PROOF-TEST DATA

$\mathrm{H}-1$ 


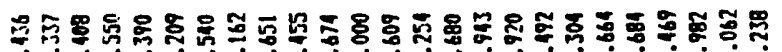

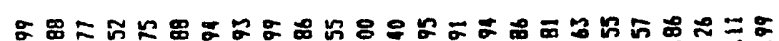

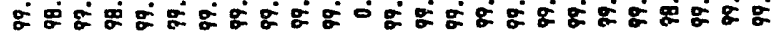

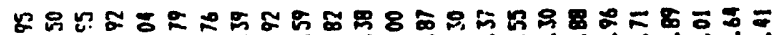

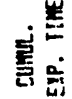

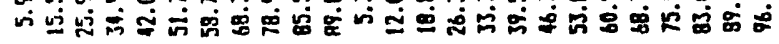

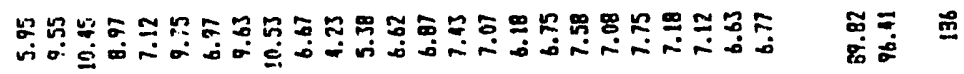

产总

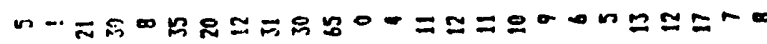

電哭

恶出

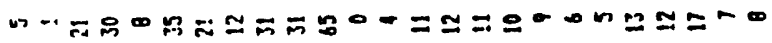
空兽

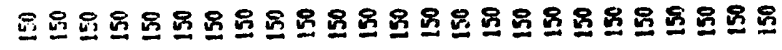

峞

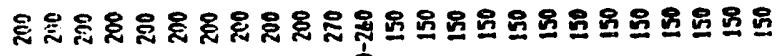
2

票䔄

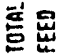

焉崖

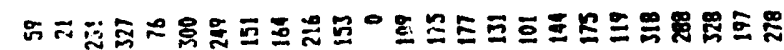

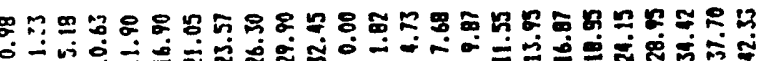

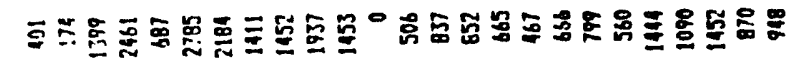

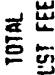

要害

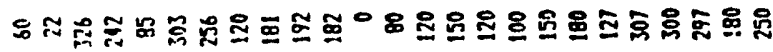

证

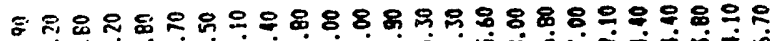

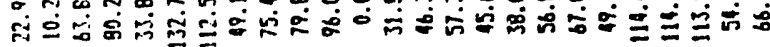

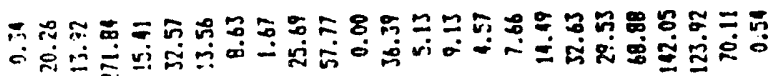

至育

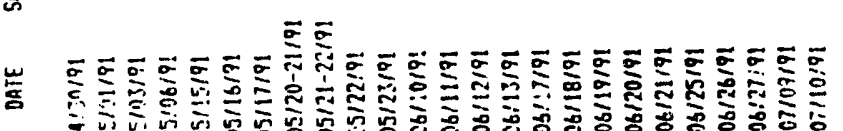

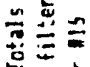

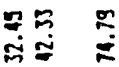

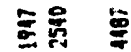

总总

$\mathrm{H}-3$ 


\begin{tabular}{|c|c|c|c|c|c|c|}
\hline ShI: & $\begin{array}{l}3+A=-E \\
M-E E\end{array}$ & $\begin{array}{l}35 \times F= \\
n^{-} \cdot 5: 3\end{array}$ & $\therefore:=5$ & 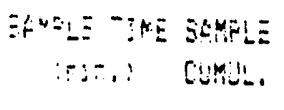 & $\begin{array}{l}\text { ITEE } \\
\text { Thri }\end{array}$ & $\begin{array}{l}\text { cante. Gut } \\
\text { ppis }\end{array}$ \\
\hline $0430 / 5:$ & $\vdots$ & 0.3 & $2.5:$ & $t:$ & $\therefore 1$ & 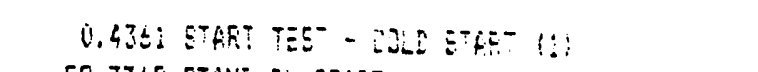 \\
\hline 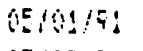 & $i$ & Oist & $: B .20$ & $\because$ & $\therefore 4$ & 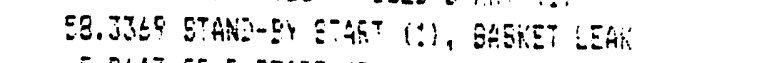 \\
\hline $0510519 !$ & $?$ & s.: $: 5$ & IA. $\because 6$ & 3 & $\therefore 4$ & 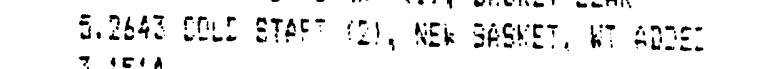 \\
\hline & 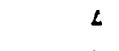 & 7.9 & 72.8 & $20 t$ &. $\pm D$ & 3.9514 \\
\hline 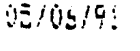 & $\vdots$ & 3.30 & 24.3 & 5 & $7 . \overline{9}$ & 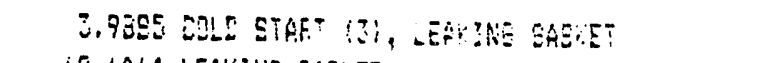 \\
\hline & t & 84.76 & $5 \overline{5} .5$ & $: 10$ & 5.9 & 62.6054 LEAKINO SAEKET \\
\hline & $\vdots$ & $354,3 i$ & $\vdots 2,4 \vdots$ & 57 & 10.8 & S30.1260 LEAKIHE - GFEKET FALLLLE \\
\hline $05 / 15 / 9 !$ & $\$$ & :E.4: & $Y . \overline{6}$ & $\underline{g}$ & 12.2 & 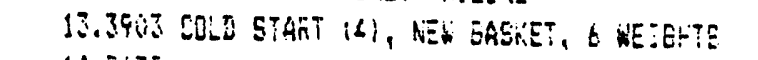 \\
\hline $05=16 / 9:$ & 与 & 14.2 & $2 E .: \therefore$ & $6 ?$ & 43.3 & 14.9672 \\
\hline & $\therefore$ & E.64 & 50.16 & 120 & $: 5.3$ & 4.7780 \\
\hline & $! !$ & $9.2 !$ & $5: .50$ & 1210 & 17.3 & 5.450 \\
\hline $05117 / 9 !$ & $: 2$ & b.89 & 54.60 & 120 & 18.3 & 3.7062 \\
\hline & 13 & 6.70 & $3 ? .90$ & 132 & $2 ! .5$ & 3.3986 \\
\hline $0_{1} / 2: 19 !$ & 14 & 8.63 & 49.10 & 120 & 23.5 & 5.1622 \\
\hline $05 / 22 / 91$ & $! \Sigma$ & 1.67 & 75.40 & 181 & 26.5 & 0.6505 \\
\hline $0=122191$ & 16 & 25.69 & 79.90 & 192 & 29.7 & 9.455: DUET LEAK. \\
\hline $05 / 23 / 91$ & 17 & 57.77 & 96.00 & 182 & 32.8 & 17.6740 DUST LEAK, EASKET FAILURE \\
\hline$(16 / 1119 !$ & 19 & 20.39 & 12.10 & 30 & 0.5 & 49.4921 STAND-BY START (I), Nen Filter $\$ 16$ \\
\hline & 19 & 16.00 & 19.70 & 50 & 1.3 & 23.8538 HET SAYMQLE \\
\hline $06 / 12 / 91$ & 20 & $5 .: 3$ & 46.30 & $: 20$ & 3.3 & 3.2542 \\
\hline $061: 3 / 91$ & $2 i$ & $9 .: 3$ & 57.30 & 150 & 5.8 & 4.6797 \\
\hline 06117191 & 22 & 4.57 & 45.60 & 120 & 7.8 & 2.9434 \\
\hline $06 / 18 / 91$ & 23 & 7.66 & 38.00 & 100 & 9.5 & 5.9204 \\
\hline $06 / 19 / 91$ & 24 & 14.49 & $5 t .80$ & 150 & 12.0 & 7.4925 \\
\hline $06 / 20 / 9 !$ & 25 & 32.63 & 67.00 & 180 & 15.0 & 14.3036 \\
\hline $0 t / 2 \$ / 9 !$ & 26 & 29.53 & 49.10 & 127 & 17.1 & 17.6639 \\
\hline $06 / 25 / 91$ & 27 & 31.38 & 67.40 & 180 & 20.1 & 13.6740 NET, DRIED PRIOR TO UEIGHING \\
\hline & 28 & 37.50 & 47.00 & 127 & 22.2 & 23.4335 HET, DRIED PRIOR TO HEJGHING \\
\hline $06 / 26 / 9 !$ & 29 & 101.31 & 69.00 & 180 & 25.2 & 43.1228 \\
\hline & 30 & 10.74 & 45.40 & 120 & 27.2 & 26.3554 \\
\hline $06 / 27 / 91$ & $3 !$ & 123.92 & 113.80 & 297 & 32.2 & 3!.9818 SAMPLE HOLDEF LEAKING, CU FT READING LOH \\
\hline $07109 / 9 !$ & 32 & 70.11 & 54.10 & 180 & 35.2 & 38.0616 \\
\hline $07 / 10 / 91$ & $3 j$ & 0.54 & 66.70 & 250 & 39.4 & 0.2378 \\
\hline
\end{tabular}




\section{APPENDIX I}

PRESSURE DROP VERSUS TIME FOR INDIVIDUAL PROOF-TEST DAYS 
ACUREX $6 \times 6$ Cross Flow Filter Performance Data

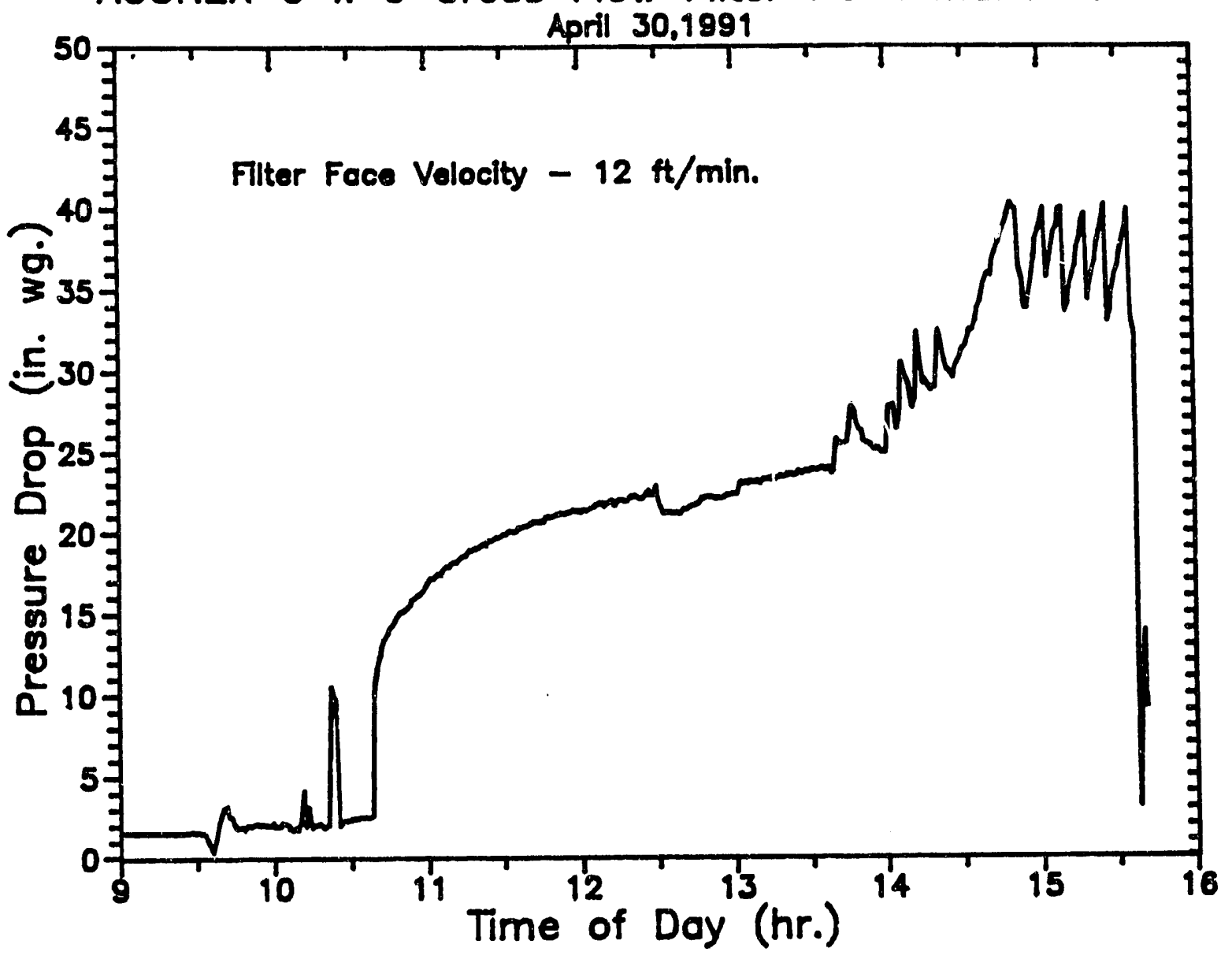

Operation Notes for April 30, 1891

0937 Flame On

delta- $P$ Trigger $=40$ in we

1500 Pulse Cleaning - 250 psig/0.1 sec

1508 Pulse Cleaning - $300 \mathrm{psig} / 0.1 \mathrm{sec}$

1525 Pulse Cleaning - 325 psig/0.1 sec

1534 Pulse Cleaning - 350 psig/0.1 sec

1534 Scheduled Shutdown 


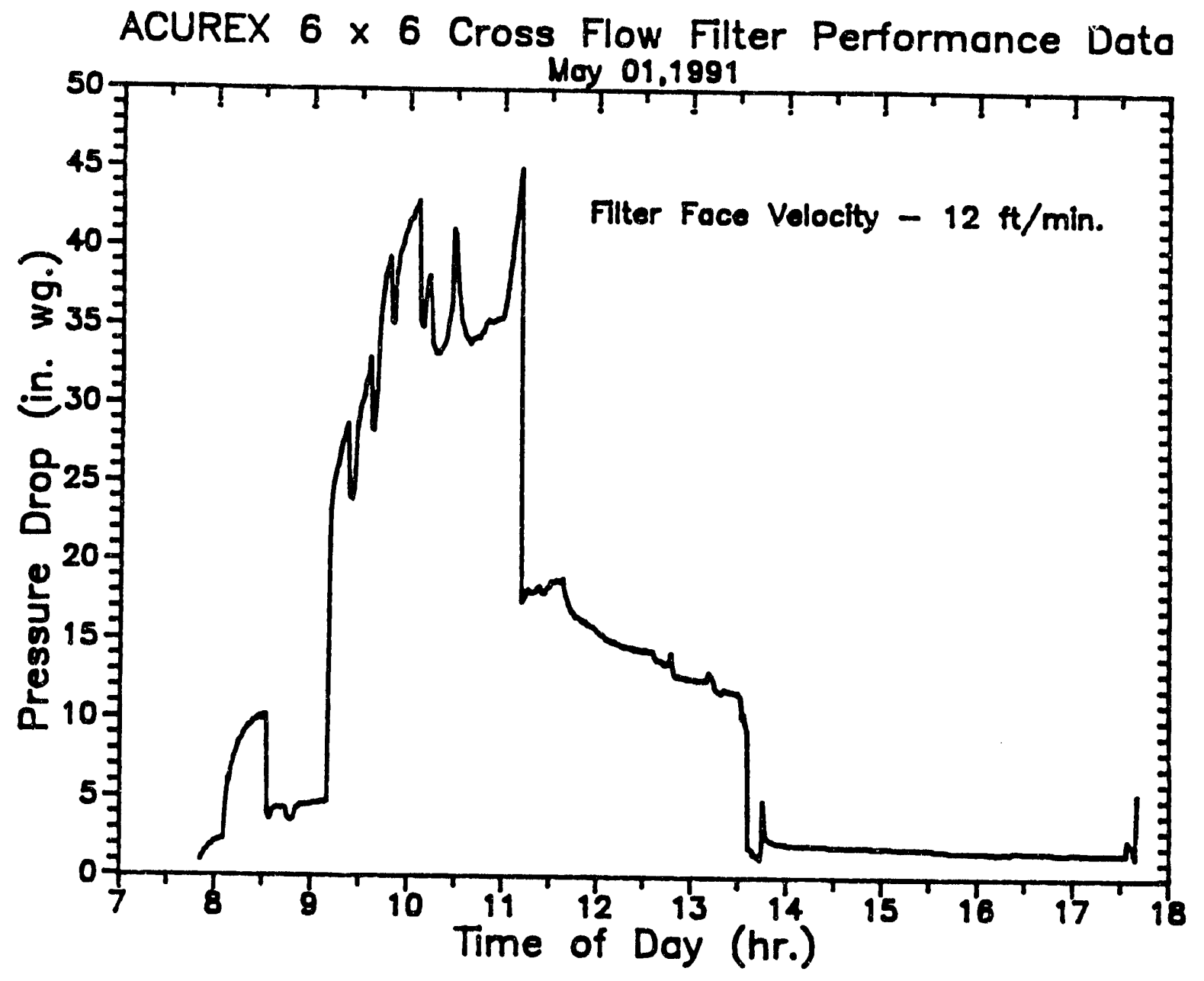

Operation Notes for May 01, 1991

O800 Flame On delto-P Trigger $=45$ in we

1111 Pulse Cleaning - 350 paig/0.1 sec

1122 Dust leakage observed

1335 flame out 
ACUREX $6 \times 6$ Cross Flow Filter Performance Dato

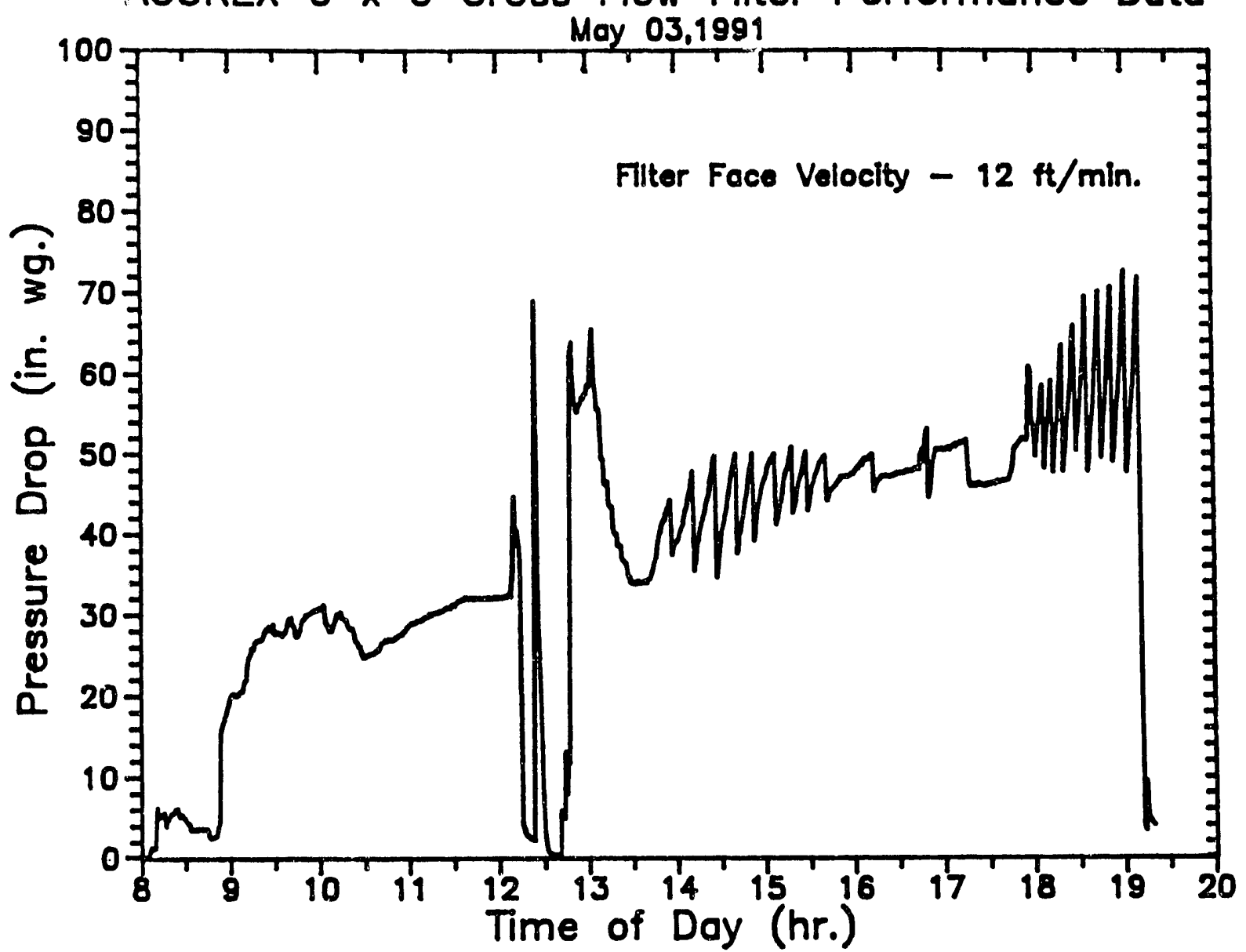

Operation Notes for Moy 03, 1991

0810 Flame On - 1216 Shutdown to repair valve delto-P Trigger $=45$ in we

1111 Pulse Cleoning - 300 paig/0.1 sec

1425 delto-P Trigger $=50$ in we

1527 Pulse Cleoning - 325 palg/0.1 sec

1645 - 1800 Dust not feeding property

1806 delto-P Trigger $=60$ in we Pulse Cleaning -350 psig/0.1 sec

1834 delta-P Trigger = 70 in wC

1243 Restart - 9910 Scheduled Shutdown 


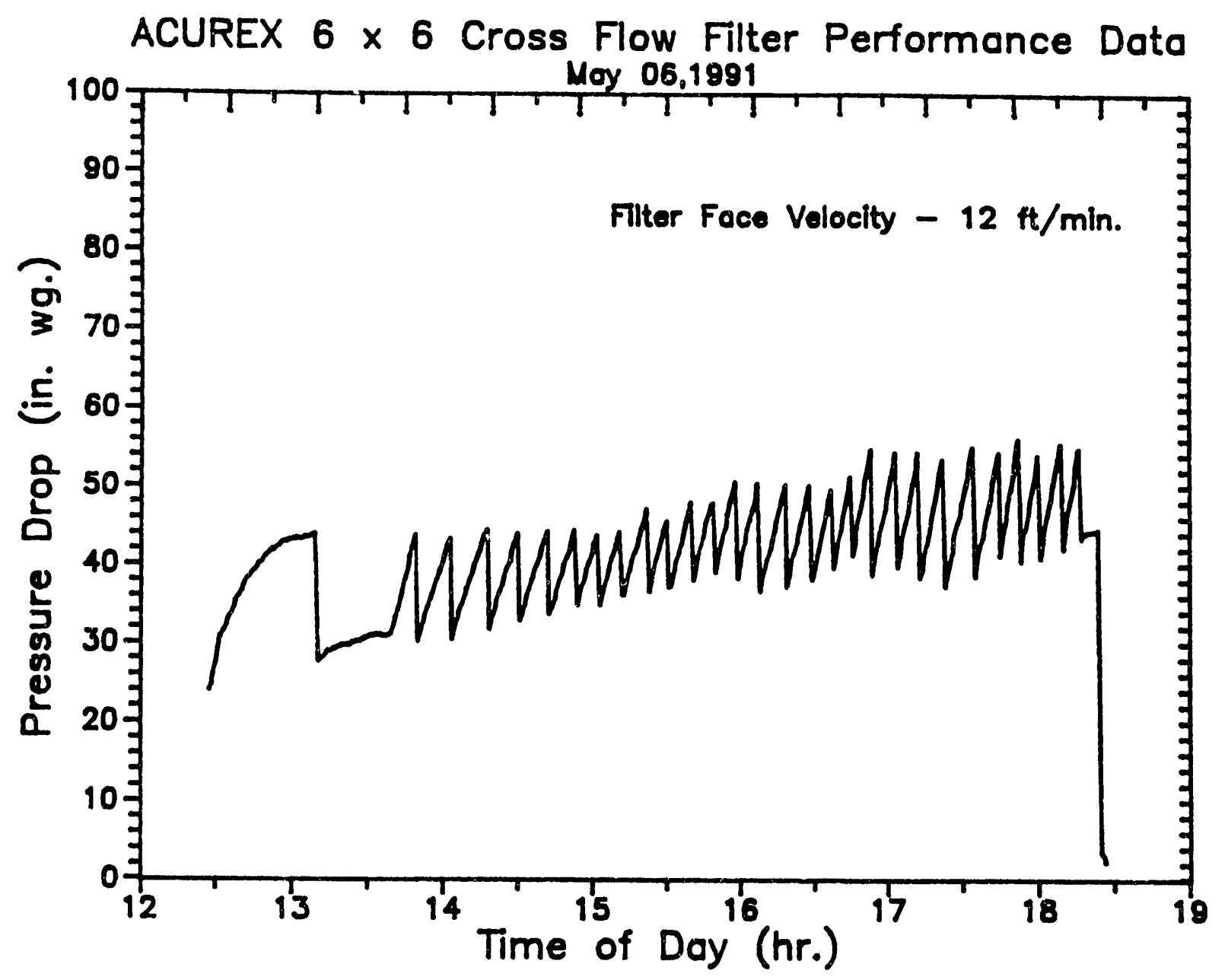

Operation Notes for Moy 06, 1991 0925 Flame On delta-P Trigger $=44$ in we

Pulse Cleoning - 350 psig $/ 0.1 \mathrm{sec}$

1557 delto-P Trigger $=50$ in we

1538 Pulse Cleaning - 375 paig/0.1 sec

1651 delta-P Trigger $=55$ in we

1823 Dust leakage observed, Shutdown 
ACUREX $6 \times 6$ Cross Flow Filter Performance Dato

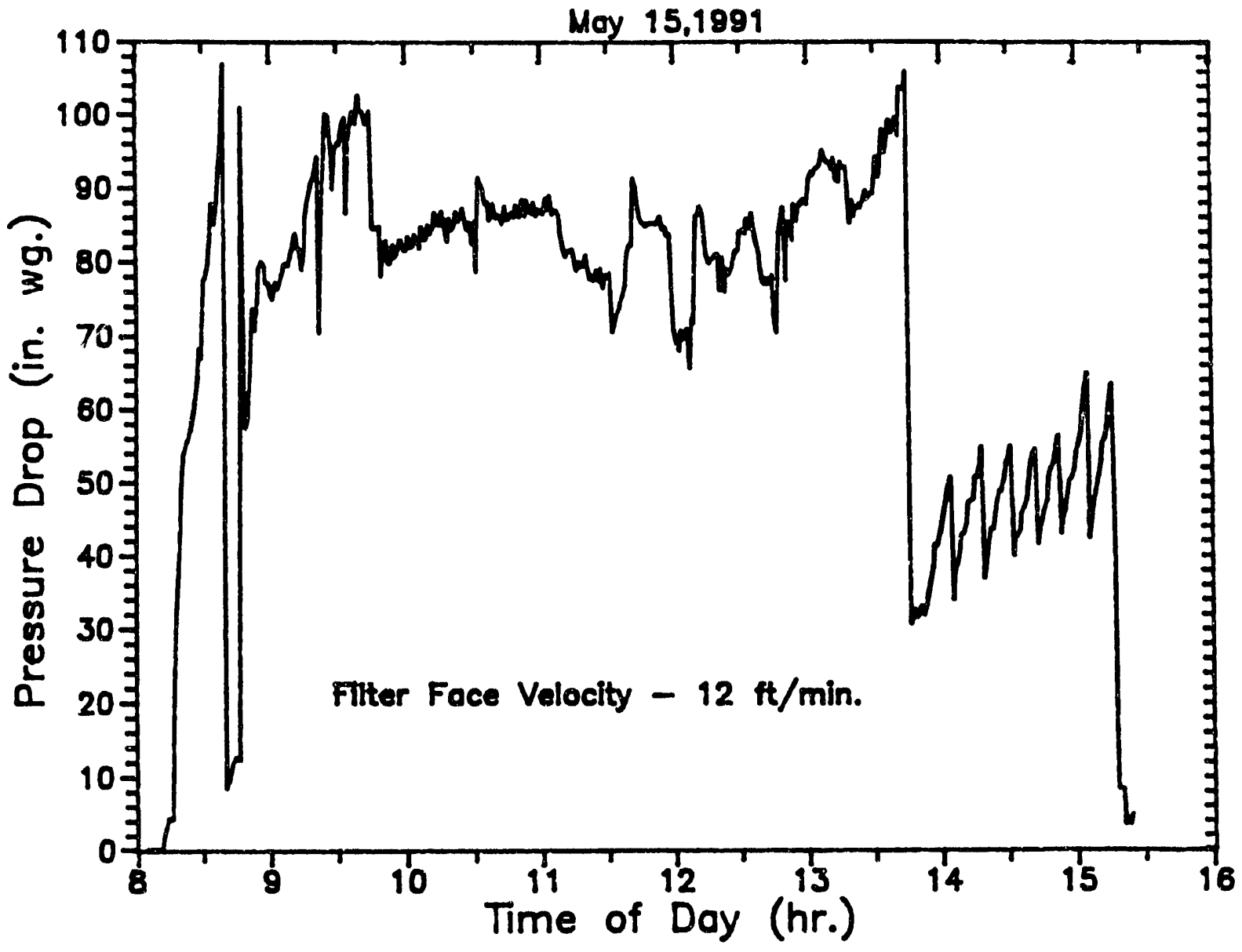

Operation Notes for May 15, 1991

0813 Flame On

delto-P Trigger $=55$ in wc

Pulse Cleaning - 375 psig/0.1 sec

1506 delto-P Trigger $=63$ in we

1520 Scheduled Shutdown 


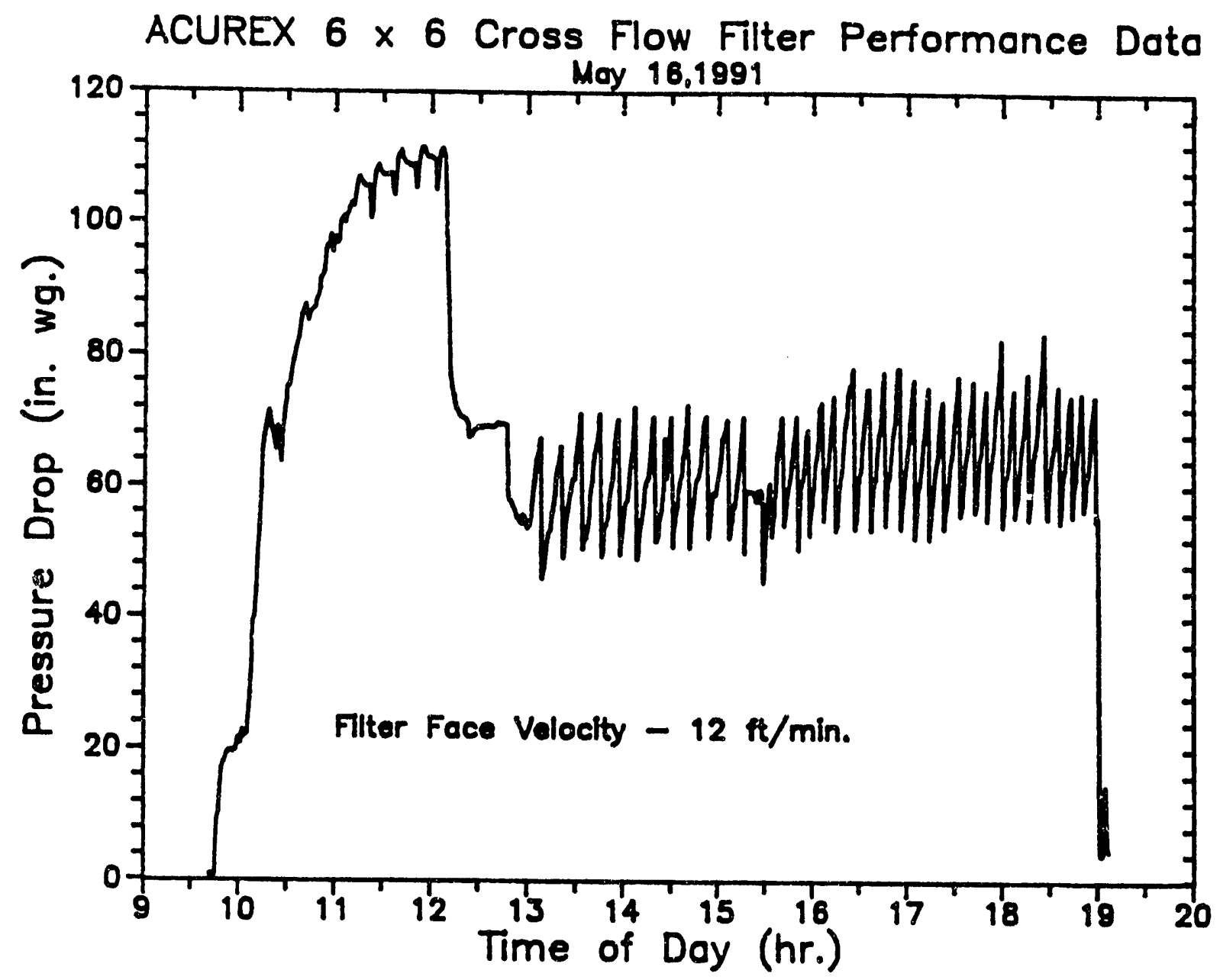

Operation Notes for Moy 16, 1991

0945 Flame On

delto- $P$ Trigger $=70$ in we

Pulse Cleaning - 375 psig/0.1 sec

1614 delto-P Trigger $=75$ in wC

1626 Pulse Cleaning - 400 psig/0.1 sec

1900 Scheduled Shutdown

delto-P during heat-up high due to increased flow to ottain temperature flow reduced prior to initial dust feed 


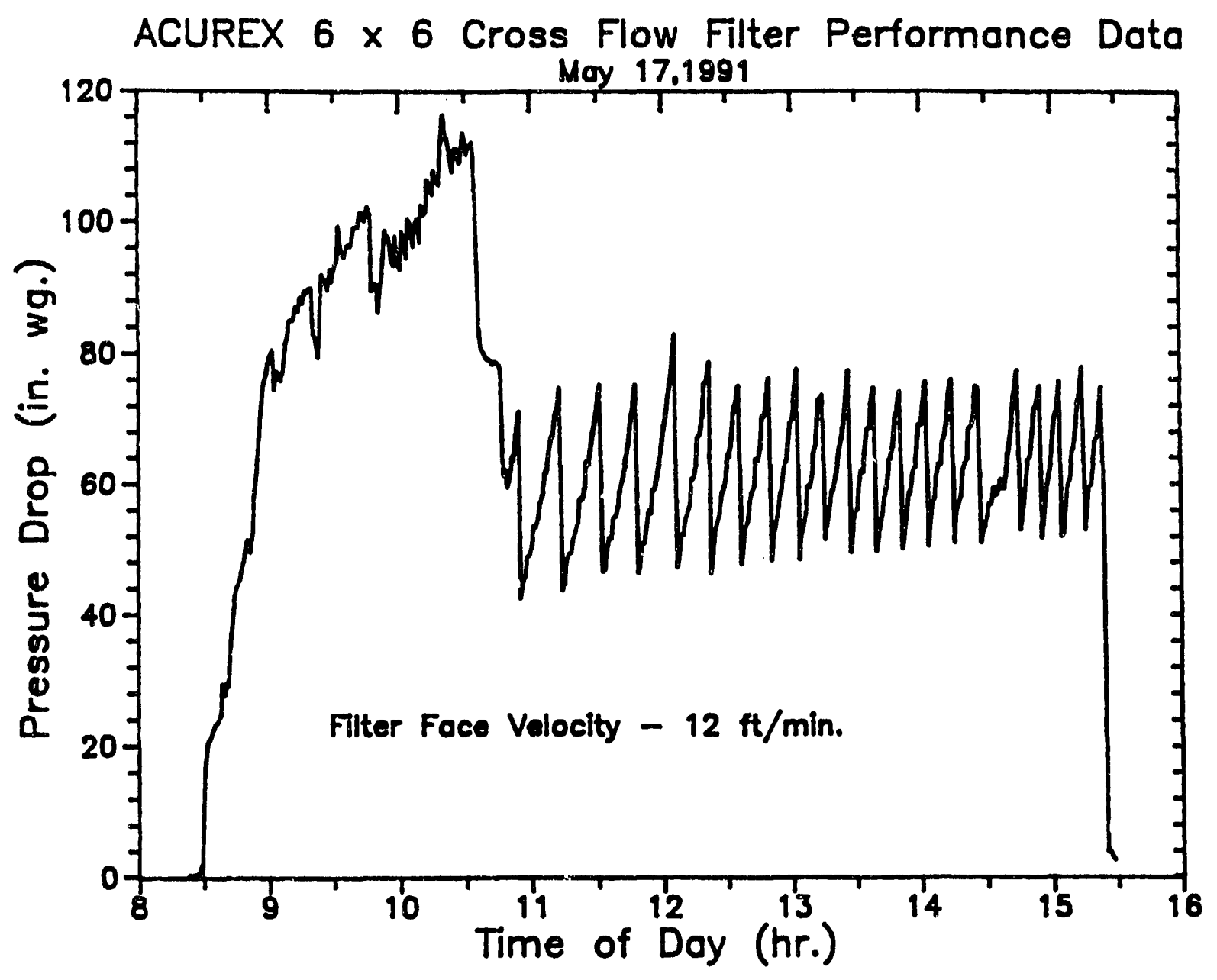

Operation Notes for May 17, 1991

0827 Flame On

delta- $P$ Trigger $=75$ in we

Pulse Cleaning - 400 psig/0.1 sec

1525 Scheduled Shutdown

delta-P during heat-up high due to increased flow to attain temperature flow reduced prior to initial dust feed 


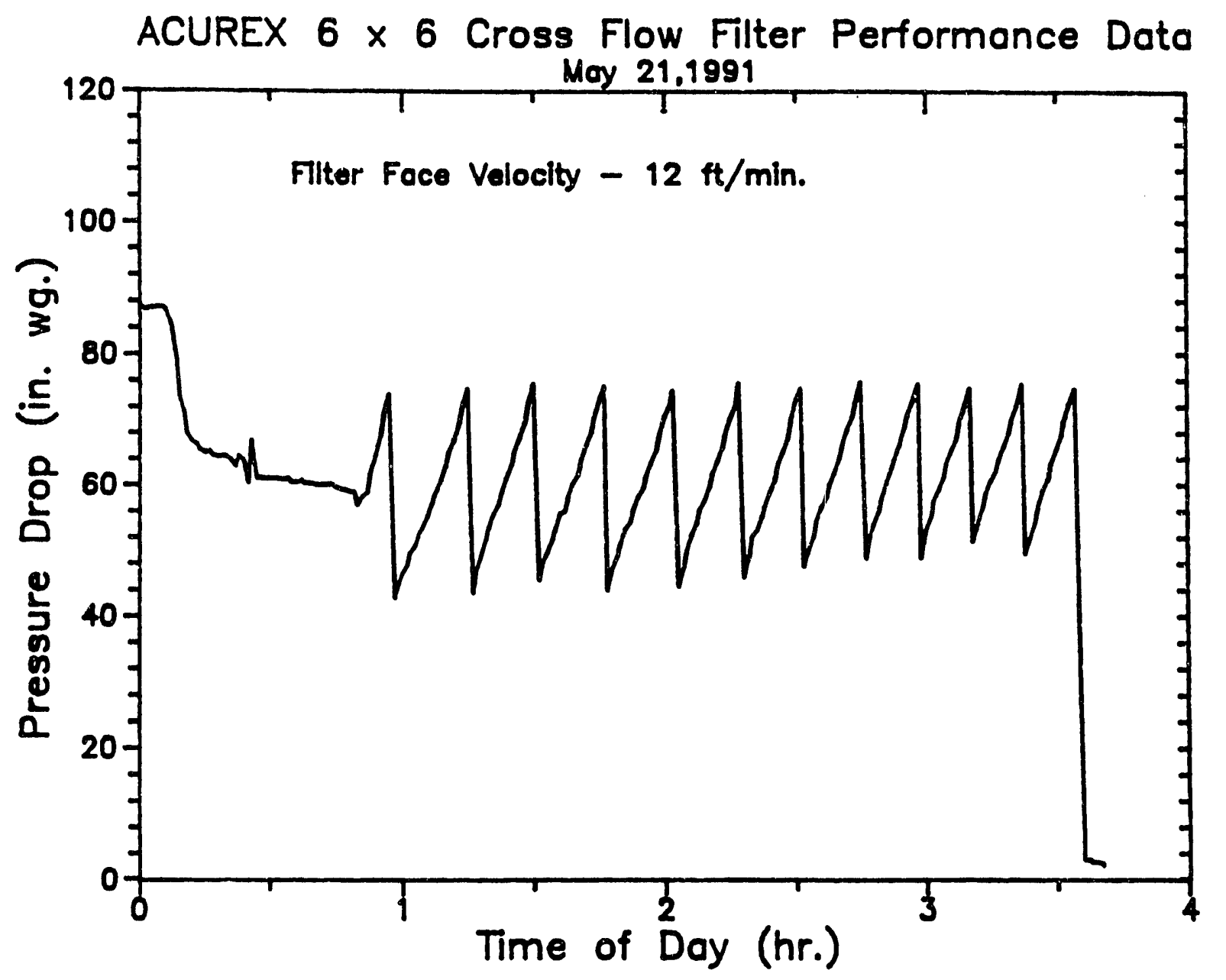

Operation Notes for Moy 21. 1981 (orn)

delto-P Trigger $=75$ in wc

Pulse Cleaning - 400 paig/0.1 sec

0335 Scheduled Shutdown

delta-p during heat-up high due to increased flow to ottoin temperoture flow reduced prior to initiol dust feed 


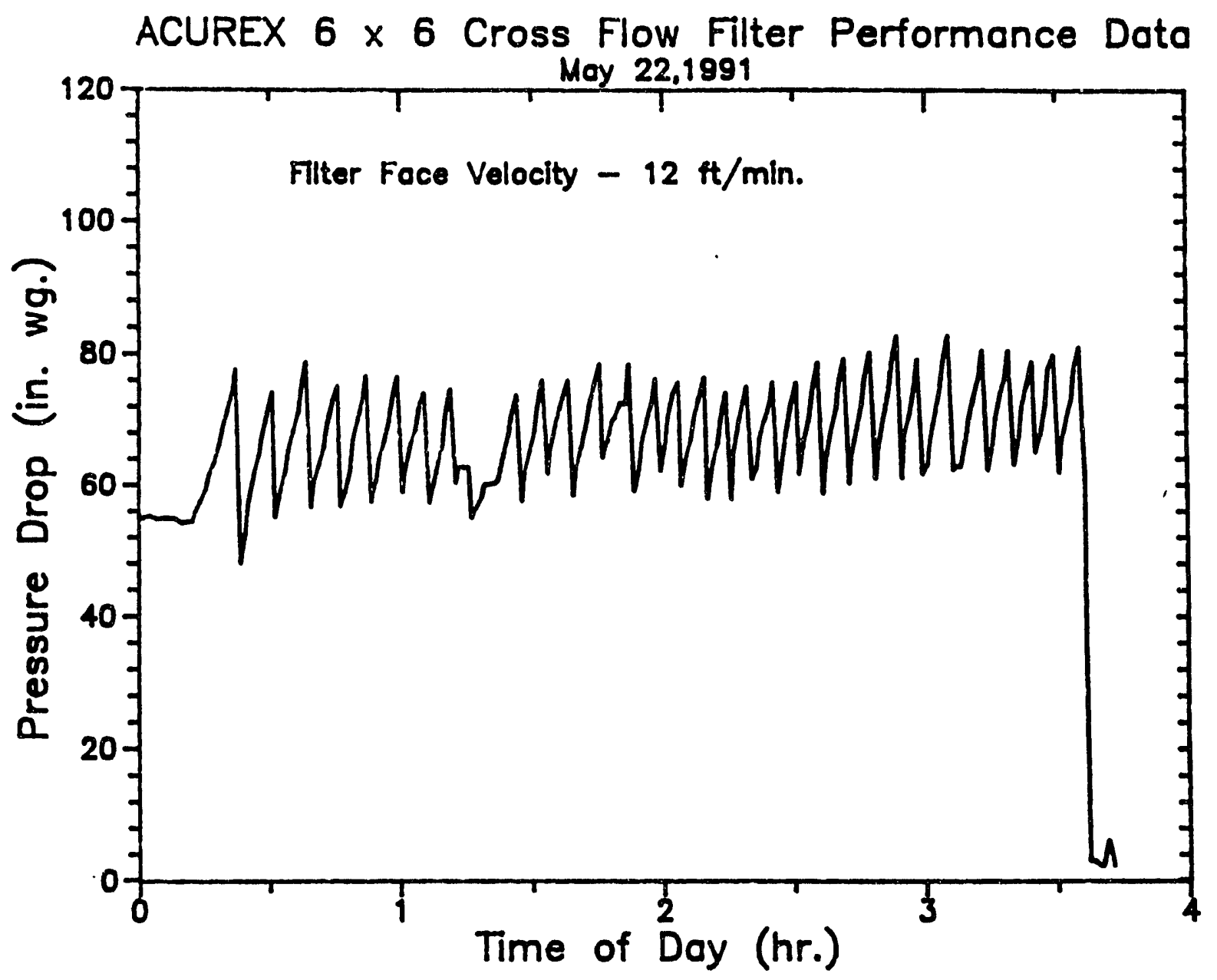

Operation Notes for Moy 22, 1991 (am)

delta-P Trigger $=75$ in $w c$

Pulse Cleaning - 400 psig/0.1 sec

0125 Pulse Cleaning raised to $410 \mathrm{psig} / 0.1$ sec

0235 delto-P Trigger $=80$ in wc

0304 Pulse Cleaning raised to 420 psig/0.1 sec

0335 Scheduled Shutdown

delta-P during heat-up high due to increased flow to attain temperature flow reduced prior to initial duat feed 
ACUREX $6 \times 6$ Cross Flow Filter Performance Dato

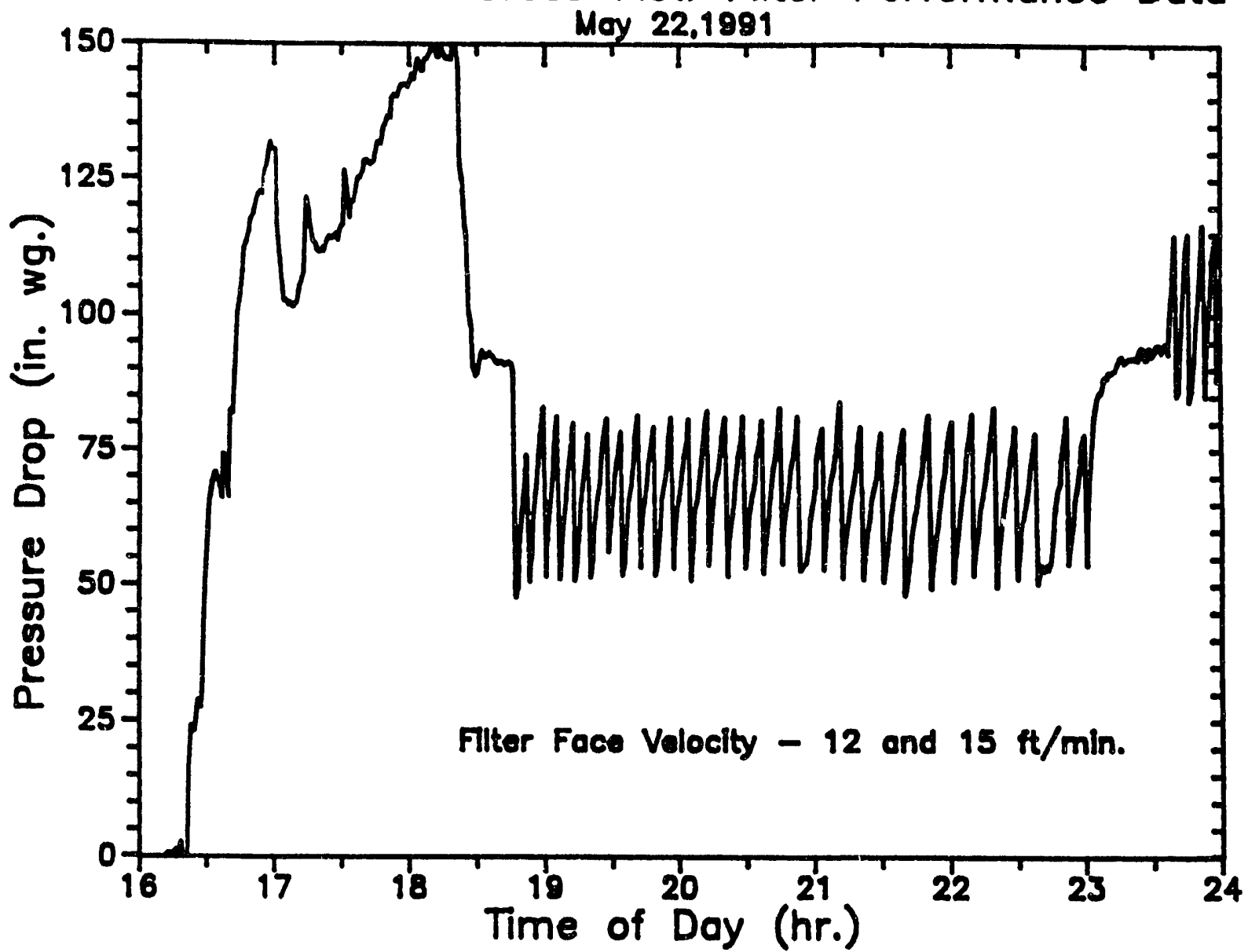

Operation Notes for May 22, 1991

delto-P Trigger 80 in wc Pulee Cleaning - 420 palg/0.1 sec

1948 Pulse Cleaning - 440 pelg/0.1 sec

2027 Pulse Cleaning - 450 palg/0.1 sec

2300 System flow increased to $270 \mathrm{lb} / \mathrm{hr}$ to attain $15 \mathrm{ft} / \mathrm{min}$ foce valocits 2339 delto-P Trigger - 115 in wC

0022 Pulse Cleaning - 460 psid/0.1 sec

0120 delta-P Trigger $=120$ in wc

0250 delta-P Trigger $=125$ in we

0314 Scheduled Shutdown 


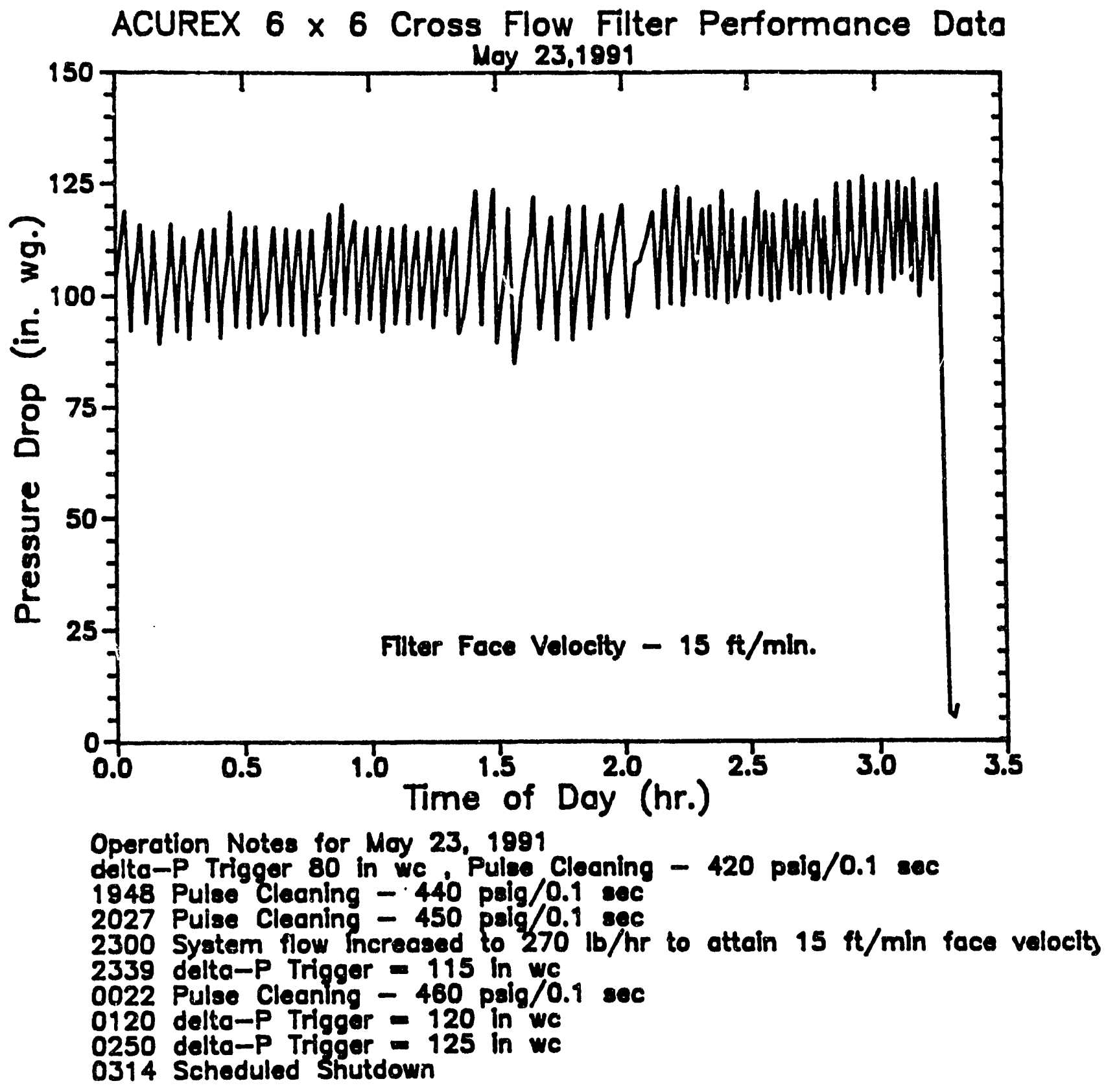




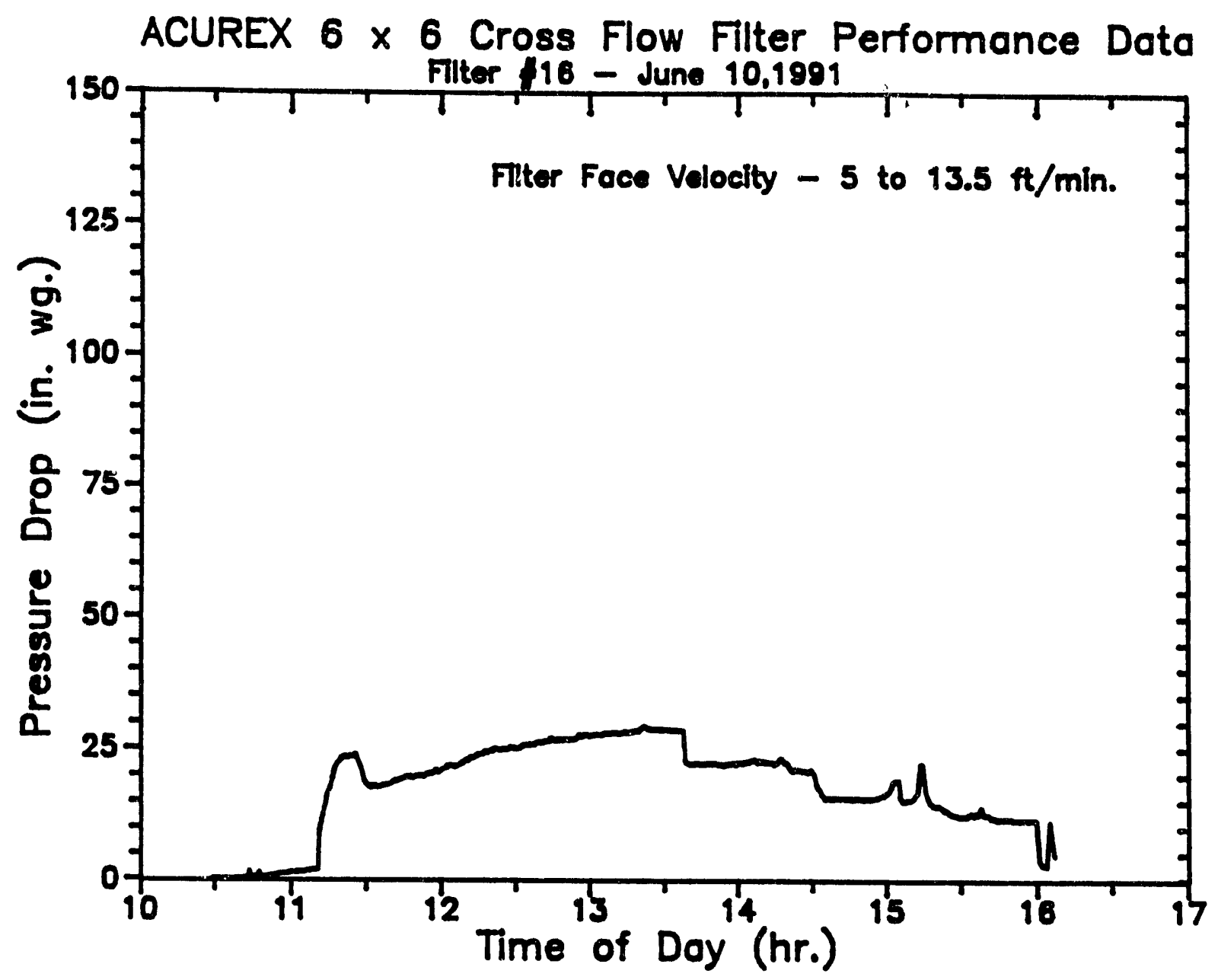

Operation Nol $0830-101$ ! 1029 Fame 1040 Flame , 1046 Flome । Bose line dell 1558 Schedul

look

120, 150, 200, and 280 PPH flow 


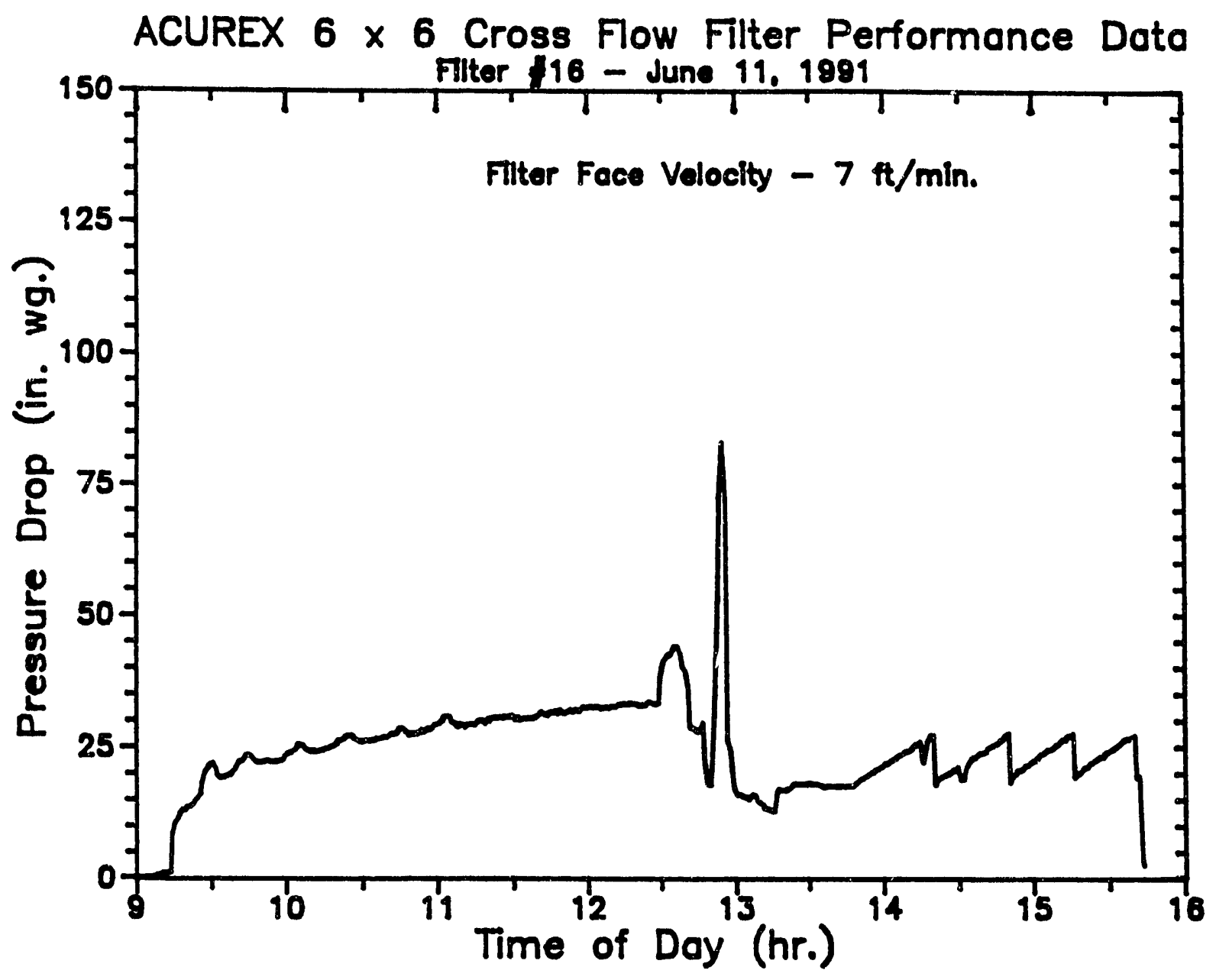

Eperation Notes for June i1, 1991 delta-P Trioger 27.5 in we

Pulse Cleaning - 400 paig/0.1 eec

0902 Flame on

1237 attempted 100 PPH flow, Combustor buming rich, producing corbon delta-P increaaing with carbon formation

1313 Flow increased to $150 \mathrm{PPH}_{1}$ carbon burned off

1540 Scheduled shutdown 


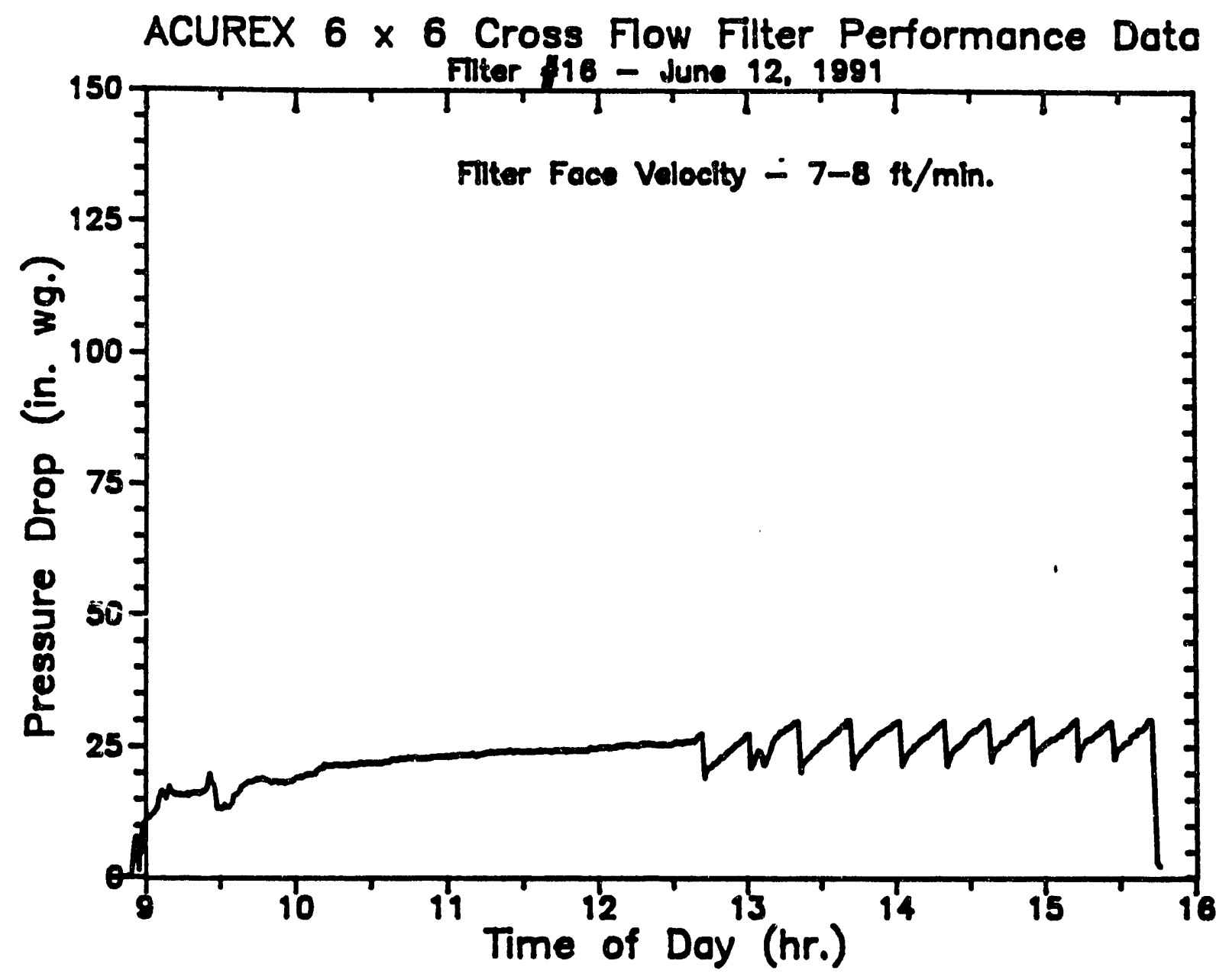

Operation Notes for Jume 12, 1991 delto-P Trigger 27.5 in we

Pulse Cleaning - 400 palg/0.1 sec

0849 Flome on

1319 delta-P Trigger incrocesed to 30 in we

1453 Pulee Cleaning - 420 paig/0.1 sec

1541 Scheduled shutdown 


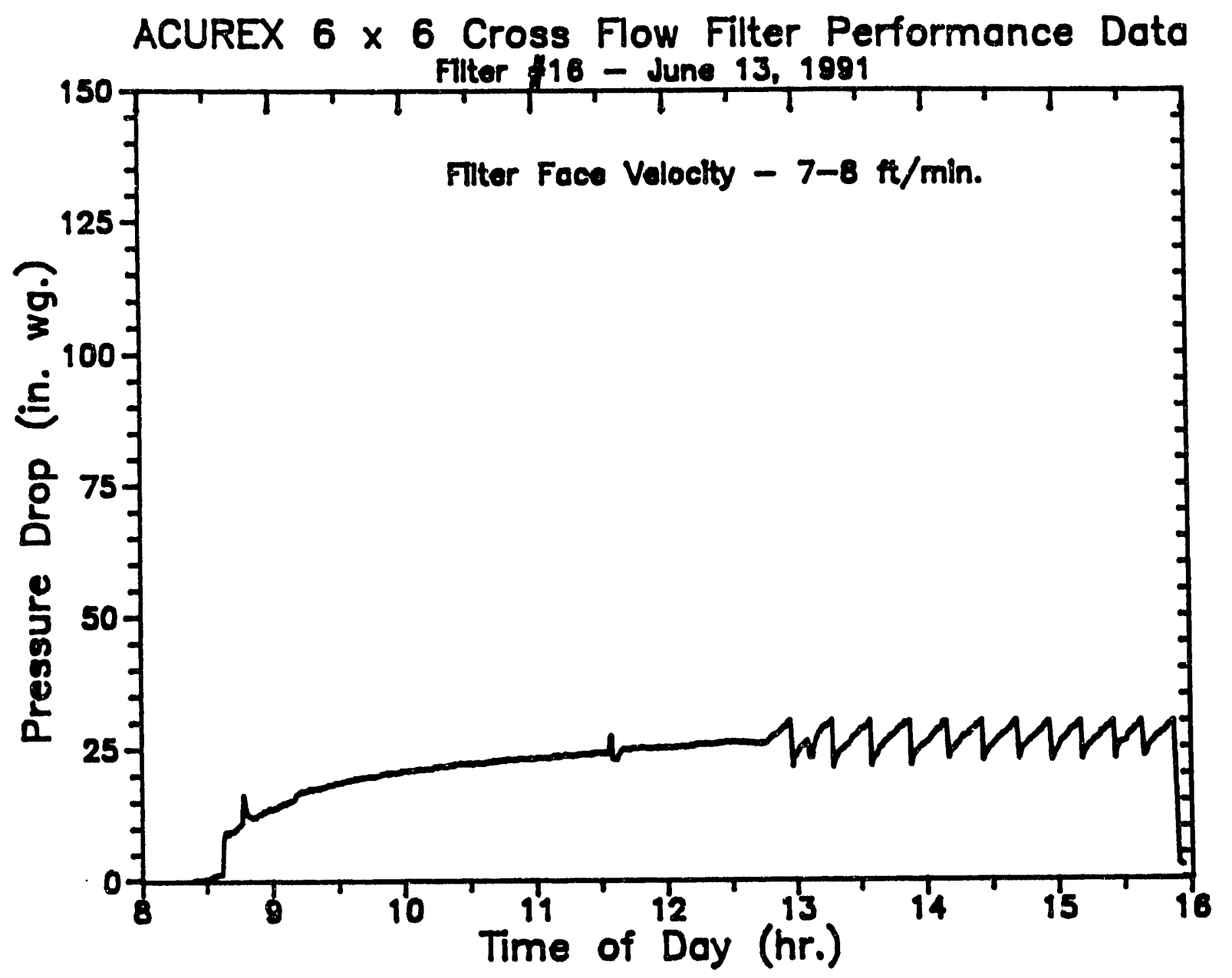

Operation Notes for June 13. 1991 delto-P Trigger 30 in we Pulse Cleaning - 420 pelg/0.1 sec 0825 Flame on

1551 Scheduled chutdown 


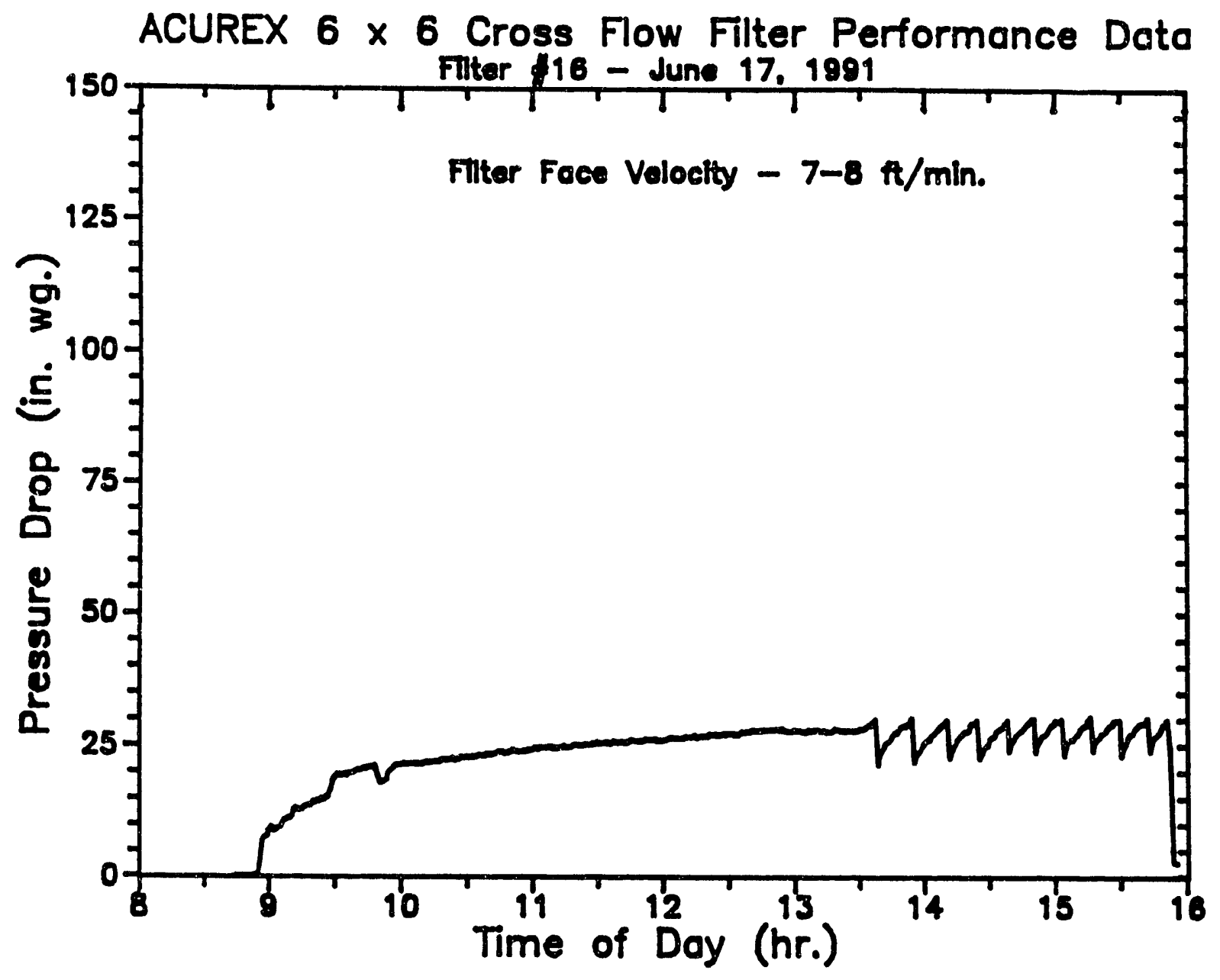

Operation Notes for June 17. 1981 delto-P Triggar 30 in we Pulse Cleaning - 420 polg/0.1 sec 0847 flame on

1551 Scheduled shutdown 


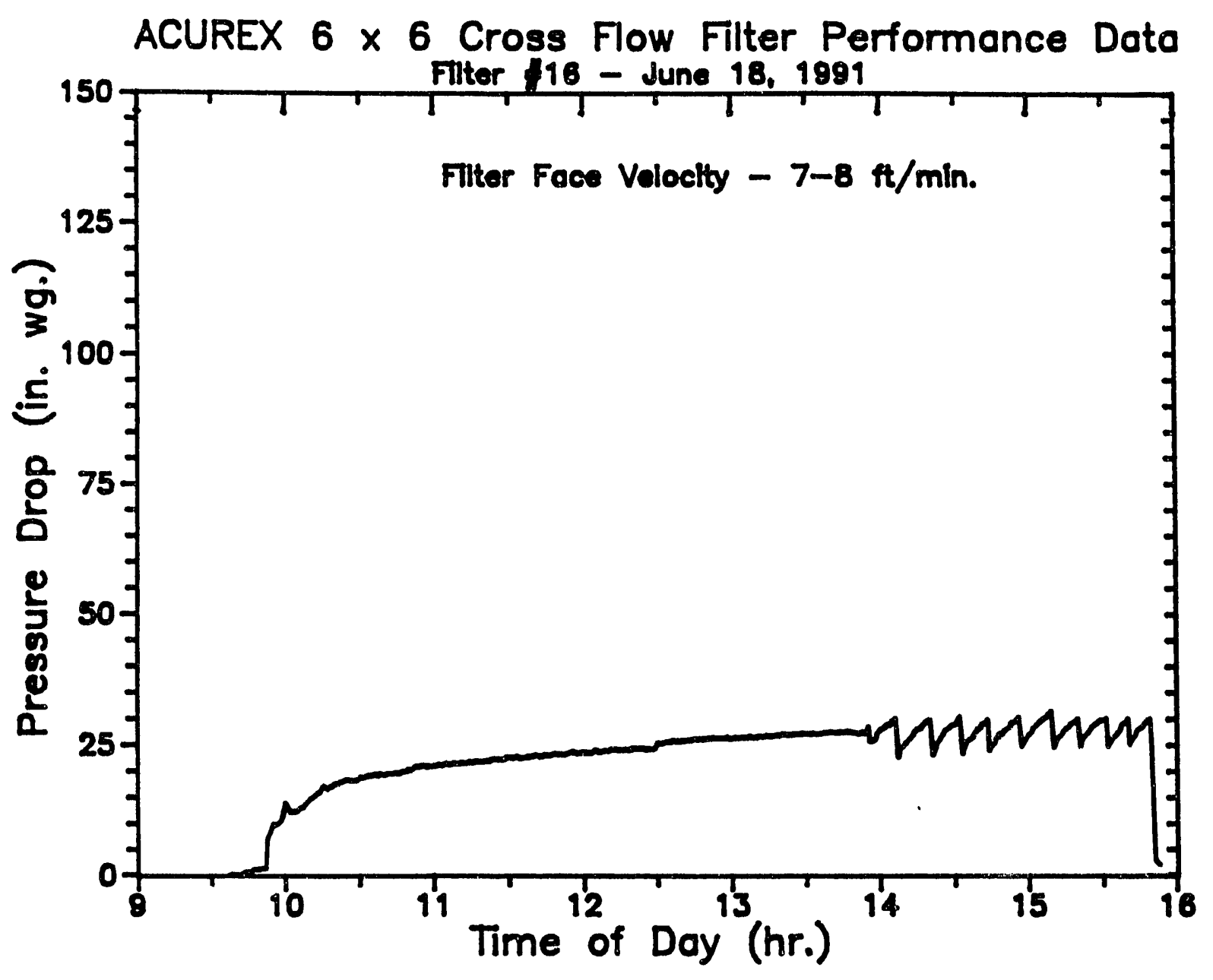

Operation Notes for June 18, 1991 delto-P Trigger 30 in we

Pulse Cleaning - 420 palg/0.1 sec

0938 Fame on

1455 Change Pulse Cleaning - 430 paig/0.1 sec

1549 Scheduled shutdown 


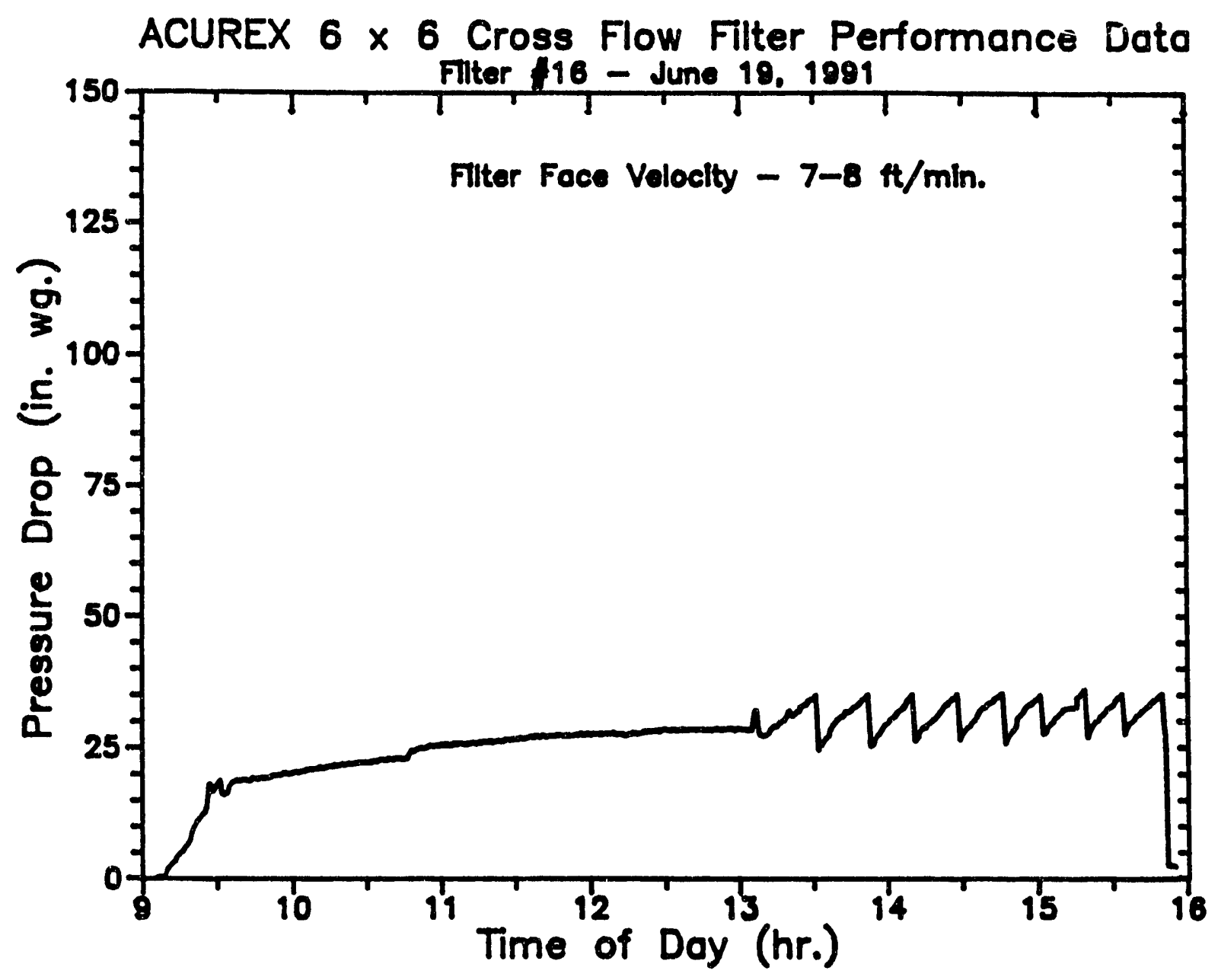

Operation Notes for June 18, 1991

dolto-P Trigger 35 in we

Pulae Cleaning - 430 paig/0.1 eec

0901 Flame on

1546 Scheduled shutdown 


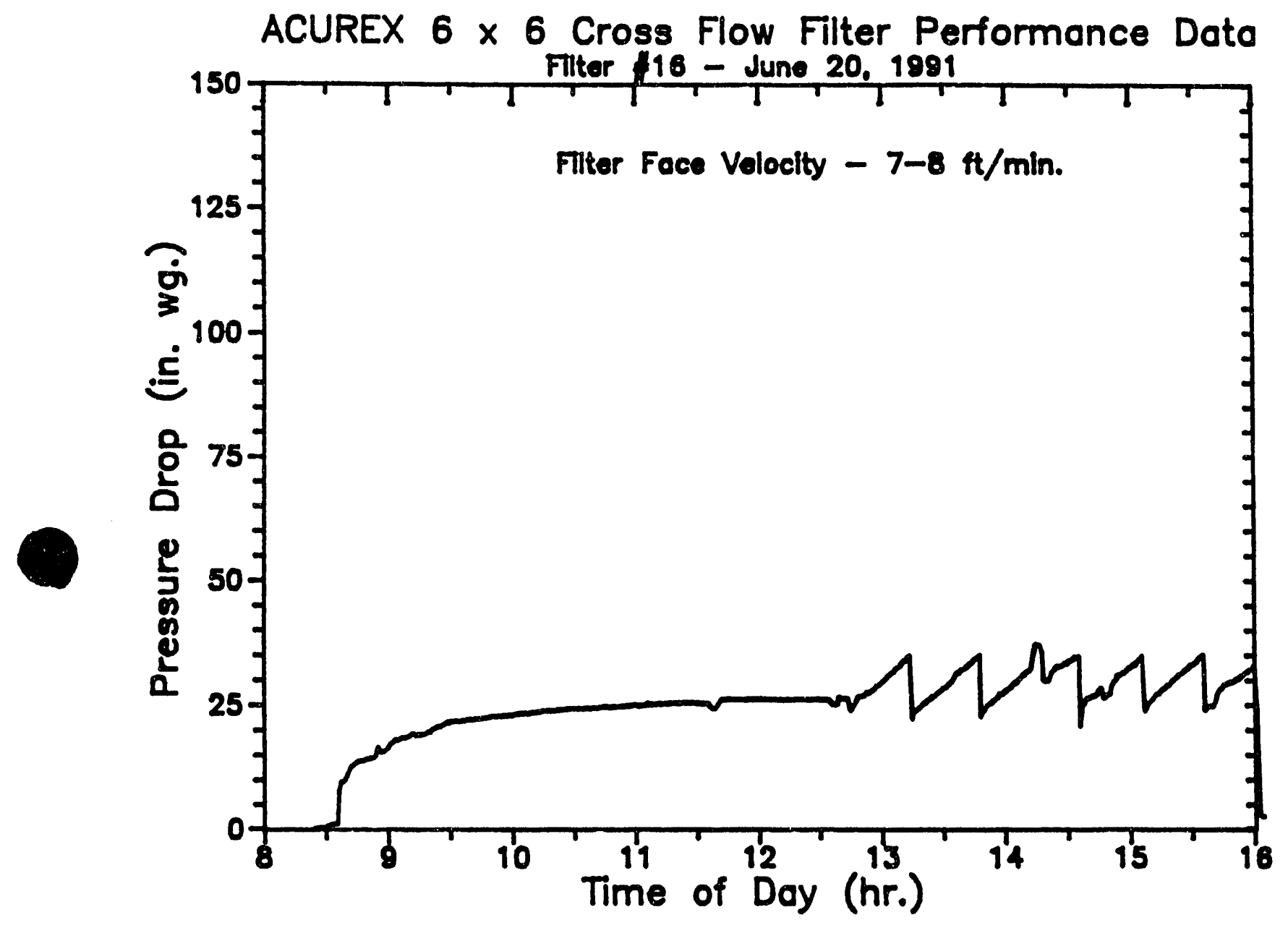

Operation Notes for June 20, 1991 delto-P Trigger 35 in we Pulse Cleaning - 430 paig/0.1 sec 0821 Flame on 1407 Dust off, dust feed line clogged, cleared, presaure stablized 1558 Scheduled shutdown 


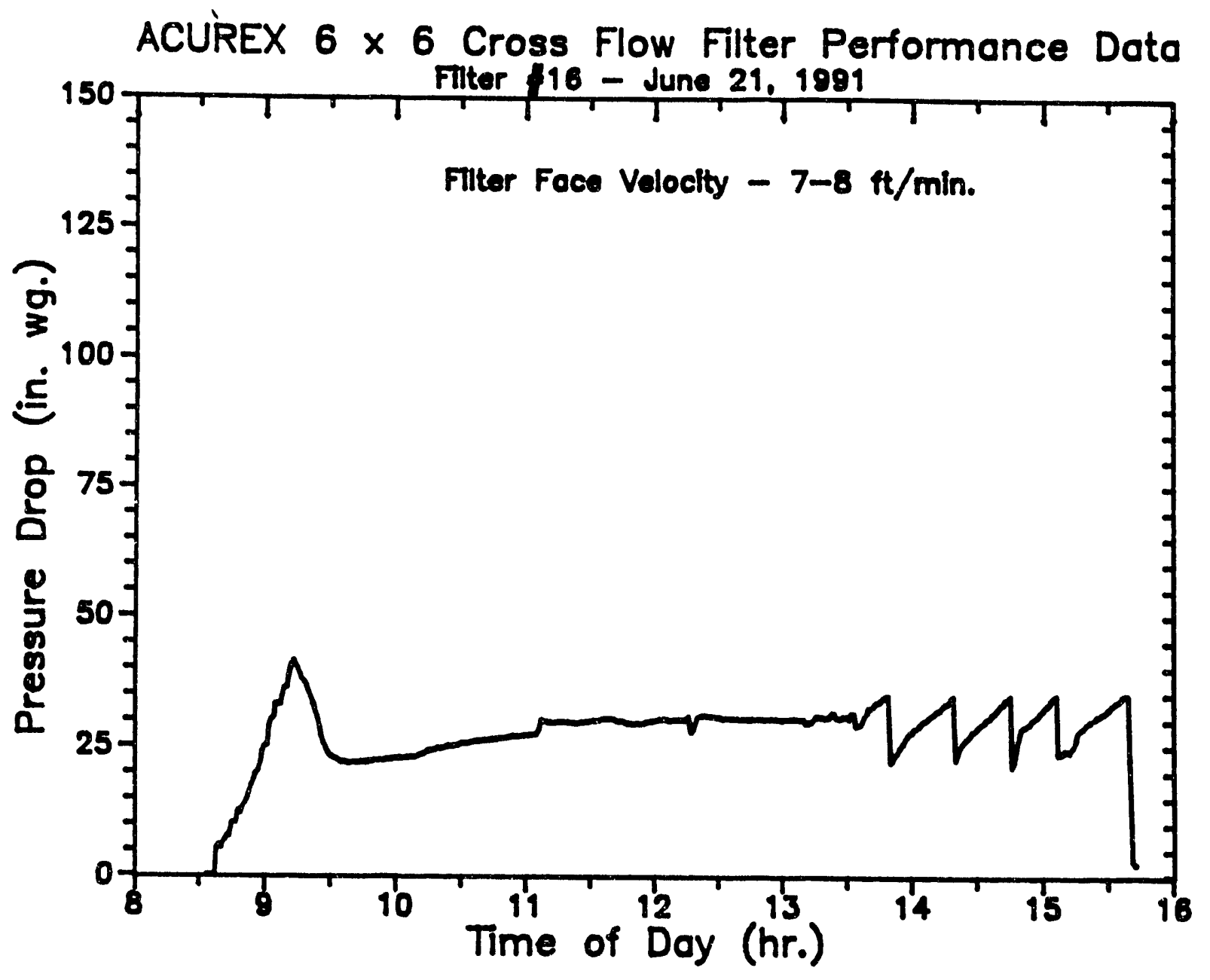

Operation Notes for June 21, 1901 delta-P Trigger 35 in we

Pulse Cleaning - 430 palg/0.1 eec

0834 Flame on

1317 Sample holder leaking, repoired

1539 Scheduled shutdown 


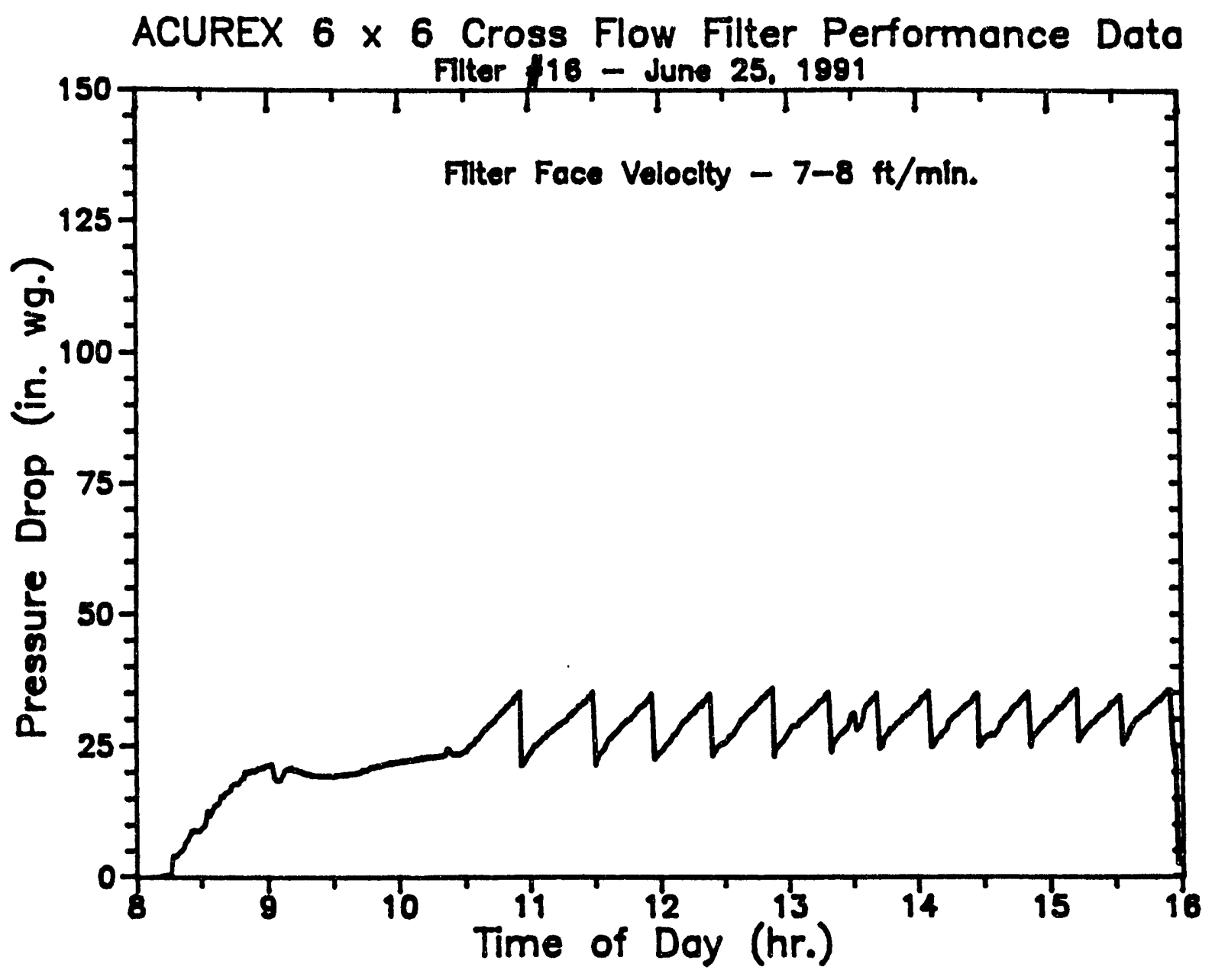

Operation Notea for June 25, 1991

delto-P Trigger 35 in we

Pulse Cleoning - 430 palg/0.1 eec

0811 Flame on

1556 Scheduled shutdown 


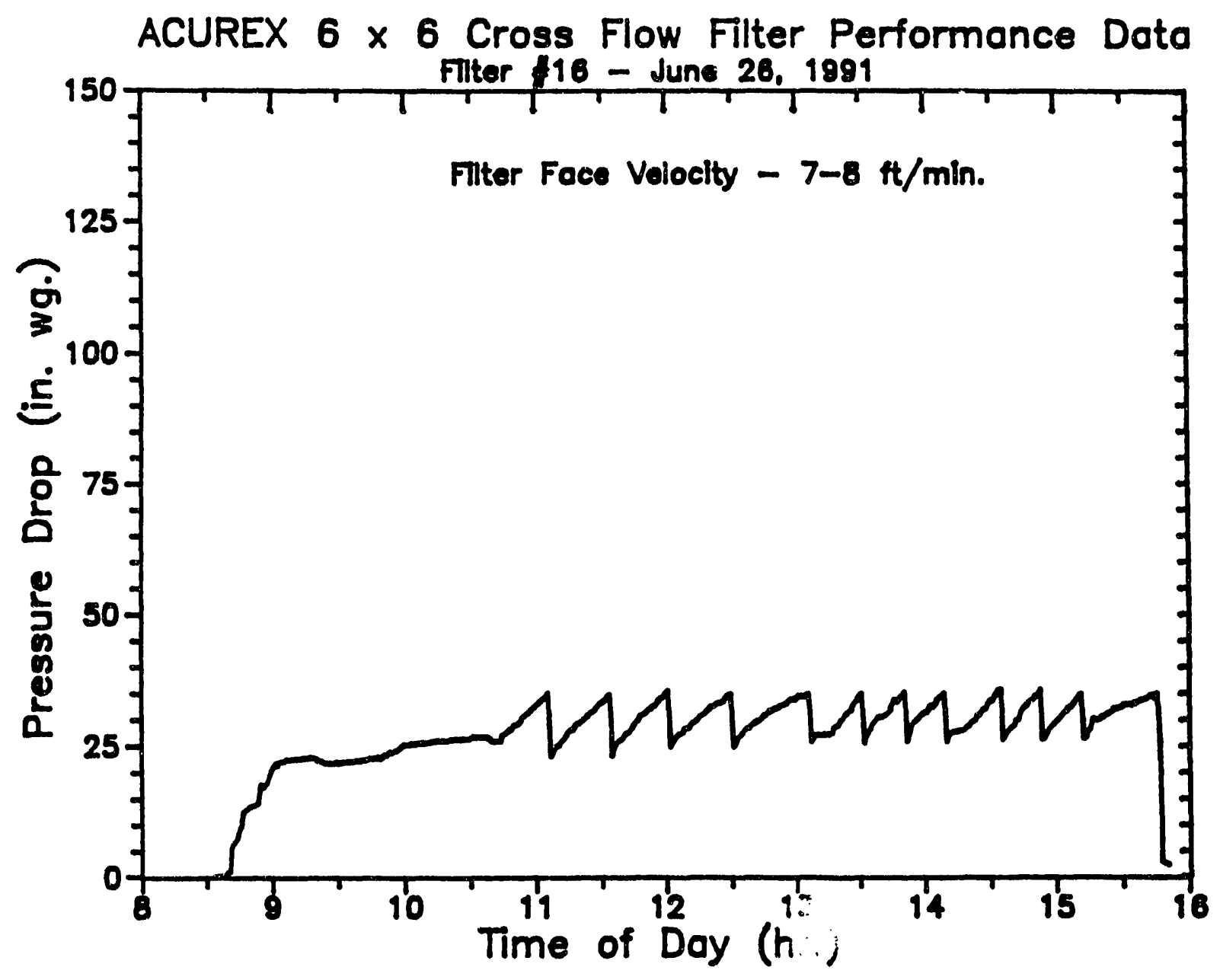

Operation Notea for June 20, 1891 delta-P Trigger 35 in we Puleo Cleaning - 430 palg/0.1 sec 0835 Flame on

1546 Scheduled shutdown 


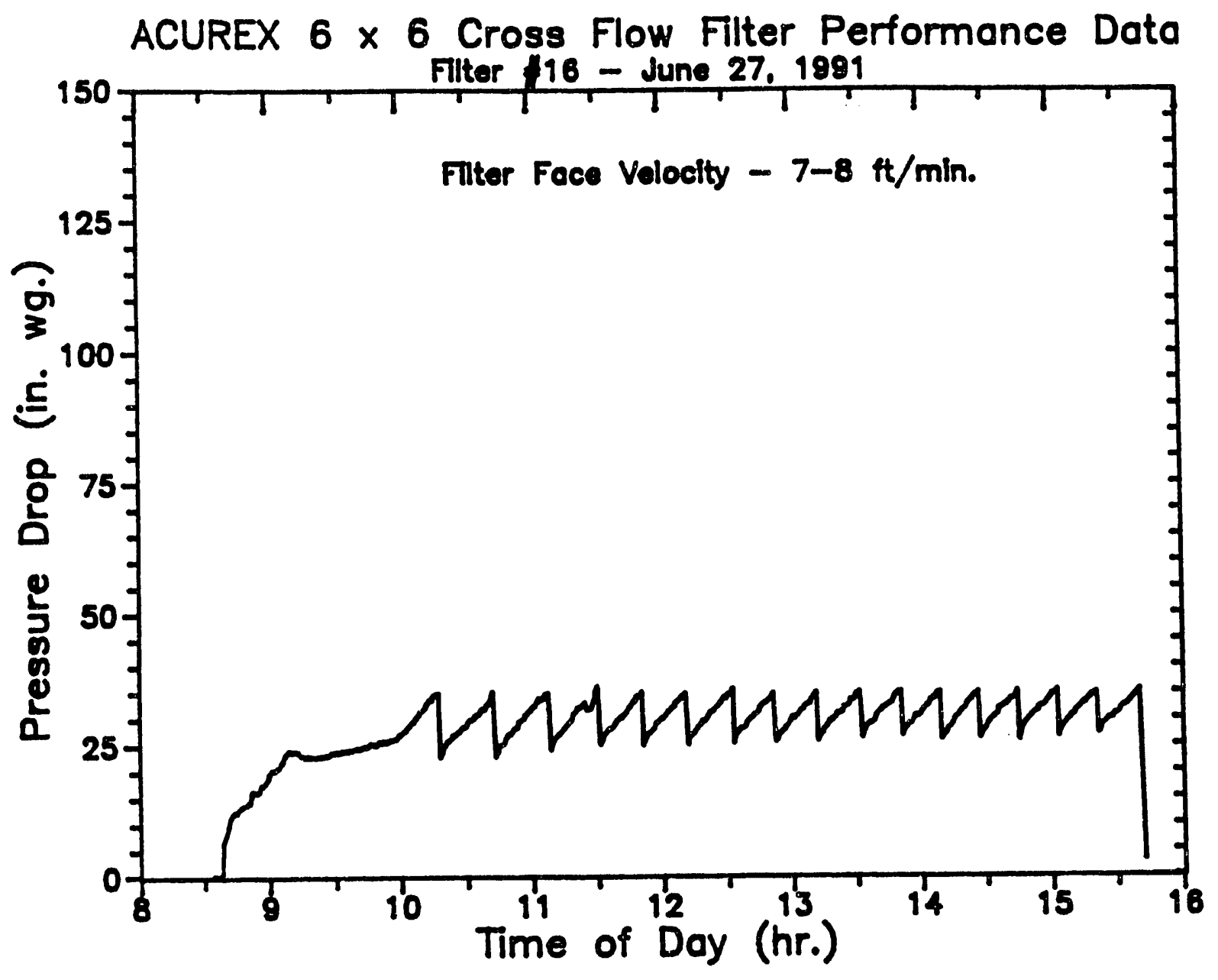

Operation Notes for June 27, 1991 delto-P Trigger 35 in we

Pulse Cleaning - $430 \mathrm{pslg} / 0.1$ sec 0834 flame on

1541 Scheduled shutdown 


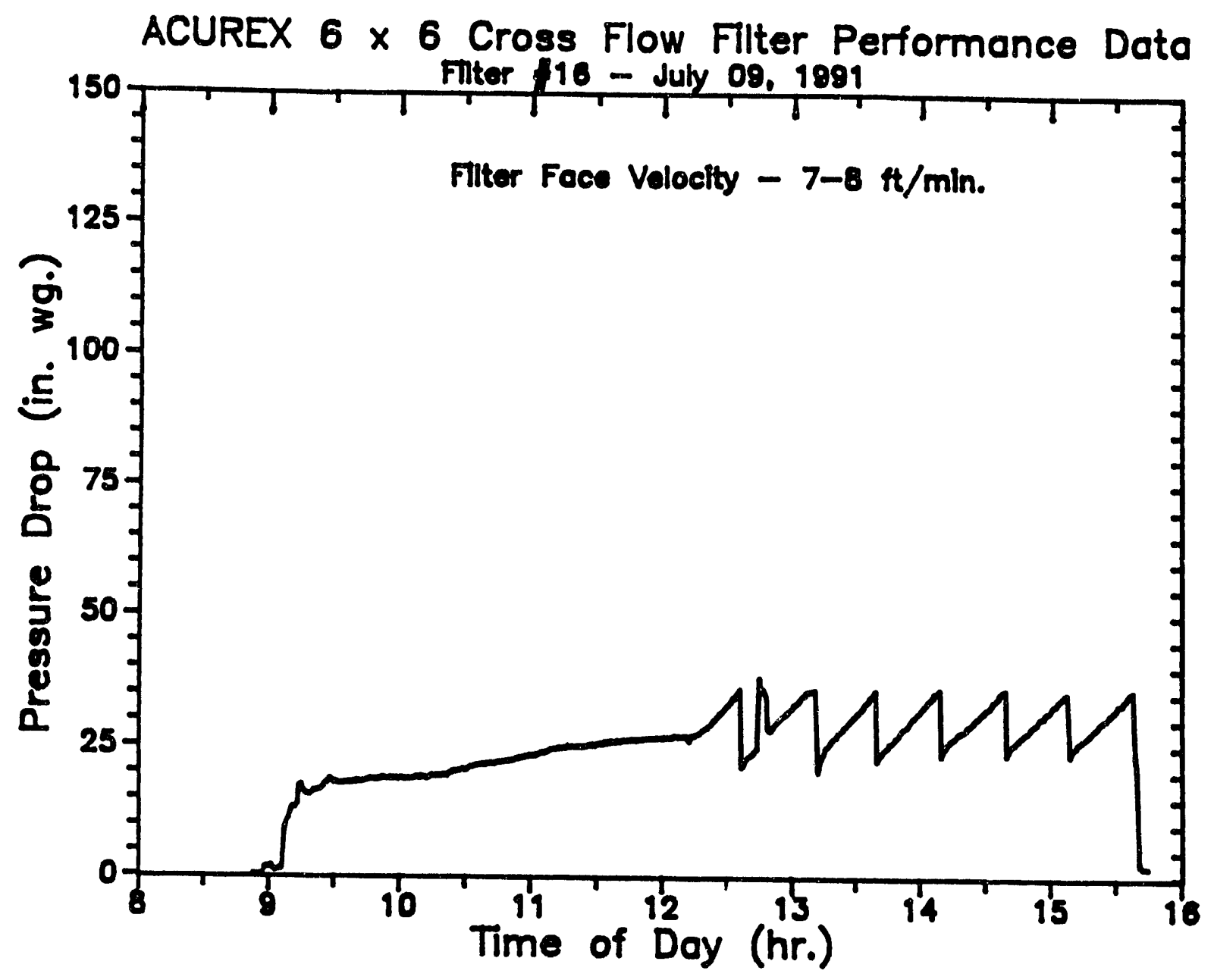

Operation Notes for July 09, 1091 delto-P Trigger 36 in we Pulso Cleaning - 430 palg/0.1 ene 0900 Flame on 1245 Syctem preseure drop, valve odjucted 1538 Scheduled shutdown 


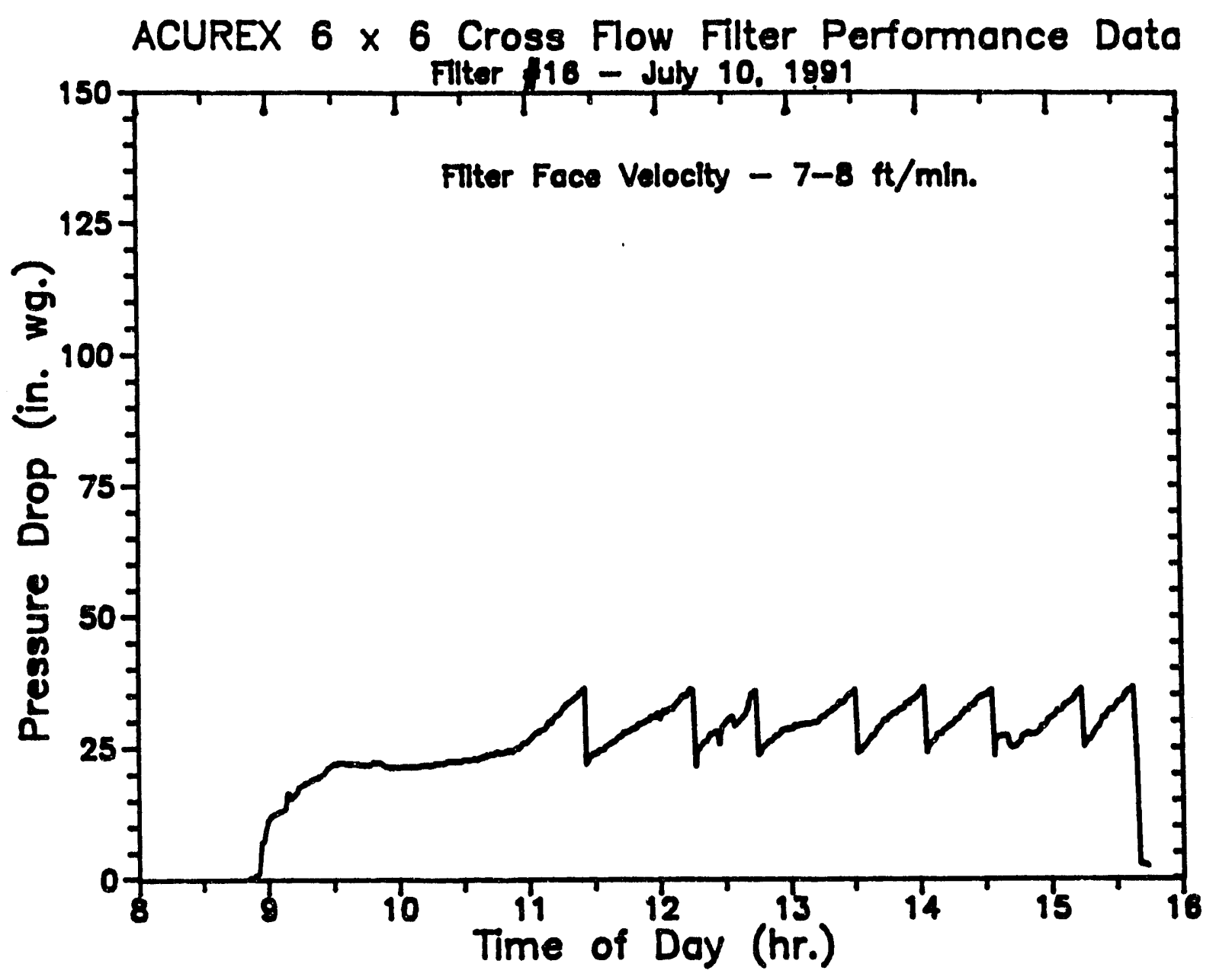

Operation Notes for July 10, 1991 delta-P Trigger 36 in we Pulse Cleaning - 430 psig/0.1 sec 0852 Flame on 1300 Dust not feeding property, corrected 1447 System pressure fluctuation, not foeding property, corrected 1538 Scheduled shutdown 

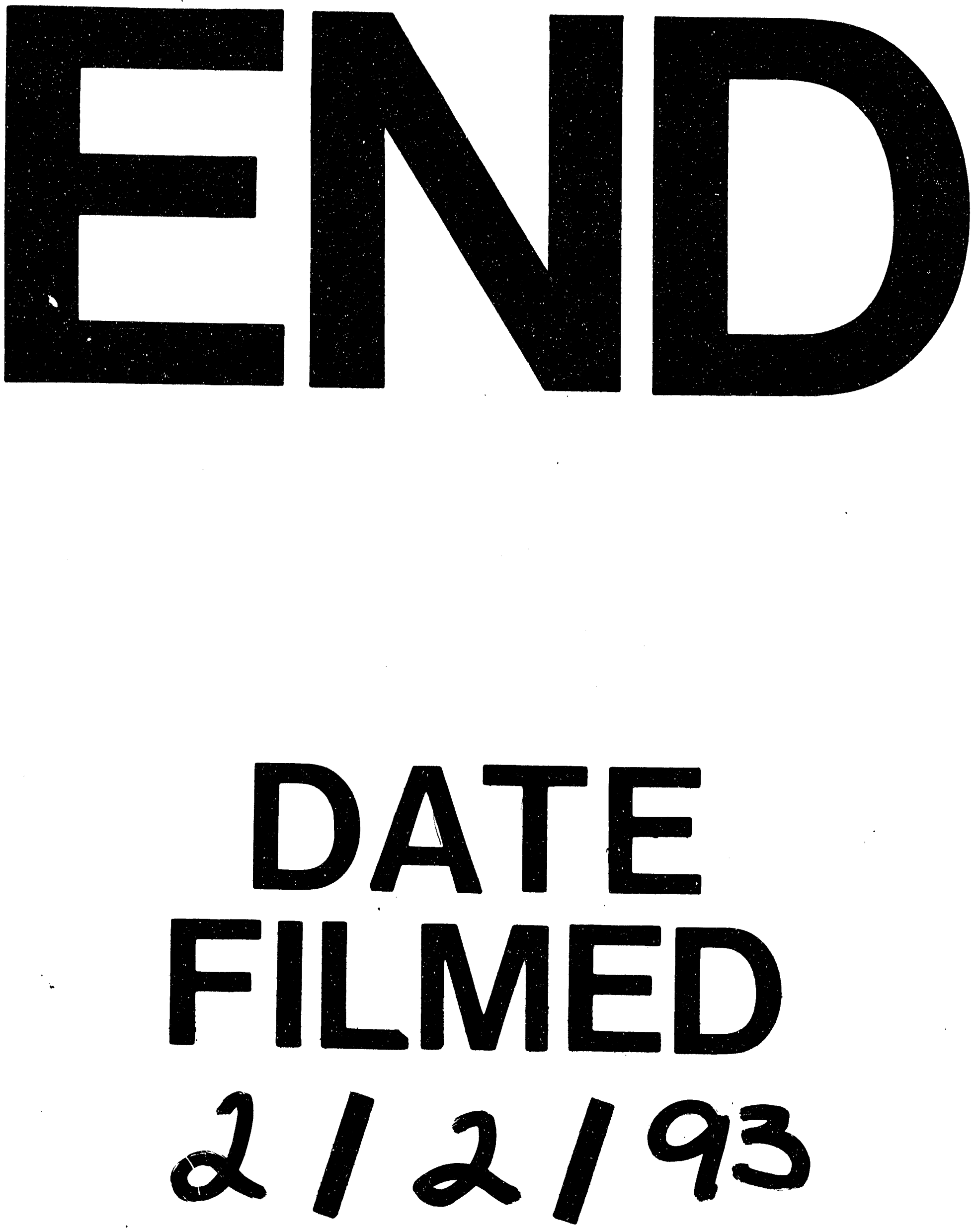
